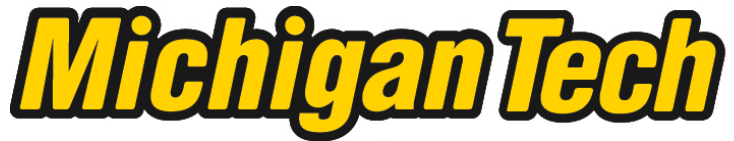 \\ Michigan Technological University Create the Future Digital Commons @ Michigan Tech
}

Dissertations, Master's Theses and Master's Reports - Open

Dissertations, Master's Theses and Master's

Reports

2006

\section{Enzyme engineering of aminotransferases for improved activity and thermostability}

Abraham Rogelio Mártin García

Michigan Technological University

Follow this and additional works at: https://digitalcommons.mtu.edu/etds

Part of the Chemical Engineering Commons

Copyright 2006 Abraham Rogelio Mártin García

\section{Recommended Citation}

García, Abraham Rogelio Mártin, "Enzyme engineering of aminotransferases for improved activity and thermostability", Dissertation, Michigan Technological University, 2006.

https://doi.org/10.37099/mtu.dc.etds/6

Follow this and additional works at: https://digitalcommons.mtu.edu/etds

Part of the Chemical Engineering Commons 
ENZYME ENGINEERING OF AMINOTRANSFERASES

FOR IMPROVED ACTIVITY AND THERMOSTABILTY

By

Abraham Rogelio Mártin García

\author{
A DISSERTATION \\ Submitted in partial fulfillment of the requirements for the \\ DOCTOR OF PHILOSOPHY degree \\ IN CHEMICAL ENGINEERING
}

MICHIGAN TECHNOLOGICAL UNIVERSITY

October 2006

Copyright (C) Abraham Rogelio Mártin García 2006 
This dissertation, "Enzyme Engineering of Aminotransferases for Improved Activity and Thermostability," is hereby approved in partial fulfillment of the requirements for the DOCTOR OF PHILOSOPHY degree IN CHEMICAL ENGINEERING.

Department of Chemical Engineering

Signatures:

Thesis Advisor:

$\overline{\text { Co-advisor: Dr. David R. Shonnard }}$

Committee:

Co-advisor: Dr. Sachin Pannuri

Dr. Tomas B. Co

Dr. Faith A. Morrison

Dr. Pushpalatha P. Murthy

Department Chair:

Dr. Michael E. Mullins

Date 


\section{Acknowledgements}

I would like to express sincere gratitude to my parents in the completion of this work, Rogelio Mártin Arvizu and Irma García Rubiano, also to María Del Rosario and Laura Elena Mártin García, my sisters. In the same form I would like to thank all the efforts done by all the members of my advisory committee on the completion of paper work, partial correction of this document, guidelines during the experimental stage, and comments during the presentation of research proposal: Dr David R. Shonnard (Advisor), Dr Sachin Pannuri (Co-Advisor), Dr Tomas B. Co (Chemical Engineering Department), Dr Faith A. Morrison (Chemical Engineering Department), and Dr Pushpalatha P. Murthy (Chemistry Department).

Also, I would like to recognize the contribution of several institutions to this work. The National Council of Science and Technology from Mexico (CONACYT) for providing full support during 45 months out of the 50 months invested in this dissertation; full support was provided by Caterpillar ${ }^{\circledR}$ for 5 months through the grant for "low greenhouse gas emissions bio-based energy technologies". Michigan Technological University and the Department of Chemical Engineering deserve special mention for accepting me in and giving the opportunity to experience their education system and their culture. Finally, I would like to thank Cambrex North Brunswick for allowing the use of their facilities and technical expertise. In the contribution on these institutions key factors were the links established between CONACYT-University of Sonora-Michigan Technological University by Ing. Jose Luis García, and between Michigan Technological University-Cambrex North Brunswick by Dr David R. Shonnard. 
Finally, I would like to thank the support of all the people I met -my friends- during the period I was working in this dissertation; during the failures and success. They are Cambrex North Brunswick personnel (Sachin Pannuri, Sanjay Kamat, Venkat Reddy, Srinivasa Eturi, Rocco DiSanto, Irina Rybina, Irina Plotnikov, Christiane Danilo, Shuba Kannan, Norma Samia, Mike Karras, and Ronnie Carroll) and Michigan Technological University Students (Luis Garcilaso Vejar, Michelle Hallack Alegria, Lennart and Henry Walqui, Agustin Robles, Alina Delgado, Julio Rivera, Juan Morinelly, Diego Villegas, Andrea Muñoz, and Nosotros student association). 


\begin{abstract}
Enzyme Engineering of Aminotransferases for Improved Activity and

Thermostability
\end{abstract}

\author{
Abraham Rogelio Mártin García \\ Department of Chemical Engineering \\ Doctor of Philosophy
}

The production by biosynthesis of optically active amino acids and amines satisfies the pharmaceutical industry in its demand for chiral building blocks for the synthesis of various pharmaceuticals. Among several enzymatic methods that allow the synthesis of optically active aminoacids and amines, the use of aminotransferase is a promising one due to its broad substrate specificity and no requirement for external cofactor regeneration. The synthesis of chiral compounds by aminotransferases can be done either by asymmetric synthesis starting from keto acids or ketones, and by kinetic resolution starting from racemic aminoacids or amines.

The asymmetric synthesis of substituted (S)-aminotetralin, an active pharmaceutical ingredient (API), has shown to have two major factors that contribute to increasing the cost of production. These factors are the raw material cost of biocatalyst used to produce it and product loss during biocatalyst separation. To minimize the cost contribution of biocatalyst and to minimize the loss of product, two routes have been chosen in this 
research: 1 . To engineer the aminotransferase biocatalyst to have greater specific activity, and 2. Improve the engineering of the process by immobilization of biocatalyst in calcium alginate and addition of cosolvents.

An (S)-aminotransferase (Mutant CNB03-03) was immobilized, not as purified enzyme but as enzyme within spray dried cells, in calcium alginate beads and used to produce substituted (S)-aminotetralin at $50{ }^{\circ} \mathrm{C}$ and $\mathrm{pH} 7$ in experiments where the immobilized biocatalyst was recycled. Initial rate of reaction for cycle 1 (6 $\mathrm{hr}$ duration) was determined to be $0.258 \mathrm{mM} / \mathrm{min}$, for cycle 2 ( $20 \mathrm{hr}$ duration) it decreased by $\sim 50 \%$ compared to cycle 1 , and for cycle 3 ( $20 \mathrm{hr}$ duration) it decreased by $\sim 90 \%$ compared to cycle 1 (immobilized preparation consisted of $50 \mathrm{mg}$ of spray dried cells per gram of calcium alginate). Conversion to product for each cycle decreased as well, from $100 \%$ in cycle 1 (About $50 \mathrm{mM}$ ), $80 \%$ in cycle 2 , and $30 \%$ after cycle 3 . This mutant was determined to be deactivated at elevated temperatures during the reaction cycle and was not stable enough to allow multiple cycles in its immobilized form.

A new mutant aminotransferase was isolated by applying error-prone polymerase chain reaction (PCR) on the gene coding for this enzyme and screening/selection: CNB04-01. This mutant showed a significant improvement in thermostability in comparison to CNB03-03. The new mutant was immobilized and tested under similar reaction conditions. Initial rate remained fairly constant $(0.2 \mathrm{mM} / \mathrm{min})$ over four cycles (each cycle with a duration of about 20 hours) with the mutant retaining almost $80 \%$ of initial rate in the fourth cycle. The final product concentrations after each cycle did not 
decrease during recycle experiments. Thermostability of CNB04-01 was much improved compared to CNB03-03.

Under the same reaction conditions as stated above, the addition of co-solvents was studied in order to increase substituted tetralone solubility. Toluene and sodium dodecylsulfate (SDS) were used. SDS at $0.01 \%(\mathrm{w} / \mathrm{v})$ allowed four recycles of the immobilized spray dried cells of CNB04-01, always reaching higher product concentration (80-85 $\mathrm{mM})$ than the system with toluene at 3\%(v/v) $-70 \mathrm{mM}-$. The long term activity of immobilized CNB04-01 in a system with SDS $0.01 \%(\mathrm{w} / \mathrm{v})$ at $50{ }^{\circ} \mathrm{C}, \mathrm{pH} 7$ was retained for three cycles (20 to 24 hours each one), reaching always final product concentration between $80-85 \mathrm{mM}$, but dropping precipitously in the fourth cycle to a final product concentration of $50 \mathrm{mM}$. Although significant improvement of immobilization on productivity and stability were observed using CNB04-01, another observation demonstrated the limitations of an immobilization strategy on reducing process costs. After analyzing the results of this experiment it was seen that a sudden drop occurred on final product concentration after the third recycle. This was due to product accumulation inside the immobilized preparation. In order to improve the economics of the process, research was focused on developing a free enzyme with an even higher activity, thus reducing raw material cost as well as improving biomass separation.

A new enzyme was obtained (CNB05-01) using error-prone PCR and screening using as a template the gene derived from the previous improved enzyme. This mutant was determined to have 1.6 times the initial rate of CNB04-01 and had a higher temperature 
optimum $\left(55^{\circ}\right)$. This new enzyme would allow reducing enzyme loading in the reaction by five-fold compared to CNB03-03, when using it at concentration of one gram of spray dried cells per liter (completing the reaction after 20-24 hours). Also this mutant would allow reducing process time to 7-8 hours when used at a concentration of 5 grams of spray dried cells per liter compared to 24 hours for CNB03-03, assuming that the observations shown before are scalable. It could be possible to improve the economics of the process by either reducing enzyme concentration or reducing process time, since the production cost of the desired product is primarily a function of both enzyme concentration and process time. 


\section{Glossary}
A
Isopropylamine
AspAT
Aspartate aminotransferase
B
Substituted tetralone
DTT
Dithioerythritol
NMR
Nuclear magnetic resonance
$\mathrm{P}$
Acetone
PLP
Pyridoxal-5-phosphate
PMP
Pyridoxamine-5-phosphate
Q
Substituted (S)-aminotetralin
S-MBA
(S)-(-)-( $\alpha)$-Methylbenzylamine
SA Sodium acetate
SOC Media composed of $20 \mathrm{~g}$ bacto tryptone, 5 grams bacto yeast extract, $2 \mathrm{ml}$ of $5 \mathrm{M} \mathrm{NaCl}, 2.5 \mathrm{ml}$ of $1 \mathrm{M} \mathrm{KCl}, 10 \mathrm{ml}$ of $1 \mathrm{M} \mathrm{MgSO}_{4}, 20 \mathrm{ml}$ of $1 \mathrm{M}$ glucose in $1000 \mathrm{ml}$ of water.
SP sodium pyruvate
TyrAT Tyrosinate aminotransferase 


\section{Table of Contents}

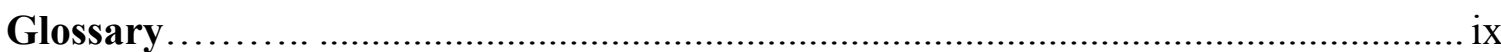

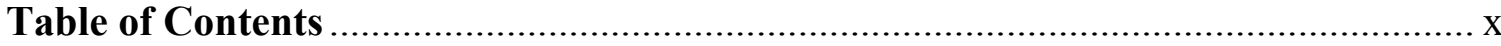

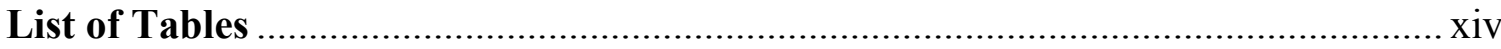

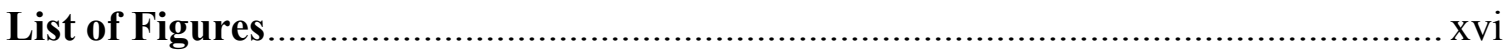

Chapter 1. Introduction ................................................................................. 1

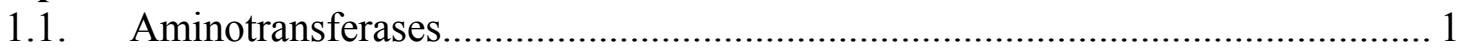

1.2. Aminotransferase Technology ...................................................................... 1

1.3. Research Objectives............................................................................. 5

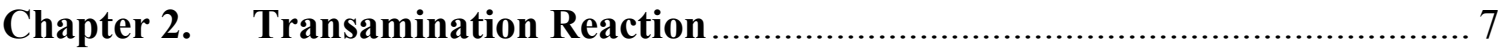

2.1. Transamination Reaction ..................................................................... 7

2.1.1. Transamination Reaction: Pyridoxal-5-phosphate Dependence................. 7

2.1.2. Mechanism of Transamination ......................................................... 10

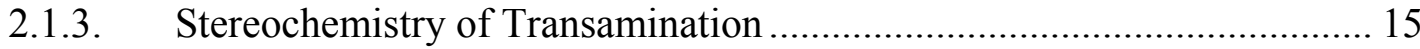

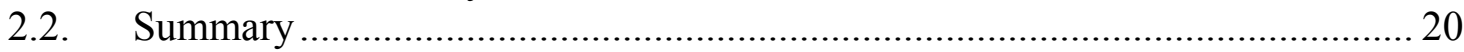

Chapter 3. Materials and Methods................................................................... 22

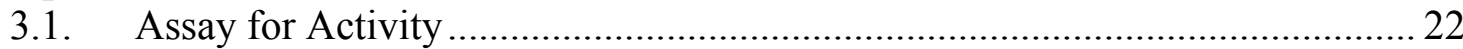

3.1.1. (S)-(-)- $\alpha$-Methylbenzylamine System (S-MBA System) ........................ 22

3.1.1.1. Measurement of Acetophenone concentration.................................. 24

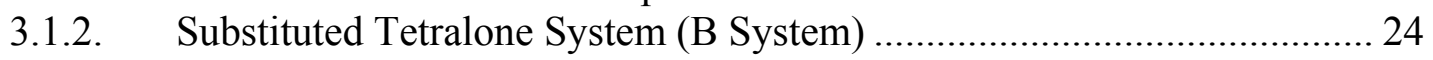

3.1.2.1. Measurement of Aminotetralin Concentration ................................ 26

3.2. Enzyme Characterization ........................................................................ 26

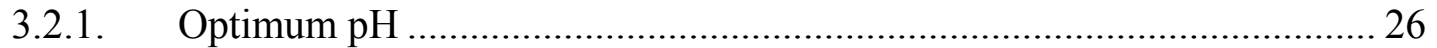

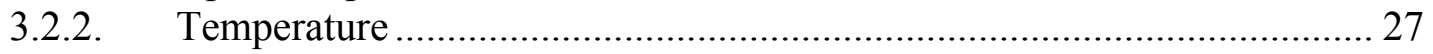

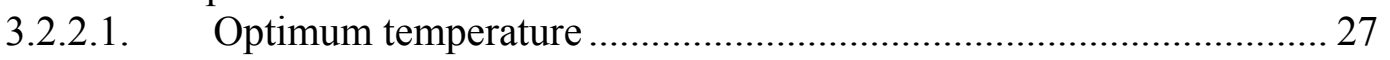

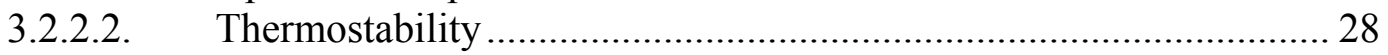

3.2.3. Substrate affinity ........................................................................... 28

3.2.4. Purification of Aminotransferase from Spray-Dried Cells by Precipitation

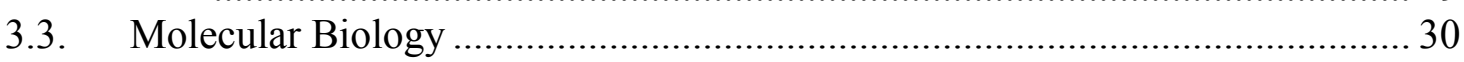

3.3.1. Error-Prone Polymerase Chain Reaction ............................................. 30

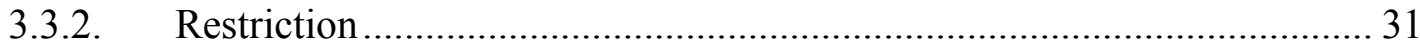

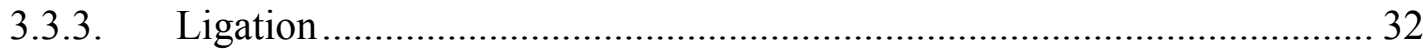

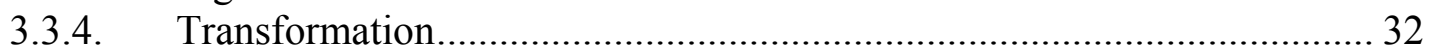

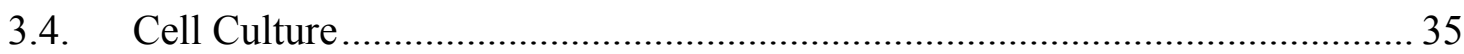

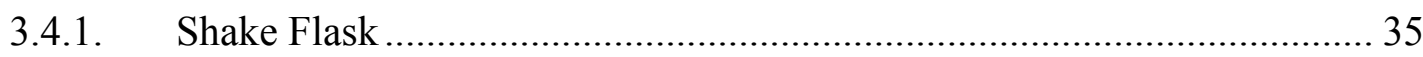

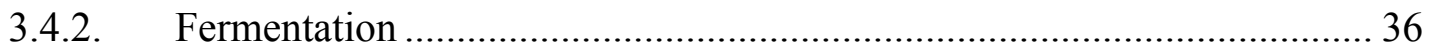

3.5. Biotransformation: Assessment of accuracy and reproducibility .................... 37 
Chapter 4. Enzyme Immobilization Procedure and Testing .............................. 41

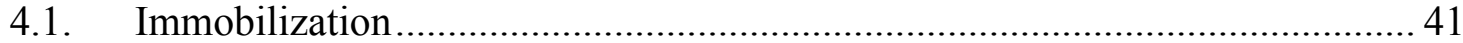

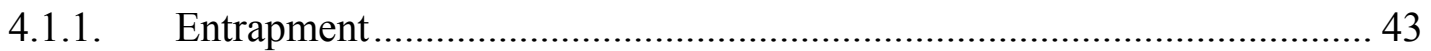

4.1.1.1. Entrapment in Calcium Alginate ................................................ 44

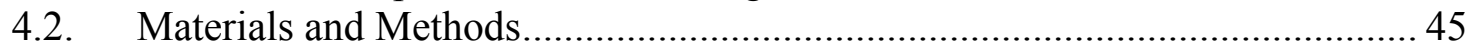

4.2.1. Immobilization Procedure ................................................................ 45

4.2.2. Disruption of Immobilized Preparation ............................................... 46

4.2.3. Gelation Time ................................................................................ 46

4.2.4. Effect of Sodium Alginate Concentration.............................................. 46

4.2.5. Effect of Calcium Chloride Concentration ........................................... 47

4.2.6. Effect of Bead Diameter .................................................................. 47

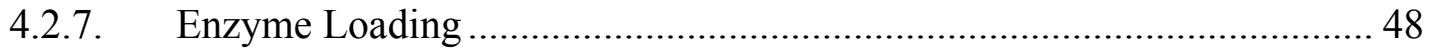

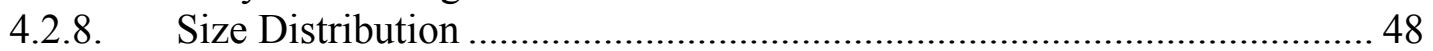

4.2.9. Drying and Reconstitution of Beads .................................................. 49

4.3. Enzyme Immobilization Results ............................................................... 49

4.3.1. Gelation Time ................................................................................ 49

4.3.2. Effect of Sodium Alginate and Calcium Chloride Concentration ............ 50

4.3.3. Effect of Bead Diameter .................................................................... 52

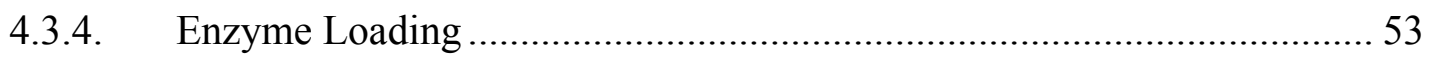

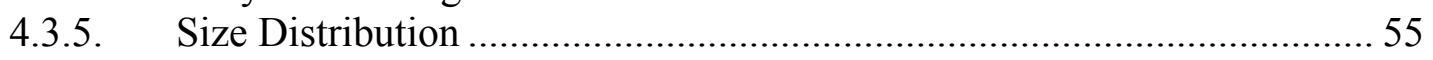

4.3.6. Drying and Reconstitution of Beads ................................................... 56

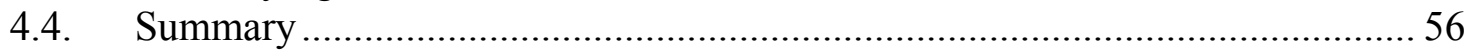

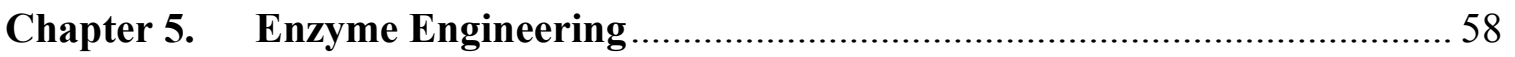

5.1. Enzyme Engineering Using CNB03-03 as Template ................................... 58

5.1.1. Enzyme Engineering Procedure ............................................................ 59

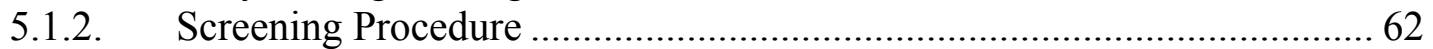

5.1.2.1. Selection of Mutants with Functional (S)-Aminotransferase ........... 63

5.1.2.2. Selection of Mutants with (S)-Aminotransferase Active at High

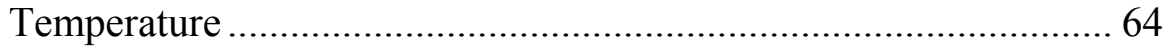

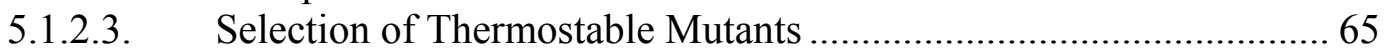

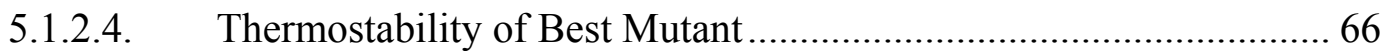

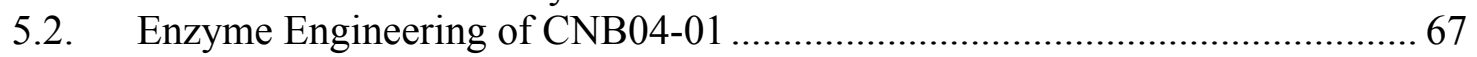

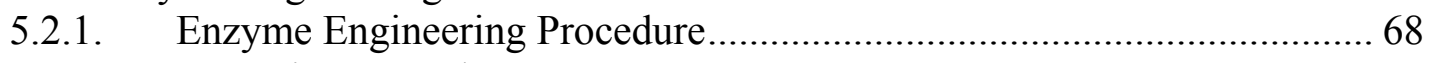

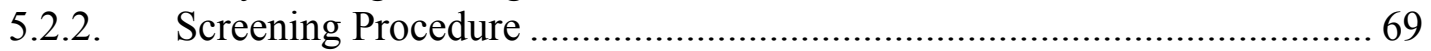

5.2.2.1. Selection of Mutants with Functional (S)-Aminotransferase ........... 69

5.2.2.2. Selection of Mutants with (S)-Aminotransferase Active at High

Temperature ...................................................................... 70

5.2.2.3. Selection of Mutants with Improved Activity ............................... 70

5.2.2.4. Selection of Mutants with Functional (S)-Aminotransferase ........... 71

Chapter 6. Mutant Characterization Based on Initial Biotransformation Rate.. 73

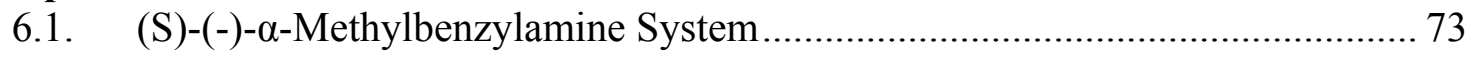

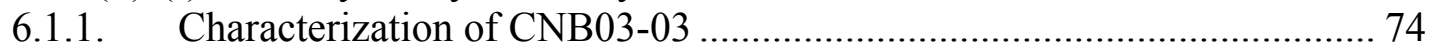

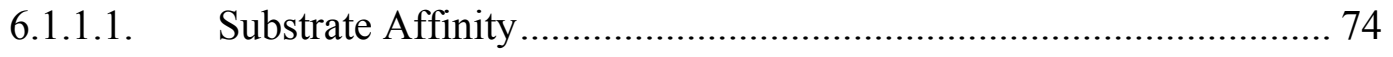

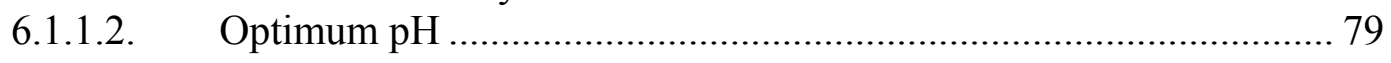




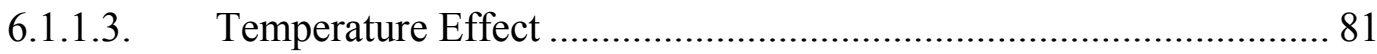

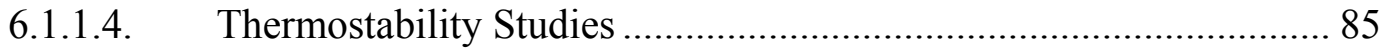

6.1.1.4.1. Analysis of Activity during Recycling ........................................ 85

6.1.1.4.2. Activity of Immobilized and Aqueous Spray Dried Cells During

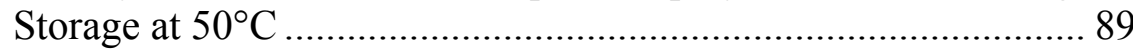

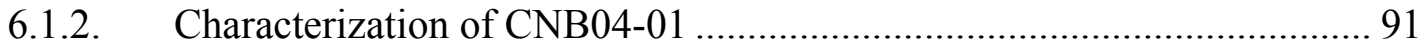

6.1.2.1. Substrate Affinity ....................................................................... 91

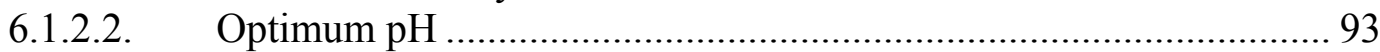

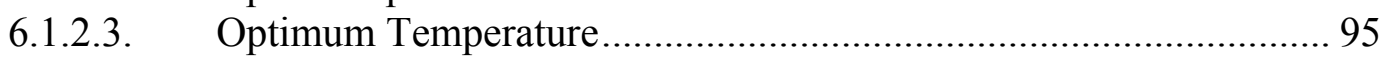

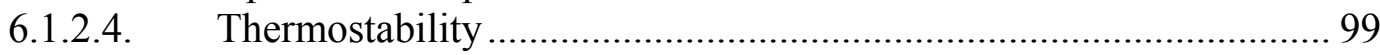

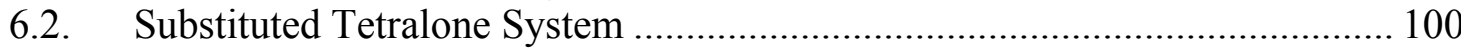

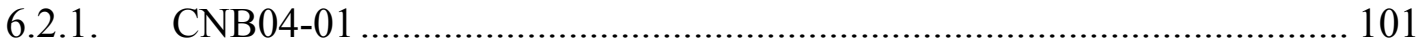

6.2.1.1. Optimum Isopropylamine Concentration ....................................... 101

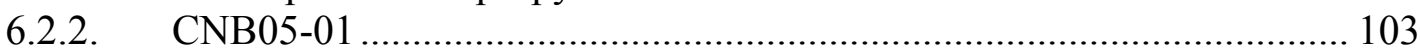

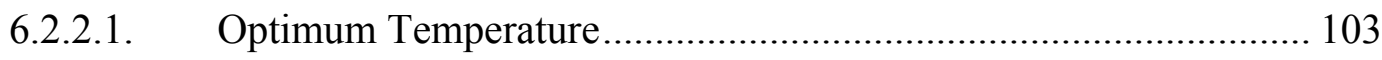

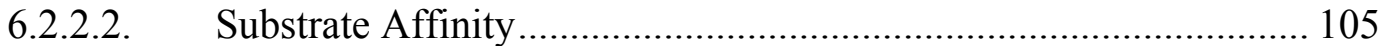

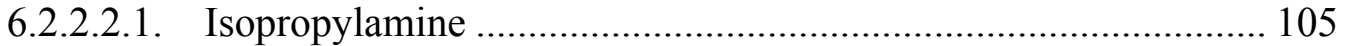

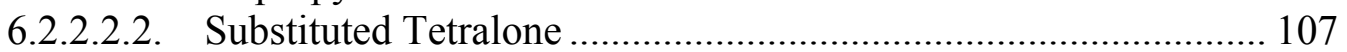

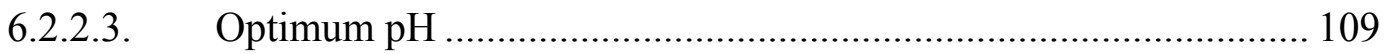

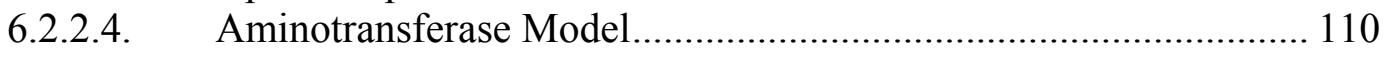

6.2.2.4.1. Effect of Pyridoxal-5-Phosphate................................................... 111

6.2.2.4.2. Effect of Isopropylamine and Substituted Tetralone Concentration..

6.2.4.3. Rate of Reverse Reaction

6.2.2.4.4. Effect of Product Concentration on Reaction Rate....................... 116

6.2.2.4.5. Kinetic model of CNB05-01 ................................................. 117

Chapter 7. Effect of Immobilized (S)-Aminotransferase with Improved Thermostability in the Production of Substituted (S)-Aminotetralin .... 128

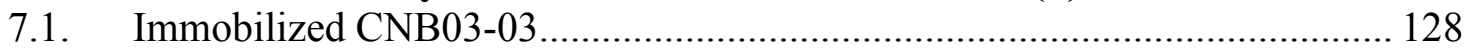

7.2. Immobilized CNB04-01......................................................................... 132

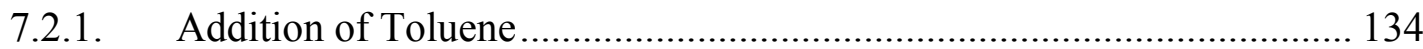

7.2.2. Addition of Sodium Dodecyl Sulfate................................................... 138

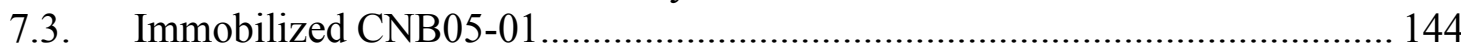

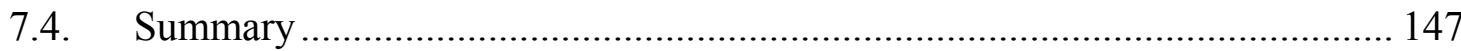

Chapter 8. Effect of Free (S)-aminotransferase with Improved Activity in the Production of Substituted (S)-Aminotetralin ............................................ 148

8.1. Free Spray Dried Cells of CNB05-01 .......................................................... 148

8.2. Comparison of CNB05-01 with CNB03-03 and CNB04-01 ........................... 149

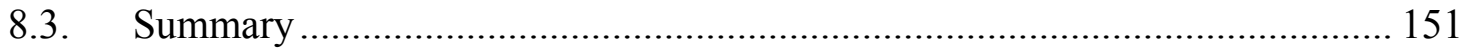

Chapter 9. Engineering of Transamination Reaction For Improved Product Yield

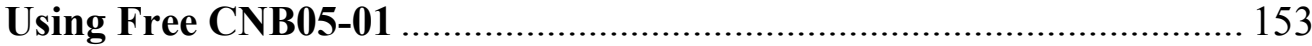

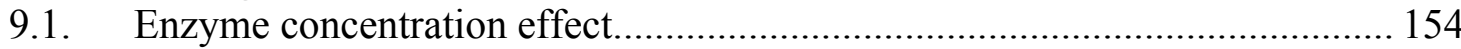

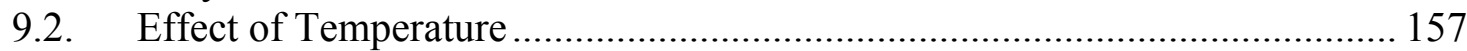




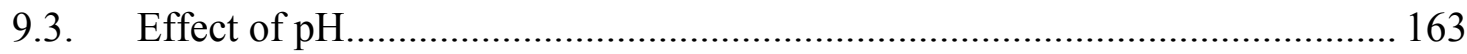

9.4. Effect of Isopropylamine Concentration...................................................... 166

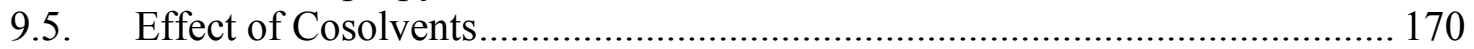

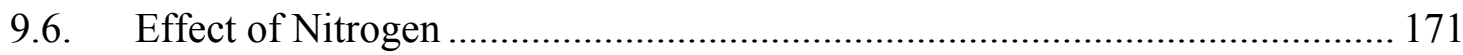

9.7. Summary of Transamination Reaction Engineering ....................................... 173

Chapter 10. Sequence and Properties of Aminotransferase Mutants .................... 175

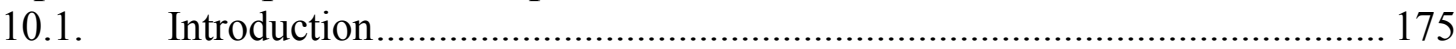

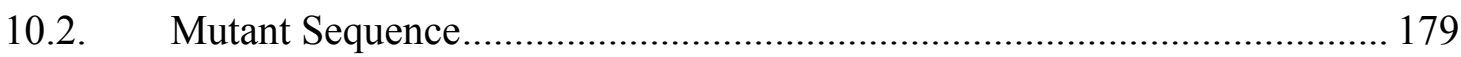

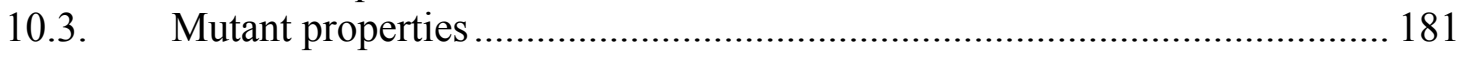

Chapter 11. Conclusions/Recommendations ………………………………........ 184

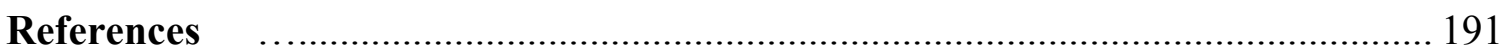

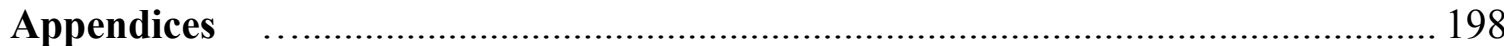

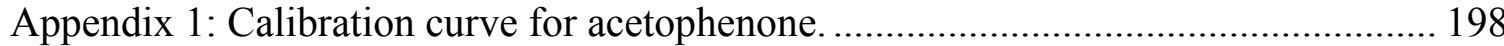

Appendix 2: Calibration curve for substituted (S)-aminotetralin. .................................. 203

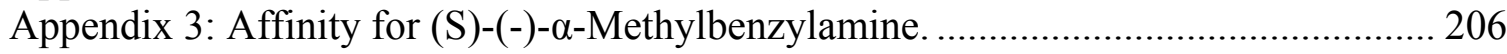

Appendix 4: Effect of gelation time on activity ........................................................... 212

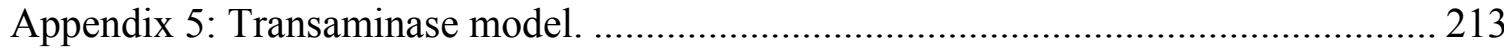

Appendix 6: Substituted (S)-Aminotetralin and Imine overall kinetics. ......................... 222

Appendix 7: Chemical structure of 21 amino acids...................................................... 227

Appendix 8: (S)-Aminotransferase purification ........................................................... 230 


\section{List of Tables}

Table 3-I: Composition of (S)-(-)- $\alpha$-methylbenzylamine solutions................................. 23

Table 3-II: Composition of substituted tetralone solutions............................................. 25

Table 3-III: Assesment of accuracy and reproducibility of (S)-MBA system at $30^{\circ} \mathrm{C}$..... 38

Table 3-IV: Assesment of accuracy and reproducibility of (S)-MBA system at $55^{\circ} \mathrm{C} . . .38$

Table 3-V: Assesment of accuracy and reproducibility of substituted tetralone system.. 39

Table 4-I: Characteristics of immobilization procedures.

Table 4-II: Impact of immobilization methods on the biotransformation of Sucrose to Isomaltulose by cells of Erwinia rhapontici.

Table 4-III: Effect of sodium alginate concentration on the activity and enzyme incorporated to the bead............................................................................... 50

Table 4-IV: Effect of diameter of the bead on enzyme incorporated. .............................. 52

Table 4-V: Effect of diameter of the bead on active enzyme of whole beads.................. 52

Table 4-VI: Amount of enzyme incorporated to the beads............................................. 53

Table 4-VII: Amount of enzyme active in whole beads................................................. 54

Table 4-VIII: Effect of drying and reconstitution of beads. ........................................... 56

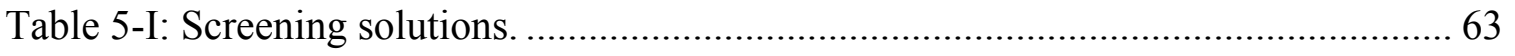

Table 6-I: Substrate affinity of CNB03-03 …………............................................... 77

Table 6-II: Substrate affinity for free CNB04-01 and free CNB03-03............................ 93

Table 6-III: Effect of isopropylamine and substituted tetralone concentration on reaction rate $(\mathrm{mM} / \mathrm{min})$ of $(\mathrm{S})$-aminotransferase CNB05-01 .................................. 113

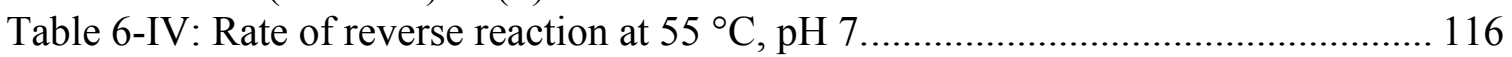

Table 6-V: Effect of product concentration on reaction rate..................................... 117

Table 6-VI: Kinetic information of CNB05-01 obtained at $55^{\circ} \mathrm{C}, \mathrm{pH} 7$, at a concentration of 1 gram per liter of it and $2 \mathrm{mM}$ pyridoxal-5-phosphate. .......................... 118

Table 6-VII: Parameter values of Model 4.............................................................. 123

Table 7-I: Kinetic parameters of immobilized CNB03-03 at 50 $0^{\circ} \mathrm{C}$............................... 130

Table 7-II: Kinetic parameters of immobilized CNB04-01 at $50{ }^{\circ} \mathrm{C}$ in the prescence of

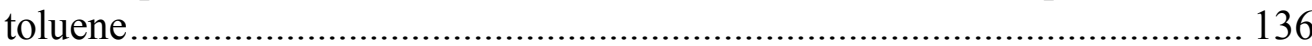

Table 7-III: Kinetic parameters of immobilized CNB04-01 at $50{ }^{\circ} \mathrm{C}$ in the prescence of

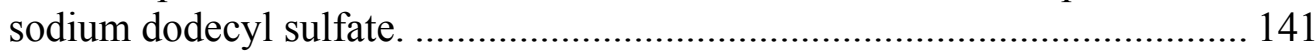

Table 7-IV: Kinetic parameters of immobilized CNB05-01 at 55 ${ }^{\circ} \mathrm{C}$............................. 146

Table 8-I: Kinetic parameters of free $\mathrm{CNB} 05-01$ at $55^{\circ} \mathrm{C}-5 \mathrm{~g} / 1$.................................. 149

Table 9-I: Substituted (S)-aminotetralin production at several enzyme (spray dried cells

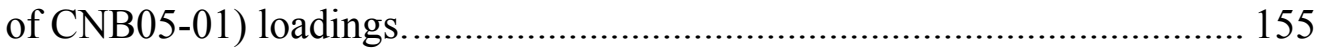

Table 9-II:Description of free CNB05-01 activity at $55^{\circ} \mathrm{C}-1,2.5$, and $5 \mathrm{~g} / 1 \ldots \ldots \ldots \ldots \ldots . . .156$

Table 9-III: Substituted (S)-aminotetralin (Q) production at several temperatures........ 161

Table 9-IV: Kinetic and equilibrium constants for Substituted (S)-aminotetralin and Imine formation at several temperatures...................................................... 162 
Table 9-V: Substituted (S)-aminotetralin (Q) production at $\mathrm{pH} 6$ and 7. 164

Table 9-VI: Kinetic and equilibrium constants for Substituted (S)-aminotetralin and Imine formation at $\mathrm{pH} 6$ and 7.

Table 9-VII: Substituted (S)-aminotetralin (Q) production at several isopropylamine concentrations.

Table 9-VIII: Kinetic and equilibrium constants for Substituted (S)-aminotetralin and Imine formation at several isopropylamine concentrations. 169

Table 10-I: List of Chiral amine intermediates produced at an industrial scale (Cambrex Corporation).

Table 10-II: Modifications of aminotransferases by Error-prone PCR ....................... 178

Table 10-III: Amino acid sequence changes in the evolution of CNB03-03 to CNB05-01.

Table 10-IV: Aminotransferase properties and major changes on aminoacids sequence 180 from CNB03-03 to CNB05-01. 


\section{List of Figures}

Figure 1-1: Synthesis of substituted (S)-aminotetralin by (S)-aminotransferase................ 2

Figure 1-2: Comparison of (S)-aminotransferase mutants in terms of production of substituted (S)-aminotetralin....................................................................... 3

Figure 1-3: Production process of substituted (S)-aminotetralin. Consists of biontransformation (1), centrifugation (2), extraction to remove ketone (3), extraction of product (4), and isolation-purification of product (Pannuri et al.,

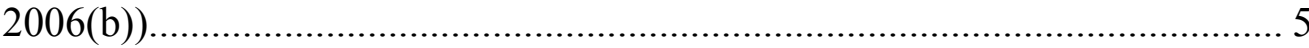

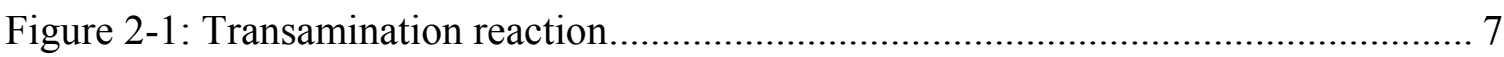

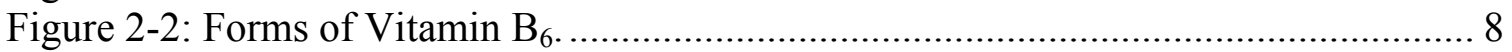

Figure 2-3: Structures of lysine, lysine residue on a polypeptide chain and aldimine

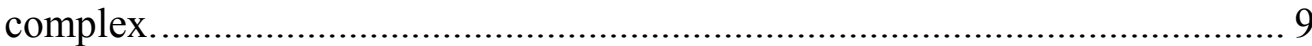

Figure 2-4: Ping-pong Bi Bi mechanism. ……………………................................ 10

Figure 2-5: Rate determining steps of ping-pong Bi Bi mechanism (Kuby; 1991).......... 11

Figure 2-6: Stereochemistry of proton removal and addition in the active site of AspAT, where $\mathrm{H}_{\mathrm{S}}$ is the hydrogen in the si face; $\mathrm{H}_{\mathrm{R}}$ is the hydrogen in the re face of the complex (Taken from Christen and Metzler, 1985)

Figure 2-7: Stereochemistry of reduction by sodium borohydride of pyridoxylaspartate compounds in the active site of AspAT (Taken from Christen and Metzler, 1985)

Figure 3-1: Transamination reaction of (S)-(-)- $\alpha$-methylbenzylamine system................ 23

Figure 4-1: Effect of Gelation time on enzymatic activity........................................... 50

Figure 4-2: Size distribution of the beads made with the needle of $221 / 2$ G.................... 55

Figure 5-1: Agarose gel for vector isolation. Line 1 is the molecular weight marker, line 2 is the product from plasmid restriction (From the top to the bottom vector -4.5

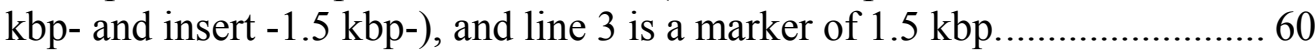

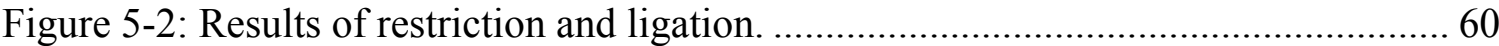

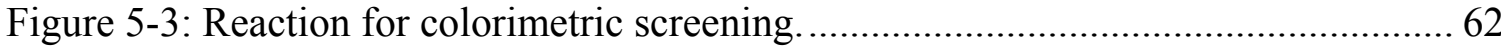

Figure 5-4: Selection of mutants with functional (S)-aminotransferase.......................... 64

Figure 5-5: Selection of mutants with (S)-aminotransferase activity at $80^{\circ} \mathrm{C}$. The two circles at the bottom of nitrocellulose paper are cells of CNB03-03, the control.

Figure 5-6: Colorimetric assay of the colonies with activity at $80^{\circ} \mathrm{C}$ incubated at temperatures $60-65^{\circ} \mathrm{C}$. The four circles at the bottom are cells of CNB03-03.

Figure 5-7: Thermostability of the best mutant and CNB03-03 under reaction like-

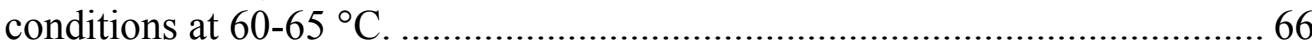

Figure 5-8: Comparison of activity of CNB03-03, CNB04-01, $\mathrm{A} 3$ and $\mathrm{C} 1 \ldots \ldots \ldots \ldots \ldots \ldots \ldots . . . . .71$ 
Figure 6-1: (S)-(-)-Methylbenzylamine system reaction 73

Figure 6-2: (S)-(-)- $\alpha$-Methylbenzylamine affinity by free spray dried cells of CNB03-03.

Figure 6-3: (S)-(-)- $\alpha$-Methylbenzylamine affinity by immobilized CNB03-03 .............. 75

Figure 6-4: Sodium pyruvate affinity for free spray dried cells of CNB03-03 .............. 75

Figure 6-5: Sodium pyruvate affinity for immobilized spray dried cells of CNB03-03 . 76

Figure 6-6: Optimum $\mathrm{pH}$ for free and immobilized CNB03-03 .................................... 80

Figure 6-7: Effect of incubation for 30 minutes at a given temperature on activity ......... 81

Figure 6-8: Effect of temperature on initial rate of CNB03-03 catalyzing the system of

(S)-(-)- $\alpha$-Methylbenzylamine ...................................................................... 82

Figure 6-9: Estimation of activation and deactivation energy for free spray dried cells of

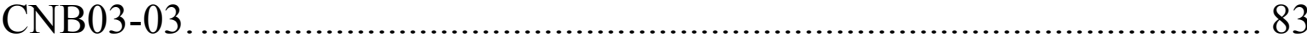

Figure 6-10: Estimation of activation and deactivation energy for immobilized spray

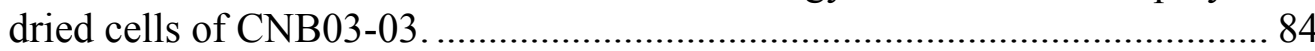

Figure 6-11: Change on activity of immobilized CNB03-03 during continuous recycling

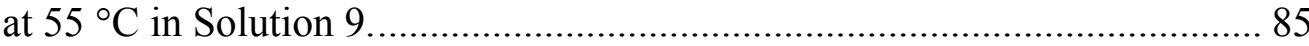

Figure 6-12: Activity during continuous recycling of immobilized CNB03-03 at $55^{\circ} \mathrm{C}$ in

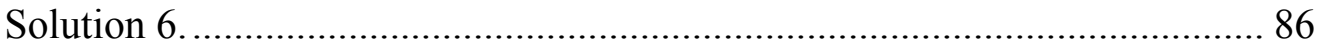

Figure 6-13: Change on mass and diameter of beads of immobilized enzyme during continuous recycling at $55^{\circ} \mathrm{C}$ on Solution $6 \mathrm{pH} 7$ (Table 3-I)..................... 87

Figure 6-14: Change on activity during continuous recycling of immobilized enzyme at $50^{\circ} \mathrm{C}$ on Solution $9 \mathrm{pH} 7$....................................................................... 88

Figure 6-15: Change on activity during continuous recycling of immobilized enzyme at

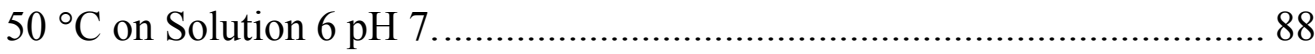

Figure 6-16: Activity of free and immobilized enzyme at $50{ }^{\circ} \mathrm{C}$; storage at $50{ }^{\circ} \mathrm{C}, \mathrm{pH} 7,1$

mM Pyridoxal 5-phosphate, and $100 \mathrm{mM}$ sodium acetate. ........................... 90

Figure 6-17: Percent of Maximal activity of free and immobilized enzyme at $50{ }^{\circ} \mathrm{C}$;

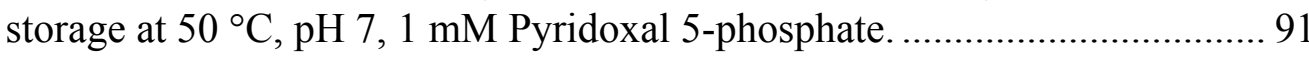

Figure 6-18: Double reciprocal plot (S)-(-)- $\alpha$-Methylbenzylamine affinity of free CNB04-

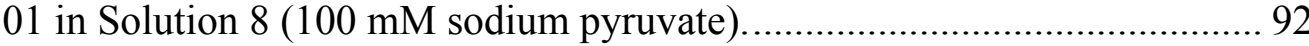

Figure 6-19: Double reciprocal plot Sodium pyruvate affinity of free CNB04-0 in

Solution 7 (15 mM (S)-(-)- $\alpha$-methylbenzylamine)...................................... 92

Figure 6-20: Effect $\mathrm{pH}$ on the activity of free and immobilized spray dried cells of

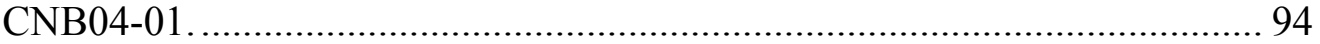

Figure 6-21: Optimum temperature for free and immobilized CNB04-01_..................... 95

Figure 6-22: Arrhenius plot for free spray dried cells of CNB04-01............................. 96

Figure 6-23: Arrhenius plot for immobilized spray dried cells of CNB04-01................ 96

Figure 6-24: Arrhenius plot for immobilized CNB04-01. Deactivation of immobilized spray dried cells. .................................................................................. 97

Figure 6-25: Arrhenius plot for immobilized CNB04-01. Activation of immobilized spray

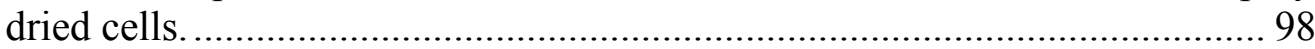

Figure 6-26: Change of (S)-aminotransferase activity as an effect of incubation at $50{ }^{\circ} \mathrm{C}$

of free and immobilized spray dried cells of CNB04-01.............................. 99

Figure 6-27: Substituted tetralone system reaction....................................................... 100

Figure 6-28: Change on reaction rate of free CNB04-01 in the production of substituted

(S)-aminotetralin as a function of Isopropylamine. 101 
Figure 6-29: Description of the effect of isopropylamine concentration on initial rate by the model of substrate inhibition (continuous trend).

Figure 6-30: Effect of temperature on initial rate of production of substituted (S)aminotetralin by free CNB05-01. 104

Figure 6-31: Arrhenius plot for free spray dried cells of (S)-aminotransferase CNB05-01.

Figure 6-32: Effect of isopropylamine concentration on initial rate of production of substituted (S)-aminotetralin by free spray dried cells of CNB05-01......... 106

Figure 6-33: Description of the effect of isopropylamine concentration on initial rate by the model of substrate inhibition -Equation (17)- (continuous trend)......... 107

Figure 6-34: Effect of substituted tetralone concentration on production rate of substituted (S)-aminotetralin by free spray dried CNB05-01. 108

Figure 6-35: Effect of $\mathrm{pH}$ on reaction rate of production of substituted (S)-aminotetralin by free CNB05-01. 110

Figure 6-36: Effect of Pyridoxal-5-phosphate (PLP) concentration on reaction rate of free (S)-aminotransferase catalyzing the reaction system of substituted tetralone at $55^{\circ} \mathrm{C}, \mathrm{pH} 7$. 112

Figure 6-37: Substrate concentration effect on reaction rate of CNB05-01. Plot A experimental data, Plot $\mathrm{B}$ reaction rate predicted by Equation 17 with $\mathrm{V}_{\mathrm{m}}=0.19 \mathrm{mM} / \mathrm{min}, \mathrm{K}_{\mathrm{mA}}=0.62 \mathrm{mM}, \mathrm{K}_{\mathrm{mB}}=0.01 \mathrm{mM}$, and $\mathrm{K}_{\mathrm{iA}}=1.22 \mathrm{mM} \ldots \ldots .115$

Figure 6-38: Correlation between experimental reaction rate and predicted by Model 4 at $55^{\circ} \mathrm{C}, \mathrm{pH} 7$, enzyme concentration of one gram per liter, and $2 \mathrm{mM}$ pyridoxal-5-phosphate.

Figure 7-1: Production of substituted (S)-aminotetralin using immobilized CNB03-03 during recycle at $50{ }^{\circ} \mathrm{C}$.

Figure 7-2: Initial rate of CNB03-03 during recycle at $50{ }^{\circ} \mathrm{C}$. 129

Figure 7-3: Change on reaction rate of immobilized CNB04-01 during continuous production of substituted (S)-aminotetralin at $50{ }^{\circ} \mathrm{C}$. R1 was the activity at 0 $\mathrm{hr}, \mathrm{R} 2$ at $20 \mathrm{hr}, \mathrm{R} 3$ at $42 \mathrm{hr}$, and R4 after $65 \mathrm{hr}$ under reactions conditions. 132

Figure 7-4: Change on initial reaction rate of immobilized CNB03-03 and CNB04-01 during continuous production of substituted (S)-aminotetralin at $50{ }^{\circ} \mathrm{C} \mathrm{pH} 7$.

Figure 7-5: Enzymatic activity of immobilized CNB04-01 during continuous production of substituted (S)-aminotetralin at $50{ }^{\circ} \mathrm{C} \mathrm{pH} 7$ at $3 \%(\mathrm{v} / \mathrm{v})$ toluene.

Figure 7-6: Change on reaction rate of immobilized CNB04-01 during continuous production of substituted (S)-aminotetralin at $50{ }^{\circ} \mathrm{C}$.

Figure 7-7: Change in initial reaction rate of immobilized CNB04-01 during continuous production of substituted (S)-aminotetralin at $50{ }^{\circ} \mathrm{C} \mathrm{pH} 7$ at $3 \%(\mathrm{v} / \mathrm{v})$ of toluene or $3 \%(\mathrm{v} / \mathrm{v})$ ethanol.

Figure 7-8: Initial reaction rate of free spray dried cells of CNB04-01 as a function of sodium dodecyl sulfate concentration.

Figure 7-9: Enzymatic activity of immobilized CNB04-01 during continuous production of substituted (S)-aminotetralin at $50^{\circ} \mathrm{C} \mathrm{pH} 7$ with $0.01 \%(\mathrm{w} / \mathrm{v})$ sodium dodecyl sulfate. 
Figure 7-10: Change in initial reaction rate of immobilized CNB04-01 during continuous production of substituted $(\mathrm{S})$-aminotetralin at $50{ }^{\circ} \mathrm{C}, \mathrm{pH} 7$, with $0.01 \%(\mathrm{w} / \mathrm{v})$ sodium dodecyl sulfate.

Figure 7-11: Change to initial reaction rate of immobilized CNB04-01 during continuous production of substituted (S)-aminotetralin at $50{ }^{\circ} \mathrm{C} \mathrm{pH} 7$ at $3 \%(\mathrm{v} / \mathrm{v})$ of toluene, $3 \%(\mathrm{v} / \mathrm{v})$ ethanol, and $0.01 \%(\mathrm{w} / \mathrm{v})$ sodium dodecyl sulfate.

Figure 7-12: Production of substituted (S)-aminotetralin by immobilized spray dried cells of CNB05-01, in two cycles (R1 and R2,) at a concentration of 1 grams per liter in $100 \mathrm{ml}$ of Solution $18 \mathrm{pH} 7$ at $55^{\circ} \mathrm{C}$.

Figure 8-1: Production of substituted (S)-aminotetralin by free spray dried cells of CNB05-01 at a concentration of 5 grams per liter in $100 \mathrm{ml}$ of Solution $18 \mathrm{pH}$ 7 at $55^{\circ} \mathrm{C}$.

Figure 8-2: Comparison of reaction rates of CNB03-03, CNB04-01 and CNB05-01 in 50 $\mathrm{ml}$ of Solution 14 at $\mathrm{pH} 7$ for different temperatures. 150

Figure 9-1: Profile concentration of total substituted (S)-aminotetralin at several enzyme (spray dried cells of CNB05-01) concentrations $\left(55^{\circ} \mathrm{C}\right.$, and $\left.\mathrm{pH} 7\right)$.

Figure 9-2: Profile concentration of substituted (S)-aminotetralin on solution at several temperatures $\left(\mathrm{E}_{\mathrm{o}}=5 \mathrm{~g} / \mathrm{l}, \mathrm{pH} 7\right)$. 160

Figure 9-3: Profile concentration of imine at several temperatures $\left(\mathrm{E}_{0}=5 \mathrm{~g} / \mathrm{l}, \mathrm{pH} 7\right) \ldots 160$

Figure 9-4: Profile concentration of substituted (S)-aminotetralin at $55^{\circ} \mathrm{C}$ using free spray dried cells of CNB05-01) $\left(\mathrm{E}_{\mathrm{o}}=5 \mathrm{~g} / \mathrm{l}\right)$.

Figure 9-5: Profile concentration of imine at $55^{\circ} \mathrm{C}$ using free spray dried cells of CNB05-01 $\left(\mathrm{E}_{\mathrm{o}}=5 \mathrm{~g} / \mathrm{l}\right)$

Figure 9-6: Profile concentration of substituted (S)-aminotetralin on solution $\mathrm{pH} \mathrm{7,} \mathrm{E}_{\mathrm{o}}=$ $5 / 1$, at several isopropylamine concentration.

Figure 9-7: Profile concentration of imine at $\mathrm{pH} 7, \mathrm{E}_{\mathrm{o}}=5 / 1$, at several isopropylamine concentration.

Figure 9-8: Profile concentration of total substituted (S)-aminotetralin concentration produced at several isopropylamine concentrations, $\mathrm{pH} 7$, (free spray dried cells of CNB05-01) $\left(\mathrm{E}_{\mathrm{o}}=5 \mathrm{~g} / \mathrm{l}\right)$.

Figure 9-9: Profile concentration of total substituted (S)-aminotetralin produced using several cosolvents at $55^{\circ} \mathrm{C}, \mathrm{pH} 7, \mathrm{E}_{\mathrm{o}}=5 \mathrm{~g} / \mathrm{l}$.

Figure 9-10: Effect of nitrogen flow in the production of (S)-aminotetralin at $55^{\circ} \mathrm{C}$ using free $\mathrm{CNB} 05-01$ at $\mathrm{E}_{\mathrm{o}}=1 \mathrm{~g} / \mathrm{l}$. 


\section{Chapter 1. Introduction}

\subsection{Aminotransferases}

Aminotransferases are enzymes belonging to the major enzyme classification known as transferases. Their function is to transfer the amino group from a donor molecule to an acceptor oxo acid, requiring pyridoxal-5-phosphate as a cofactor. Since aminotransferases require a cofactor, they are also classified as holoenzymes, where a holoenzyme is formed by a chain of aminoacids (Apoenzyme) and the cofactor.

\subsection{Aminotransferase Technology}

Use of aminotransferases at an industrial scale have some significance because they allow the production chiral amino acids and amines (Stirling, 1993), since they show stereoselectivity. The need for chiral aminoacids and imines is present in the pharmaceutical industry, since it requires such compounds as active pharmaceutical ingredients. An example of active pharmaceutical ingredient is substituted (S)aminotetralins, which have some potential in the treatment of Parkinson disease (Scheller et al., 2005(b); Warawa et al., 1998), depression (Scheller et al., 2005(a)), and cardiovascular problems (Montanari et al., 1998; Chiesi et al., 1996). Since the treatment of Parkinson disease, depression and cardiovascular problems represents a huge business opportunity, several companies have chosen to produce the active pharmaceutical ingredient: substituted (S)-aminotetralins. One company, Cambrex (C), has started the production of such active pharmaceutical ingredient based on aminotransferase-utilizing 
processes. Aminotransferases allow for the production of substituted (S)-aminotetralin at high purity due to its stereoselectivity. The aminotransferase technology developed at Cambrex (C) is based on the (S)-aminotransferase gene isolated from Athrobacter citreus (Pannuri et al, 2006(a)), sub-cloned into plasmid pSE420, and expressed as intracellular protein in the host Escherichia coli MG1655. The wild type gene has been engineered further following the procedure called directed evolution. The directed evolution of the (S)-aminotransferase from Athrobacter citreus consists of the improvement of activity and thermostability by means error prone polymerase chain reaction mutagenesis (PCR). The improved mutants of (S)-aminotransferase are targeted to perform the synthesis of substituted (S)-aminotetralin (Figure 1-1). The synthesis of this active pharmaceutical ingredient requires substituted tetralone and isopropylamine as amine donor, obtaining as a byproduct acetone.

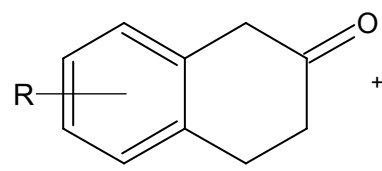

Substituted Tetralone

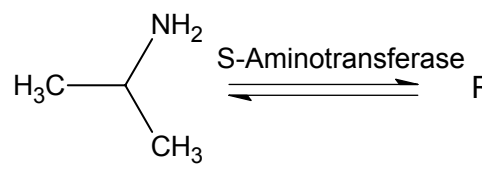

Isopropylamine

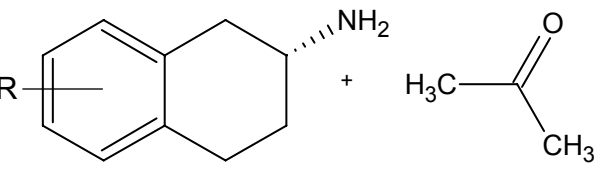

Substituted (S)-Aminotetralin

Acetone

Figure 1-1: Synthesis of substituted (S)-aminotetralin by (S)-aminotransferase.

As a result of the directed evolution of the (S)-aminotransferase from Athrobacter citreus towards improve activity and thermostability, several mutants were obtained. These mutants showed improvement in activity, final product concentration, and optimum temperature over the wild type (S)-aminotransferase. The improvements of these mutants in terms of product concentration are shown in Figure 1-2. 


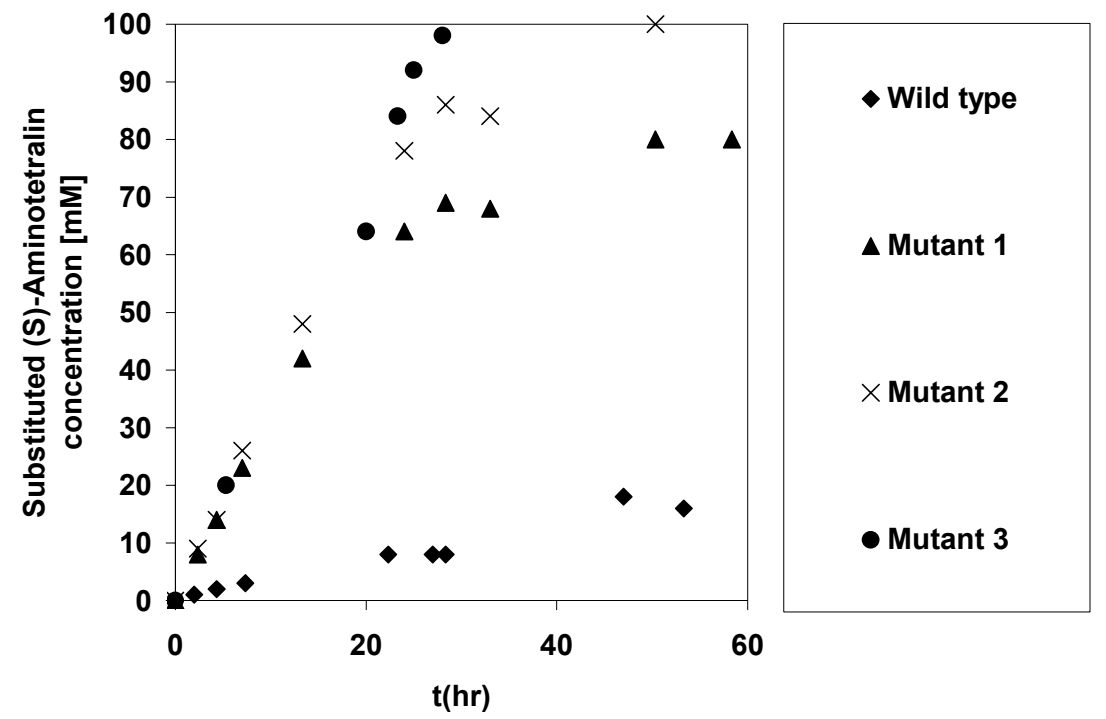

Figure 1-2: Comparison of (S)-aminotransferase mutants in terms of production of substituted (S)-aminotetralin.

Figure 1-2 shows the profile concentration of the desired product given by wild type, mutant 1 , mutant 2, and mutant 3 from the first, second, and third generations of mutagenesis. The profiles of concentrations were obtained using for wild type a total load of 15 grams of spray dried cells (cells of E. coli MG1655 with (S)-aminotransferase over expressed) per liter at $30^{\circ} \mathrm{C}, 15$ grams of spray dried cells per liter of mutant 1 at $30^{\circ} \mathrm{C}$, 15 grams of spray dried cells per liter of mutant 2 at $45{ }^{\circ} \mathrm{C}$, and 5 grams of spray dried cells per liter of mutant 3 at $50{ }^{\circ} \mathrm{C}$. Mutant 1 exhibited a four-fold increase on final product concentration in comparison to wild type (S)-aminotransferase, Mutant 2 a fivefold increase on the same basis. Mutant 3 -later on referred as CNB03-03- allowed a three-fold reduction on spray dried cells and about a six-fold increase on final product concentration, in comparison to wild type (S)-aminotransferase. 
The results shown in Figure 1-2 were obtained using spray dried cells as biocatalyst instead of purified (S)-aminotransferase. The choice of using spray dried cells over purified enzyme is done when the enzyme retains activity for an extended period of time, can be stored at room temperature, and can be used directly in the reaction without further processing (Pannuri et al, 2002). Such requirements are met by the (S)aminotransferase mutants derived from Athrobacter citreus. Furthermore, the purification of (S)-aminotransferase has been shown to be not feasible from the industrial point of view, as it involved many steps and loses of (S)-aminotransferase, as shown in Appendix 8. In prior directed evolution work, in the third generation of mutagenesis a mutant aminotransforase was obtained that allowed for a three-fold reduction in concentration of spray dried cells and an increase of about six-fold in concentration of the desired product in comparison to wild type (S)-aminotransferase. Due to the nature of the synthesis of substituted (S)-aminotetralin (Figure 1-3), some problems are found during its production.

1) Even though spray dried cells present some economical advantages over purified enzymes, it is still a significant factor in the final product cost to use a load of 5 grams of spray dried cells per liter.

2) The process time of the synthesis reaction using mutant 3 (about 24 hours) contributes significantly to the final product costs, which is directly related with the enzyme activity. 3) Finally, during the steps of isolation/purification of the product, the activity of (S)aminotransferase is lost because of the addition of $\mathrm{HCl}_{(\mathrm{aq})}$, and some product is lost when 
the spray dried cells are removed by centrifugation (decreasing the overall yield of product recovery and contributing to the production cost significantly).

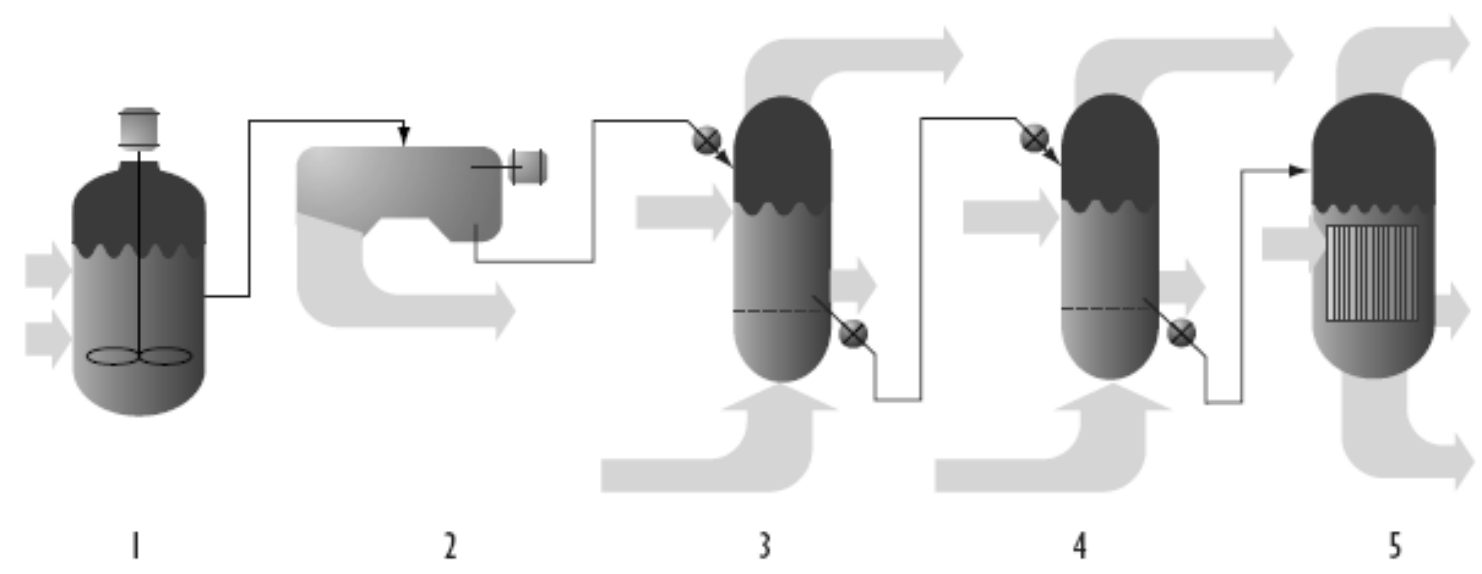

Figure 1-3: Production process of substituted (S)-aminotetralin. Consists of biontransformation (1), centrifugation (2), extraction to remove ketone (3), extraction of product (4), and isolation-purification of product (Pannuri et al., 2006(b)).

\subsection{Research Objectives}

As listed above the use of mutant 3 (CNB03-03) to produce substituted (S)-aminotetralin at industrial scale has the following limitations (when used at 5 grams of spray dried cells per liter):

1) High cost of spray dried cells

2) Long reaction time (24 hours)

3) Lower yield during product isolation 
All of these factors contribute to the production cost of substituted (S)-aminotetralin, which is a function of costs of raw materials, use of (S)-aminotransferases as spray dried cells, and reaction time. If the production cost of substituted (S)-aminotetralin is decreased, then the overall profits per unit of product would decrease. Therefore to minimize the spray dried cells cost contribution to the production cost of substituted (S)-aminotetralin, two research strategies were selected:

1) Immobilize and engineer of (S)-aminotransferase as spray dried cells (Chapter 7 and Chapter 5, respectively), and

2) Increase the specific activity of spray dried cells using enzyme engineering methods described later in this dissertation (Chapter 8 and Chapter 5, respectively).

Immobilization would allow the recycle of spray dried cells and facilitate their removal from the reaction mixture; leading to reduced cost for total production. By means of error-prone PCR it may be possible to obtain a mutant with higher specific activity. This would allow a reduction in the amount of free spray dried cells used in the synthesis reaction. In addition, product isolation would be more efficient since biomass concentration (spray-dried cells) would be lower and product association with spray-dried cells would be minimized.

Chapter 2 describes the general features of the aminotransferase reaction, and in doing so, establishes a conceptual foundation for the research presented in this dissertation in subsequent chapters. 


\section{Chapter 2. Transamination Reaction}

\subsection{Transamination Reaction}

The reaction that is the object of this work is transamination. In this chapter is a description of the reaction mechanism and kinetic model. The rapid reversible transfer of the $\mathrm{NH}_{2}$ group, together with an electron pair and a proton, between a donor amino acid and an acceptor oxo acid, shown in Figure 2-1, was designated as transamination reaction (Braunstein, 1957).

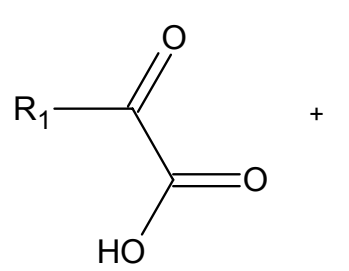

Acceptor oxo acid

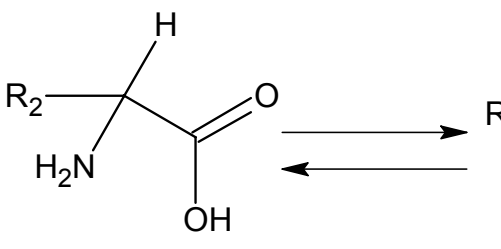

Donor amino acid<smiles>[Z7]C(N)C(=O)O</smiles>

Amino acid<smiles>[R2]C(=O)C(=O)O</smiles>

Oxo acid

Figure 2-1: Transamination reaction

\subsubsection{Transamination Reaction: Pyridoxal-5-phosphate Dependence}

The transamination reaction is catalyzed by holoenzymes named aminotransferases. Aminotransferases need pyridoxal-5-phosphate (PLP) as a coenzyme. PLP is one of the six naturally occurring derivatives of 3-hydroxy-2-methylpyridine, commonly known as vitamin $\mathrm{B}_{6}$. Figure 2-2 shows the naturally occurring forms of vitamin $\mathrm{B}_{6}$. 


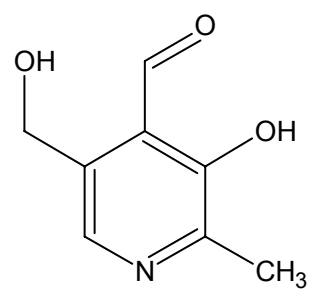

Pyridoxal

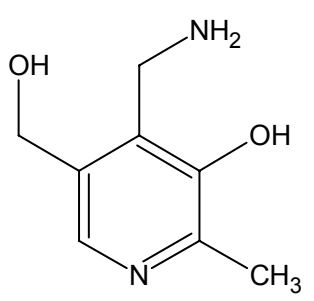

Pyridoxamine

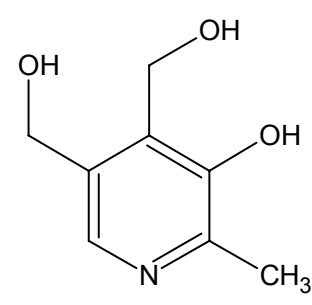

Pyridoxine<smiles>Cc1ncc(COP(=O)(O)O)c(C=O)c1O</smiles>

Pyridoxal-5-phosphate

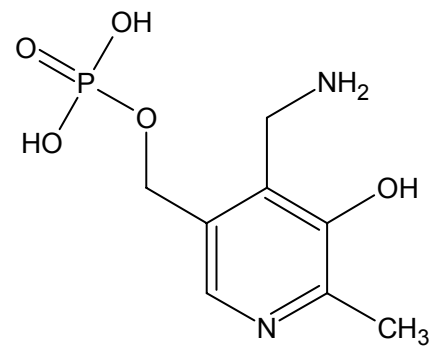

Pyridoxamine-5-phosphate<smiles>Cc1ncc(COP(=O)(O)O)c(CO)c1O</smiles>

Pyridoxine-5-phosphate

Figure 2-2: Forms of Vitamin $B_{6}$.

Pyridoxal-5-phosphate (PLP) is bound in the active site of the apoenzyme to a lysine residue. Pyridoxal-5-phosphate reacts with the exposed $\mathrm{NH}_{2}$ group of lysine residue to form an aldimine (pyridoxamine-5-phosphate or PMP). Figure 2-3 shows the structures of lysine, lysine residue and the aldimine complex. The complex pyridoxal-5-phosphate apoenzyme (Aldimine complex) undergoes several changes. The amine donor binds to the active non-protonated PLP enzyme. Next one proton is transferred from the substrate's $\mathrm{NH}_{3}{ }^{+}$group to the aldimine nitrogen atom or the 3-phenolic oxygen atom of the coenzyme. After that, the substrate's deprotonated amino (nucleophilic) group attacks the $\mathrm{C}^{\prime}$ ' of the coenzyme and displaces the lysine $\varepsilon-\mathrm{NH}_{2}$ group from PLP, giving rise to the formation of a new aldimine between PLP and the substrate's deprotonated amino group. 


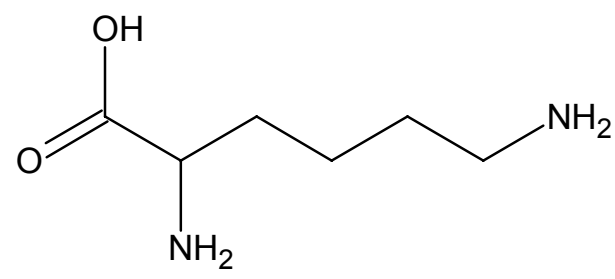

Lysine
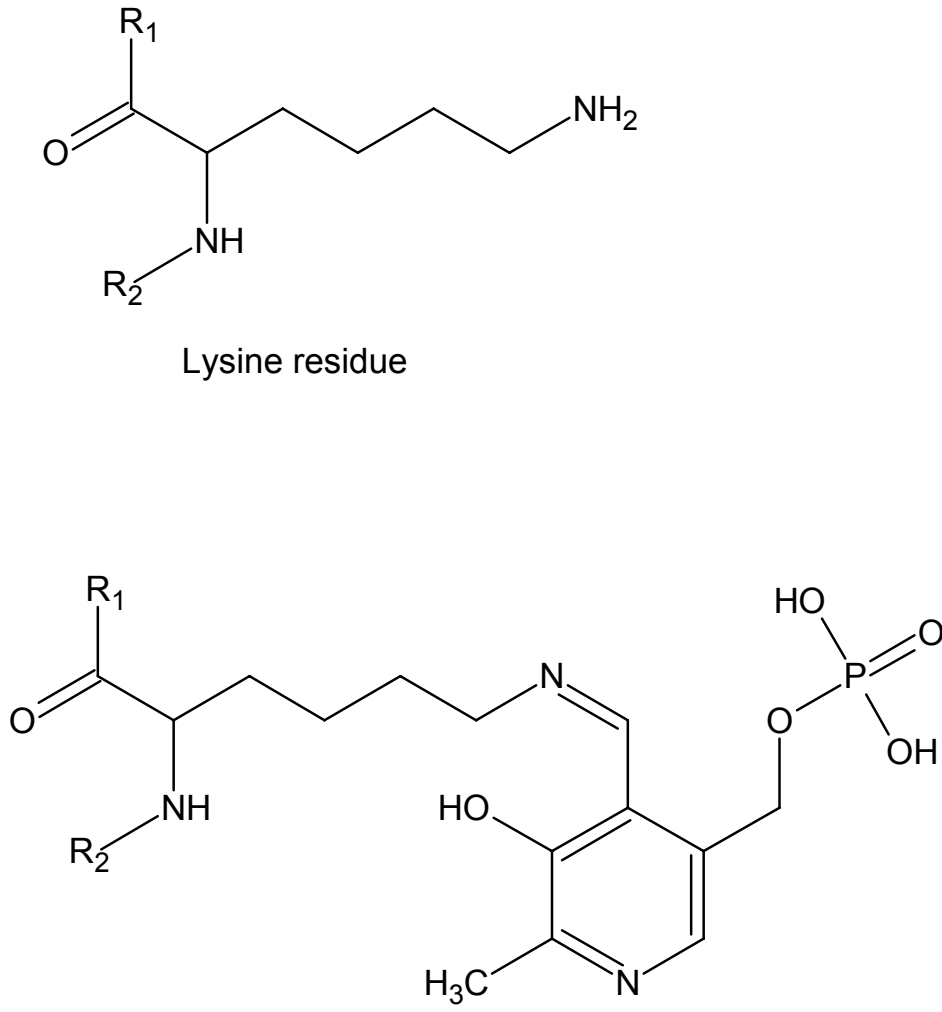

Aldimine complex

Figure 2-3: Structures of lysine, lysine residue on a polypeptide chain and aldimine complex.

After this a carbanionic intermediate quinonoid structure is formed by the dissociation of the $\alpha-\mathrm{H}$ of the aldimine formed previously. Then, the quinonoid intermediate is protonated at the $\mathrm{C}^{\prime}$ ' atom to give pyridoxamine-5-phosphate ketimine (PMP ketimine) 
as the product. Finally, there is hydrolysis of the ketimine to release the PMP-enzyme and the oxo acid product. The sequence of steps described previously involves the formation of an aldimine between the amino group of the donor and PLP, it could lead to a stable aldimine that would sequestrate the coenzyme, resulting in inactivation as an overall effect (Rando \& Bangerter, 1976; Kobayashi et al., 1977; Rando, 1977; Kim et al., 1981).

\subsubsection{Mechanism of Transamination}

During the reaction of transamination a product is released between the additions of the two substrates following a reaction mechanism known as ping-pong $\mathrm{Bi} \mathrm{Bi}$ (Cleland, 1963), where there are two substrates and two products. The ping-pong Bi Bi mechanism is shown in Figure 2-4.

$\mathrm{A}+\mathrm{B} \rightleftarrows \mathrm{P}+\mathrm{Q}$

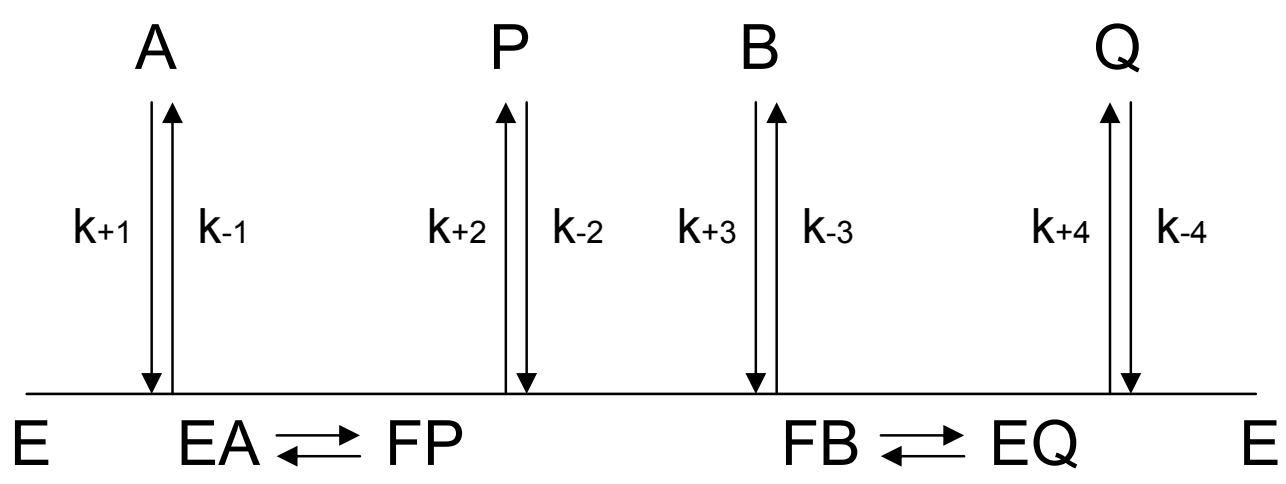

Figure 2-4: Ping-pong Bi Bi mechanism. 
In Figure 2-4, A is the amine donor [isopropylamine on Figure 1-1], B amine acceptor [substituted tetralone on Figure 1-1], P deaminated donor [acetone on Figure 1-1], Q aminated acceptor [substituted aminotetralin on Figure 1-1], E is PLP-enzyme complex, and F is PMP-enzyme complex. The mechanism involves two different stable enzymes forms, (E) and (F), and two sets of central complexes; (EA) and (FP), (FB) and (EQ). The interconversion of the central complexes is ignored during the analysis of this mechanism. The steps that will be considered are shown in Figure 2-5.

The rate expression for themechanism of ping-pong $\mathrm{Bi} \mathrm{Bi}$ is obtained from the following derivation (Kuby, 1999; Cleland, 1963).

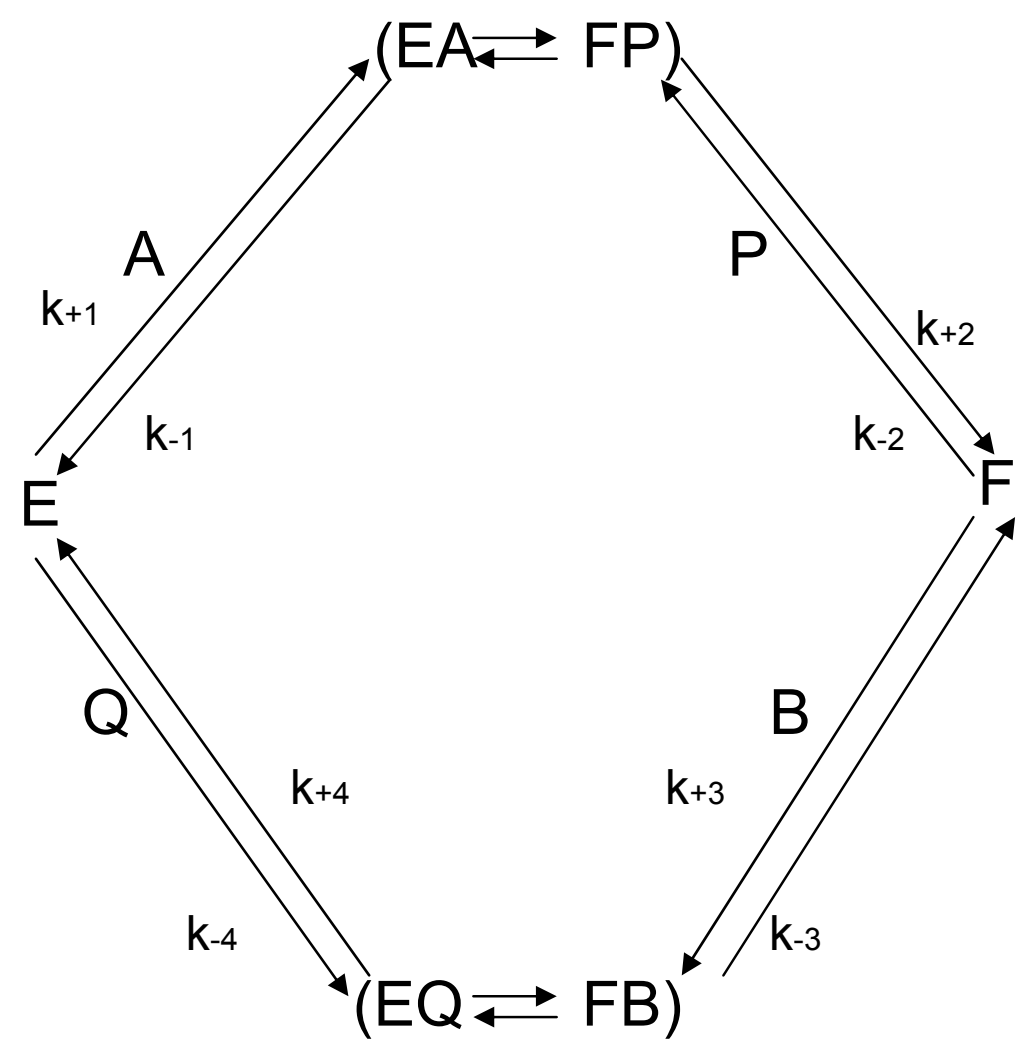

Figure 2-5: Rate determining steps of ping-pong Bi Bi mechanism (Kuby; 1991). 
Applying mass balance to diagram shown in Figure 2-5 for the enzyme

$E o=E+(E A+F P)+F+(E Q+F B)$

Then determining the net rate of formation of complexes (EA+FP), (F), and (EQ+FB).

$$
\begin{aligned}
& \frac{d(E A+F P)}{d t}=k_{+1} A E+k_{-2} F P-\left(k_{-1}+k_{+2}\right)(E A+F P) \\
& \frac{d(F)}{d t}=k_{+2}(E A+F P)+k_{-3}(E Q+F B)-\left(k_{+3} B+k_{-2} P\right) F \\
& \frac{d(E Q+F B)}{d t}=k_{+3} B F+k_{-4} Q E-\left(k_{-3}+k_{+4}\right)(E Q+F B)
\end{aligned}
$$

Now, applying the conditions of steady state for Equations (2), (3) and (4)

$$
\frac{d(E A+F P)}{d t}=\frac{d(F)}{d t}=\frac{d(E Q+F B)}{d t}=0
$$

Using Equations (1) to (5) and solving for (E), (EA+FP), (F), and (FB+EQ) was obtained Equations (6) to (9)

$$
\frac{(E)}{E O}=\frac{k_{+3} k_{+4}\left(k_{-1}+k_{+2}\right) B+k_{-1} k_{-2}\left(k_{-3}+k_{+4}\right) P}{\left[\begin{array}{l}
k_{+1} k_{+2}\left(k_{-3}+k_{+4}\right) A+k_{+3} k_{+4}\left(k_{-1}+k_{+2}\right) B \\
+k_{-1} k_{-2}\left(k_{-3}+k_{+4}\right) P+k_{-3} k_{-4}\left(k_{-1}+k_{+2}\right) Q \\
+k_{+1} k_{+3}\left(k_{+2}+k_{+4}\right) A B+k_{+1} k_{-2}\left(k_{-3}+k_{+4}\right) A P \\
+k_{-2} k_{-4}\left(k_{-1}+k_{-3}\right) Q P+k_{+3} k_{-4}\left(k_{-1}+k_{+2}\right) Q B
\end{array}\right]}
$$




$$
\begin{aligned}
& \frac{(E A+F P)}{E O}=\frac{k_{++1} k_{+3} k_{+4} A B+k_{+1} k_{-2}\left(k_{-3}+k_{+4}\right) A P+k_{-2} k_{-3} k_{-4} Q P}{\left[\begin{array}{l}
k_{+1} k_{+2}\left(k_{-3}+k_{+4}\right) A+k_{+3} k_{+4}\left(k_{-1}+k_{+2}\right) B \\
+k_{-1} k_{-2}\left(k_{-3}+k_{+4}\right) P+k_{-3} k_{-4}\left(k_{-1}+k_{+2}\right) Q \\
+k_{+1} k_{+3}\left(k_{+2}+k_{+4}\right) A B+k_{+1} k_{-2}\left(k_{-3}+k_{+4}\right) A P \\
+k_{-2} k_{-4}\left(k_{-1}+k_{-3}\right) Q P+k_{+3} k_{-4}\left(k_{-1}+k_{+2}\right) Q B
\end{array}\right]} \\
& \frac{(F)}{E O}=\frac{k_{+1} k_{+2}\left(k_{-3}+k_{+4}\right) A+k_{-3} k_{-4}\left(k_{-1}+k_{+2}\right) Q}{\left[\begin{array}{l}
k_{+1} k_{+2}\left(k_{-3}+k_{+4}\right) A+k_{+3} k_{+4}\left(k_{-1}+k_{+2}\right) B \\
+k_{-1} k_{-2}\left(k_{-3}+k_{+4}\right) P+k_{-3} k_{-4}\left(k_{-1}+k_{+2}\right) Q \\
+k_{+1} k_{+3}\left(k_{+2}+k_{+4}\right) A B+k_{+1} k_{-2}\left(k_{-3}+k_{+4}\right) A P \\
+k_{-2} k_{-4}\left(k_{-1}+k_{-3}\right) Q P+k_{+3} k_{-4}\left(k_{-1}+k_{+2}\right) Q B
\end{array}\right]} \\
& \frac{(F B+E Q)}{E O}=\frac{k_{+1} k_{+2} k_{+3} A B+k_{+3} k_{-4}\left(k_{-1}+k_{+2}\right) Q B+k_{-1} k_{-2} k_{-4} Q P}{\left[\begin{array}{l}
k_{+1} k_{+2}\left(k_{-3}+k_{+4}\right) A+k_{+3} k_{+4}\left(k_{-1}+k_{+2}\right) B \\
+k_{-1} k_{-2}\left(k_{-3}+k_{+4}\right) P+k_{-3} k_{-4}\left(k_{-1}+k_{+2}\right) Q \\
+k_{+1} k_{+3}\left(k_{+2}+k_{+4}\right) A B+k_{+1} k_{-2}\left(k_{-3}+k_{+4}\right) A P \\
+k_{-2} k_{-4}\left(k_{-1}+k_{-3}\right) Q P+k_{+3} k_{-4}\left(k_{-1}+k_{+2}\right) Q B
\end{array}\right]}
\end{aligned}
$$

Defining the rate of reaction by the following expression

$v=k_{+1}(E) A-k_{-1}(E A+F P)$

Substituting (E) and (EA+FP) in Equation (10)

$$
v=\frac{k_{+1} k_{+2} k_{+3} k_{+4} E O A B-k_{-1} k_{-2} k_{-3} k_{-4} E O Q P}{\left[\begin{array}{l}
k_{+1} k_{+2}\left(k_{-3}+k_{+4}\right) A+k_{+3} k_{+4}\left(k_{-1}+k_{+2}\right) B \\
+k_{-1} k_{-2}\left(k_{-3}+k_{+4}\right) P+k_{-3} k_{-4}\left(k_{-1}+k_{+2}\right) Q \\
+k_{+1} k_{+3}\left(k_{+2}+k_{+4}\right) A B+k_{+1} k_{-2}\left(k_{-3}+k_{+4}\right) A P \\
+k_{-2} k_{-4}\left(k_{-1}+k_{-3}\right) Q P+k_{+3} k_{-4}\left(k_{-1}+k_{+2}\right) Q B
\end{array}\right]}
$$

Multiplying the numerator and denominator of Equation (11) by the following expression 
$\frac{k_{-1} k_{-3}}{k_{+1} k_{+3}\left(k_{+2}+k_{+4}\right)\left(k_{-1}+k_{-3}\right)}$

And multiplying the coefficients of P, Q, AP, and PQ terms by

$\frac{k_{+1} k_{+2} k_{+3} k_{+4}}{k_{+1} k_{+2} k_{+3} k_{+4}}$

The expression for rate of reaction for the mechanism of ping-pong $\mathrm{Bi} \mathrm{Bi}$ is shown in Equation (14).

$$
v=\frac{v_{\max }^{f} v_{\max }^{r}\left((A)(B)-\frac{(P)(Q)}{K e q}\right)}{\left[\begin{array}{l}
v_{\max }^{r} K_{m B}(A)+v_{\max }^{r} K_{m A}(B)+v_{\max }^{f} \frac{K_{m Q}}{K e q}(P) \\
+v_{\max }^{f} \frac{K_{m P}}{K e q}(Q)+v_{\max }^{r}(A)(B)+\frac{v_{\max }^{f} K_{m Q}}{K e q K_{i q}}(A)(P) \\
+\frac{v_{\max }^{f}}{K e q}(Q)(P)+\frac{v_{\max }^{r} K_{m A}}{K_{i q}}(Q)(B)
\end{array}\right]}
$$

Where

$$
\begin{aligned}
\frac{v_{\operatorname{mxx}}^{f}}{E O} & =\frac{k_{+2} k_{+4}}{\left(k_{+2}+k_{+4}\right)} \\
\frac{v_{\max }^{r}}{E O} & =\frac{k_{-1} k_{-3}}{\left(k_{-1}+k_{-3}\right)} \\
K e q & =\frac{k_{+1} k_{+2} k_{+3} k_{+4}}{k_{-1} k_{-2} k_{-3} k_{-4}} \\
K_{m B} & =\frac{k_{+2}\left(k_{-3}+k_{+4}\right)}{k_{+3}\left(k_{+2}+k_{+4}\right)} \\
K_{m A} & =\frac{k_{+4}\left(k_{-1}+k_{+2}\right)}{k_{+1}\left(k_{+2}+k_{+4}\right)}
\end{aligned}
$$




$$
\begin{aligned}
& K_{m Q}=\frac{k_{-1}\left(k_{-3}+k_{+4}\right)}{k_{-4}\left(k_{-1}+k_{-3}\right)} \\
& K_{m P}=\frac{k_{-3}\left(k_{-1}+k_{+2}\right)}{k_{-2}\left(k_{-1}+k_{-3}\right)} \\
& K_{\text {iQ }}=\frac{k_{-1}}{k_{+1}} \\
& K_{\text {iq }}=\frac{k_{+4}}{k_{-4}}
\end{aligned}
$$

The derivation of Equation (14) was showed in order to follow step by step the mechanism of transamination. This understanding could help when trying to account for some issues not considered, for example substrate or product inhibition. Besides this, Equation (14) has direct application in Section 6.2.2.4; which has as objective to determine the model that best describes the engineered (S)-aminotransferases from this research.

\subsubsection{Stereochemistry of Transamination}

PLP and PMP at the active site of aminotransferases exist in a chiral environment. After condensation with amino or oxo acid substrates, the chirality persists. The removal or addition of a proton at $\mathrm{C} \alpha$ of the substrate as well as at $\mathrm{C} 4$ ' of the aldimine or ketimine proceeds with a defined stereoselectivity (Christen and Metzler, 1985). Similar selectivity is noticed in a variety of PLP-dependent enzymes.

The fact that chirality persists after transamination reaction, is also present during nonenzymatic transamination. Longenecker and Snell observed in 1956 that in a system mediated by pyridoxal and $\mathrm{Cu}$ (II), L-alanine and 2-oxoglutarate underwent 
nonenzymatic transamination with preferential production of L-glutamate. Similarly, when D-alanine was used, more D-glutamate than L-glutamate was produced. Based on these results, Longenecker and Snell proposed that in enzymatic transamination, asymmetric chelates between holoenzymes and substrate would explain the optical specificity of the reaction, since it was already known that reactions requiring Laminoacids and oxo acids produced only new L-amino acids arising from the oxo acid substrate (Christen and Metzler, 1985). It was later shown that stereochemical preferences were also present even for base-catalyzed transamination that did not involve pyridoxal compounds (Guthrie et al., 1967). Transamination may occur in several ways as stated above, but the pathway selected for enhanced rate and selectivity by evolution was the one where the reaction is catalyzed by aminotransferases.

The presence of the phosphate group in the cofactor (PLP) is essential for efficient catalytic transamination. It is necessary for proper orientation of the coenzyme substrate complex. The phosphate group does not appear to participate directly in catalysis and seems to exist as a diionic phosphate in cytosolic aspartate aminotransferase (AspAT) (Martinez-Carrion, 1975) and as a mono- or diionic ester in mitochondrial AspAT (Metzler, Jansonius et al., 1982).

The critical need for the phosphate ester for consistency of stereoespecificity of transamination was assessed with AspAT (Martinez-Carrion, Slebe \& Gonzalez, 1979). Catalysis in this enzyme differs from that detected in transaminations involving nonphosphorylated coenzymes in that the removal of the $\alpha$ proton is $\mathrm{pH}$-independent and 
is not the rate-limiting step (Golichowski et al., 1978). In AspAT carbamylated at lysine 258 a transamination reaction in $\mathrm{D}_{2} \mathrm{O}$ can be carried out involving single-turnover stoichiometry between PLP of the holoenzyme and amino-acid-produced monodeuterated PMP. By a correlation method it was determined (Martinez-Carrion, Slebe \& Gonzalez, 1979) that the deuterium addition occurs from the si face and that the addition to PMP takes place at the pro-S position of C4'as shown in Figure 2-6 (Christen and Metzler, 1985).

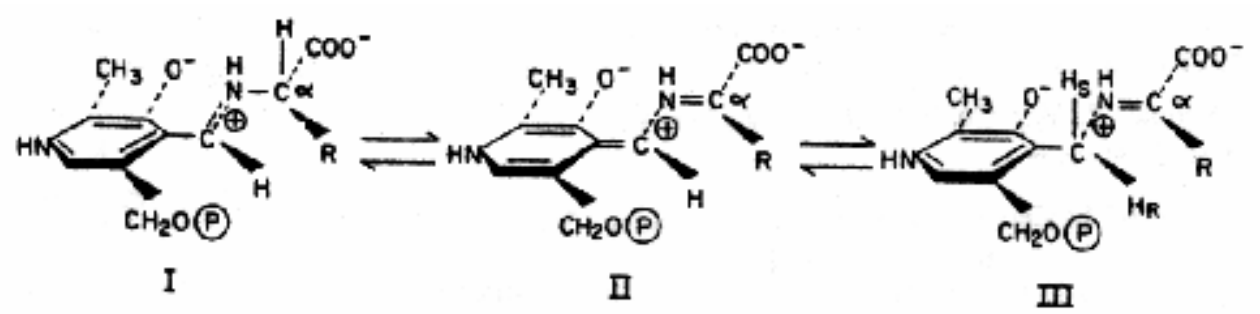

Figure 2-6: Stereochemistry of proton removal and addition in the active site of AspAT, where $H_{S}$ is the hydrogen in the si face; $H_{R}$ is the hydrogen in the re face of the complex (Taken from Christen and Metzler, 1985).

Since the reaction was mediated by an enzyme in which lysine 258 at the active site had been blocked by carbamylation, the results also illustrated that lysyl residue is not essential for maintenance of reaction stereospecificity. Active-site-bound coenzyme exists in a chiral environment provided by the protein in which the sidedness of the molecule toward it can be tested. This technique was developed in Arigoni's laboratory (Austermühle-Bertola, 1973) using an externally added reducing agent, sodium borohydride, as a probe for the exposed side of the aldimine. If the side opposite the solvent-exposed side is sheltered by the protein, reduction must be stereospecific. 
During the formation of the external aldimine, the active-site lysyl residue is freed and the movement of the pyridine ring in at least one aminotransferase, mitochondrial AspAT (Metzler, Jansonius et al., 1982) results in perturbation of the phosphate environment (Mattingly et al., 1982). The changes in the relationship of the pyridine ring to the protein vicinal residue can be detected by circular dichroism measurements (Ivanov et al., 1967; Martinez-Carrion, Tiemeir \& Peterson, 1970). The external aldimine exists in a chiral environment not necessarily identical to that of internal aldimine. Trapping the external aldimine by adding reducing agents is cumbersome; because the differences in reduction rate between it and the internal aldimine. Cytosolic AspAT reduction is at least 3 to 4 orders of magnitude faster in the internal aldimine. Since saturation concentrations of substrates produce equilibrium between all aldimines and ketimines in the reaction pathway, the difference in reactivity favors high yield of reduced internal Schiff base, the result being a predominance of pyridoxyl-lysine. Nevertheless, attempts were made to use this approach, and sodium borohydride reduction, after addition of aspartate to cytosolic AspAT, produced a very small amount of a compound that after dilution with an excess of chemically prepared pyridoxalaspartate was used to assign a si attack (Austermühle-Bertola, 1973). If the active-site lysyl residue is blocked through carbamylation, producing an enzyme able to undergo half-transamination but unable to equilibrate as an aldimine with lysine 258 , reduction can take place only at pyridoxylaspartate compounds. Treatment with sodium borohydride produces high yields of pyridoxylaspartate, which can be directly degraded and assayed as shown in Figure $2-7$. 

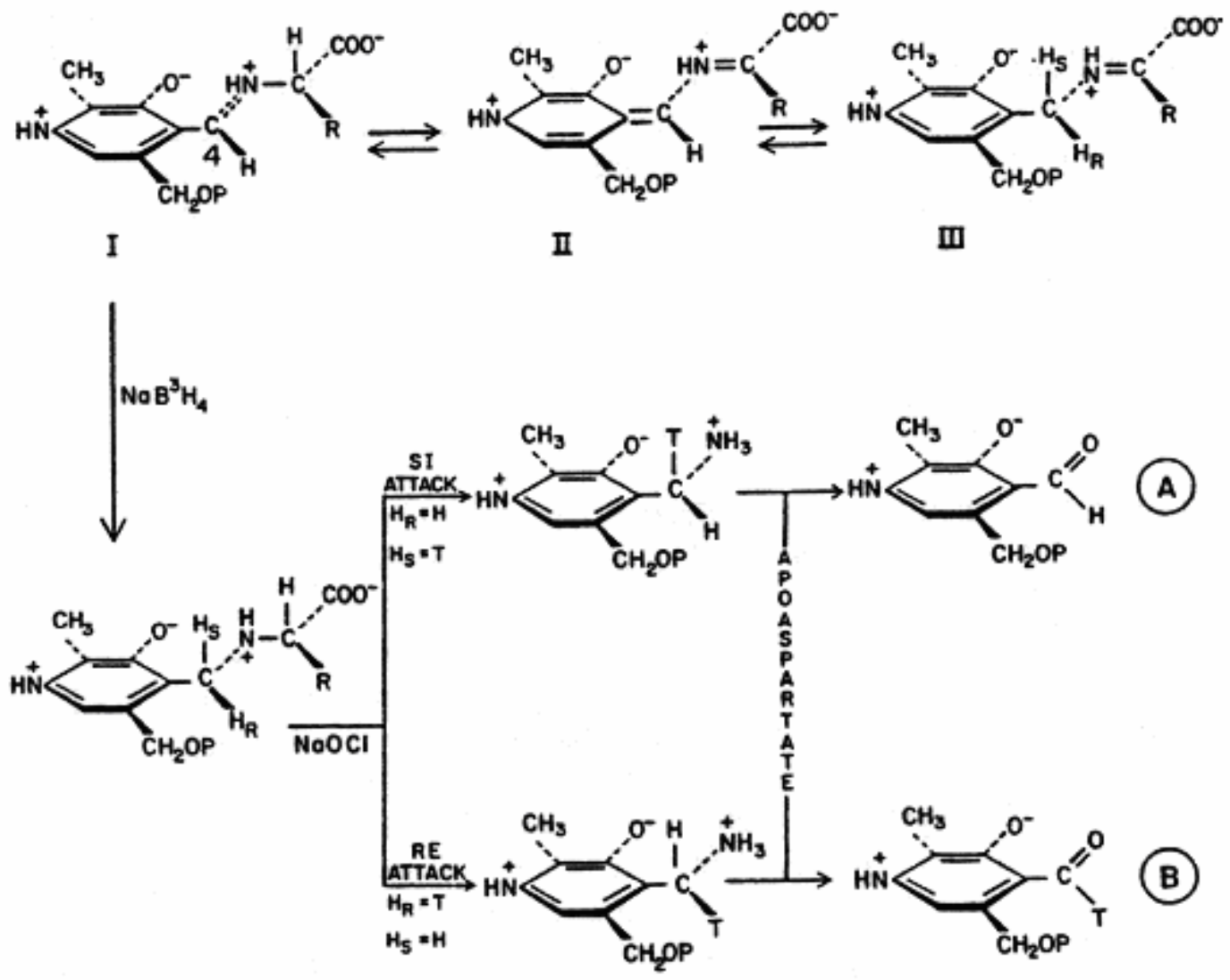

Figure 2-7: Stereochemistry of reduction by sodium borohydride of pyridoxylaspartate compounds in the active site of AspAT (Taken from Christen and Metzler, 1985).

The treatment with sodium borohydride produced evidence that hydride reduction of the coenzyme substrate compound at the enzyme active site occurs from the re face as for the internal aldimine (Zito \& Martinez-Carrion, 1980). A possible interpretation is that the transformation of the internal aldimine to the external aldimine involves a rotation of the coenzyme that does not alter the side of exposure of the aldimine to external hydride attack. Formation of pyridoxal Schiff bases (aldimines) also provides some clues regarding stereochemical requirements. NMR studies or theoretical calculations (Tumanyan et al., 1974; Tsai, Byrn et al., 1978) show that, as proposed for enzymatic active sites, the bond orthogonal to the $\pi$ system of the Schiff base has the greatest probability of being broken because of maximum $\boldsymbol{\sigma}-\boldsymbol{\pi}$ overlap. From these studies, it is 
apparent that the conformation around $\mathrm{C} 5-\mathrm{C} 5$ ' bond appears to be very susceptible to change. In the mitochondrial isoenzymes of AspAT have been detected (Mattingly et al., 1982) that this bond might underlie the ${ }^{31} \mathrm{P}-\mathrm{NMR}$ chemical shift anomalies observed between holoenzyme, enzyme-substrate complex, and sodium borohydride-reduced holoenzyme.

Reduction of Schiff bases of amines and PLP with many model amino acids has been used to test the ability of these transition-state-like analogues to bind to enzyme active sites. In tyrosinate aminotransferase (TyrAT) and AspAT, enzymatic and thermodynamic analysis of binding parameters shows that a variety of amino acids can be introduced at the active site if they are covalently linked to PLP (Voltattorni et al., 1975; Relimpio et

al., 1975). Since ${ }^{31}$ P-NMR measurement point toward a proper occupancy of the phosphate pocket in the apoenzyme by the phosphate ester of these transition-state-like analogues, it indicates that the active site is exquisitely sensitive to the configuration at $\mathrm{C} \alpha$ position of the amino acid.

\subsection{Summary}

Transamination reaction is the rapid reversible transfer of the amino group, together with an electron pair and a proton, between a donor amino acid (or amine) and an acceptor oxo acid (ketone). Such transfer of the amino group is done by mediation of pyridoxal-5phosphate complexed to aminotransferase. The amine donor binds to the active nonprotonated PLP-enzyme complex, and through a series of reactions the donor amine transfers the amine group to PLP, forming PMP. In subsequent reactions PMP transfers 
the amino group to the amine acceptor. Since a step prior to the formation of PMP an aldimine is formed between PLP and the donor amine, sometimes it could lead to a stable aldimine that could sequestrate PLP resulting in inactivation as an overall result. PLP and PMP at the active site of aminotransferases exist in a chiral environment. After condensation with amino or oxo acids substrates (to form aldimines or ketimines) the chirality persists. In the chirality of this reaction the phosphate group in PLP is essential for efficient catalytic transamination, since it is necessary for proper orientation of the PLP substrate complex.

Chapter 3 describes the general procedures used during the experiments done in order to accomplish the research objectives. It focuses in the procedures to monitor the synthesis reaction of substituted (S)-aminotetralin, to engineer aminotransferase, and to characterize the aminotransferase mutants (optimum temperature, optimum $\mathrm{pH}$, and substrate affinity). The procedures followed to immobilize aminotransferases are discussed on Chapter 4. 


\section{Chapter 3. Materials and Methods}

This chapter describes the general procedures used during the experiments done in order to accomplish the research objectives. The procedures focus on how to monitor the synthesis reaction of substituted (S)-aminotetralin, to engineer aminotransferase, and to characterize the aminotransferase mutants (optimum temperature, optimum $\mathrm{pH}$, and substrate affinity). The procedures followed to immobilize aminotransferases are discussed on Chapter 4.

\subsection{Assay for Activity}

\subsection{1. (S)-(-)-a-Methylbenzylamine System (S-MBA System)}

The progress of transamination reaction using (S)-(-)- $\alpha$-methylbenzylamine (Figure 3-1) from Aldrich (S-MBA) as a donor amine and sodium pyruvate from Sigma (SP) as an amine acceptor was followed by measuring the concentration of acetophenone (See

Appendix 1). The activity of substituted (S)-aminotransferase was measured directly using the initial rate of acetophenone generation. The rate was determined by obtaining acetophenone concentrations at 2, 4, 6, and 8 minutes after withdrawing a sample of 200 $\mu \mathrm{l}$ and mixing it with $800 \mu \mathrm{l}$ of $0.1 \mathrm{~N} \mathrm{HCl}$ (Sigma); and analyzing by HPLC. The reaction mixture of the systems tested for (S)- aminotransferase activity was composed of, in addition to S-MBA and SP, pyridoxal-5-phosphate from Schweizer Hall (PLP), potassium phosphate from Fisher Scientific $\left(\mathrm{KH}_{2} \mathrm{PO}_{4}\right)$, 3-[N-mopholino]propane sulfonic 
acid from Sigma (MOPS), sodium acetate from Sigma (SA), and calcium chloride from J. T. Baker $\left(\mathrm{CaCl}_{2}\right)$. Concentrations are provided in Table 3-I..<smiles>CC(=O)c1ccccc1</smiles>

Figure 3-1: Transamination reaction of (S)-(-)- $\alpha$-methylbenzylamine system.

Through the characterization of the (S)-aminotransferases using the system of (S)-(-)- $\alpha-$ methylbenzylamine (S-MBA), some modifications of substrate concentrations as well as additions of substances were made in order to achieve the desired goal of the experiment. The goal of these experiment was to catalyze this system by immobilized (S)aminotransferase on calcium alginate. To accomplish this the buffer was changed, and to increase mechanical stability of the bead $\mathrm{Ca}^{+2}$ was added. To test the affinity for substrates, solutions of several concentrations of them were prepared. The compositions of the solutions used to characterize (S)-aminotransferases are given in Table 3-I.

Table 3-I: Composition of (S)-(-)-a-methylbenzylamine solutions.

\begin{tabular}{|l|l|l|l|l|l|l|l|}
\hline & $\begin{array}{l}\text { S-MBA } \\
\mathbf{m M}\end{array}$ & $\begin{array}{l}\mathbf{S P} \\
\mathbf{m M}\end{array}$ & $\begin{array}{l}\mathbf{P L P} \\
\mathbf{m M}\end{array}$ & $\begin{array}{l}\mathbf{K H}_{2} \mathbf{P O}_{4} \\
\mathbf{m M}\end{array}$ & $\begin{array}{l}\mathbf{M O P S} \\
\mathbf{m M}\end{array}$ & $\begin{array}{l}\mathbf{S A} \\
\mathbf{m M}\end{array}$ & $\begin{array}{l}\mathbf{C a C l}_{\mathbf{2}} \\
\mathbf{m M}\end{array}$ \\
\hline 1 & 15 & 100 & 1 & 100 & & & \\
\hline 2 & Range & 100 & 1 & 100 & & & \\
\hline 3 & 15 & 100 & 1 & & 100 & & \\
\hline 4 & 15 & 100 & 1 & & & & \\
\hline 5 & 15 & 100 & 1 & & & 100 & \\
\hline 6 & 15 & 100 & 1 & & & 100 & 100 \\
\hline 7 & 15 & Range & 1 & & & 100 & 100 \\
\hline 8 & Range & 100 & 1 & & & 100 & 100 \\
\hline 9 & 70 & 100 & 2 & & & 200 & 140 \\
\hline
\end{tabular}




\subsubsection{Measurement of Acetophenone concentration}

The reactions that involved (S)-(-)- $\alpha$-methylbenzylamine and sodium pyruvate was monitored as described in Section 3.1.1. Two hundred $\mu$ l of sample were mixed with 800 $\mu 10.1 \mathrm{~N} \mathrm{HCl}$ and centrifuged. After centrifugation, $25 \mu \mathrm{l}$ samples were analyzed by HPLC (Hewlett-Packard Model 1100 Series) using UV detection. Absorbance was measured at $254 \mathrm{~nm}$ using a flow rate of $1.5 \mathrm{ml} / \mathrm{min}$ for 5 minutes through a Nova-Pack Phenyl column (Waters). The composition of the elution phase was $45 \%$ (v/v) 2-propanol (Sigma) and 55\% (v/v) of aqueous phase. The composition of aqueous phase, on a basis of 4 liters, was 9.85 grams of 1-octanesulfonic acid (Janssen Chimica); and $6 \mathrm{ml}$ of concentrated $\mathrm{H}_{3} \mathrm{PO}_{4}$ (Sigma). The elution time of acetophenone (Aldrich) was $3.7 \pm .2$ minutes.

\subsubsection{Substituted Tetralone System (B System)}

The progress of transamination reaction using substituted tetralone (Figure 1-1) (B) from Cambrex, as the amine acceptor, and isopropylamine from Sigma (A) as an amine donor was followed by measuring the concentration of substituted (S)-aminotetralin (Q) from Cambrex (See Appendix 2). The activity of (S)-aminotransferase was measured directly using the initial rate of $\mathrm{Q}$ generation. The rate was determined by obtaining $\mathrm{Q}$ concentrations at 20,40,60, 80, and 100 minutes, unless specified otherwise, after withdrawing a sample of $0.5 \mathrm{ml}$ and mixing it with $9.5 \mathrm{ml}$ of $\mathrm{HCl}$ (Sigma) $0.1 \mathrm{~N}$, unless specified otherwise; and analyzing by HPLC. The reaction mixture of the systems tested for (S)-aminotransferase activity was composed of (in addition to B, A, and Q) pyridoxal5-phosphate from Schweizer Hall (PLP), potassium phosphate from Fisher Scientific 
$\left(\mathrm{KH}_{2} \mathrm{PO}_{4}\right)$, sodium acetate from Sigma (SA), ethanol from Aldrich (EOH), toluene from Sigma (T), acetone from Aldrich (P) and calcium chloride from J. T. Baker $\left(\mathrm{CaCl}_{2}\right)$. Concentration of these components is shown in Table 3-II.

During the characterization of the (S)-aminotransferases using the system of substituted tetralone, some modifications of substrate concentrations; as well as additions of substances were made in order to achieve the desired goal of the experiment. The goal was to catalyze this system by immobilized (S)-aminotransferase on calcium alginate. To accomplish this the buffer was changed; to increase mechanical stability of the bead $\mathrm{Ca}^{+2}$ was added. To test the affinity for substrates solutions of several concentrations of them were prepared. The compositions of the solutions used to characterize (S)aminotransferases are given in Table 3-II.

Table 3-II: Composition of substituted tetralone solutions.

\begin{tabular}{|l|l|l|l|l|l|l|l|l|l|l|}
\hline & $\mathbf{B}$ & $\mathbf{A}$ & $\mathbf{P L P}$ & $\mathbf{S A}$ & $\begin{array}{l}\mathbf{C a C l}_{2} \\
\mathbf{m M}\end{array}$ & $\begin{array}{l}\mathbf{E O H} \\
(\mathbf{v} / \mathbf{v}) \%\end{array}$ & $\begin{array}{l}\mathbf{T} \\
(\mathbf{v} / \mathbf{v}) \%\end{array}$ & $\begin{array}{l}\mathbf{P} \\
\mathbf{m M}\end{array}$ & $\begin{array}{l}\mathbf{Q} \\
\mathbf{m M}\end{array}$ & $\begin{array}{l}\mathbf{K H}_{2} \mathbf{P O}_{4} \\
\mathbf{m M}\end{array}$ \\
\hline 10 & 110 & 1 & 2 & 200 & 140 & 3 & & & & \\
\hline 11 & 110 & 1 & 2 & 200 & 140 & & 3 & & & \\
\hline 12 & 110 & 1 & 2 & & & & & & & 100 \\
\hline 13 & 110 & $\mathrm{R}$ & 2 & 200 & 140 & & & & & \\
\hline 14 & 110 & 0.5 & 2 & 200 & 140 & & & & & \\
\hline 15 & 35 & 0.5 & 2 & 200 & 140 & & & & & \\
\hline 16 & 110 & 0.5 & 2 & 200 & & & & & & \\
\hline 17 & 130 & $\mathrm{R}$ & 2 & 200 & & & & & & \\
\hline 18 & 130 & 0.75 & 2 & 200 & & & & & & \\
\hline 19 & $\mathrm{R}$ & 0.75 & 2 & 200 & & & & & & \\
\hline 20 & 130 & 0.75 & $\mathrm{R}$ & 200 & & & & & & \\
\hline 21 & $\mathrm{R}$ & $\mathrm{R}$ & 2 & 200 & & & & & & \\
\hline 22 & $\mathrm{R}$ & 0.75 & 2 & 200 & & & & $\mathrm{R}$ & $\mathrm{R}$ & \\
\hline 23 & 30 & 0.75 & 2 & 200 & & & & $\mathrm{R}$ & $\mathrm{R}$ & \\
\hline 24 & & & 2 & 200 & & & & $\mathrm{R}$ & $\mathrm{R}$ & \\
\hline 25 & 130 & 0.75 & 2 & & & & & & & 100 \\
\hline 26 & 130 & $\mathrm{R}$ & 2 & & & & & & & 100 \\
\hline
\end{tabular}

$\mathrm{R}$ implies a range of concentrations for the specific substance 


\subsubsection{Measurement of Aminotetralin Concentration}

Prior to analysis, the samples were incubated at $80{ }^{\circ} \mathrm{C}$ for 30 minutes to hydrolyze formed imine (a product of reaction between substituted tetralone -B- and substituted (S)-aminotetralin -Q-), and then centrifuged. After that $25 \mu 1$ samples were analyzed by HPLC (Hewlett-Packard Model 1100 Series). Absorbance was measured at $254 \mathrm{~nm}$ using a flow rate of $1.5 \mathrm{ml} / \mathrm{min}$ for 20 minutes through a Nova-Pack Phenyl (Waters) column. The composition of the elution phase was 30\% (v/v) 2-propanol (Sigma) and 70\% (v/v) of aqueous phase. The composition of aqueous phase, on a basis of 4 liters, was 9.85 grams of 1-octanesulfonic acid (Janssen Chimica) and $6 \mathrm{ml}$ of concentrated $\mathrm{H}_{3} \mathrm{PO}_{4}$ (Sigma). The elution time of substituted (S)-aminotetralin-Q- (Cambrex) was $10.5 \pm .5$ minutes.

\subsection{Enzyme Characterization}

\subsubsection{Optimum pH}

For each pH value, $20 \mathrm{ml}$ of Solution 6 (Table 3-I) or Solution 14 (Table 3-II) or Solution 18 (Table 3-II) was added to the reaction mixture. The reaction systems, under agitation and incubated at $55{ }^{\circ} \mathrm{C}$, were started by the addition of the free or immobilized enzyme, and analyzed for 8 minutes (S-MBA system) or for 100 minutes (B system). Unless specified otherwise, free enzyme (spray dried cells) was added using $1 \mathrm{ml}$ containing 10 mg of spray dried cells, and immobilized enzyme was added with 1 gram of beads of 10 $\mathrm{mg}$ of spray dried cells/gram bead or 0.4 grams of beads of $25 \mathrm{mg}$ of spray dried 
cells/gram bead; prepared as described in Section 3.4.2. The solution of free spray dried cells was prepared as follows; $0.1 \mathrm{~g}$ of spray dried cells was dissolved in $10 \mathrm{ml}$ of an aqueous solution $(\mathrm{pH}$ 7) having the same concentration of buffer (sodium acetate or potassium phosphate) and pyridoxal-5-phosphate as Solution 6 or Solution 14 or Solution 18. Under the above conditions the rate of acetophenone formation, as well as formation of substituted (S)-aminotetralin-Q-, are linear with time for at least the first 20 minutes (up to $120 \mathrm{~min}$ for the formation of substituted (S)-aminotetralin). Under these conditions all the changes on rate of product formation were directly related with changes on $\mathrm{pH}$ of reaction mixture.

\subsubsection{Temperature}

\subsubsection{Optimum temperature}

For each temperature, $20 \mathrm{ml}$ of Solution $6(\mathrm{pH} \mathrm{7)}$ was added (Table 3-I) or Solution 14 (pH 7) (Table 3-II) or Solution $18(\mathrm{pH} 7)$ (Table 3-II), unless specified otherwise. The reaction systems, under agitation and incubated at $55^{\circ} \mathrm{C}$, were started by the addition of free or immobilized enzyme, and analyzed for 8 minutes (S-MBA system) or for 100 minutes (B system). Unless specified otherwise, free enzyme (spray dried cells) was added using $1 \mathrm{ml}$ containing $10 \mathrm{mg}$ of spray dried cells and immobilized enzyme was added in 1 gram of beads composed of $10 \mathrm{mg}$ of spray dried cells/gram bead or 0.4 grams of beads of $25 \mathrm{mg}$ of spray dried cells/gram bead; prepared as described in Section 3.4.2. The solution of free spray dried cells was prepared as follows; $0.1 \mathrm{~g}$ of spray dried cells were dissolved in $10 \mathrm{ml}$ of an aqueous solution $(\mathrm{pH}$ 7) having the same concentration of buffer (sodium acetate or potassium phosphate) and pyridoxal-5-phosphate as Solution 6 
or Solution 14 or Solution 18. Under the above conditions the velocity of acetophenone formation, as well as formation of Q, are linear with time for at least the first 20 minutes (up to $120 \mathrm{~min}$ for the formation of Q). Then all the changes on rate of product formation were directly related with the temperature at which the system was incubated.

\subsubsection{Thermostability}

Ten $\mathrm{ml}$ of a solution containing $10 \mathrm{mg}$ of spray dried cells per $\mathrm{ml}, 1 \mathrm{mM}$ pyridoxal-5phosphate, $100 \mathrm{mM}$ sodium acetate, and 10 grams of beads comprised of $10 \mathrm{mg}$ of spray dried cells per gram bead (prepared as described in Section 3.4.2) were incubated at several temperatures for 30 minutes. Then, immediately, $1 \mathrm{ml}$ of solution of free enzyme or 1 gram of immobilized enzyme were transferred to reactors at $55^{\circ} \mathrm{C}$. The reactors were under agitation, with $20 \mathrm{ml}$ of Solution $6 \mathrm{pH} 7$ (Table 3-I). Under the above conditions the rate of acetophenone formation is linear with time for at least the first 20 minutes. Therefore, all the changes on rate of acetophenone formation were directly related with the amount of enzyme active after incubation for 30 minutes at several temperatures.

\subsubsection{Substrate affinity}

Unless specified otherwises, $20 \mathrm{ml}$ of Solution 2 at $\mathrm{pH} 7$ (Table 3-I), Solution 7 at $\mathrm{pH} 7$ (Table 3-I), Solution 8 at pH 7 (Table 3-I), Solution 13 at pH 7 (Table 3-II), Solution 17 at pH 7 (Table 3-II), Solution 19 at pH 7 (Table 3-II), Solution 20 at pH 7 (Table 3-II), Solution 21 at pH 7 (Table 3-II), and Solution 22 at pH 7 (Table 3-II) was incubated at a

given temperature (specified in the next chapters). Then predetermined amounts of 
immobilized spray dried cells (prepared as described in section 3.4.2) and free spray dried cells were added, and reaction rate was measured. The solution of spray dried cells used in each case was made dissolving 0.1 grams of spray dried cells in $10 \mathrm{ml}$ of solution pH 7 with the same concentration of pyridoxal-5-phosphate and buffer (sodium acetate or potassium phosphate) as the solution incubated in the reactors. Initial substrate concentration increased until achieving a constant value of reaction rate.

\subsubsection{Purification of Aminotransferase from Spray-Dried Cells by Precipitation}

One gram of spray dried cells was added into $100 \mathrm{ml}$ of a solution containing $50 \mathrm{mM}$ $\mathrm{KH}_{2} \mathrm{PO}_{4}$ (Fisher Scientific), $0.5 \mathrm{mM}$ pyridoxal-5-phosphate (Schweizer Hall), $1 \mathrm{mM} \mathrm{1,4-}$ dithioerythritol from Sigma (DTT); and separated in several fractions by $\left(\mathrm{NH}_{4}\right)_{2} \mathrm{SO}_{4}$ (J. T. Baker) precipitation. The steps of the procedure are indicated below. To evaluate the efficiency of purification, samples were taken from all the steps, from pellets and supernatants, and enzymatic activity was measured using the S-MBA (Aldrich) system (Section 3.1.1).

1. The solution of spray dried cells was sonicated using a Branson SONIFIER 450 for 3 minutes, alternating one minute of sonication with one minute of cooling on ice.

2. The solution was centrifuged at $1500 \mathrm{rpm}$ for 20 minutes in a SORVALL RC-5CPLUS.

3. $\left(\mathrm{NH}_{4}\right)_{2} \mathrm{SO}_{4}$ was added to supernatant at $0{ }^{\circ} \mathrm{C}$ to form a solution of $40 \%(\mathrm{w} / \mathrm{w})$ while agitating for 30 minutes.

4. The solution from step 3 was centrifuged at $1500 \mathrm{rpm}$ for 20 minutes. 
5. $\left(\mathrm{NH}_{4}\right)_{2} \mathrm{SO}_{4}$ was added to supernatant from step 4 , at $0{ }^{\circ} \mathrm{C}$, to form a solution of $55 \%$ (w/w) with agitation for 30 minutes.

6. The solution from step 5 was centrifuged at $1500 \mathrm{rpm}$ for 20 minutes.

7. $\left(\mathrm{NH}_{4}\right)_{2} \mathrm{SO}_{4}$ was added to supernatant from step 6 , at $0{ }^{\circ} \mathrm{C}$, to form a solution of $70 \%$ (w/w) while applying agitation for 30 minutes.

8. A solution from step 7 was centrifuged at $1500 \mathrm{rpm}$ for 20 minutes; the pellet was recovered and supernatant discharged.

\subsection{Molecular Biology}

\subsubsection{Error-Prone Polymerase Chain Reaction}

Error-prone polymerase chain reaction was conducted using the GeneMorph ${ }^{\mathrm{TM}}$ Mutagenesis Kit. This kit is composed of Mutazyme ${ }^{\circledR}$ DNA polymerase, 10X Mutazyme $^{\circledR}$ reaction buffer, $40 \mathrm{mM}$ dNTP mixture, and $1.1 \mathrm{~kb}$ Gel standard. The reactions conditions were the following: incubation at $95{ }^{\circ} \mathrm{C}$ for 5 minutes followed by 30 cycles of incubation at $96{ }^{\circ} \mathrm{C}$ for 30 seconds, $53{ }^{\circ} \mathrm{C}$ for 30 seconds, and $72{ }^{\circ} \mathrm{C}$ for 4 minutes. Afterwards, the reaction system was incubated at $72{ }^{\circ} \mathrm{C}$ for 10 minutes; and finally the temperature was held at $4{ }^{\circ} \mathrm{C}$. The reaction system was composed of $41.5 \mu 1$ of RNA'se free water, $5 \mu 1$ of 10X Mutazyme Buffer, $1 \mu 1$ of $40 \mathrm{mM}$ dNTP mixture, $0.5 \mu 1$ of a mixture of Primer $1\left(5^{\prime}\right.$ AATAAGGAGGAATAAACCATGGG 3', $\left.\mathrm{T}_{\mathrm{m}}=57.1^{\circ} \mathrm{C}\right)$ and Primer 2 (3' TTCGAACCGACAAAACCGCCT 5 , $\mathrm{T}_{\mathrm{m}}=59.8{ }^{\circ} \mathrm{C}$ ) of concentration 250 $\mathrm{ng} / \mu \mathrm{l}$ of each primer, $1 \mu \mathrm{l}$ of Mutazyme DNA Polymerase, and $1 \mu \mathrm{l}$ of plasmid template having a concentration between $10 \mathrm{pg} / \mu \mathrm{l}$ to $100 \mathrm{ng} / \mu \mathrm{l}$. 


\subsubsection{Restriction}

The PCR product was purified using QIAquick PCR Purification Kit (Qiagen) and restricted using the enzymes Hind III (Promega) and Nco I (Promega). Hind III (Promega) recognizes the sequence 3'...TTCGA*A...5' and Nco I (Promega) the sequence 5'...C*CATGG...3'. The protocols followed during restriction are given below.

Protocol 1: Incubation for 2 hour long at $37^{\circ} \mathrm{C}$ of $8 \mu$ l of RNA'se free water, $4 \mu \mathrm{l}$ of MULTI-CORE $^{\mathrm{TM}}$ Buffer (Promega), $1 \mu \mathrm{l}$ of Bovine Serum Albumin BSA (Promega), 25 $\mu \mathrm{l}$ of purified PCR product, $1 \mu \mathrm{l}$ of Hind III (Promega), and $1 \mu \mathrm{l}$ of Nco I (Promega); with product purification using QIAquick PCR Purification Kit (Qiagen).

Protocol 2: Incubation for 12 hours long at $37{ }^{\circ} \mathrm{C}$ of $8 \mu$ l of RNA'se free water, $4 \mu \mathrm{l}$ of MULTI-CORE ${ }^{\mathrm{TM}}$ Buffer (Promega), $1 \mu \mathrm{l}$ of BSA (Promega), $25 \mu \mathrm{l}$ of purified PCR product, $1 \mu \mathrm{l}$ of Hind III (Promega), and $1 \mu \mathrm{l}$ of Nco I (Promega); with product purification using QIAquick PCR Purification Kit (Qiagen).

Protocol 3: Incubation for 2 hours long at $37^{\circ} \mathrm{C}$ of $9 \mu$ of RNA'se free water, $4 \mu \mathrm{l}$ of Buffer D (Promega), $1 \mu 1$ of BSA (Promega), $25 \mu$ l of purified PCR product, and $1 \mu 1$ of Nco I (Promega); with product purification using QIAquick PCR Purification Kit (Qiagen). This was followed by incubation for 2 hours long at $37^{\circ} \mathrm{C}$ of $9 \mu$ of RNA'se free water, $4 \mu \mathrm{l}$ of Buffer E (Promega), $1 \mu \mathrm{l}$ of BSA (Promega), $25 \mu \mathrm{l}$ of product of the previous step, and $1 \mu \mathrm{l}$ of Hind III (Promega); with product purification using QIAquick PCR Purification Kit.

Protocol 4: Incubation for 12 hours long at $37^{\circ} \mathrm{C}$ of $9 \mu \mathrm{l}$ of RNA'se free water, $4 \mu \mathrm{l}$ of Buffer D (Promega), $1 \mu \mathrm{l}$ of BSA (Promega), $25 \mu$ of purified PCR product, and $\mu 1$ of 
Nco I (Promega); with product purification using QIAquick PCR Purification Kit (Qiagen). This was followed by incubation for 12 hours long at $37^{\circ} \mathrm{C}$ of $9 \mu 1$ of RNA'se free water, $4 \mu \mathrm{l}$ of Buffer E (Promega), $1 \mu \mathrm{l}$ of BSA (Promega), $25 \mu \mathrm{l}$ of product of the previous step, and $1 \mu \mathrm{l}$ of Hind III (Promega); with product purification using QIAquick PCR Purification Kit (Qiagen).

\subsubsection{Ligation}

Ligation was done by mixing $20 \mathrm{ng}$ of purified restricted PCR product, $20 \mathrm{ng}$ of plasmid fragment (pSE420), $5 \mu$ l of 2X Rapid Ligation Buffer (Promega), $1 \mu$ of T4 DNA Ligase (Promega), and nuclease free water to complete $10 \mu$ l. After 5 minutes at room temperature the reaction system was diluted to a final concentration of $1 \mathrm{ng} / \mu \mathrm{l}$. The ligation mixture was then ready for transformation or for storage at $-20{ }^{\circ} \mathrm{C}$.

\subsubsection{Transformation}

Transformation was done into LIBRARY EFFICIENCY ${ }^{\circledR}$ DH5 $\alpha^{\mathrm{TM}}$ Competent Cells (Invitrogen), XL1-Blue MR Supercompetent Cells (STRATAGENE), and Escherichia coli MG1655 competent cells. The protocols followed are shown below.

Transformation into DH5 $\alpha$ competent cells (Invitrogen)

1. Thaw competent cells on wet ice. Place required number of $17 \times 100 \mathrm{~mm}$ Falcon ${ }^{\circledR}$ tubes on wet ice. 
2. Gently mix cells, then aliquot $100 \mu \mathrm{l}$ competent cells into chilled polypropylene tubes.

3. Add $5 \mu \mathrm{l}(50 \mathrm{pg})$ control DNA to one tube containing $100 \mu \mathrm{l}$ competent cells.

4. Add 1 to $10 \mathrm{ng}$ of DNA to $100 \mu \mathrm{l}$ of competent cells in Falcon tubes.

5. Incubate on ice for 30 minutes.

6. Heat-shock cells 45 seconds in a $42{ }^{\circ} \mathrm{C}$ water bath.

7. Place on ice for 2 minutes.

8. Add $0.9 \mathrm{ml}$ of room temperature $\mathrm{SOC}$ medium

9. Shake at $225 \mathrm{rpm}\left(37^{\circ} \mathrm{C}\right)$ for 1 hour.

10. Dilute the reaction containing the control plasmid DNA 1:10 with SOC medium. Spread $100 \mu \mathrm{l}$ of this dilution on LB plates with $100 \mu \mathrm{g} / \mathrm{ml}$ ampicillin (Sigma).

11. Dilute experimental reactions as necessary and spread 100-200 $\mu \mathrm{l}$ of this dilution as described in Step 10.

12. Incubate overnight at $37^{\circ} \mathrm{C}$.

Transformation into XL1-Blue MR Supercompetent cells (STRATAGENE)

1. Pre-chill two 14-ml BD Falcon polypropylene round-bottom tubes on ice. Preheat SOC medium (Invitrogen) to $42{ }^{\circ} \mathrm{C}$.

2. Thaw the supercompetent cell on ice. When thawed, gently mix and aliquot 100 $\mu l$ of cells into each of the two pre-chilled tubes.

3. Add $1.7 \mu 1$ of $\beta$-mercaptoethanol (STRATAGENE) to each aliquot of cells.

4. Swirl the contents of the tubes gently. Incubate the cells on ice for 10 minutes, swirling gently every 2 minutes. 
5. Add 0.1 to $50 \mathrm{ng}$ of the experimental DNA to one aliquot of cells $(100 \mu \mathrm{l})$ and add $1 \mu 1$ of the pUC18 (STRATAGENE) control DNA to the other aliquot. Swirl the tubes gently.

6. Incubate the tubes on ice for 30 minutes.

7. Heat-pulse the tubes in a $42{ }^{\circ} \mathrm{C}$ water bath for 45 seconds.

8. Incubate the tubes on ice for 2 minutes.

9. Add $0.9 \mathrm{ml}$ of preheated SOC (Invitrogen) medium and incubate the tubes at 37 ${ }^{\circ} \mathrm{C}$ for 1 hour with shaking at $225-250 \mathrm{rpm}$.

10. Plate $200 \mu \mathrm{l}$ of the transformation mixture on LB agar plates containing the appropriate antibiotic. For the pUC18 control transformation, plate $2.5 \mu 1$ of the transformation on LB-ampicillin (Sigma) agar plates.

11. Incubate the plates at $37^{\circ} \mathrm{C}$ overnight.

Transformation into Escherichia coli MG1655 competent cells

1. After treating Escherichia coli MG1655 with $\mathrm{CaCl}_{2}$ (J. T. Baker) to make them competent, transfer $200 \mu \mathrm{l}$ of each suspension of competent cells to a sterile, chilled 17 x 100-mm polypropylene tube using a chilled micropipette tip. Add DNA (no more than $50 \mathrm{ng}$ in a volume of $10 \mu \mathrm{l}$ or less) to each tube. Mix the contents of the tubes by swirling gently. Store the tubes on ice for 30 minutes.

2. Transfer the tubes to a rack placed in a preheated $42{ }^{\circ} \mathrm{C}$ circulating water bath. Store the tubes in the rack for exactly 90 seconds without shaking.

3. Rapidly transfer the tubes to an ice bath. Allow the cells to chill for 1-2 minutes. 
4. Add $800 \mu \mathrm{l}$ of SOC (Invitrogen) medium to each tube. Incubate the cultures for 45 minutes in a water bath set at $37^{\circ} \mathrm{C}$ to allow the bacteria to recover and express the antibiotic resistance marker encoded by the plasmid.

5. Transfer the appropriate volume (up to $200 \mu \mathrm{l}$ per $90-\mathrm{mm}$ plate) of transformed competent cells onto agar SOB medium containing $20 \mathrm{mM} \mathrm{MgSO}_{4}$ (Aldrich) and the appropriate antibiotic.

6. Store the plates at room temperature until the liquid has been absorbed.

7. Invert the plates and incubate at $37^{\circ} \mathrm{C}$. Transformed colonies should appear in 12-16 hours.

\subsection{Cell Culture}

\subsubsection{Shake Flask}

Transformed cells of Escherichia coli were grown in shake flasks for three purposes; for plasmid purification, for transaminase expression; and for inoculation for transaminase production at 8 liters scale.

Plasmid Purification: In a Falcon tube were added $5 \mathrm{ml}$ of LB media (Accugene) with $100 \mu \mathrm{g} / \mathrm{ml}$ of ampicillin (Sigma) and a loop of thawed cells on glycerol $50 \%(\mathrm{v} / \mathrm{v}$ ) (Sigma) and then it was incubated overnight at $30{ }^{\circ} \mathrm{C}$ shaking at $250 \mathrm{rpm}$.

Transaminase Expression: In a $250 \mathrm{ml}$ shake flask were added $50 \mathrm{ml}$ of LB media (Accugene) with $100 \mu \mathrm{g} / \mathrm{ml}$ of ampicillin (Sigma) and a loop of thawed cells on glycerol $50 \%(\mathrm{v} / \mathrm{v})\left(\right.$ Sigma). Then it was incubated overnight at $30^{\circ} \mathrm{C}$ shaking at $250 \mathrm{rpm}$. After 
that, a $50 \mathrm{ml}$ volume of the last culture was transferred to a $1000 \mathrm{ml}$ shake flask having $200 \mathrm{ml}$ of LB media (Accugene) with ampicillin from Sigma $(100 \mu \mathrm{g} / \mathrm{ml})$, and the flask was incubated for 3 hours at $30^{\circ} \mathrm{C}$ shaking at $250 \mathrm{rpm}$. After that, $20 \mathrm{mg}$ of Isopropyl- $\beta$ D-thiogalactopyranoside from Sigma (IPTG) was added, and the system was left 2 more hours at $30{ }^{\circ} \mathrm{C}$ shacking at $250 \mathrm{rpm}$. Then the cells were harvested by centrifugation (4100 rpm in a Sorvall GSA rotor for then minutes at $4{ }^{\circ} \mathrm{C}$ ).

Transaminase Production: In a $250 \mathrm{ml}$ shake flask were added $50 \mathrm{ml}$ of LB media (Accugene) with $100 \mu \mathrm{g} / \mathrm{ml}$ of ampicillin (Sigma) and a loop of thawed cells on glycerol $50 \%(\mathrm{v} / \mathrm{v})\left(\right.$ Sigma) was added. Then it was incubated overnight at $30{ }^{\circ} \mathrm{C}$ shaking at 250 rpm. After that, $5 \mathrm{ml}$ of the last culture was transferred to a $1000 \mathrm{ml}$ shake flask having $200 \mathrm{ml}$ of LB media (Accugene) with ampicillin from Sigma $(100 \mu \mathrm{g} / \mathrm{ml})$. Next the flask was incubated for 6 hours at $30^{\circ} \mathrm{C}$ shaking at $250 \mathrm{rpm}$, and then added to the fermentor.

\subsubsection{Fermentation}

To a 15-liter fermentor (New Brunswick ${ }^{\circledR}$ ) was added 8 liters of water, 55 grams of $\mathrm{KH}_{2} \mathrm{PO}_{4}$ (Fisher Scientific), 18 grams of $\mathrm{MgSO}_{4} \cdot 7 \mathrm{H}_{2} \mathrm{O}$ (Fisher Scientific), $2 \mathrm{ml}$ of Antifoam (Sigma), and $80 \mathrm{ml}$ of a solution whose composition per liter was 6 grams of Fe (III) citrate hydrate (Aldrich), 1.6 grams of EDTA free acid (Aldrich), 1.5 grams of $\mathrm{MnCl}_{2} \cdot 2 \mathrm{H}_{2} \mathrm{O}$ (Aldrich), 0.8 grams of $\mathrm{Zn}\left(\mathrm{CH}_{3} \mathrm{COO}\right)_{2} \cdot 2 \mathrm{H}_{2} \mathrm{O}$ (Aldrich), 0.3 grams of $\mathrm{H}_{3} \mathrm{BO}_{3}$ (Aldrich), 0.25 grams of $\mathrm{Na}_{2} \mathrm{MoO}_{4} \cdot 2 \mathrm{H}_{2} \mathrm{O}$ (Aldrich), 0.25 grams of $\mathrm{CoCl}_{2} \cdot 6 \mathrm{H}_{2} \mathrm{O}$ (Aldrich), and 0.118 grams $\mathrm{CuCl}_{2}$ (Aldrich). After that, the fermentor was sterilized at $121{ }^{\circ} \mathrm{C}$ for 30 minutes. The system was chilled to $30{ }^{\circ} \mathrm{C}$ and then a sterile solution of $300 \mathrm{ml}$ with 
150 grams of glucose -sterilized at $121{ }^{\circ} \mathrm{C}$ for 30 minutes - was added and the $\mathrm{pH}$ was adjusted to 7 by addition of $\mathrm{NH}_{4} \mathrm{OH}$ (Sigma). After that, the cells grown following the protocol for aminotransferase Production were added. After 18 hours of growth, the glucose supplied at inoculation time had been consumed. Then a solution of glucose (50\% (w/w) and 2\% (w/w) $\mathrm{MgSO}_{4} \cdot 7 \mathrm{H}_{2} \mathrm{O}$ (Fisher Scientific), sterilized at $121{ }^{\circ} \mathrm{C}$ for 30 minutes) was started to be supplied by a peristaltic pump -equipped with tubes sterilized at $121{ }^{\circ} \mathrm{C}$ for 30 minutes- controlled by the fermenter concentration of dissolved oxygen. 10 hours later 0.6 grams of Isopropyl- $\beta$-D-thiogalactopyranoside (IPTG) from Sigma was added to the fermentor, and then 12 hours later the cells were harvested by spray drying (Temperature: Furnace $205^{\circ} \mathrm{F}$, Inlet $32^{\circ} \mathrm{F}$, Outlet $160^{\circ} \mathrm{F}$, Flow rate: $40 \mathrm{ml} / \mathrm{min}$ ). Typical yields were 250-350 grams of spray dried cells per 8 liters of fermentation.

\subsection{Biotransformation: Assessment of accuracy and reproducibility}

Given the necessity of conducting a large number of kinetic characterization experiments in a relatively short period of time in this research, it was decided to conduct only single trial experiments, but only after establishing reproducibility using triplicate or higher replicate experiments using the system of substituted tetralone and (S)-(-)-( $(\alpha)-$ methylbenzylamine.

To assess the system of (S)-(-)-( $(\alpha)$-methylbenzylamine, a system was selected that consisted on $20 \mathrm{ml}$ of Solution $1 \mathrm{pH} 7$ (Table 3-I) incubated at $30^{\circ} \mathrm{C}$ catalyzed by free spray dried cells of (S)-aminotransferase 20065 (Cambrex Corporation), at a 
concentration of $0.2 \mathrm{mg} / \mathrm{ml}(0.2 \mathrm{~g} / \mathrm{l})$. Samples were withdrawn at 2, 4, 6, and $8 \mathrm{~min}$ as described in Section 3.1.1. The results are presented in Table 3-III.

Table 3-III: Assesment of accuracy and reproducibility of (S)-MBA system at $30^{\circ} \mathrm{C}$.

\begin{tabular}{|c|c|c|c|}
\hline t(min) & Experiment 1 [mM] & Experiment 2 [mM] & Experiment 3 [mM] \\
\hline 2 & 0.38 & 0.36 & 0.37 \\
\hline 4 & 0.44 & 0.44 & 0.46 \\
\hline 6 & 0.52 & 0.56 & 0.54 \\
\hline 8 & 0.61 & 0.59 & 0.62 \\
\hline Rate [mM/min] & $\mathbf{0 . 0 4}$ & $\mathbf{0 . 0 4}$ & $\mathbf{0 . 0 4}$ \\
\hline Correlation coefficient & 0.99 & 0.98 & 0.99 \\
\hline $\begin{array}{l}\text { Standard deviation } \\
\text { [mM/min] }\end{array}$ & $\mathbf{2 . 0 \times 1 0 ^ { - 3 } \mathbf { 0 . }}$ & \\
\hline STDEV*100/Rate & 4.56 & 4.23 & 4.26 \\
\hline
\end{tabular}

Table 3-III shows that the biotransformation rate results are reproducible within approximately 5\%. Another experiment was done using the system of S-MBA at a higher temperature. It consisted in incubating $20 \mathrm{ml}$ of Solution $9 \mathrm{pH} 7$ (Table 3-I) at $55^{\circ} \mathrm{C}$ with $0.5 \mathrm{mg} / \mathrm{ml}(0.5 \mathrm{~g} / \mathrm{l})$ of free spray dried cells of (S)-aminotransferase 20065 (Cambrex Corporation). The results are shown inTable 3-IV.

Table 3-IV: Assesment of accuracy and reproducibility of (S)-MBA system at $55^{\circ} \mathrm{C}$.

\begin{tabular}{|c|c|c|c|}
\hline t(min) & Experiment 1 [mM] & Experiment 2 [mM] & Experiment 3 [mM] \\
\hline 2 & 2.37 & 2.15 & 2.40 \\
\hline 4 & 4.19 & 4.20 & 4.59 \\
\hline 6 & 5.91 & 5.84 & 5.81 \\
\hline 8 & 6.94 & 7.11 & 7.09 \\
\hline Rate [mM/min] & $\mathbf{0 . 7 7}$ & $\mathbf{0 . 8 3}$ & $\mathbf{0 . 7 7}$ \\
\hline Correlation coefficient & 0.99 & 0.99 & 0.989 \\
\hline $\begin{array}{l}\text { Standard deviation } \\
\text { [mM/min] }\end{array}$ & $\mathbf{0 . 0 3}$ & 4.03 & 4.35 \\
\hline STDEV*100/Rate & 4.31 & & \\
\hline
\end{tabular}

The biotransformation rates shown in Table 3-IV were also reproducible within about 5\%. Table 3-III and Table 3-IV show that kinetic characterization of aminotransferaase 
biotransformation using the system of S-MBA is reproducible and accurate. Therefore, valuable kinetic information can be obtained from single experiments using the S-MBA system.

To assess the system of substituted tetralone for production of substituted (S)aminotetralin, a system was selected that consisted on $50 \mathrm{ml}$ of Solution $18 \mathrm{pH} 7$ (Table 3-II) incubated at $55^{\circ} \mathrm{C}$ catalyzed by free spray dried cells of (S)-aminotransferase CNB05-01 (Cambrex Corporation), at a concentration of 5 grams of spray dried cells per liter. Samples were withdrawn at 20,40,60,80, and $100 \mathrm{~min}$ as described in Section 3.1.2. The results are presented in Table 3-V.

Table 3-V: Assesment of accuracy and reproducibility of substituted tetralone system.

\begin{tabular}{|c|c|c|c|c|c|c|}
\hline $\mathbf{t}(\mathbf{m i n})$ & $\begin{array}{c}\text { F1 } \\
{[\mathbf{m M}]}\end{array}$ & $\begin{array}{c}\text { F2 } \\
{[\mathbf{m M}]}\end{array}$ & $\begin{array}{c}\mathbf{F 4 ( a )} \\
{[\mathbf{m M}]}\end{array}$ & $\begin{array}{c}\mathbf{F 4}(\mathbf{b}) \\
{[\mathbf{m M}]}\end{array}$ & $\begin{array}{c}\mathbf{F 4 ( c )} \\
{[\mathbf{m M}]}\end{array}$ & $\begin{array}{c}\text { F4(d) } \\
{[\mathbf{m M}]}\end{array}$ \\
\hline 20 & 12.62 & 16.71 & 18.12 & 16.55 & 15.44 & 17.10 \\
\hline 40 & 22.5 & 26.83 & 32.45 & 28.72 & 27.30 & 28.94 \\
\hline 60 & 30.99 & 38.99 & 41.17 & 37.39 & 38.57 & 39.37 \\
\hline 80 & 37.69 & 45.95 & 50.09 & 46.30 & 48.31 & 45.41 \\
\hline 100 & 51.04 & 51.99 & 68.57 & 52.17 & 53.83 & 54.66 \\
\hline Rate [mM/min] & $\mathbf{0 . 4 6}$ & $\mathbf{0 . 4 5}$ & $\mathbf{0 . 5 9}$ & $\mathbf{0 . 4 4}$ & $\mathbf{0 . 4 9}$ & $\mathbf{0 . 4 6}$ \\
\hline Correlation coefficient & 0.99 & 0.99 & 0.99 & 0.99 & 0.99 & 0.99 \\
\hline Standard deviation [mM/min] & $\mathbf{0 . 0 6}$ & \multicolumn{5}{|l}{} \\
\hline STDEV*100/Rate & 12.27 & 12.59 & 9.53 & 12.71 & 11.54 & 12.33 \\
\hline
\end{tabular}

Table 3-V shows the activity of (S)-aminotransferase $\mathrm{CNB} 05-01$ at $55^{\circ} \mathrm{C}$. These data correspond to the activity of three fermentations (F1, F2, and F4) of E. coli MG1655 to produce CNB05-01, starting from three vials of glycerol stock of mutant CNB05-01 and ending with to the correspondind spray drying of the harvested cells. Analyzing these results it is seen that a reproducibility to within about $12 \%$ is expected for this system, and with the absence of F4(a), about $4 \%$. Since the information with this degree of 
reproducibility was considered still acceptable for design/improvement of the system, it was decided to perform single run experiments to advance in the general purpose of the project, saving time and resources. An example of representative good reproducibility is presented in Section 6.2.2.4.1 where saturation kinetics in the presence of pyridoxal-5phosphate is exhibited.

Chapter 4 shows the immobilization procedure of aminotransferase, and its development. It shows the results obtained while changing the main variables of the procedure: concentration of alginate and calcium chloride, gelation time, and enzyme loading. The information presented in Chapter 4 regarding to S-MBA system posses a coefficient of variation of 0.05 , whereas the information regarding to the substituted tetralone system posses a coefficient of variation of about $12 \%$. 


\section{Chapter 4. Enzyme Immobilization Procedure and Testing}

This chapter shows the immobilization procedure of aminotransferase, and its development. It shows the results obtained while changing the main variables of the procedure; such as concentration of alginate and calcium chloride, gelation time, and enzyme loading.

\subsection{Immobilization}

Enzyme immobilization is a technique specifically designed to greatly restrict the freedom of movement of an enzyme. Immobilization allows for easy recovery and reuse of valuable enzymes, provided that activity remains high over a sufficiently long period of time. In doing so the first consideration is to decide on the support material, then the main method of immobilization, taking into account the intended use or application. There are five principal methods for immobilization of enzymes/cells: adsorption, covalent binding, entrapment, encapsulation, and crosslinking (Bickerstaff, 1997). Some major characteristics of these procedures are shown in Table 4-I. Application of the immobilization techniques in Table 4-I at an industrial scale is shown in Table 4-II. As stated on Table 4-I, adsorption does not damage the biocatalyst. For example, the activity for biotransformation of sucrose for adsorbed Erwinia rhapontici is $97 \%$ the activity of free cells, and the half-life is 10 times longer than the same for free cells. Cells of Erwinia rhapontici entrapped in calcium alginate beads have $54 \%$ of the activity of free cells, but a half life 230 times longer. The lattice gel of calcium alginate seems to 
stabilize the viability of Erwinia rhapontici for long periods of time. This effect could also be obtained for the system of $(\mathrm{S})$-aminotransferase for the production of substituted (S)-aminotetralin. In addition to stabilization, calcium alginate is a substance that has been approved by the FDA, making it suitable to be used in the production of chiral drugs and pharmaceutical intermediates.

Table 4-I: Characteristics of immobilization procedures.

\begin{tabular}{|c|c|c|c|}
\hline Procedure & $\begin{array}{l}\text { Attachment of enzyme/cell } \\
\text { to support }\end{array}$ & Advantages & Disadvantages \\
\hline Adsorption & $\begin{array}{l}\text { By reversible surface } \\
\text { interactions between } \\
\text { enzyme/cell and support } \\
\text { material through Van Der } \\
\text { Waals forces, ionic and } \\
\text { hydrogen interactions, and } \\
\text { hydrophilic bonding }\end{array}$ & $\begin{array}{l}\text { Little or no damage to } \\
\text { enzyme/cells } \\
\text { Simple, cheap, quick } \\
\text { No chemical change to support } \\
\text { or enzyme/cell } \\
\text { Reversible to allow regeneration } \\
\text { with fresh enzyme/cells }\end{array}$ & $\begin{array}{l}\text { Leakage of enzyme/cells } \\
\text { Non specific binding } \\
\text { Steric hindrance }\end{array}$ \\
\hline $\begin{array}{l}\text { Covalent } \\
\text { Binding }\end{array}$ & $\begin{array}{l}\text { By formation of a covalent } \\
\text { bond between the enzy me/cell } \\
\text { and a support material }\end{array}$ & $\begin{array}{l}\text { There is not leakage of the } \\
\text { enzyme/cell to reaction mix ture }\end{array}$ & $\begin{array}{l}\text { Use of toxic compounds } \\
\text { for activation of the support } \\
\text { i.e. } \mathrm{CNBr}\end{array}$ \\
\hline Entrapment & $\begin{array}{l}\text { The enzyme/cells are free in } \\
\text { solution; but restricted in } \\
\text { movement by the lattice of a } \\
\text { gel }\end{array}$ & $\begin{array}{l}\text { Harmful cells, proteins, and } \\
\text { enzymes do not interact with } \\
\text { immobilized biocatalyst }\end{array}$ & $\begin{array}{l}\text { Support is a barrier to } \\
\text { mass transfer }\end{array}$ \\
\hline Encapsulation & $\begin{array}{l}\text { Enveloping of enzyme/cells } \\
\text { within various forms of } \\
\text { semipermeable membranes }\end{array}$ & $\begin{array}{l}\text { Harmful cells, proteins, and } \\
\text { enzymes do not interact with } \\
\text { immobilized biocatalyst }\end{array}$ & - Diffusion resistances \\
\hline Crosslinking & $\begin{array}{l}\text { It is support-free and involves } \\
\text { joining the cells (or the } \\
\text { enzymes) to each other to form } \\
\text { a large, three-dimensional } \\
\text { complex structure }\end{array}$ & $\begin{array}{l}\text { Allow enhancement other } \\
\text { methods of immobilization } \\
\text { normally by reducing biocatalyst } \\
\text { leakage in other systems }\end{array}$ & $\begin{array}{l}\text { Use of toxic compounds } \\
\text { for formation of three- } \\
\text { dimensional structures i.e. } \\
\text { Toluene diisocyanate } \\
\text { Poor stability }\end{array}$ \\
\hline
\end{tabular}

Adapted from (Bickerstaff, 1997)

Table 4-II: Impact of immobilization methods on the biotransformation of Sucrose to Isomaltulose by cells of Erwinia rhapontici.

\begin{tabular}{|l|c|c|}
\hline Technique & Activity [g/g wet cells/h] & Half-life [h] \\
\hline Free cells & 0.60 & 36 \\
\hline Entrapment in calcium alginate & 0.33 & 8500 \\
\hline Entrapment in polyacrylamide & 0.13 & 570 \\
\hline Adsorption to DEAE-cellulose & 0.58 & 400 \\
\hline Crosslinking with glutaraldehyde & 0.15 & 40 \\
\hline Entrapment in $\kappa$-carrageenan & 0.26 & 38 \\
\hline Entrapment in agar & 0.34 & 27 \\
\hline Adsorption to bone char & 0.01 & 25 \\
\hline
\end{tabular}

Data from (Bucke, 1983) 


\subsubsection{Entrapment}

In immobilization by entrapment, enzymes/cells are free in solution but restricted in movement by the lattice structure of a gel (Bickerstaff, 1995; O’Driscoll, 1976). The porosity of the gel lattice is controlled to ensure that the structure is tight enough to prevent leakage of enzymes or cells, and allowing at the same time transport of substrate and product. Inevitably, the support will act as a barrier to mass transfer, and although this can have serious implications for reactions kinetics, it can have useful advantages since harmful cells, proteins, and enzymes are prevented from interaction with the immobilized biocatalyst (Brodelius, 1985).

There are several major methods of entrapment:

Ionotropic gelation of macromolecules with multivalent cations (e.g., alginate)

Temperature-induced gelation (e.g., agarose, gelatin)

Organic polymerization by chemical/photochemical reaction (e.g., polyacrylamide)

Precipitation from an immiscible solvent (e.g., polystyrene)

Entrapment can be achieved by mixing an enzyme with a polyionic polymer material and then crosslinking the polymer with multivalent cations in an ion-exchange reaction to form a lattice structure that traps the enzymes/cells (Ionotropic gelation). Temperature change is a simple method of gelation by phase transition using solutions of concentrations 1-4\% agarose or gelatin. It is possible to mix the enzyme with chemical monomers that are then polymerized to form a crosslinked polymeric network, trapping 
the enzyme in the interstitial spaces of the lattice. Precipitation occurs by phase separation rather than by chemical reaction, but precipitation does bring the cells/enzymes into contact with a water-miscible organic solvent, and most cells/enzymes are not tolerant of such solvents. Thus, this method is limited to highly stable/previously stabilized enzymes or nonliving cells.

\subsubsection{Entrapment in Calcium Alginate}

Entrapment of enzymes and/or cells in alginate is one of the simplest methods of immobilization. Alginates are available commercially as water-soluble sodium alginates, and have been used for more than 75 years in the food and pharmaceutical industries as thickening, emulsifying, film forming, and gelling agents. Entrapment in calcium alginate is recognized as rapid, nontoxic, inexpensive, and versatile method for immobilization of enzymes and cells (Park, 1995). Alginic acid is a polyuronic acid extracted from seaweeds, and is composed of varying proportions of 1-4 linked $\beta$-D-mannuronic (M) and $\alpha$-L-guluronic acids $(\mathrm{G})$. The residues occur in varying proportions depending on the source, and the residues are arranged in block patterns comprised of homopolymeric regions (MM blocks and GG blocks) interspersed with alternating regions of heteropolymeric regions (MG blocks). The binding of divalent cations and subsequent gel formation is dependent on the composition and arrangement of the blocks of residues. In particular, gel strength is related to $\mathrm{G}$ content, which varies from $20-75 \%$ depending on the seaweed source. Alginates from Laminaria hyperborean have typical G content values of around $70 \%$. The GG blocks have preferential binding sites for divalent cations, such as $\mathrm{Ca}^{+2}$. Upon addition of a sodium alginate solution to a calcium chloride solution, 
interfacial polymerization is instantaneous with precipitation of calcium alginate followed by a more gradual gelation of the interior as calcium ions permeate through the alginate (Cheetham, 1979). Enzyme/cell leakage can occur from the gel beads. This is influenced by initial alginate concentration, mechanical treatment of the beads, and cell productivity if dividing cells have been immobilized. The open lattice structure, although a disadvantage in allowing leakage of small proteins, does provide high porosity for large substrates and efficient exchange of products. Electron microscopy of a $2 \%$ calcium alginate bead showed pores that ranged from 5-200 $\mathrm{nm}$ in diameter (Smidsrød, 1990). Destabilization of calcium alginate is promoted by chelating agents that remove calcium ions and by other divalent cations that can exchange with calcium ions. Phosphate, citrate, EDTA, as well as $\mathrm{Mg}^{+2}$ should be avoided.

\subsection{Materials and Methods}

\subsubsection{Immobilization Procedure}

If not specified otherwise, the general procedure to immobilize the (S)-aminotransferase was the following. After choosing concentration and amount of beads to prepare (e.g. estimating the volume of immobilization mixture), the right amount of spray dried cells was mixed with $0.03 \%(\mathrm{w} / \mathrm{v})$ pyridoxal-5-phosphate (Schweizer Hall), $8 \%(\mathrm{v} / \mathrm{v})$ of Cracking solution (50 mM KH $2 \mathrm{PO}_{4}$ (Fisher Scientific), $0.5 \mathrm{mM}$ pyridoxal-5-phosphate, 1 mM DTT (Sigma)), and 92\% (v/v) of sodium alginate (Fluka). Then this solution was dropped though a needle $-22(1 / 2) \mathrm{G}$ - into a solution of $2 \%(\mathrm{w} / \mathrm{v})[0.40 \mathrm{~N}] \mathrm{CaCl}_{2}(\mathrm{~J} . \mathrm{T}$. Baker), leaving the system under gentle agitation for 2 hours and then the immobilized preparation was harvested. Once the beads were harvested, they were washed with water, 
10 times their volume, i.e. if the volume of beads is one $\mathrm{ml}$, the volume of water would be $10 \mathrm{ml}$.

\subsubsection{Disruption of Immobilized Preparation}

To know the efficiency of immobilization and other information involving immobilized aminotransferases, it was required to disrupt the beads. In order to do this, 1 gram of immobilized preparation was incubated with $10 \mathrm{ml}$ of $1 \mathrm{M} \mathrm{KH}_{2} \mathrm{PO}_{4}$ (Fisher Scientific), at room temperature, and gently agitated for 1 hour. Activity was measured for (S)-(-)- $\alpha-$ methylbenzylamine system, as described in Section 3.1.1.

\subsubsection{Gelation Time}

Beads of $10 \mathrm{mg}$ spray dried cells of mutant 1 (S)-aminotransferase/g bead of were formed on $\mathrm{CaCl}_{2}$ (J. T. Baker) 2\% (w/v) keeping the beads in calcium chloride for 7, 15, 30, 45, 60 and $120 \mathrm{~min}\left(10 \mathrm{ml}\right.$ of $\mathrm{CaCl}_{2} 2 \%(\mathrm{w} / \mathrm{v})$ per $\mathrm{ml}$ of sodium alginate-enzyme mixture was used). One gram of beads was added to $20 \mathrm{ml}$ of Solution 3 at $\mathrm{pH} 7$ (Table 3-I) to measure enzymatic activity at $30^{\circ} \mathrm{C}$.

\subsubsection{Effect of Sodium Alginate Concentration}

Immobilized preparations (beads) of concentration $10 \mathrm{mg}$ of spray dried cells of CNB0303 (Mutant 3) per gram were prepared with sodium alginate of concentrations 3\% and 4\% $(\mathrm{w} / \mathrm{v})$, which is the maximum workable concentration (Bickerstaff, 1997). The amount of enzyme incorporated to the bead was obtained by measuring activities and the results related to sodium alginate concentration. It was done as follows: 1.43 gram of disrupted beads, made with sodium alginate 3 or $4 \%(\mathrm{w} / \mathrm{v})$, was added to $20 \mathrm{ml}$ of Solution $1 \mathrm{pH} 7$ 
(Table 3-I) and (S)-aminotransferase activity was measured at $55^{\circ} \mathrm{C}$. The results were compared with the activity of $10 \mathrm{mg}$ of free CNB03-03 in $20 \mathrm{ml}$ of Solution $5 \mathrm{pH} 7$ (Table $3-\mathrm{I})$ at $55^{\circ} \mathrm{C}(0.59)$, chosen as a control.

\subsubsection{Effect of Calcium Chloride Concentration}

Beads of $10 \mathrm{mg}$ of spray dried cells of CNB03-03 per gram were made using calcium chloride of concentrations $0.05 \mathrm{M}$ and $0.20 \mathrm{M}$. The amount of enzyme incorporated to the bead was estimated by comparison of activities, and the results were correlated to calcium chloride concentration. To do so one gram of disrupted beads, formed in calcium chloride $0.05 \mathrm{M}$ or $0.20 \mathrm{M}$, was added to $20 \mathrm{ml}$ of Solution $1 \mathrm{pH} 7$ (Table 3-I) and (S)aminotransferase activity was measured at $55^{\circ} \mathrm{C}$; the results were compared with the control in Section 4.2.4.

\subsubsection{Effect of Bead Diameter}

Beads of $10 \mathrm{mg}$ of spray dried cells of CNB03-03 per gram of 2 and $5 \mathrm{~mm}$ in diameter were prepared. The amount of enzyme incorporated was determined by comparison of (S)-aminotransferase activity of whole versus disrupted beads $(0.59 \mathrm{mM} / \mathrm{min}$, at 0.5 $\mathrm{mg} / \mathrm{ml}$ of free spray dried cells of CNB03-03 -Section 4.2.4-); enzyme incorporated to the bead was directly related to diameter of the bead, since other properties, such gelation time and calcium chloride concentration, remained constant. To estimate the amount of enzyme incorporated, one gram of whole beads of 2 or $5 \mathrm{~mm}$ in diameter (to test enzyme activity) was added to $20 \mathrm{ml}$ of Solution $5 \mathrm{pH} 7$ (Table 3-I); and one gram of disrupted 
beads of 2 or $5 \mathrm{~mm}$ in diameter (to test for enzyme incorporated to the beads) was added to $20 \mathrm{ml}$ of Solution $1 \mathrm{pH} 7$ (Table 3-I) and (S)-aminotransferase activity was measured at $55^{\circ} \mathrm{C}$. The results were compared with the control listed above.

\subsubsection{Enzyme Loading}

Immobilized preparations of (S)-aminotransferase CNB03-03 of 10, 25, 50, 75, and 100 $\mathrm{mg}$ of spray dried cells/g bead of $2 \mathrm{~mm}$ in diameter were made as described before. The effect on enzyme incorporated and activity was determined by measuring (S)aminotransferase activity at $55^{\circ} \mathrm{C}$ for the system. To $20 \mathrm{ml}$ of Solution 1 at $\mathrm{pH} 7$ (Table 3-I) enough disrupted beads to have $10 \mathrm{mg}$ were added (since the activity is going to be compared with the activity of $10 \mathrm{mg}$ of free CNB03-03), and to $20 \mathrm{ml}$ of Solution $5 \mathrm{pH} 7$ (Table 3-I) were added enough whole beads to have $10 \mathrm{mg}$. The results were compared to the control.

\subsubsection{Size Distribution}

The diameter distribution of a representative sample of beads prepared as described in Section 4.2.1, using the needle of gauge 22(1/2) producing beads about $2 \mathrm{~mm}$ in diameter, was measured and analyzed. Bead diameter was measured using a vernier caliper. 


\subsubsection{Drying and Reconstitution of Beads}

Beads of $10 \mathrm{mg} / \mathrm{g}$ of $(\mathrm{S})$-aminotransferase CNB03-03 were prepared in $0.20 \mathrm{M}$ calcium chloride using 3 and $4 \%(\mathrm{w} / \mathrm{v})$ sodium alginate, with a diameter of 2 and $5 \mathrm{~mm}$. One gram of those beads was taken and dried for 8 hours under nitrogen flow. Then they were

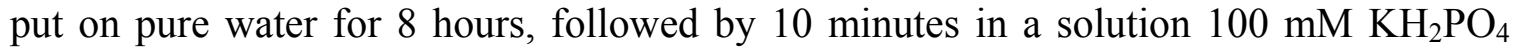
(Fisher Scientific), and finally, 30 minutes in $0.20 \mathrm{M}$ calcium chloride (J. T. Baker). The hydrated beads were added to $20 \mathrm{ml}$ of Solution $5 \mathrm{pH} 7$ (Table 3-I), and their activity was compared to the activity of fresh-whole beads at $55^{\circ} \mathrm{C}$.

\subsection{Enzyme Immobilization Results}

\subsubsection{Gelation Time}

The effect of gelation time on activity of beads of $10 \mathrm{mg}$ of spray dried cells of mutant 1 (S)-aminotransferase per gram at $30{ }^{\circ} \mathrm{C}$ is shown in Figure $4-1$. The values of activity of the beads formed at gelation times of 7, 15, 30, 45, 60 and 120 min, shown in Figure 4-1, are statistically different $\left(\mathrm{F}=14.4312\right.$ and $\mathrm{P}=9.24 \times 10^{-6}$ at a significance level of 0.05 , Appendix 4). Based on the value of activity, and on the apparent better mechanical properties of the beads (not measured), the gelation time of 120 minutes was selected as an established parameter to prepare all the immobilizations. It has been reported that the mechanicals properties of calcium alginate vary progressively with gelation time (Edwards- Lévy and Lévy, 1999). Since mechanical properties of calcium alginate vary with time, when the beads formed at gelation times between 7 and 60 minutes were 
washed, physical loses of enzyme occurred because the linkages of alginate were still under formation.

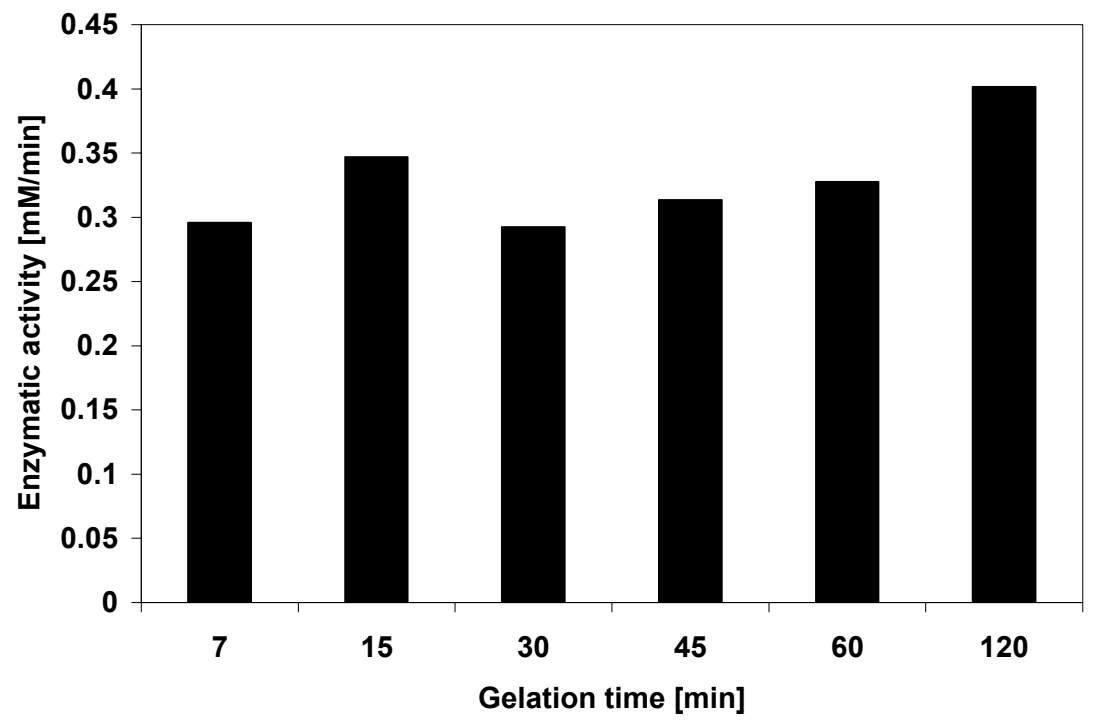

Figure 4-1: Effect of Gelation time on enzymatic activity.

\subsubsection{Effect of Sodium Alginate and Calcium Chloride Concentration}

The effect of sodium alginate of concentration 3 and $4 \%(\mathrm{w} / \mathrm{v})$ in the making of beads of $10 \mathrm{mg}$ of spray dried cells of CNB03-03 per gram, during a gelation time of 2 hours, is shown in Table 4-III. This table also shows other details of the making of the beads, such calcium chloride concentration and bead diameter.

Table 4-III: Effect of sodium alginate concentration on the activity and enzyme incorporated to the bead.

\begin{tabular}{|l|c|c|c|c|c|}
\hline \multirow{2}{*}{$\begin{array}{l}\mathbf{C a C l}_{2} \\
{[\mathbf{M}]}\end{array}$} & \multirow{2}{*}{$\begin{array}{l}\text { Diameter } \\
{[\mathbf{m m}]}\end{array}$} & \multicolumn{2}{|l|}{ Sodium alginate 3\% (w/v) } & \multicolumn{2}{l|}{ Sodium alginate 4\% (w/v) } \\
\cline { 3 - 6 } & & $\begin{array}{l}\text { Activity [mM/min] per } \\
\text { gram of beads }\end{array}$ & $\begin{array}{l}\text { Enzyme } \\
\text { incorporated }\end{array}$ & $\begin{array}{l}\text { Activity [mM/min] per } \\
\text { gram of beads }\end{array}$ & Enzyme incorporated \\
\hline 0.05 & 2 & 0.42 & $70 \%$ & 0.27 & $45 \%$ \\
\hline 0.05 & 5 & 0.41 & $69 \%$ & 0.31 & $53 \%$ \\
\hline 0.20 & 2 & 0.42 & $71 \%$ & 0.25 & $41 \%$ \\
\hline 0.20 & 5 & 0.39 & $66 \%$ & 0.26 & $43 \%$ \\
\hline
\end{tabular}

1.43 grams of each of beads type were used to evaluate the effect of sodium alginate and $\mathrm{CaCl}_{2}$ concentration. 
Table 4-III shows the activity and an estimation of the total enzyme incorporated to the bead. The activity shown in the table refers to the enzymatic activity at $55{ }^{\circ} \mathrm{C}$, for the system of (S)-(-)- $\alpha$-methylbenzylamine, per gram of disrupted beads. The estimation of enzyme incorporated is done as follows: the activity per gram of disrupted beads, of concentration $10 \mathrm{mg}$ of spray dried cells of CNB03-03, is divided by the activity of 10 $\mathrm{mg}$ of free CNB03-03 under the same condition $(0.59 \mathrm{mM} / \mathrm{min})$, and multiplied by one hundred. Table 4-III shows that the beads formed with sodium alginate $3 \%(\mathrm{w} / \mathrm{v})$ had almost about $70 \%$ incorporation of the enzyme. The beads made with sodium alginate $4 \%$ (w/v) showed an incorporation of between $45 \%$, due to the high viscosity of this solution, resulting in poor mixing of spray dried cells and alginate solution.

The effect of calcium chloride of concentration 0.05 and $0.20 \mathrm{M}$ in the making of beads of $10 \mathrm{mg}$ of spray dried cells of CNB03-03 per gram, during a gelation time of 2 hours, is shown in Table 4-III. This table also shows other details of the making of the beads, such sodium alginate concentration and bead diameter. From data shown in Table 4-III it was concluded that using $0.20 \mathrm{M}$ calcium chloride and a gelation time of 120 minutes the amount of enzyme incorporated to the bead is higher than for the case of using a concentration of $0.05 \mathrm{M}$ calcium chloride. In addition, beads made in $0.05 \mathrm{M}$ calcium chloride have poor mechanical properties, as they are broken by agitation. 


\subsubsection{Effect of Bead Diameter}

The effect of diameter of the bead on enzyme incorporated was tested during the making of beads of concentration $10 \mathrm{mg}$ of spray dried cells per gram, and diameter of 2 and 5 mm. The results are shown in Table 4-IV. The effect of diameter of the bead on enzymatic activity is shown in Table 4-V.

Table 4-IV: Effect of diameter of the bead on enzyme incorporated.

\begin{tabular}{|c|l|l|}
\hline Case & $\begin{array}{l}\text { Activity of 1 gram of disrupted } \\
\text { beads D= 2 mm } \\
{[\mathbf{m M} / \mathbf{m i n}]}\end{array}$ & $\begin{array}{l}\text { Enzyme incorporated to the } \\
\text { bead }\end{array}$ \\
\hline 1 & \multicolumn{1}{|c|}{0.43} & \multicolumn{1}{|c|}{0.43} \\
\hline 3 & \multicolumn{1}{|c|}{$51 \%$} \\
\hline Case & $\begin{array}{l}\text { Activity of } \mathbf{~ g r a m ~ o f ~ d i s r u p t e d ~} \\
\text { beads D=5 mm } \\
{[\mathbf{m M} / \mathbf{m i n}]}\end{array}$ & $\begin{array}{l}\text { Enzyme incorporated to the } \\
\text { bead }\end{array}$ \\
\hline 2 & \multicolumn{1}{|c|}{0.37} & $62 \%$ \\
\hline 4 & 0.33 & $55 \%$ \\
\hline
\end{tabular}

Beads formed in $\mathrm{CaCl}_{2} 0.20 \mathrm{M}$, gelation time 2 hours, with sodium alginate 3\% (w/v) (Cases 1 and 2); and $4 \%(w / v)($ Cases 3 and 4$)$.

Table 4-V: Effect of diameter of the bead on active enzyme of whole beads.

\begin{tabular}{|c|c|c|c|}
\hline Case & $\begin{array}{l}\text { Activity of } 1 \text { gram of } \\
\text { disrupted beads } \\
\mathrm{D}=2 \mathrm{~mm} \\
{[\mathrm{mM} / \mathrm{min}]}\end{array}$ & $\begin{array}{l}\text { Activity of } 1 \text { gram of } \\
\text { whole beads } \\
\text { D=2 mm } \\
{[\mathrm{mM} / \mathrm{min}]}\end{array}$ & $\begin{array}{l}\text { Percent of active } \\
\text { enzyme in whole beads }\end{array}$ \\
\hline 1 & 0.43 & 0.42 & $97 \%$ \\
\hline 3 & 0.43 & 0.31 & $70 \%$ \\
\hline Case & $\begin{array}{l}\text { Activity of } 1 \text { gram of } \\
\text { disrupted beads } \\
D=5 \mathrm{~mm} \\
{[\mathrm{mM} / \mathrm{min}]}\end{array}$ & $\begin{array}{l}\text { Activity of } 1 \text { gram of } \\
\text { whole beads } \\
\text { D=5 mm } \\
{[\mathrm{mM} / \mathrm{min}]}\end{array}$ & $\begin{array}{l}\text { Percent of active } \\
\text { enzyme in whole beads }\end{array}$ \\
\hline 2 & 0.37 & 0.26 & $69 \%$ \\
\hline 4 & 0.33 & 0.22 & $69 \%$ \\
\hline
\end{tabular}

From the data in Table 4-IV and Table 4-V it was concluded that the diameter that allows the highest efficiency of immobilization, measured as the ratio of activity of whole beads 
to activity of disrupted beads, was $\mathrm{D}=2 \mathrm{~mm}$ for beads made with sodium alginate at $3 \%$ $(\mathrm{w} / \mathrm{v})$.

\subsubsection{Enzyme Loading}

Immobilized beads preparations of $2 \mathrm{~mm}$ in diameter were made in $0.20 \mathrm{M} \mathrm{CaCl}_{2}$, with a gelation time of 2 hours. The theoretical concentrations of those beads were $10,25,50$, 75 and $100 \mathrm{mg}$ of spray dried cells of CNB0-03 per gram of bead. The results of total enzyme incorporated to the beads of different concentration are presented in Table 4-VI.

Table 4-VI: Amount of enzyme incorporated to the beads.

\begin{tabular}{|l|l|l|l|l|l|}
\hline $\begin{array}{l}\text { Bead enzyme } \\
\text { concentration } \\
{[\mathbf{m g} / \mathbf{g}]}\end{array}$ & $\begin{array}{l}\text { Amount } \\
\text { of beads } \\
\text { disrupted } \\
{[\mathbf{g}]}\end{array}$ & $\begin{array}{l}\text { Enzymatic } \\
\text { activity } \\
{[\mathbf{m M / m i n}]}\end{array}$ & $\begin{array}{l}\text { Normalized } \\
\text { activity } \\
{[\mathbf{m M / ( m i n * g}} \\
\text { bead)] }\end{array}$ & $\begin{array}{l}\text { Enzyme } \\
\text { incorporated } \\
{[\mathbf{m g} / \mathbf{g}]}\end{array}$ & $\begin{array}{l}\text { Percent of } \\
\text { enzyme lost }\end{array}$ \\
\hline 10 & 1.026 & 0.43 & 0.42 & 7.0 & 29.9 \\
\hline 25 & 0.405 & 0.43 & 1.05 & 17.7 & 29.2 \\
\hline 50 & 0.201 & 0.43 & 2.12 & 35.7 & 28.5 \\
\hline 75 & 0.138 & 0.45 & 3.24 & 54.7 & 27.1 \\
\hline 100 & 0.107 & 0.45 & 4.24 & 71.6 & 28.4 \\
\hline
\end{tabular}

Table 4-VI shows the amount of beads of the specific enzyme concentration that were disrupted in order to know the total enzyme (spray dried cells of CNB03-03) incorporated to the bead. After disrupting the beads, enzymatic activity was measured under the conditions specified in Section 4.2.7. Since the goal of the experiment is to find out the incorporated enzyme per gram of bead, the activity was normalized to one gram of bead, i.e. the activity given by a certain amount of beads was divided by this quantity. Since the activity of $10 \mathrm{mg}$ of free spray dried cells under the same conditions is known $(0.59$ $\mathrm{mM} / \mathrm{min}$ ), the amount of enzyme incorporated was estimated. Finally, the percent of 
enzyme lost was calculated using the desired theoretical concentration of the enzyme and the amount of it incorporated. Table 4-VI shows loses of enzyme of about $30 \%$ for all the desired theoretical concentrations. Apparently $30 \%(\mathrm{w} / \mathrm{w})$ of spray dried cells is a property inherent to the immobilization procedure. During the preparation of beads of different concentration, another parameter determined besides total enzyme incorporated was the amount of enzyme available to catalyze the reaction of transamination in whole beads. Such information is presented in Table 4-VII.

Table 4-VII: Amount of enzyme active in whole beads.

\begin{tabular}{|c|c|c|c|c|c|}
\hline $\begin{array}{l}\text { Bead } \\
\text { concentration } \\
{[\mathrm{mg} / \mathrm{g} \text { bead }]}\end{array}$ & $\begin{array}{l}\text { Amount of } \\
\text { whole beads } \\
\text { [g] }\end{array}$ & $\begin{array}{l}\text { Enzymatic } \\
\text { activity } \\
{[\mathrm{mM} / \mathrm{min}]}\end{array}$ & $\begin{array}{l}\text { Normalized } \\
\text { activity } \\
{\left[\mathrm{mM} / \text { min }^{*} \mathrm{~g}\right.} \\
\text { bead) }]\end{array}$ & $\begin{array}{l}\text { Active } \\
\text { enzyme }[\mathrm{mg} / \mathrm{g} \\
\text { bead }]\end{array}$ & $\begin{array}{l}\text { Active } \\
\text { enzyme in } \\
\text { bead }(\%)\end{array}$ \\
\hline 10 & 1.018 & 0.52 & 0.51 & 8.6 & 100 \\
\hline 25 & 0.401 & 0.33 & 0.81 & 13.7 & 77 \\
\hline 50 & 0.206 & 0.15 & 0.74 & 12.5 & 35 \\
\hline 75 & 0.133 & 0.14 & 1.08 & 18.2 & 33 \\
\hline 100 & 0.104 & 0.12 & 1.14 & 19.2 & 27 \\
\hline
\end{tabular}

Table 4-VII shows the amount of active enzyme per gram of whole beads. This amount was calculated using the values of normalized activity (Table 4-VII) and the activity given by $10 \mathrm{mg}$ of free spray dried cells of CNB03-03 measured under the same conditions. The percent of active enzyme in the bead was calculated by dividing the values of active enzyme per gram of bead (Table 4-VII) by the values of enzyme incorporated per gram of bead (Table 4-VII) and multiplying by one hundred for each concentration tested. Analyzing the information from the Table 4-VI and Table 4-VII it was concluded that the best enzyme load per gram of calcium alginate was $10 \mathrm{mg}$, since this load shows the highest ratio of active enzyme to enzyme incorporated. 


\subsubsection{Size Distribution}

The size distribution of beads made as described in Section 4.2.1, with the needle $201 / 2$ $\mathrm{G}$, is shown in Figure 4-2.

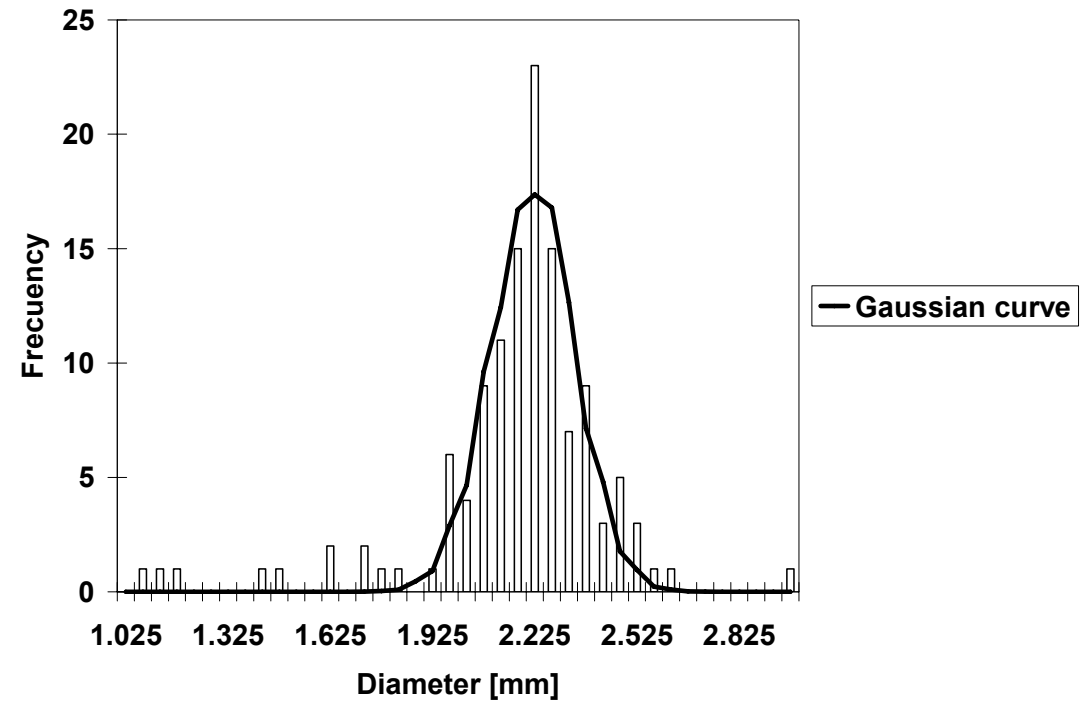

Figure 4-2: Size distribution of the beads made with the needle of $221 / 2 \mathrm{G}$.

The size distribution of the beads made as described in Section 4.2.1 follows closely a Gaussian distribution. The mean diameter is $2.22 \mathrm{~mm}$ and the standard deviation is 0.12 $\mathrm{mm}$. The beads of apparent diameter of $5 \mathrm{~mm}$, made with tube of 1/16 inches of internal diameter, were not characterized regarding to their size distribution, since those beads showed lower percent of enzyme active per gram of beads than the beads of $2 \mathrm{~mm}$ (Table 4-V). 


\subsubsection{Drying and Reconstitution of Beads}

Immobilized preparations (beads) of $10 \mathrm{mg}$ of spray dried cells per gram were prepared in calcium chloride of $0.20 \mathrm{M}$, with a gelation time of 2 hours. Those beads were made with sodium alginate of concentration 3 and $4(\mathrm{w} / \mathrm{v})$ and diameters of $2 \mathrm{~mm}$ and $5 \mathrm{~mm}$. One gram of each type of beads was taken and dried and reconstituted as described in Section 4.2.9. The effects of these operations are shown in Table 4-VIII.

Table 4-VIII: Effect of drying and reconstitution of beads.

\begin{tabular}{|l|l|l|l|}
\hline $\begin{array}{l}\text { Sodium alginate } \\
\text { concentration \% } \mathbf{( w / v )}\end{array}$ & $\begin{array}{l}\text { Diameter } \\
{[\mathbf{m m}]}\end{array}$ & $\begin{array}{l}\text { Normalized activity of whole } \\
\text { beads prior to drying } \\
{[\mathbf{m M} /(\mathbf{m i n} * \mathbf{g} \text { bead)] }}\end{array}$ & $\begin{array}{l}\text { Normalized activity of } \\
\text { reconstituted beads } \\
{[\mathbf{m M} /(\mathbf{m i n} \mathbf{g} \text { bead)] }}\end{array}$ \\
\hline 3 & 2 & 0.42 & 0.04 \\
\hline 3 & 5 & 0.26 & No detected activity \\
\hline 4 & 2 & 0.43 & 0.05 \\
\hline 4 & 5 & 0.22 & No detected activity \\
\hline
\end{tabular}

From Table 4-VIII it was concluded that the drying and reconstitution of the bead, seeking for storage in small volume of the immobilized enzyme, almost completely eliminated the catalytic properties of the immobilized preparation. After drying, the mass of the immobilized material had one tenth of its original weight. After drying and reconstitution there was a full recovery in mass, diameter, and mechanical properties, but not in activity.

\subsection{Summary}

The immobilization of spray dried cells of CNB03-03 by entrapment into calcium alginate was seen to have a higher enzyme incorporation using sodium alginate $3 \%(\mathrm{w} / \mathrm{v})$, and a gelation time of 2 hours. Also, beads of about $2 \mathrm{~mm}$ in diameter showed a higher 
amount of enzyme available to catalyze the reaction. Calcium chloride of concentration $0.20 \mathrm{M}$ produced beads with better mechanical properties than calcium chloride of concentration $0.05 \mathrm{M}$. Combining all the parameters that apparently optimize the amount of enzyme available to catalyze the reaction, the method showed an inherent loses of spray dried cells of about $30 \%(\mathrm{w} / \mathrm{w})$, which was observed during the making of beads of several concentrations. Beads of theoretical concentrations of 10, 25, 50, 75, and $100 \mathrm{mg}$ of spray dried cells per gram had an incorporation of enzyme of $70 \%(w / w)$ of the theoretical concentration. The effectiveness factor of the beads of $10,25,50,75$, and 100 mg per gram of beads, estimated as the ratio of enzyme available to catalyze the reaction to enzyme incorporated, were $1,0.77,0.35,0.33$, and 0.27 , respectively (Table 4 -VII).

Chapter 5 describes the results of enzyme engineering of aminotransferase, including the goals and strategies followed in order to achieve the desired outcomes, which is the development of aminotransferase mutants with higher thermostability and/or activity than their predecesors. 


\section{Chapter 5. Enzyme Engineering}

The research objectives were to minimize enzyme cost contribution to production cost as stated in Section 1.3. The pathways followed in order to achieve this goal were:

1) Immobilization of (S)-aminotransferase as spray dried cells

2) Increase the specific activity of spray dried cells (higher activity)

The following sections show the details of enzyme engineering by directed evolution to obtain two new mutant enzymes, CNB04-01 and CNB05-01.

\subsection{Enzyme Engineering Using CNB03-03 as Template}

The development of an improved enzyme was accomplished by error prone polymerase chain reaction and a proper screening procedure with the goal of obtaining a thermostable enzyme.

Error prone polymerase chain reaction as well as site directed mutagenesis, random mutagenesis, and DNA-shuffling have demonstrated improvement in the quality of industrially important enzymes (Chirumamilla et al, 2001). Some examples are shown below.

a). The enantioselectivity of a bacterial lipase from Pseudomonas aeruginosa was increased from $2 \%$ ee (enantiomeric excess) to $90 \%$ ee after several rounds of mutagenesis and screening (Reetz, 2000). 
b). Barley $\alpha$-amylase isozyme 2 was cloned into Saccharomyces cerevisiae. This gene, which codes for the wild-type enzyme, was subjected to three rounds of mutagenesis and screening. One mutant showed an improvement of 1000 times in activity, from $0.45 \mathrm{U} / \mathrm{ml}$ in the wild-type gene to $480 \mathrm{U} / \mathrm{ml}$ (Wong et al, 2004)

c). The thermostability and catalytic activity of phospholipase $A_{1}$, from Serratia $s p$. Strain MK1 and subcloned into Escherichia coli XL1-Blue, were enhanced simultaneously by enzyme engineering (Song and Rhee, 2000).

\subsubsection{Enzyme Engineering Procedure}

A plasmid (6 kilo base pairs [kbp]) was obtained from CNB03-03 using the plasmid purification kit from Qiagen, and $25 \mu$ of this plasmid solution was incubated for 1 hour at $37{ }^{\circ} \mathrm{C}$ with a solution of $8 \mu \mathrm{l}$ of RNA'se free water, $4 \mu \mathrm{l}$ of MULTI-CORE ${ }^{\mathrm{TM}}$ Buffer (Promega), $1 \mu$ of Bovine Serum Albumin BSA (Promega), $1 \mu 1$ of Hind III (Promega), and $1 \mu \mathrm{l}$ of Nco I (Promega). The products of this reaction were insert $(1.5 \mathrm{kbp})$ and vector $(4.5 \mathrm{kbp})$. Ten $\mu \mathrm{l}$ of this product was mixed with $10 \mu \mathrm{l}$ of DNA loading buffer (Promega) and loaded into $0.8 \%(\mathrm{w} / \mathrm{w})$ agarose gel (Cambrex) on 1X TBS buffer (Invitrogen). The gel was run at $120 \mathrm{~V}$ for $45 \mathrm{~min}$ to obtain vector and insert. The results are shown in Figure 5-1. The pieces of gel containing the vector and the insert were cut, and they were isolated using a Gel Extraction Purification Kit (Qiagen). The insert was subjected to a round of error prone polymerase chain reaction (PCR) (Section 3.3.1). The products of PCR were purified and restricted following Protocol 1 (Section 3.3.2). 


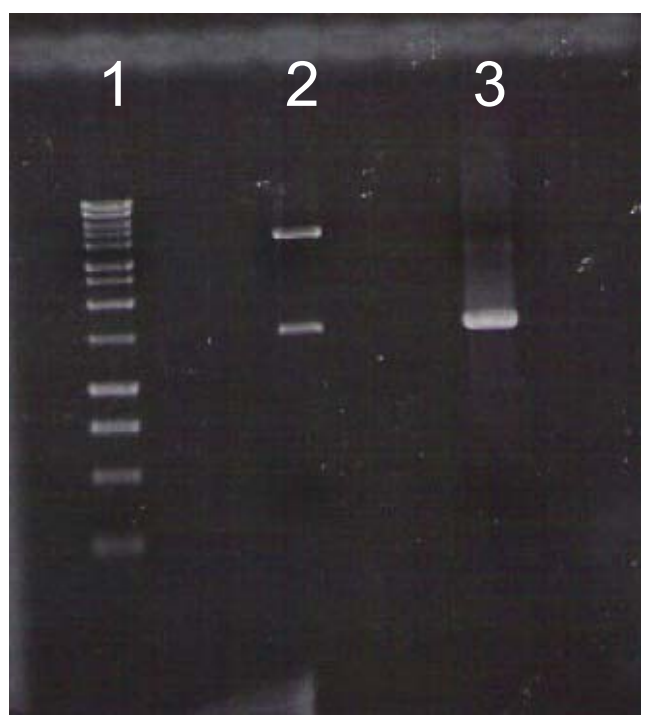

Figure 5-1: Agarose gel for vector isolation. Line 1 is the molecular weight marker, line 2 is the product from plasmid restriction (From the top to the bottom vector $-4.5 \mathrm{kbp}$ - and insert $1.5 \mathrm{kbp}-)$, and line 3 is a marker of $1.5 \mathrm{kbp}$.

Ligation using the purified restricted product obtained following Protocol 1 was not successful. In order to obtain a successful ligation (Section 3.3.3) several protocols of restriction were used. Those were Protocols 2, 3, and 4 (Section 3.3.2). The results of restriction as well as ligation are shown in Figure 5-2.

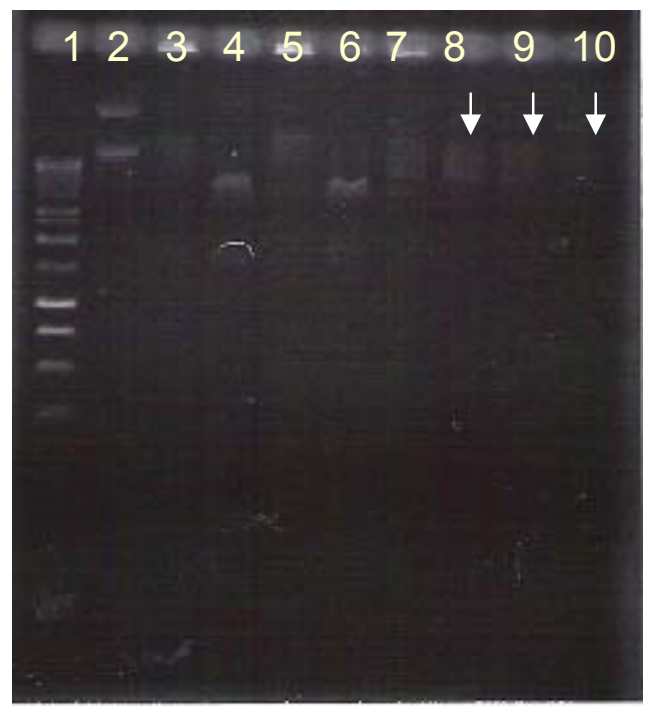

Figure 5-2: Results of restriction and ligation. 
From left to rightFigure 5-2 was loaded the molecular weight marker (1), self ligation of vector (2), purified restricted product from Protocol 2 (3), purified partially restricted product from Protocol 3 after NcoI addition (4), purified restricted product from Protocol 3 after HindIII addition (5), purified partially restricted product from Protocol 4 after NcoI addition (6), purified restricted product from Protocol 4 after HindIII addition (7), ligation of product from Protocol 2 (8), ligation of product from Protocol 3 (9), and ligation of product from Protocol 4 (10).

Figure 5-2 shows that restriction Protocols 2, 3, and 4 were successful since products of molecular weight higher than 1.5 and $4.5 \mathrm{kbp}$ are present. Following ligation, transformation (Section 3.3.4) was done into LIBRARY EFFICIENCY ${ }^{\circledR}$ DH5 $\alpha^{\mathrm{TM}}$ Competent Cells (Invitrogen), obtaining 5 to 10 colonies per plate after plating $200 \mu \mathrm{l}$ of transformation mixture. Transformation into LIBRARY EFFICIENCY ${ }^{\circledR}$ DH5 $\alpha^{\mathrm{TM}}$ Competent Cells (Invitrogen) was done several times obtaining always 5 to 10 colonies per plate. Since transformation into LIBRARY EFFICIENCY ${ }^{\circledR}$ DH5 $\alpha^{\mathrm{TM}}$ Competent Cells (Invitrogen) was not efficient, then another strain of competent cell was tried. This strain was XL1-Blue MR Supercompetent Cells (STRATAGENE). Transformation into XL1Blue MR Supercompetent Cells (STRATAGENE) gave 50 to 80 colonies per plate, after plating $200 \mu$ of transformation mixture, obtaining in this way over 1000 colonies. 


\subsubsection{Screening Procedure}

The selection of the mutant with improved thermostability was done based on a colorimetric assay. The colorimetric assay is based on the colored product (substituted tetralone) produced by the reaction shown in Figure 5-3.

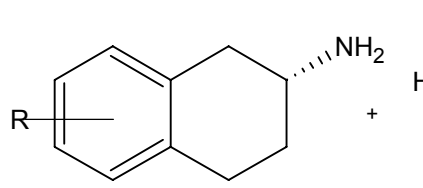

Substituted (S)-Aminotetralin

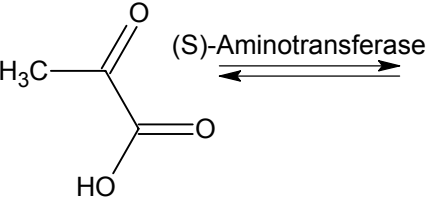

Pyruvic acid

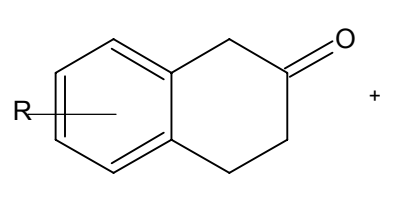

Substituted Tetralone (Colored product)

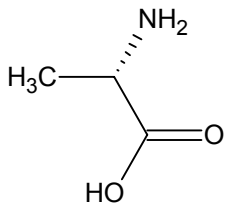

Alanine

Figure 5-3: Reaction for colorimetric screening.

In the reaction of colorimetric assay substituted (S)-aminotetralin is the amine donor, and pyruvic acid the amine acceptor. The products of the reaction are alanine and substituted tetralone, which is a brownish product.

The colonies obtained after transformation were grown at $37{ }^{\circ} \mathrm{C}$ in $200 \mu \mathrm{l}$ of LB media (Accugene) with $100 \mu \mathrm{g} / \mathrm{ml}$ of ampicillin (Sigma), after that, the colonies were transferred to LB agar plates with $100 \mu \mathrm{g} / \mathrm{ml}$ of ampicillin (Sigma) and incubated overnight at $37{ }^{\circ} \mathrm{C}$. Finally, the colonies were transferred from the agar plate to nitrocellulose paper and put over filter paper on a Petri dish. To the cells on Petri dishes were added predetermined volumes of solution shown in Table 5-I, in amounts and for reasons specified in the next sections. 
Table 5-I: Screening solutions.

\begin{tabular}{|c|c|}
\hline Solution & Composition \\
\hline A & Luria-Bertani medium ( $\mathrm{pH} 7,100 \mu \mathrm{g} / \mathrm{ml}$ Ampicillin) \\
\hline B & $100 \mathrm{mM} \mathrm{KH}{ }_{2} \mathrm{PO}_{4}, 100 \mathrm{mM}$ Sodium pyruvate, $2 \mathrm{mM}$ Pyridoxal 5-phosphate $(\mathrm{pH} 7)$ \\
\hline$\overline{\mathrm{C}}$ & $\begin{array}{l}100 \mathrm{mM} \mathrm{KH}_{2} \mathrm{PO}_{4}, 100 \mathrm{mM} \text { Sodium pyruvate, } 2 \mathrm{mM} \text { Pyridoxal 5-phosphate, } 15 \mathrm{mM} \\
\text { substituted }(\mathrm{S}) \text {-aminotetralin }(\mathrm{pH} \mathrm{7})\end{array}$ \\
\hline
\end{tabular}

\subsubsection{Selection of Mutants with Functional (S)-Aminotransferase}

The product of the transformation was about 1000 colonies, not all of them being able to perform the reaction of transamination (Figure 5-3) because a lethal mutation for the gene of (S)-aminotransferase was present in them. To isolate these mutants from the mutants with functional (S)-aminotransferase, a filter paper in a Petri dish was soaked with $2 \mathrm{ml}$ of Solution C (Table 5-I). Over it was put the cells on nitrocellulose paper, and then the system was incubated at $50{ }^{\circ} \mathrm{C}$ for one hour. Representative results are shown in Figure 5-4. This figure shows the mutants with functional (S)-aminotransferase, and at the same time it shows the signal of CNB03-03, represented by the two dark-brownish circles at the bottom of the picture. As a result of the first screening, 250 out of 1000 were shown to have functional (S)-aminotransferase, since they gave a positive result for the colorimetric assay. The colonies that showed (S)-aminotransferase activity were grown in 96 well plates (200 $\mu 1 /$ well) on LB media, transferred to agar plates using a pin replicator and then to nitrocellulose paper. 


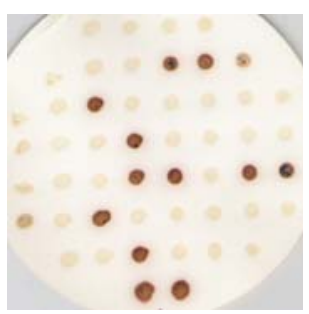

Figure 5-4: Selection of mutants with functional (S)-aminotransferase.

\subsubsection{Selection of Mutants with (S)-Aminotransferase Active at High}

\section{Temperature}

After the first screening (Section 5.1.2.1), 250 colonies were obtained. Since the goal of the screening procedure was to find a mutant with higher thermostability than CNB03-03, the colorimetric assay was conducted at high temperature $\left(80^{\circ} \mathrm{C}\right)$. Filter paper in a Petri dish was soaked with $2 \mathrm{ml}$ of Solution C (Table 5-I), then over it was put the colonies on nitrocellulose paper, and then the system was incubated at $80{ }^{\circ} \mathrm{C}$ for 1 hour. Representative results are shown in Figure 5-5.

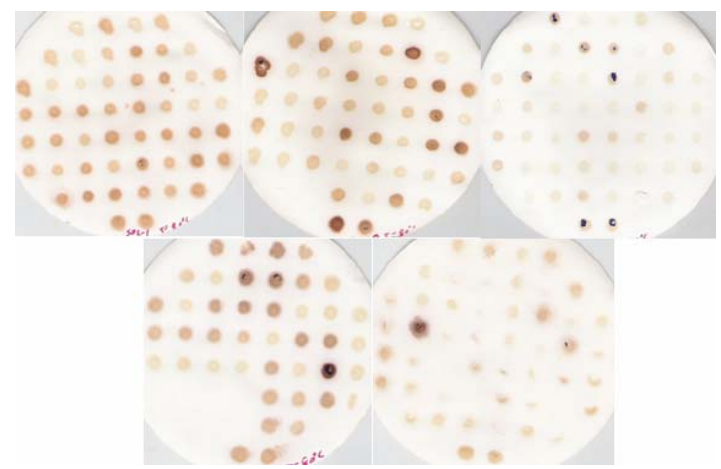

Figure 5-5: Selection of mutants with (S)-aminotransferase activity at $80^{\circ} \mathrm{C}$. The two circles at the bottom of nitrocellulose paper are cells of $\mathrm{CNB03-03}$, the control. 
As a result of the second screening 12 colonies were shown to have activity at $80{ }^{\circ} \mathrm{C}$, those colonies were grown in LB media, and transferred to LB agar plates.

\subsubsection{Selection of Thermostable Mutants}

The colonies that showed activity at $80{ }^{\circ} \mathrm{C}$ were transferred in triplicates to LB agar plates and then transferred to nitrocellulose paper. Filter paper in a Petri dish was soaked with $2 \mathrm{ml}$ of Solution A (Table 5-I), and over it was put the cells on nitrocellulose paper, and then the system was incubated between 60 to $65{ }^{\circ} \mathrm{C}$, and every 24 hours $2 \mathrm{ml}$ of Solution C (Table 5-I) were added. The system was then incubated for one hour between 60 to $65^{\circ} \mathrm{C}$. The results are shown in Figure 5-6.

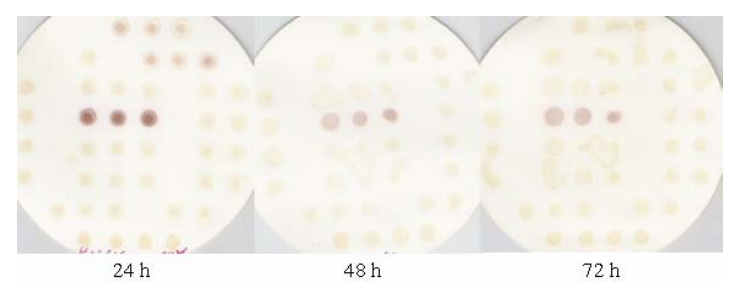

Figure 5-6: Colorimetric assay of the colonies with activity at $80^{\circ} \mathrm{C}$ incubated at temperatures 60-65 ${ }^{\circ} \mathrm{C}$. The four circles at the bottom are cells of $\mathrm{CNB03-03}$.

The results obtained in Figure 5-6 for CNB03-03 match the results obtained at $50{ }^{\circ} \mathrm{C}$ during its recycling, where its activity had decreased considerably after 24 hours (Section 7.1). Comparatively, the activity of one colony plated by triplicate still remained after 72 hours of being stored at 60 to $65^{\circ} \mathrm{C}$. 


\subsubsection{Thermostability of Best Mutant}

The colony of cells that showed activity up to $72 \mathrm{~h}$ after incubation at temperatures $60-65$ ${ }^{\circ} \mathrm{C}$ was grown in $5 \mathrm{ml}$ of LB-media. Its plasmids were extracted and then transformed into Escherichia coli MG1655. The transformed cells of Escherichia coli MG1655 were plated four times, in order to isolate healthier colonies (the ones that grew in a circular pattern of larger diameter). The healthier colony of transformed Escherichia coli MG1655, with the gene that codes for the enzyme with apparent higher thermostability, was plated together with CNB03-03, which is also in Escherichia coli MG1655. Several copies containing both enzymes were produced, and then transferred to nitrocellulose paper. To filter paper in a Petri dish was added $1 \mathrm{ml}$ of Solution A (Table 5-I) and $1 \mathrm{ml}$ of Solution B (Table 5-I), and over it was put the nitrocellulose paper with the cells, the system was then closed and incubated at $60-65{ }^{\circ} \mathrm{C}$. After 24 hours, to one plate was added $2 \mathrm{ml}$ of Solution $\mathrm{C}$ (Table 5-I), running colorimetric assay every day; to the rest of them was added $1 \mathrm{ml}$ of Solution A (Table 5-I) and $1 \mathrm{ml}$ of Solution B (Table 5-I). The results are shown in Figure 5-7.

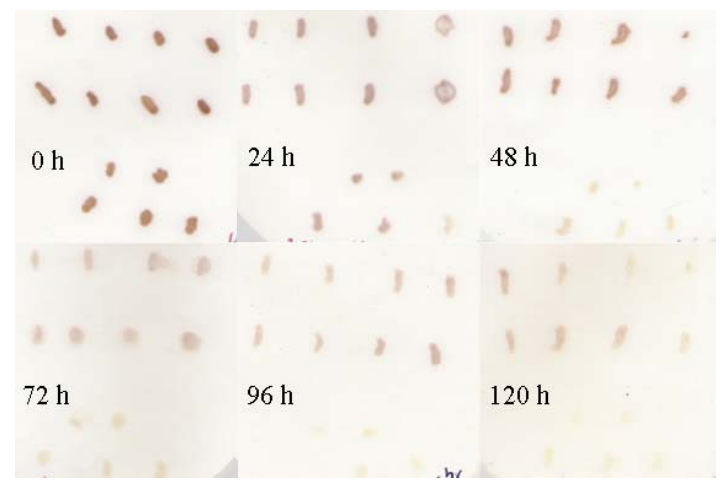

Figure 5-7: Thermostability of the best mutant and $\mathrm{CNB03-03}$ under reaction like-conditions at $60-65^{\circ} \mathrm{C}$. 
Figure 5-7 shows that the activity of the remaining mutant was still detectable at 120 hours later, although the intensity of the signal had decreased after 48 hours. Nevertheless, it was decided to choose this mutant and characterize it, since its activity lasted longer than the activity of CNB03-03. If it does not match the requirements for recycling, it will serve as a template for future rounds of mutagenesis to achieve the requirements of recycling (long thermostability). This new (S)-aminotransferase was fermented, in an 8 liters scale, and spray dried, obtaining about $0.5 \mathrm{~kg}$ of dried product. This mutant was named CNB04-01.

\subsection{Enzyme Engineering of CNB04-01}

Foreseeing problems with mass transfer limitations of immobilization systems, an attempt to improve the economics of the process of production of substituted (S)aminotetralin was changed, from decreasing enzyme cost contribution by immobilization to decreasing enzyme cost contribution by reducing free enzyme concentration during the process of synthesis. The last approach implies that it is necessary to create an enzyme with higher activity i.e. to decrease enzyme concentration by $50 \%$, the enzyme must have twice the activity of the original enzyme. In order to improve the activity of (S)aminotransferase the technique of error prone polymerase chain reaction was implemented using as a template CNB04-01. Error-prone PCR appears from the literature to be promising as a mean of increasing enzyme activity. The activity of native luciferase was improved over a factor of three by means of error prone polymerase chain reaction compared to commercial enzyme (Kim-Choi, 2004). The activity of barley $\alpha$-amylase 
isozyme 2 subcloned into Saccharomyces cerevisiae was improved 1000 times from 0.45

$\mathrm{U} / \mathrm{ml}$ in the wild-type gene to $480 \mathrm{U} / \mathrm{ml}$ (Wong et al, 2004).

\subsubsection{Enzyme Engineering Procedure}

The transformed colony of Escherichia Coli MG1655 producing (S)-aminotransferase CNB04-01 was grown in $5 \mathrm{ml}$ scale on LB media (Accugene), with further extraction of the plasmid (6 kilo base pairs [kbp]). Twenty-five $\mu$ of this plasmid solution was incubated for 1 hour long at $37{ }^{\circ} \mathrm{C}$ with a solution of $8 \mu \mathrm{l}$ of RNA'se free water, $4 \mu \mathrm{l}$ of MULTI-CORE ${ }^{\mathrm{TM}}$ Buffer (Promega), $1 \mu$ of Bovine Serum Albumin BSA (Promega), 1 $\mu \mathrm{l}$ of Hind III (Promega) restriction endonuclease enzyme, and $1 \mu \mathrm{l}$ of Nco I (Promega) restriction endonuclease enzyme. The products of this reaction were insert (1.5 kbp) and vector $(4.5 \mathrm{kbp})$. Ten $\mu \mathrm{l}$ of this product was mixed with $10 \mu \mathrm{l}$ of DNA loading buffer (Promega) and loaded into $0.8 \%(\mathrm{w} / \mathrm{w})$ agarose gel (Cambrex) on 1X TBS buffer (Invitrogen). The gel was run at $120 \mathrm{~V}$ for 45 min to obtain vector and insert. The pieces of gel containing the vector and the insert were cut, and they were isolated using a Gel Extraction Purification Kit (Qiagen). The insert was subjected to a round of error prone polymerase chain reaction (PCR) (Section 3.3.1). The products of PCR were purified and restricted following Protocol 3 (Section 3.3.2). The purified products from PCR were used to do ligation (Section 3.3.3), and then transformation (Section 3.3.4). Transformation was done into XL1-Blue MR Supercompetent Cells (STRATAGENE), and about 1500 colonies were obtained. 


\subsubsection{Screening Procedure}

The selection of the mutant with improved activity was done based on a colorimetric assay. The colorimetric assay is based on the colored product (substituted tetralone) produced by the reaction shown in Figure 5-3. The colonies obtained after transformation were grown at $37{ }^{\circ} \mathrm{C}$ in $200 \mu \mathrm{l}$ of LB media (Accugene) with $100 \mu \mathrm{g} / \mathrm{ml}$ of ampicillin (Sigma). After that, the colonies were transferred to LB agar plates using a pin replicator with $100 \mu \mathrm{g} / \mathrm{ml}$ of ampicillin (Sigma) added and incubated overnight at $37^{\circ} \mathrm{C}$. Finally, the colonies were transferred from the agar plate to nitrocellulose paper and put over filter paper on a Petri dish. To the cells on Petri dishes were added predetermined volumes of solution shown in Table 5-I, in amounts and for reasons specified in the next sections.

\subsubsection{Selection of Mutants with Functional (S)-Aminotransferase}

The product of the transformation was about 1500 colonies, but not all of them were able to perform the reaction of transamination (Figure 5-3). To isolate these mutants from the mutants with functional (S)-aminotransferase, a filter paper in a Petri dish was soaked with $2 \mathrm{ml}$ of Solution C (Table 5-I). Over it was put the cells on nitrocellulose paper, and then the system was incubated at $80^{\circ} \mathrm{C}$ for half an hour. As a result of this screening 350 colonies showed the ability to catalyze the reaction of transamination (Figure 5-3), because they developed a brown color after incubation at $80^{\circ} \mathrm{C}$ for half an hour, similar as shown in Figure 5-4. 


\subsubsection{Selection of Mutants with (S)-Aminotransferase Active at High Temperature}

After the first screening (Section 5.2.2.1), 350 colonies were obtained. These colonies were screened further. In a Petri dish was put 2 layers of filter paper soaked with $2 \mathrm{ml}$ of Solution A (Table 5-I) and $2 \mathrm{ml}$ of Solution B (Table 5-I); over it nitrocellulose paper containing the cells, and over the nitrocellulose paper 2 layers of filter paper soaked with $2 \mathrm{ml}$ of Solution C (Table 5-I). Finally the Petri dish was submerged in a water bath at 90 ${ }^{\circ} \mathrm{C}$, avoiding water to enter the Petri dish by sealing the system, and incubated for half an hour. As a result of screening 14 colonies were obtained, following the criterion of brown color development, as explained earlier.

\subsubsection{Selection of Mutants with Improved Activity}

The colonies obtained from the second screening (Section 5.1.2.2) were plated four times and then grown in a $5 \mathrm{ml}$ scale in LB media (Accugene). The plasmids of these colonies were extracted and then transformed into cells of Escherichia coli MG1655, following the protocol for transformation into Escherichia coli MG1655 (Section 3.3.4). These colonies were grown, as well as Escherichia coli MG1655 producing CNB04-01, in a one liter scale in LB media (Accugene) as specified in Section 3.4.1. The cells from these cultures were spun down and used in a reaction of $20 \mathrm{ml}$ scale at $50{ }^{\circ} \mathrm{C}$ (in duplicates). To $19 \mathrm{ml}$ of Solution $16 \mathrm{pH} 7$ (Table 3-II) was added $1 \mathrm{ml}$ of sonicated cells of optical density 85 , measured at $600 \mathrm{~nm}$ using a spectrophometer. Those cells were sonicated using 5 pulses in a Branson SONIFIER. Concentration of substituted (S)-aminotetralin 
was measured after 5 hours, obtaining 4 colonies with activity higher than the activity of CNB04-01. These colonies were named A1, C1, 3A1, A3.

\subsubsection{Selection of Mutants with Functional (S)-Aminotransferase}

The colonies named A1, C1, 3A1, and A3 were fermented at 8 liters scale and spray dried as described in Section 3.4.2. During this last step of the screening procedure A1 and 3A1 showed a poor rate of growth. The activities of $\mathrm{C} 1$ and $\mathrm{A} 3$ were compared with the activities of CNB03-03 and CNB04-01 in a $50 \mathrm{ml}$ scale at $55^{\circ} \mathrm{C}$. The reaction mixture was $50 \mathrm{ml}$ of Solution 16 at pH 7 (Table 3-II) with an enzyme concentration of 5 grams per liter. The results are shown in Figure 5-8.

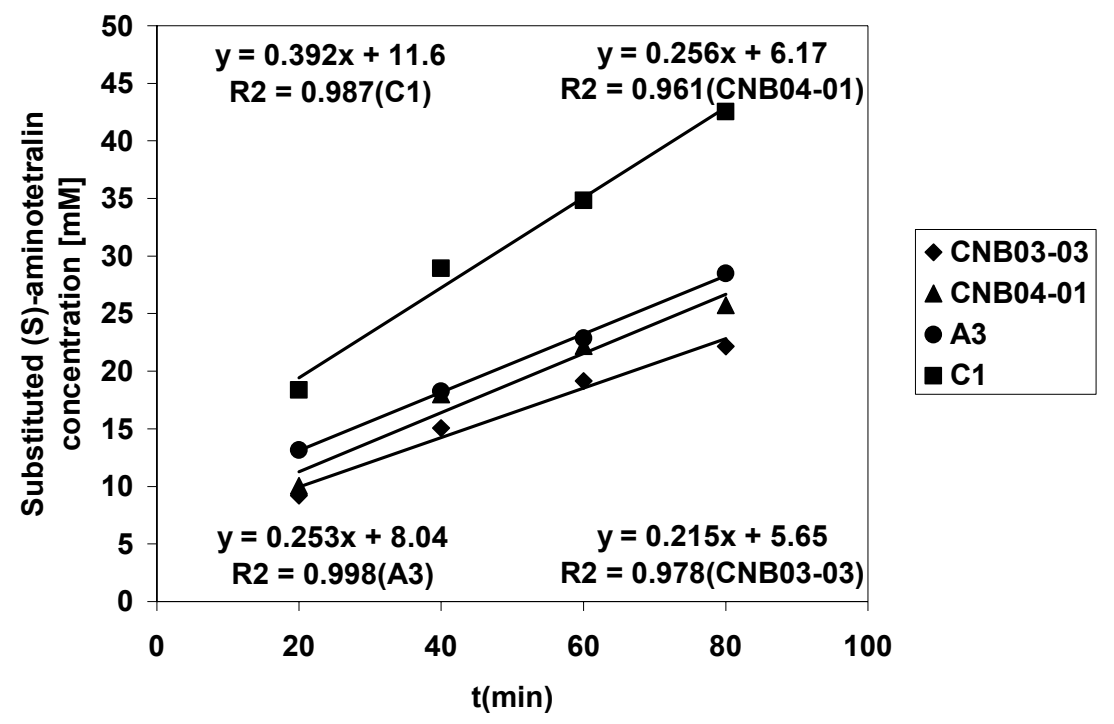

Figure 5-8: Comparison of activity of CNB03-03, CNB04-01, A3 and C1. 
Figure 5-8 shows that the activity of the colony named $\mathrm{C} 1$ has almost twice the activity of CNB03-03. C1 may also have better thermostability than CNB03-03 since it was derived from CNB04-01. The new (S)-aminotransferase, C1, was named CNB05-01.

Chapter 6 shows the characterization of the aminotransferase mutants, using the system of (S)-(-)- $\alpha$-methylbenzylamine and substituted tetralone, which is the system that allows the synthesis of substituted (S)-aminotetralin. 


\section{Chapter 6. Mutant Characterization Based on Initial Biotransformation Rate}

(S)-Aminotransferase mutants CNB03-03, CNB04-01, and CNB05-01 were characterized using the system of (S)-(-)- $\alpha-$ methylbenzylamine [S-MBA] (Section 3.1.1) and substituted tetralone [B] (Section 3.1.2). (S)-(-)- $\alpha$-Methylbenzylamine system was used to develop the immobilization procedure, and evaluate thermostability of CNB03-03 and CNB04-01, but also to estimate other properties. The system of substituted tetralone was used to evaluate the ability of the mutants to produce substituted (S)-aminotetralin [Q]. The following sections present the experiments performed to estimate optimum conditions of $\mathrm{pH}$, temperature, substrate concentrations for the different mutants using both systems: (S)-(-)- $\alpha$-methylbenzylamine and substituted tetralone.

\section{1. (S)-(-)-a-Methylbenzylamine System}

The (S)-(-)- $\alpha$-methylbenzylamine system involves the reaction between this substance and pyruvic acid mediated by (S)-aminotransferase, given as products acetophenone and alanine. The reaction is shown below.

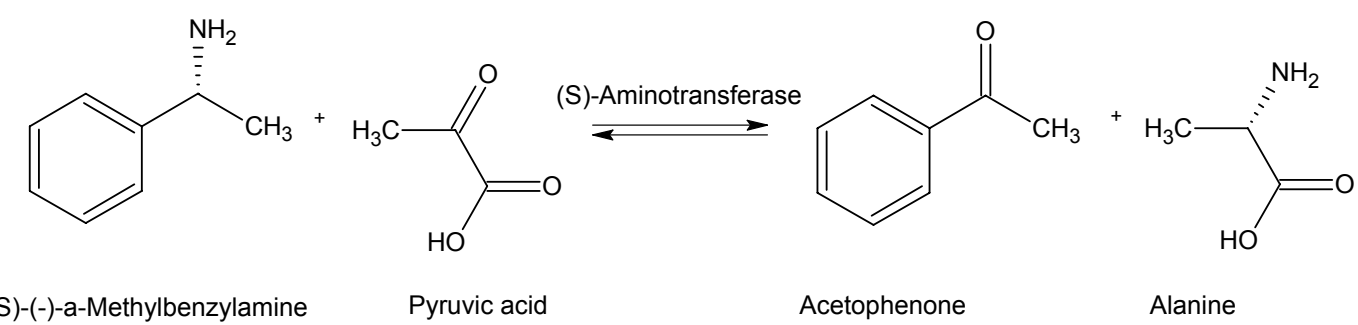

Figure 6-1: (S)-(-)-Methylbenzylamine system reaction 


\subsubsection{Characterization of $\mathrm{CNB03-03}$}

\subsubsection{Substrate Affinity}

The affinity of CNB03-03 for (S)-(-)- $\alpha$-Methylbenzylamine and Pyruvate was determined by incubating $20 \mathrm{ml}$ of Solution 8 and Solution 7 (Table 3-I), respectively, at $55^{\circ} \mathrm{C}$. To those solutions at the specified temperature were added $1 \mathrm{mg}$ of enzyme (spray dried cells) free or immobilized. Free enzyme was added with $100 \mu$ of solution containing 10 mg spray dried cells per ml. Immobilized enzyme was added using $0.143 \mathrm{~g}$ of beads of concentration $10 \mathrm{mg}$ enzyme/g bead (From Table 4-VI enzyme incorporated is $70 \%$ of the planned concentration; i.e. $10 \mathrm{mg} / \mathrm{g}$ would be $7 \mathrm{mg} / \mathrm{g})$. The affinity for (S)-(-)- $\alpha-$ methylbenzylamine by free and immobilized enzyme is shown in Figure 6-2 and Figure 6-3, respectively and the affinity for pyruvate is shown in Figure 6-4 and Figure 6-5, respectively.

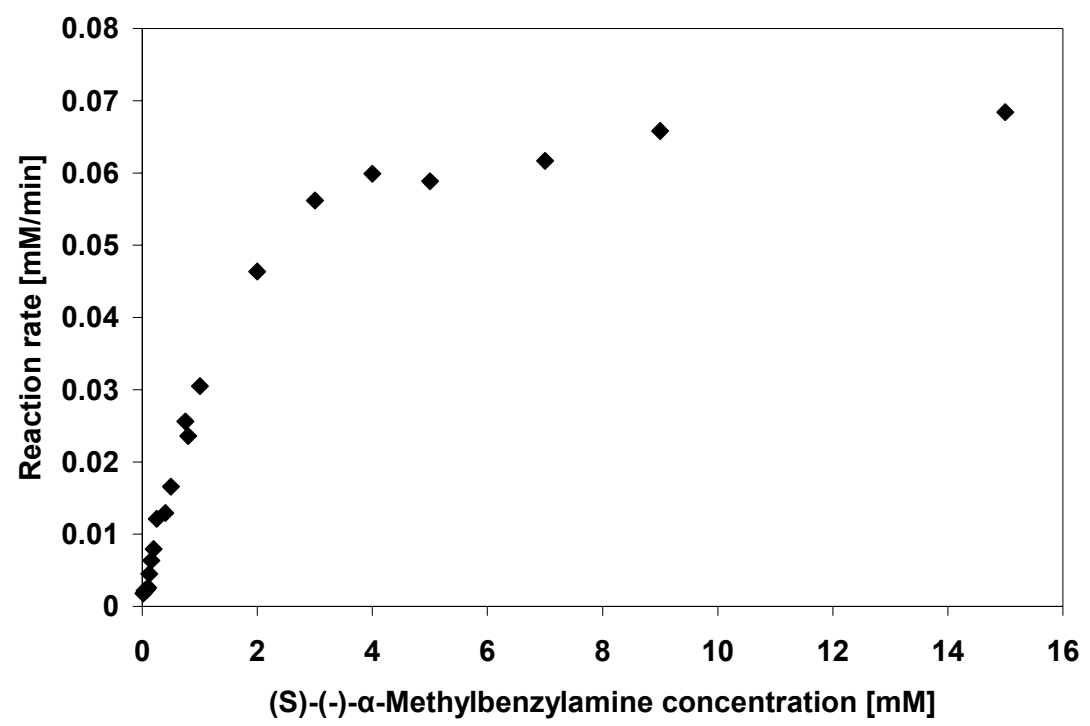

Figure 6-2: (S)-(-)-a-Methylbenzylamine affinity by free spray dried cells of CNB03-03. 


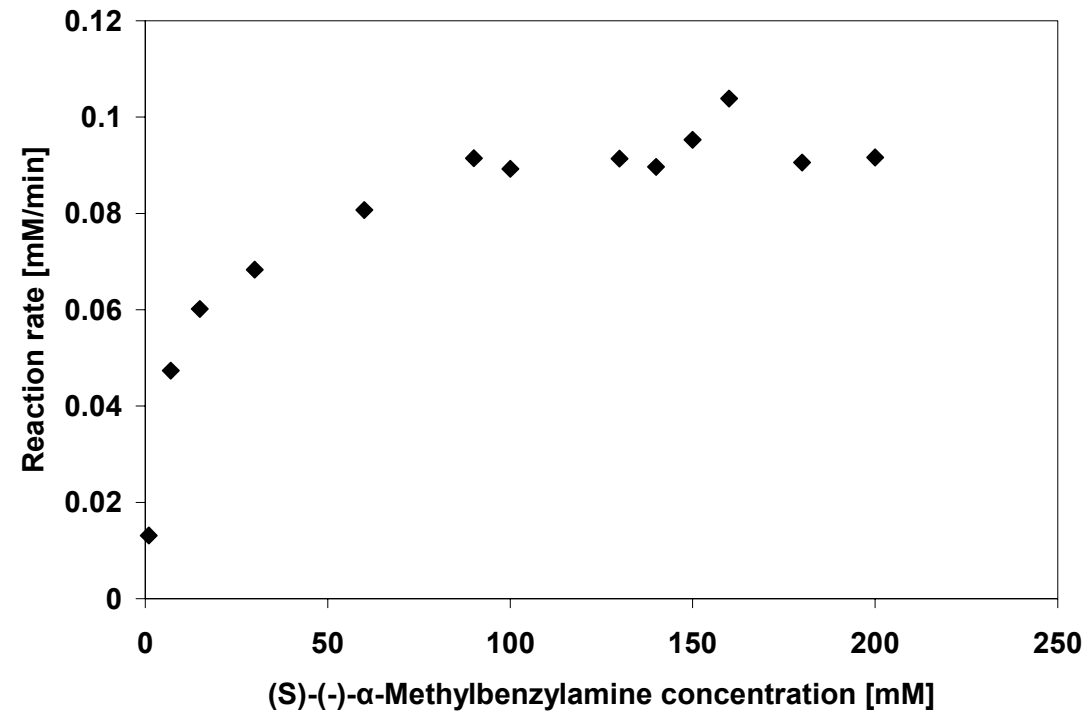

Figure 6-3: (S)-(-)-a-Methylbenzylamine affinity by immobilized CNB03-03.

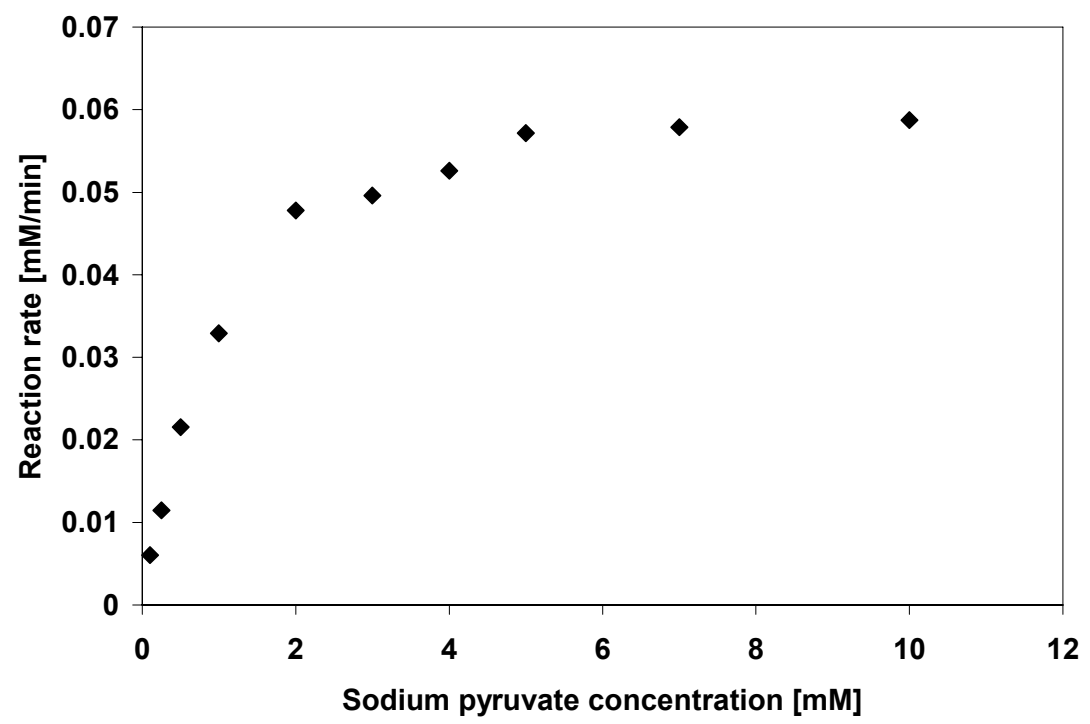

Figure 6-4: Sodium pyruvate affinity for free spray dried cells of CNB03-03. 


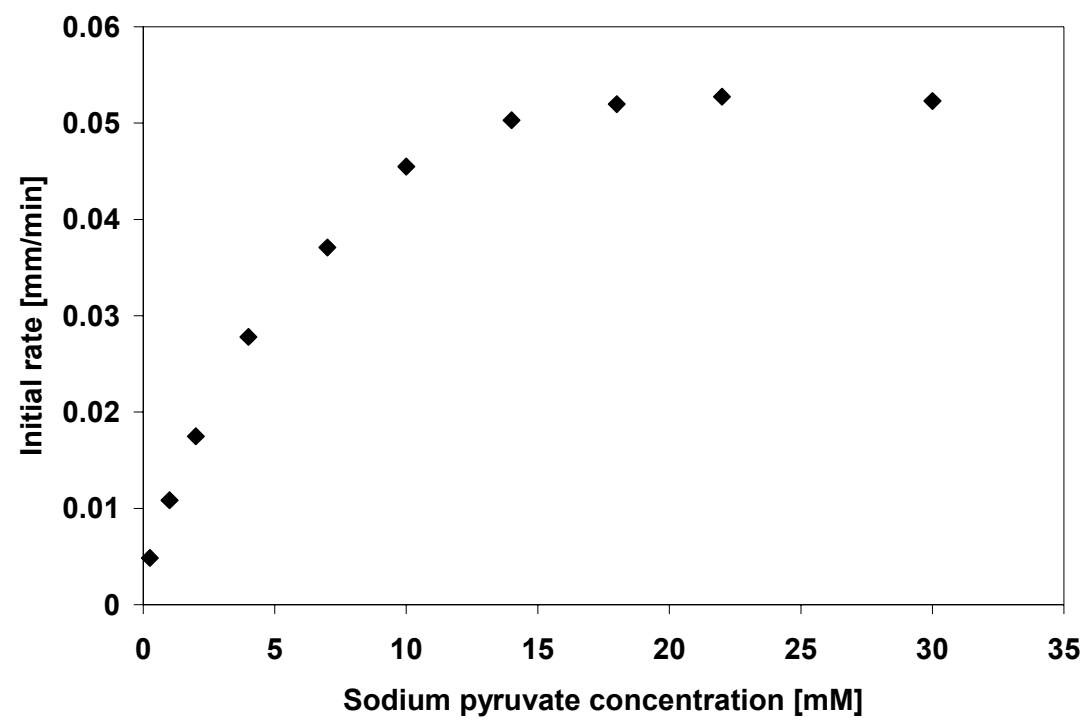

Figure 6-5: Sodium pyruvate affinity for immobilized spray dried cells of CNB03-03.

The information shown in Figure 6-2, Figure 6-3, Figure 6-4, and Figure 6-5 was analyzed by non-linear regression using the solver tool from Microsoft ${ }^{\circledR}$ Office Excel 2003, fitting the data to the model given in Equation (15), which corresponds to a simplification of Equation (14) when one of the substates is in a concentration higher than the values of its $\mathrm{K}_{\mathrm{m}}$. Under this condition the terms relarting to this substrate in Equation (14) becomes a constant, which is lumped in the $\mathrm{K}_{\mathrm{m}}$ shown in Equation (15).

$r=\frac{V_{m} S}{K_{m}+S}$

$\mathrm{V}_{\mathrm{m}}$ is the apparent maximum velocity, $\mathrm{K}_{\mathrm{m}}$ is the apparent Michaelis-Menten constant; and $\mathrm{S}$ is the concentration of (S)-(-)- $\alpha-$ methylbenzylamine or pyruvic acid. The maximum velocity $\left(\mathrm{V}_{\mathrm{m}}\right)$ and substrate affinity $\left(\mathrm{K}_{\mathrm{m}}\right)$, for $(\mathrm{S})-(-)-\alpha-$-methylbenzylamine and pyruvate, for free and immobilized CNB03-03 are presented in Table 6-I. 
Table 6-I: Substrate affinity of CNB03-03.

\begin{tabular}{|l|c|c|c|c|}
\hline \multirow{2}{*}{$\begin{array}{c}\text { Kinetics } \\
\text { parameters }\end{array}$} & \multicolumn{2}{|c|}{ (S)-(-)-a-Methylbenzylamine affinity } & \multicolumn{2}{c|}{ Sodium Pyruvate affinity } \\
\cline { 2 - 5 } & Free & Immobilized & Free & Immobilized \\
\hline $\mathrm{Km}[\mathrm{mM}]$ & 1.77 & 6.05 & 1.01 & 5.00 \\
\hline $\mathrm{Vm}$ & 0.08 & 0.09 & 0.07 & 0.07 \\
{$[\mathrm{mM} / \mathrm{min}]$} & & & & \\
\hline
\end{tabular}

Table 6-I shows that the values of substrate affinity, $K_{m}$, for (S)-(-)- $\alpha$-methylbenzylamine and for sodium pyruvate, are higher for immobilized CNB03-03 than for free CNB03-03. Similar cases, of higher $\mathrm{K}_{\mathrm{m}}$ after immobilization had been reported, some of them are the following.

a). L-Aminoacid acid oxidase immobilized by diazobinding in porous glass, whose substrate is L-leucine, has a $\mathrm{K}_{\mathrm{m}}$ of $1 \mathrm{mM}$ in the native state (free); and $\mathrm{K}_{\mathrm{m}}$ of $4 \mathrm{mM}$ in the immobilized state (Weetall, 1971).

b). NADH dehydrogenase immobilized by cross-linking in glutaraldehyde, whose substrate is NADH, has a $\mathrm{K}_{\mathrm{m}}$ of $6.7 \times 10^{-2} \mathrm{mM}$ in the native state; and $\mathrm{K}_{\mathrm{m}}$ of $31 \times 10^{-2} \mathrm{mM}$ in the immobilized state (Kawai and Eguchi, 1975).

c). Chymotrypsin immobilized by peptide binding in $\mathrm{CNBr}$-activated sepharose, whose substrate is $\alpha$-N-acetyl-L-tyrosine ethyl ester, has a $\mathrm{K}_{\mathrm{m}}$ of $3.3 \mathrm{mM}$ in the native state; and $\mathrm{K}_{\mathrm{m}}$ of $30 \mathrm{mM}$ in the immobilized state (Axén et al., 1970).

Higher values of $\mathrm{K}_{\mathrm{m}}$ for immobilized enzyme than for the enzyme in the native state have been attributed to electrostatic interaction between the carrier and substrate, and to diffusion of the substrate and product in the carrier. $\mathrm{K}_{\mathrm{m}}$ for creatine kinase (Hornby, 1968), whose substrates are ATP and creatine, immobilized by peptide binding with CM- 
cellulose azide became 10 ten times higher than that of native enzyme, from $0.65 \mathrm{mM}$ to $7.0 \mathrm{mM}$, due to repulsion between the polyanionic carrier and negatively charged ATP or creatine. For chymotrypsin immobilized in CNBr-activated sephadex, whose substrate is acetyl-L-tyrosine ethyl ester, $\mathrm{K}_{\mathrm{m}}$ was calculated to be $30 \mathrm{mM}$. This value was ten times higher than that of the native enzyme $(3.3 \mathrm{mM})$. When this immobilized enzyme was treated with dextranase to partially hydrolyze sephadex, $\mathrm{K}_{\mathrm{m}}$ for the treated enzyme preparation was $5 \mathrm{mM}$ (Axén et al., 1970). This result showed that the increase on $\mathrm{K}_{\mathrm{m}}$ was due to diffusion of the substrate in the carrier. For the case of changes on $\mathrm{K}_{\mathrm{m}}$ for free to immobilized CNB03-03, it was believed that it was due to diffusion of the substrate in the carrier, which is supported by the information presented in Chapter 5. This chapter shows that not all the enzyme entrapped on the bead is available to catalyze the reaction of transamination, therefore implying mass-transfer limitations.

Table 6-I also shows the values of $V_{m}$ for free and immobilized enzyme. For (S)-(-)- $\alpha-$ methylbenzyalmine and free CNB03-03 $\mathrm{V}_{\mathrm{m}}$ is $0.079 \mathrm{mM} / \mathrm{min}$, and for immobilized $\mathrm{V}_{\mathrm{m}}$ is $0.092 \mathrm{mM} / \mathrm{min}$. Similar results have been published in which $\mathrm{V}_{\mathrm{m}}$ of immobilized enzyme is higher than for native (free) enzyme. $V_{m}$ of native aminoacylase is $1.52 \mu \mathrm{M} / \mathrm{hr}$ and when it was immobilized by ionic binding on DEAE-sephadex $V_{m}$ was $3.33 \mu \mathrm{M} / \mathrm{hr}$ (Tosa et al, 1969). When immobilized by alkylation on iodoacetylcellulose $V_{m}$ was $4.65 \mu \mathrm{M} / \mathrm{hr}$ (Sato et al, 1971), and when immobilized by entrapping in polyacrylamide gel $V_{m}$ was $2.33 \mu \mathrm{M} / \mathrm{hr}$ (Mori et al., 1972). Also the opposite results have been published, when $\mathrm{V}_{\mathrm{m}}$ of immobilized enzymes is smaller than $V_{m}$ of native enzyme. One example is invertase 
(Usami and Kuratsu, 1973) immobilized by entrapping in polyacrylamide gel, the $\mathrm{V}_{\mathrm{m}}$ values decreased to $1 / 10$ of those of native enzymes.

\subsubsection{Optimum pH}

The characterization of optimum $\mathrm{pH}$ for free and immobilized CNB03-03 at $55{ }^{\circ} \mathrm{C}$ was conducted in a volume of $20 \mathrm{ml}$ of Solution 6 (Table 3-I). Ten $\mathrm{mg}$ of the enzyme in both free and immobilized forms were added to the system. Free enzyme was added in a volume of $1000 \mu \mathrm{l}$ of a solution containing $10 \mathrm{mg}$ spray dried cells per ml. Immobilized enzyme was added in $1.430 \mathrm{~g}$ of beads of a concentration of $10 \mathrm{mg} / \mathrm{g}$ (due to enzyme loss during bead formation -Table 4-VI-, $10 \mathrm{mg}$ of enzyme was assumed to be contained in the $1.43 \mathrm{~g}$ beads). The results of optimum $\mathrm{pH}$ for free and immobilized enzyme are shown in Figure 6-6.

Figure 6-6 shows the optimum $\mathrm{pH}$ of free and immobilized CNB03-03. Free CNB03-03 has the highest activity at $\mathrm{pH} 7.7$, whereas immobilized CNB03-03 has the highest activity at $\mathrm{pH} 8.1$. As a result of immobilization a shift of 0.4 units of $\mathrm{pH}$ was observed. Similar results have been published; some of them are shown below.

a). Polynucleotide phosphorilase, whose substrate is ADP, immobilized by diazo binding on porous glass, shifted optimum $\mathrm{pH}$ from 9.0, native state, to 9.4 in immobilized state (Smith et al., 1973). 


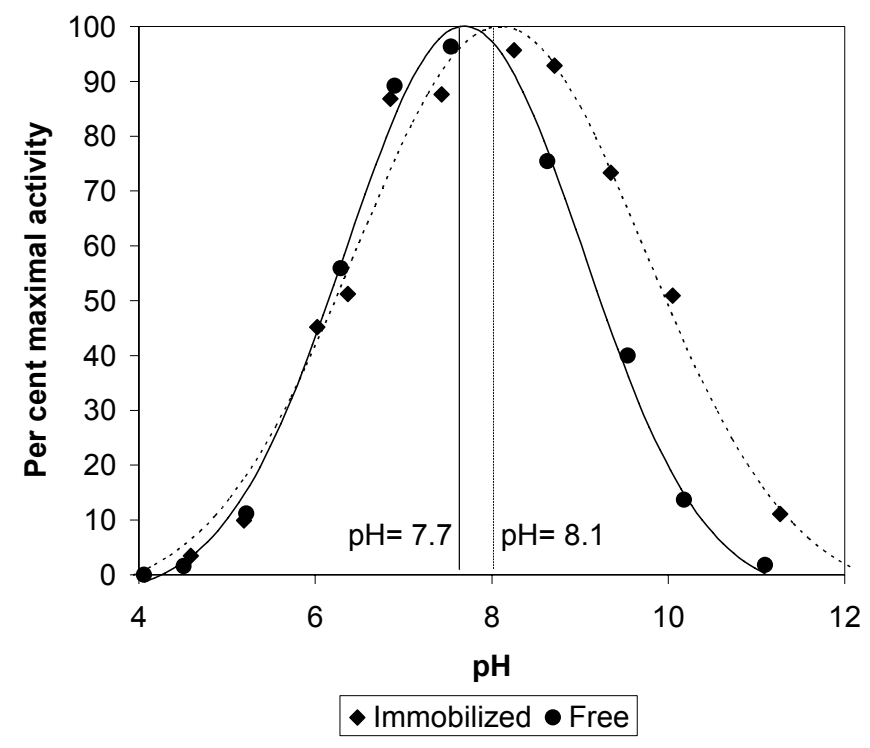

Figure 6-6: Optimum pH for free and immobilized CNB03-03.

b). Invertase, whose substrate is sucrose, immobilized by physical adsorption on bentonite, shifted optimum pH from 5.2, native state, to 6.3 in immobilized state (Monsan and Durand, 1971).

c). Chymotrypsin, whose substrate is casein, immobilized by peptide binding on CMactivated sephadex, shifted optimum $\mathrm{pH}$ from 8.0 , native state, to 8.5 in immobilized state (Takami and Ando, 1968).

The shift toward the alkaline side for chymotrypsin may be explained by an increase of negative charge due to carboxyl groups of CM-cellulose. That is, the microenvironment of the immobilized enzymes becomes more acidic than that of the external solution (Chibata et al, 1978). The same may happen with immobilized CNB03-03 on calcium alginate, since alginate is a polyuronic acid (Section 4.1). 


\subsubsection{Temperature Effect}

The effect of temperature on CNB03-03 activity was tested in two ways: the effect of incubation of spray dried cells at certain temperatures for 30 minutes prior to determining activity left at $55^{\circ} \mathrm{C}$, and the effect of temperature on initial rate without incubation.

The effect of incubation for 30 minutes at different temperatures (in a constant temperature chamber) was done using $10 \mathrm{ml}$ of $10 \mathrm{mg} / \mathrm{ml}$ spray dried cells of CNB03-03 or 10 grams of $10 \mathrm{mg} / \mathrm{g}$ of immobilized spray dried cells of CNB03-03. After the incubation time, $1 \mathrm{ml}$ of free enzyme or 1.430 grams of immobilized enzyme were added to $20 \mathrm{ml}$ of Solution 6 at $55{ }^{\circ} \mathrm{C}$. Activity (initial rate of reaction) was measured, and the results are shown in Figure 6-7.

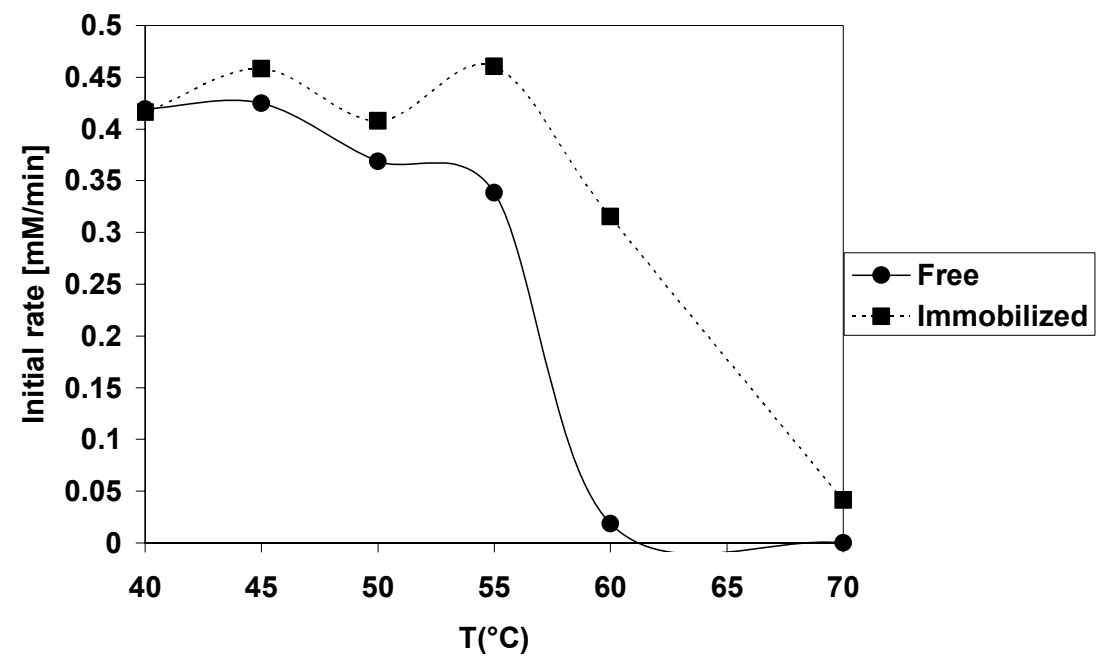

Figure 6-7: Effect of incubation for 30 minutes at a given temperature on activity.

Figure 6-7 shows that, after incubation at a given temperature for 30 minutes, immobilized spray dried cells have higher activity than free spray dried cells. These 
results may be considered unusual, since when an immobilized enzyme is used it is expected to have lower activity. Similar results, in which the activity of immobilized enzyme is higher than the activity of free enzyme, have been reported (Section 6.1.1.1).

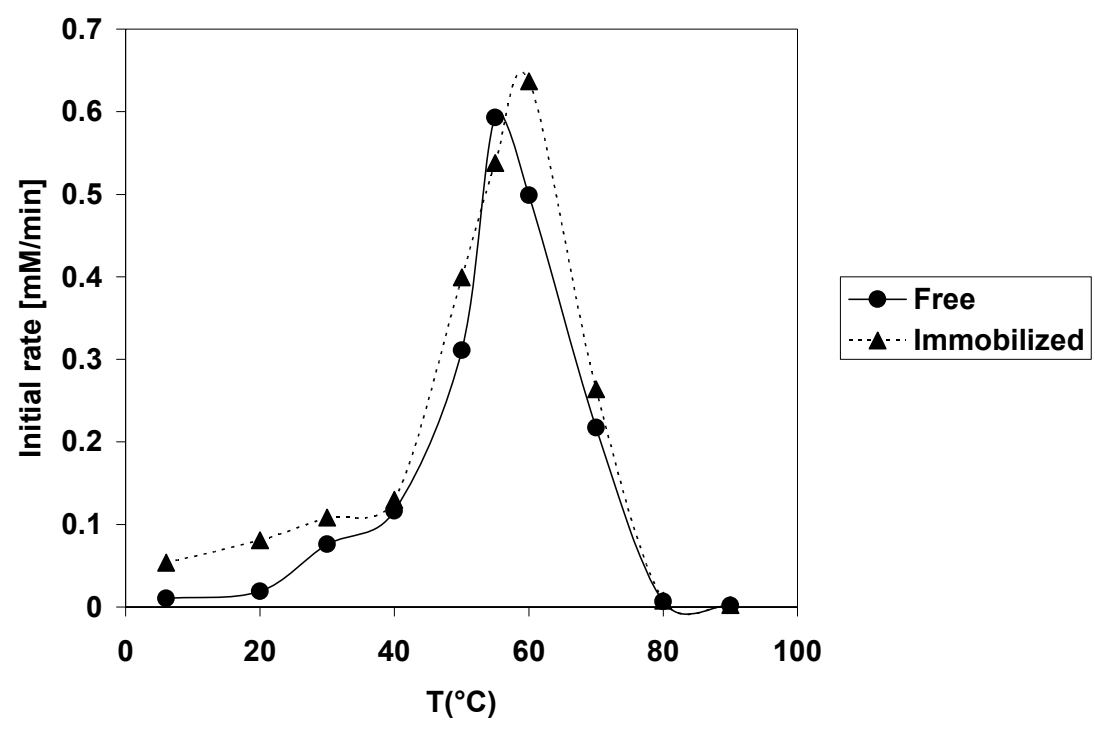

Figure 6-8: Effect of temperature on initial rate of $\mathrm{CNB03-03}$ catalyzing the system of (S)-(-)a-Methylbenzylamine.

Figure 6-8 shows that in the range of temperatures tested, the activity of immobilized enzyme is mostly higher than the activity of free enzyme, similar to the phenomenon observed in Figure 6-7. The activities shown in Figure 6-8 are 0.2 to 0.25 units of activity $(\mathrm{mM} / \mathrm{min})$ higher to the activities shown in Figure 6-7. Such difference is related with the fact that the enzyme represented by the data shown in Figure 6-7 were incubated for 30 minutes at a given temperature. Such difference in activity may be related with deactivation of the enzyme during incubation. From Figure 6-8, it was estimated that the optimum temperature for free spray dried cells of CNB03-03 is about $55{ }^{\circ} \mathrm{C}$ and for immobilized form it is about $60{ }^{\circ} \mathrm{C}$. Some enzymes upon immobilization have an 
optimum temperature 5 to $15{ }^{\circ} \mathrm{C}$ higher than that of native enzyme: tripsin (Takami and Ando, 1968; Brümmer et al, 1972), and chymotrypsin (Takami and Ando, 1968) immobilized by peptide binding with CM-cellulose azide, and tryptophanase (Ikeda and Fukui, 1973) immobilized by covalent binding with pyridoxal phosphate-sepharose derivative, with all of them showing an increase between 5 to $15^{\circ} \mathrm{C}$ in optimum temperature upon immobilization.

The data shown in Figure 6-8 were plotted as the natural logarithm of the activity as a function of $1 /$ (absolute temperature) in Kelvin degrees. Activation and deactivation energies for free and immobilized CNB03-03 were estimated and the results are shown in Figure 6-9 and Figure 6-10.

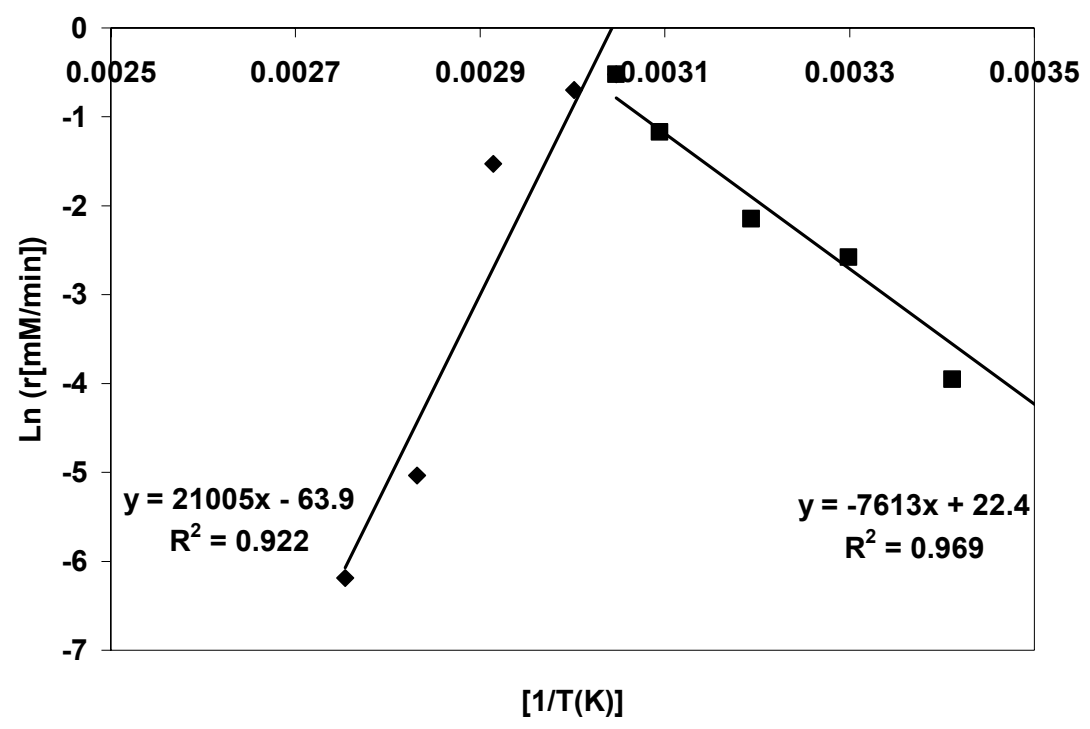

Figure 6-9: Estimation of activation and deactivation energy for free spray dried cells of CNB03-03. 


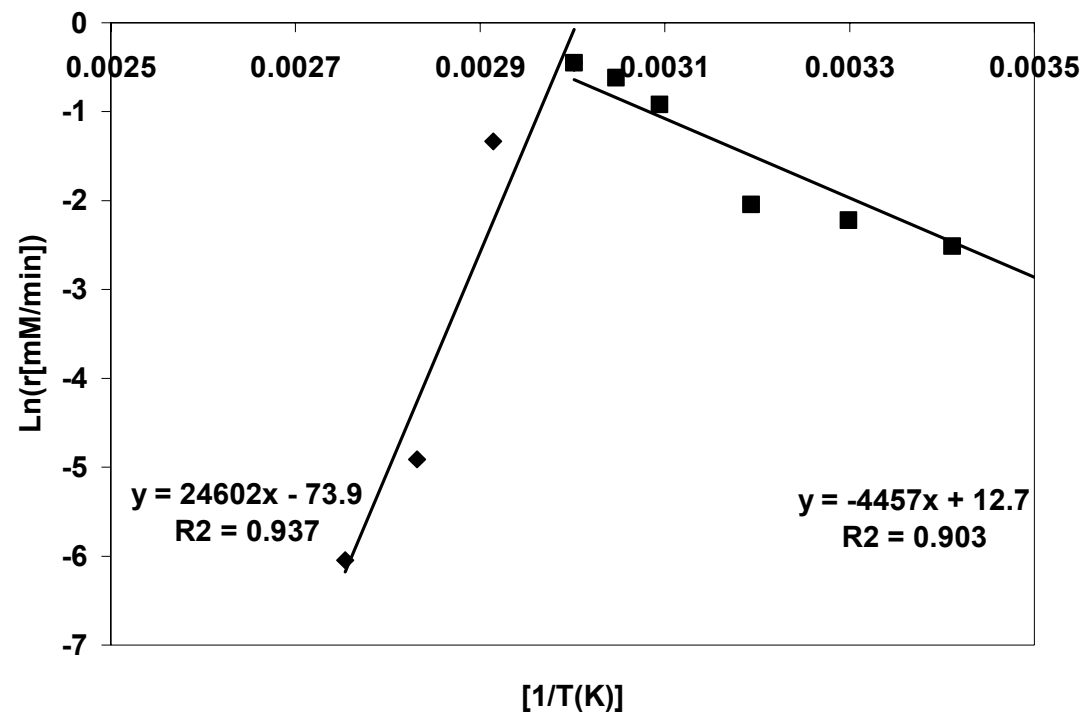

Figure 6-10: Estimation of activation and deactivation energy for immobilized spray dried cells of CNB03-03.

From Figure 6-9 activation energy was estimated for free spray dried cells of about 15.1 $\mathrm{kcal} / \mathrm{mol}$ and a deactivation energy of about $41.7 \mathrm{kcal} / \mathrm{mol}$. From Figure $6-10$ an activation energy was estimated for immobilized spray dried cells of about $8.9 \mathrm{kcal} / \mathrm{mol}$ and a deactivation energy of about $48.8 \mathrm{kcal} / \mathrm{mol}$. Activation and deactivation energies for free and immobilized CNB03-03 are between the range of reported values (Shuler and Kargi, 2002), where activation energies of enzyme-catalyzed reactions are within 4 to 20 $\mathrm{kcal} / \mathrm{mol}$ (mostly about $11 \mathrm{kcal} / \mathrm{mol}$ ), and deactivation energies vary between 40 to 130 $\mathrm{kcal} / \mathrm{mol}$ (mostly about $70 \mathrm{kcal} / \mathrm{mol}$ ). The apparent activation energy for free spray dried cells of CNB03-03 was estimated to be greater than for immobilized spray dried cells. Similar results have been reported, i.e. the activation energy of native aminoacylase was estimated to be about $6.7 \mathrm{kcal} / \mathrm{mol}$ (Tosa et al., 1967), and upon immobilization by alkylation on iodoacetylcellulose it was $3.9 \mathrm{kcal} / \mathrm{mol}$ (Sato et al., 1971). 


\subsubsection{Thermostability Studies}

\subsection{Analysis of Activity during Recycling}

To determine the change in activity during continuous recycling, to $50 \mathrm{ml}$ of Solution 9 at $\mathrm{pH} 7$ (Table 3-I) and at $55^{\circ} \mathrm{C}$ were added 3.570 grams of beads of $10 \mathrm{mg}$ of spray dried cells of CNB03-03/g. After some time, the reaction mixture was separated from immobilized enzyme, and fresh Solution 9 at $55{ }^{\circ} \mathrm{C}$ was added. Initial reaction rates were measured, and the results are shown in Figure 6-11.

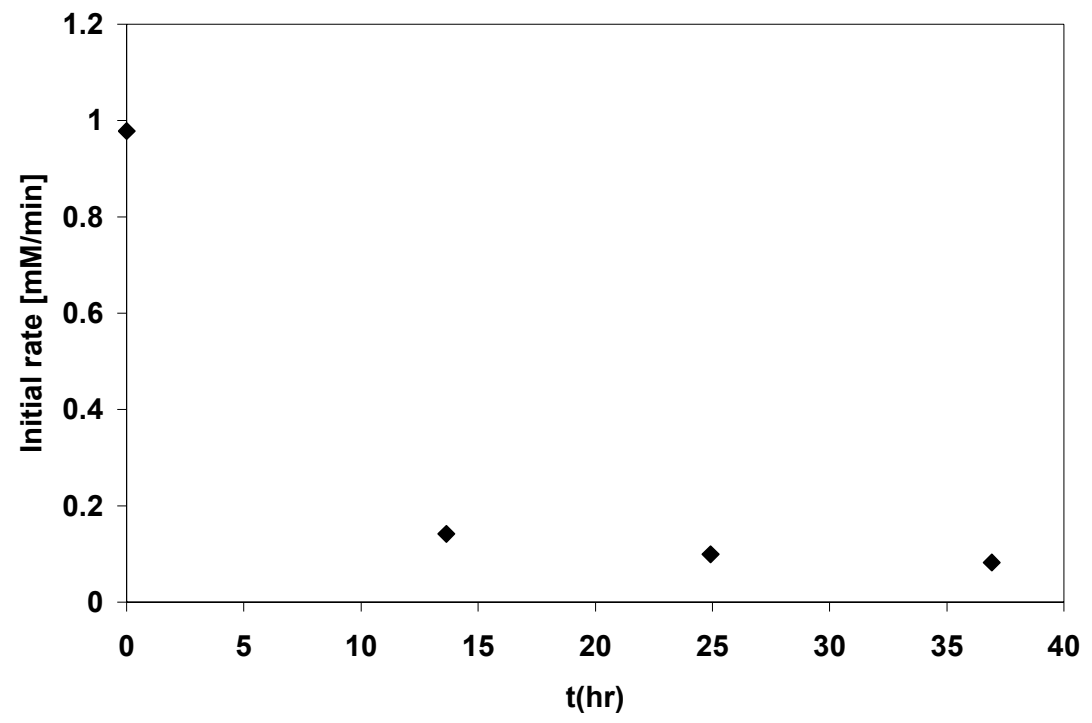

Figure 6-11: Change on activity of immobilized CNB03-03 during continuous recycling at 55 ${ }^{\circ} \mathrm{C}$ in Solution 9.

Figure 6-11 shows that enzymatic activity is lost quickly under these conditions. The half life for the enzyme under these conditions was about 8 hours. A similar experiment was run but using Solution 6 pH 7 (Table 3-I). The results are shown in Figure 6-12. 


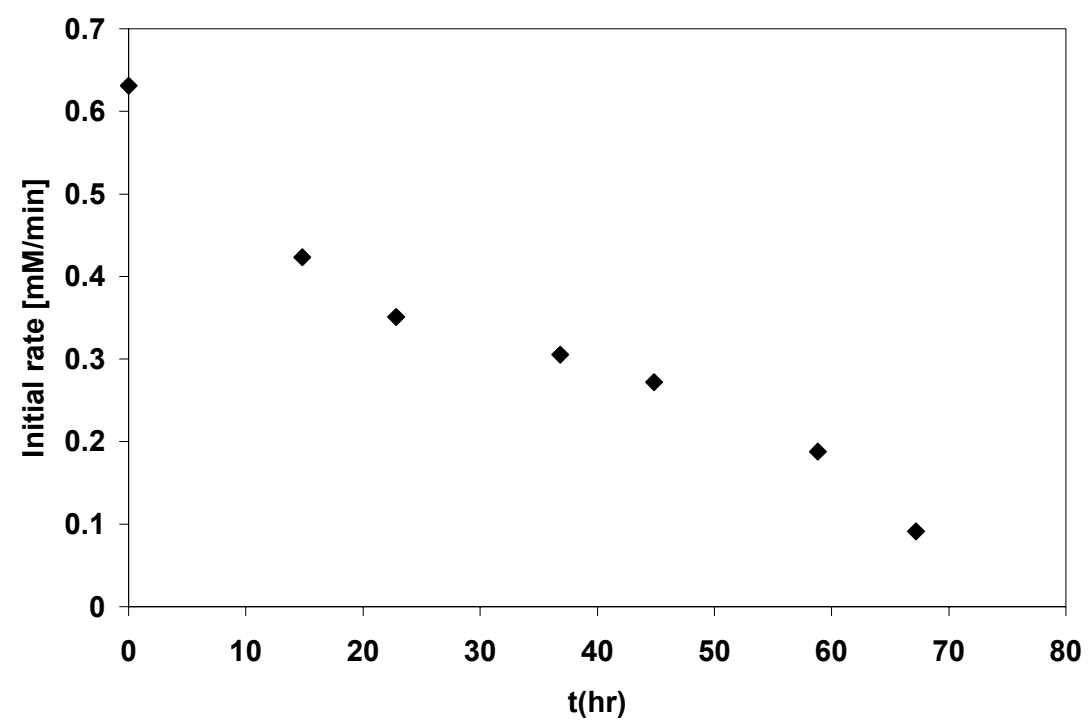

Figure 6-12: Activity during continuous recycling of immobilized $\mathrm{CNB03-03}$ at $55{ }^{\circ} \mathrm{C}$ in Solution 6.

Figure 6-12 shows that the enzyme has better performance in this system than the performance shown in Figure 6-11. The half life of immobilized CNB03-03 in Solution 6 $\mathrm{pH} 7$ (Table 3-I) at $55{ }^{\circ} \mathrm{C}$ was around 36 hours. The recycle of the immobilized enzyme in Solution 6 was expected to give better performance than Solution 9 because of the difference on S-MBA concentration. S-MBA concentration on Solution 6 was $15 \mathrm{mM}$ and $70 \mathrm{mM}$ in Solution 9. Although S-MBA inhibition was not shown during the experiments for S-MBA affinity, it was known by experience at Cambrex North Brunswick that S-MBA caused inhibition at long term reactions.

During the experiments made to characterize enzymatic activity with Solution $6 \mathrm{pH} 7$ (Table 3-I) at $55{ }^{\circ} \mathrm{C}$, a careful characterization of immobilized preparation was made, 
during each recycle, the mass and diameter of immobilized preparation were measured; the results are shown in Figure 6-13.

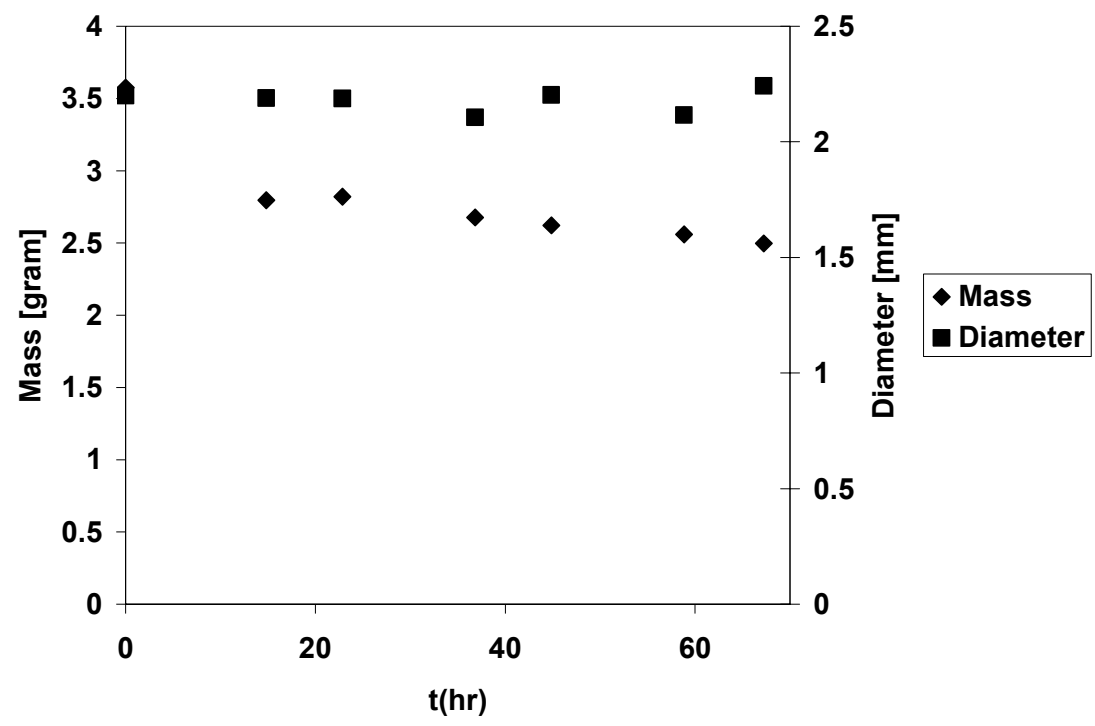

Figure 6-13: Change on mass and diameter of beads of immobilized enzyme during continuous recycling at $55{ }^{\circ} \mathrm{C}$ on Solution $6 \mathrm{pH} 7$ (Table 3-I).

Figure 6-13 shows a significant change on the mass of the immobilized enzyme preparation. After 10 hours the mass had decreased around $30 \%$ of the original and after that no significant changes in mass were noticed. Figure 6-13 also shows that the diameter of the beads did not change significantly.

The experiments done with Solutions 9 and 6 at pH 7 (Table 3-I) were repeated, but at 50 ${ }^{\circ} \mathrm{C}$ instead of $55^{\circ} \mathrm{C}$. The results are shown in Figure 6-14 and Figure 6-15. 


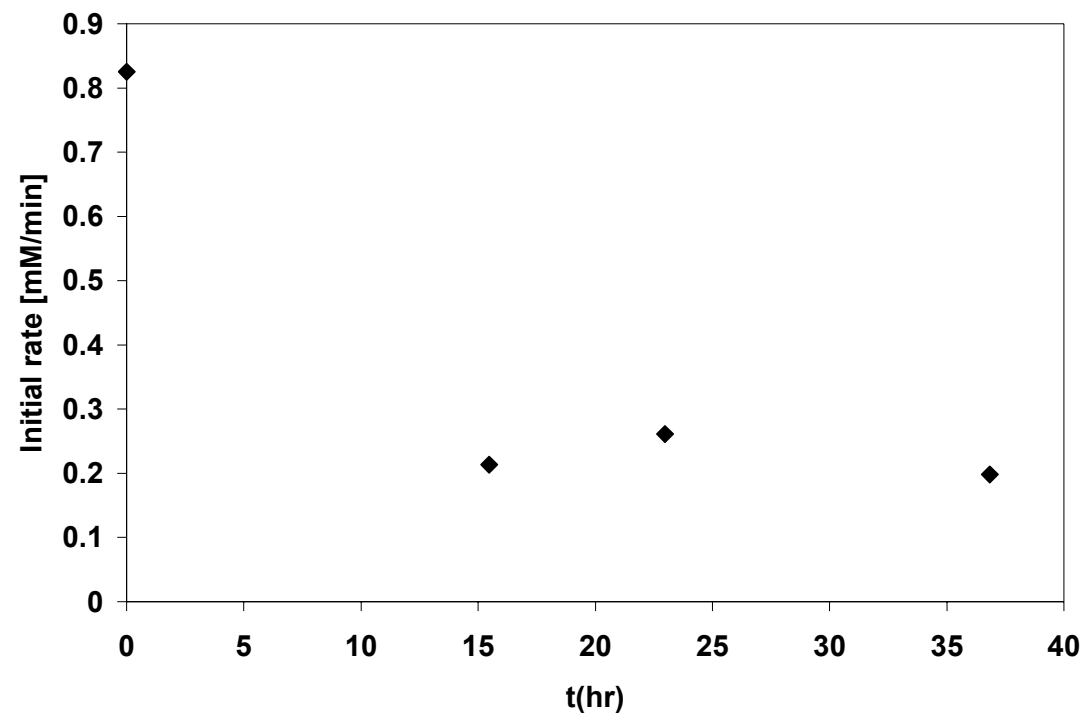

Figure 6-14: Change on activity during continuous recycling of immobilized enzyme at $50{ }^{\circ} \mathrm{C}$ on Solution 9 pH 7.

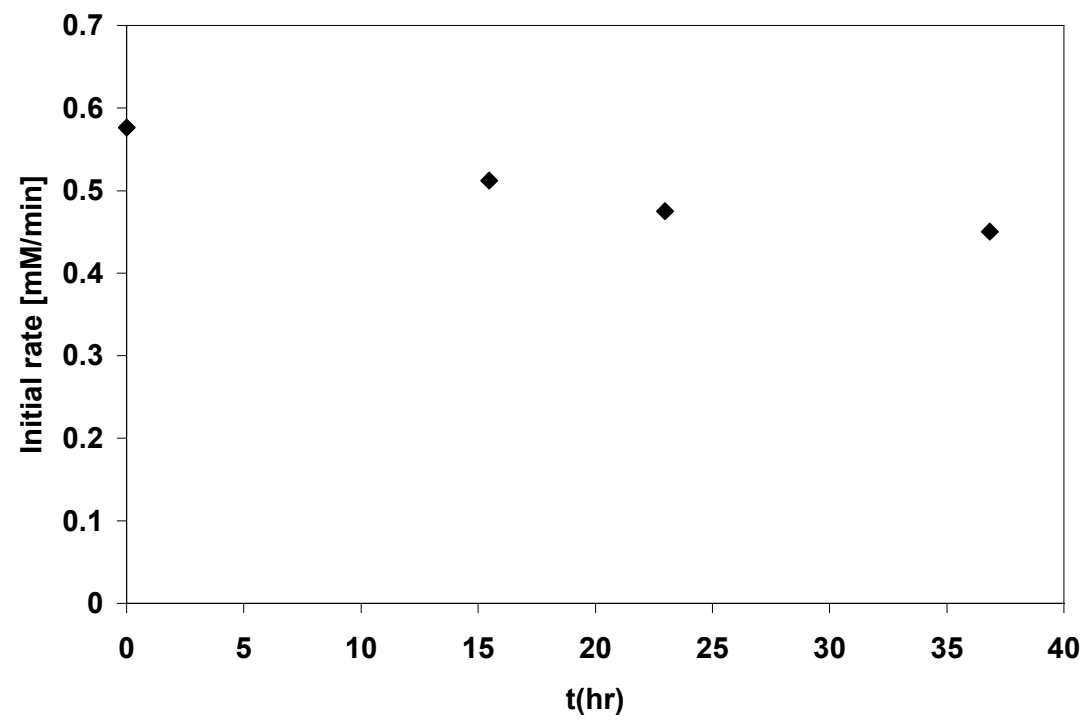

Figure 6-15: Change on activity during continuous recycling of immobilized enzyme at $50{ }^{\circ} \mathrm{C}$ on Solution 6 pH 7.

From data shown in Figure 6-14 and Figure 6-15 it was estimated that, at $50{ }^{\circ} \mathrm{C}$, the half life of immobilized CNB03-03 on Solution $9 \mathrm{pH} 7$ (Table 3-I) was about 10 hours; on Solution $6 \mathrm{pH} 7$ (Table 3-I) it was about 100 hours. 
Figure 6-11, Figure 6-12, Figure 6-14, and Figure 6-15 show the activities of immobilized CNB03-03 during continuous recycling. Figure 6-11 and Figure 6-12 show the activity at $55^{\circ} \mathrm{C}$, Figure $6-14$ and Figure $6-15$ show the activity at $50{ }^{\circ} \mathrm{C}$. The reaction mixture used in the experiments presented in Figure 6-11 and Figure 6-14 was Solution 9 pH 7 (Table 3-I), which has a concentration of $70 \mathrm{mM}(\mathrm{S})-(-)-\alpha$-methylbenzylamine; the reaction mixture used in the experiments shown in Figure 6-12 and Figure 6-15 was Solution $6 \mathrm{pH} 7$ (Table 3-I), which has a concentration of $15 \mathrm{mM}$ (S)-(-)- $\alpha-$ methylbenzylamine. From the information shown in the figures mentioned above, the half life on immobilized enzyme was estimated: $8 \mathrm{hr}$, recycling at $55^{\circ} \mathrm{C}$ with $70 \mathrm{mM}(\mathrm{S})$ (-)- $\alpha$-methylbenzylamine (Figure 6-11); $36 \mathrm{hr}$, recycling at $55^{\circ} \mathrm{C}$ with $15 \mathrm{mM}(\mathrm{S})-(-)-\alpha-$ methylbenzylamine (Figure 6-12); $70 \mathrm{hr}$, recycling at $50{ }^{\circ} \mathrm{C}$ with $70 \mathrm{mM}$ (S)-(-)- $\alpha-$ methylbenzylamine (Figure 6-14); $100 \mathrm{hr}$, recycling at $50{ }^{\circ} \mathrm{C}$ with $15 \mathrm{mM}$ (S)-(-)- $\alpha$ methylbenzylamine (Figure 6-15). Then from the analysis of half life and recycling conditions, it was concluded that the conditions that tend to improve the operational stability of immobilized CNB03-03 for the system of (S)-(-)- $\alpha$-methylbenzylamine were lower temperature, and lower amine concentration, e.g. $50{ }^{\circ} \mathrm{C}$ and $15 \mathrm{mM}(\mathrm{S})-(-)-\alpha-$ methylbenzylamine.

\subsection{Activity of Immobilized and Aqueous Spray Dried Cells During Storage at $50^{\circ} \mathrm{C}$}

Ten milliliters of a solution of concentration $10 \mathrm{mg} / \mathrm{ml}$ of spray dried cells of CNB0303/ml, and 10 grams of immobilized enzyme of concentration $50 \mathrm{mg}$ of spray dried cells of CNB03-03 per gram of calcium alginate were incubated at $50{ }^{\circ} \mathrm{C}, \mathrm{pH} 7$, with $1 \mathrm{mM}$ 
pyridoxal 5-phosphate, and $100 \mathrm{mM}$ sodium acetate. Periodically enzymatic activity was measured by adding $1 \mathrm{ml}$ of solution with free enzyme and 0.3 grams of immobilized enzyme to $20 \mathrm{ml}$ of Solution $6 \mathrm{pH} 7$ (Table $3-\mathrm{I}$ ) at $50{ }^{\circ} \mathrm{C}$. The results are shown in Figure 6-16 and Figure 6-17.

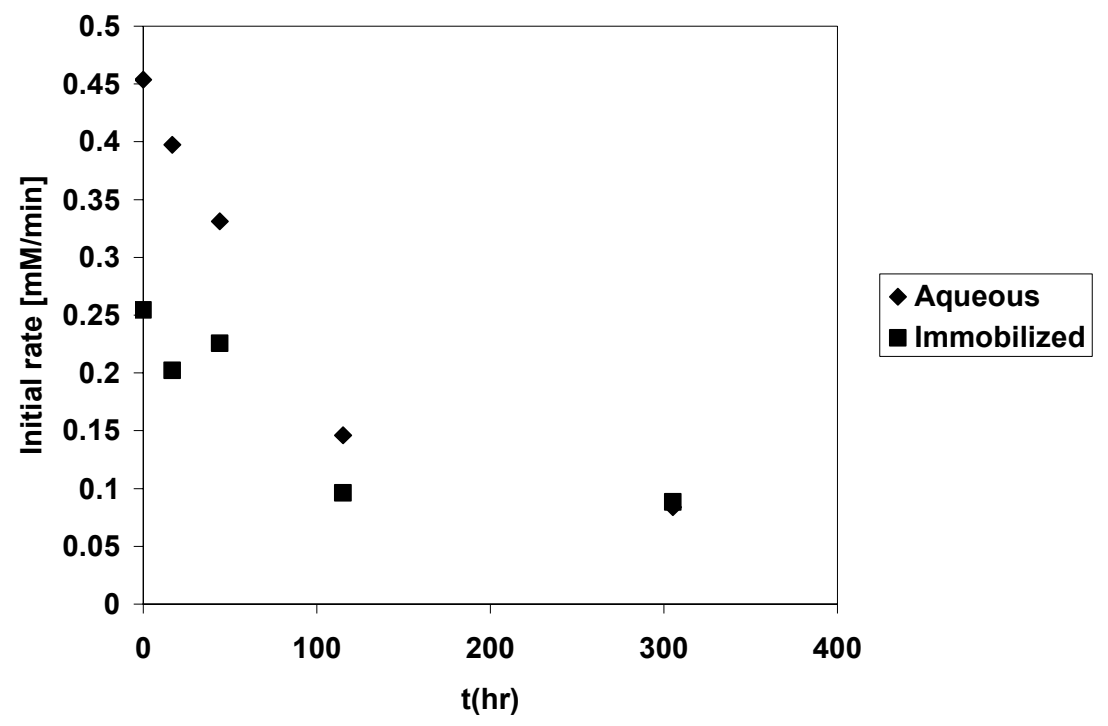

Figure 6-16: Activity of free and immobilized enzyme at $50{ }^{\circ} \mathrm{C}$; storage at $50{ }^{\circ} \mathrm{C}, \mathrm{pH} 7,1 \mathrm{mM}$ Pyridoxal 5-phosphate, and $100 \mathrm{mM}$ sodium acetate.

Figure 6-16 shows deactivation of both preparations of CNB03-03, where apparently activity of free enzyme decays faster. But Figure 6-17 indicates that the activity in both preparations decays with a similar half life. The last observation is supported by the results of fitting first order decay to the data shown in Figure 6-17; the deactivation constant for free enzyme is $0.011 \mathrm{hr}^{-1}, 0.011 \mathrm{hr}^{-1}$ for the immobilized enzyme. 


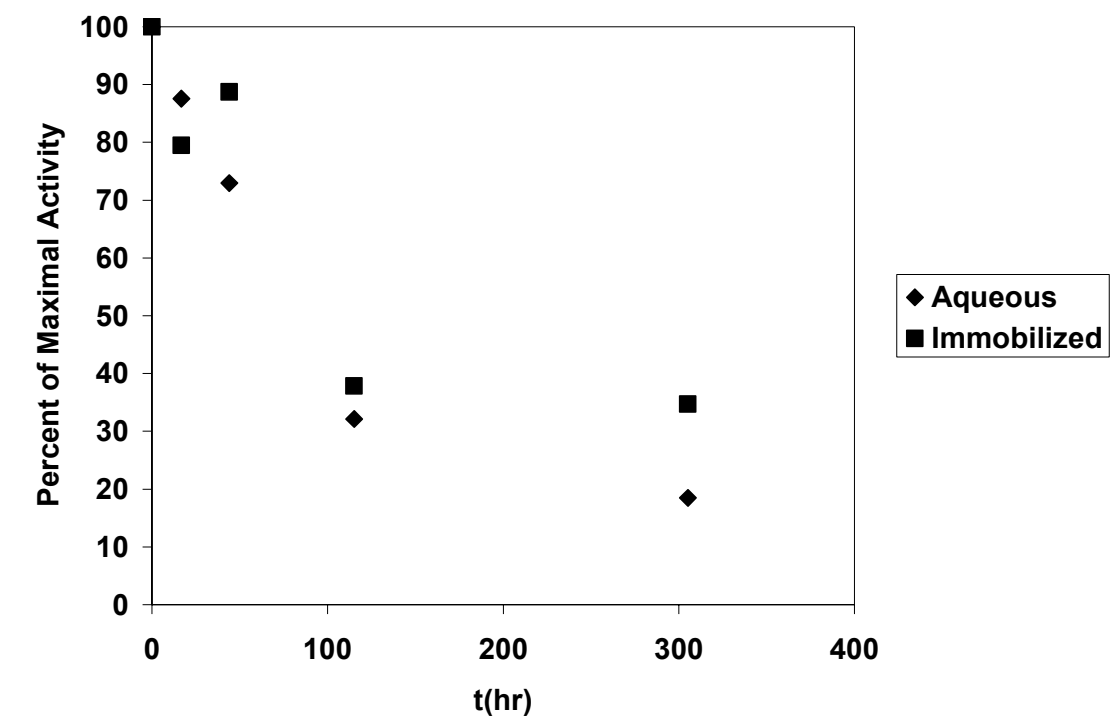

Figure 6-17: Percent of Maximal activity of free and immobilized enzyme at $50{ }^{\circ} \mathrm{C}$; storage at $50{ }^{\circ} \mathrm{C}, \mathrm{pH}$ 7, 1 mM Pyridoxal 5-phosphate.

\subsubsection{Characterization of CNB04-01}

\subsubsection{Substrate Affinity}

The affinities of free spray dried cells of CNB04-01 for (S)-(-)- $\alpha$-methylbenzylamine and sodium pyruvate were determined by incubating $20 \mathrm{ml}$ of Solution $8 \mathrm{pH} 7$ and Solution 7 $\mathrm{pH} 7$ (Table 3-I), respectively, at $55^{\circ} \mathrm{C}$. To those solutions at the specified temperature were added $50 \mu \mathrm{l}$ of a solution containing $10 \mathrm{mg}$ of spray dried cells per $\mathrm{ml}$. The doublereciprocal plots (Lineweaver-Burk) of the initial rates for (S)-(-)- $\alpha$-methylbenzylamine and for pyruvic acid are shown in Figure 6-18 and Figure 6-19. 


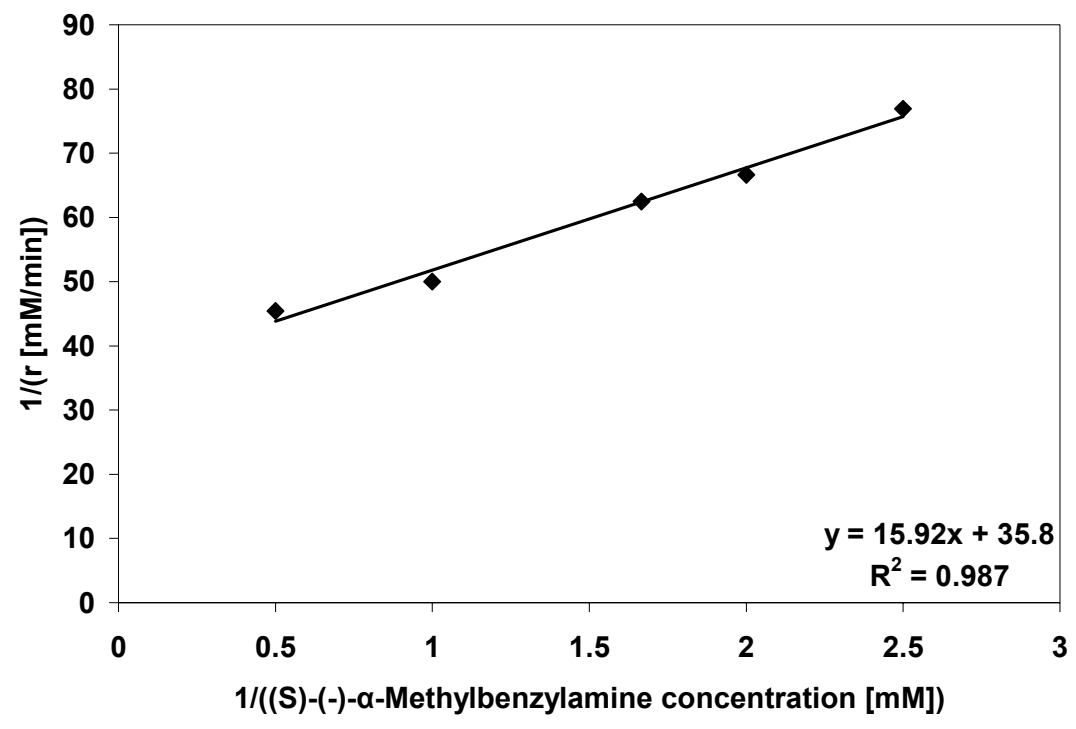

Figure 6-18: Double reciprocal plot (S)-(-)- $\alpha$-Methylbenzylamine affinity of free CNB04-01 in Solution 8 (100 mM sodium pyruvate).

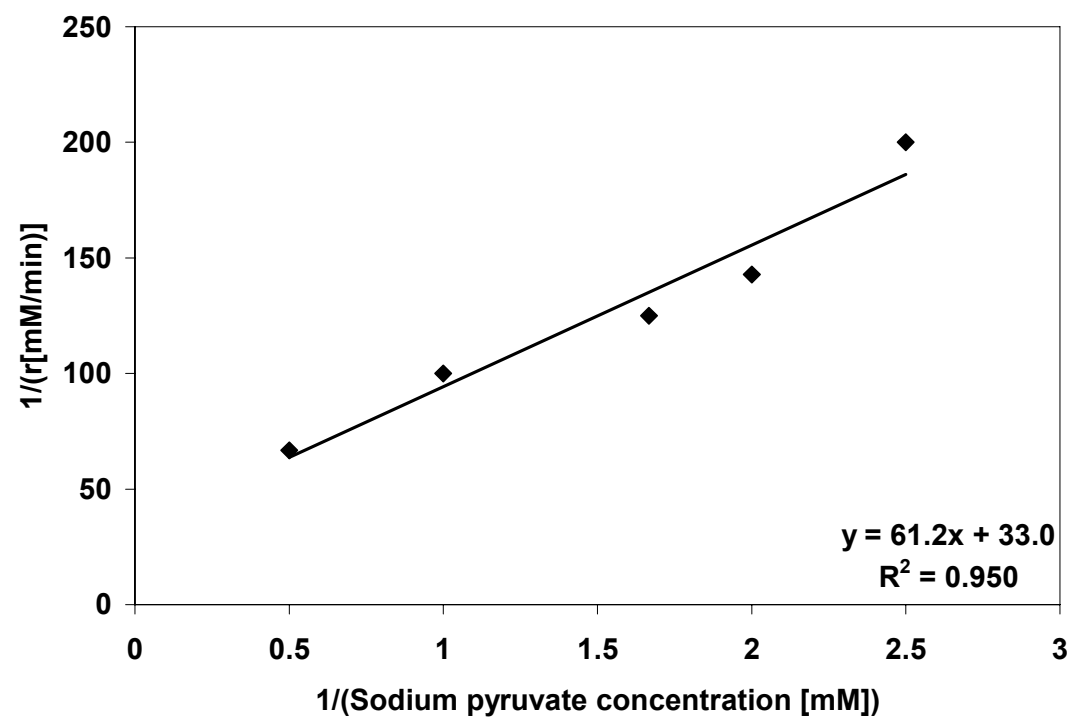

Figure 6-19: Double reciprocal plot Sodium pyruvate affinity of free CNB04-0 in Solution 7 (15 mM (S)-(-)- $\alpha$-methylbenzylamine).

From Figure 6-18 and Figure 6-19 $\mathrm{K}_{\mathrm{m}}$ and $\mathrm{V}_{\mathrm{m}}$ were estimated for CNB04-01 using Equation (15) and the results are presented in Table 6-II, with comparison to CNB03-03. 
Table 6-II: Substrate affinity for free CNB04-01 and free CNB03-03.

\begin{tabular}{|c|c|c|c|c|}
\hline \multirow[t]{2}{*}{ Parameter } & \multicolumn{2}{|c|}{$\begin{array}{c}\text { CNB04-01 } \\
\text { Enzyme concentration: } 0.025 \mathrm{mg} / \mathrm{ml} \\
\end{array}$} & \multicolumn{2}{|c|}{$\begin{array}{c}\text { CNB03-03 } \\
\text { Enzyme concentration: } 0.050 \mathrm{mg} / \mathrm{ml} \\
\end{array}$} \\
\hline & (S)-(-)-a-Methylbenzylamine & Sodium Pyruvate & $\begin{array}{l}(\mathrm{S})-(-)-\alpha- \\
\text { Methylbenzylamine }\end{array}$ & Sodium Pyruvate \\
\hline $\mathrm{K}_{\mathrm{m}}[\mathrm{mM}]$ & 0.44 & 1.85 & 1.77 & 1.01 \\
\hline $\begin{array}{l}\mathrm{V}_{\mathrm{m}} \\
{[\mathrm{mM} / \mathrm{min}]}\end{array}$ & 0.03 & 0.03 & 0.08 & 0.07 \\
\hline
\end{tabular}

The value of $\mathrm{V}_{\mathrm{m}}$ is given by the product of the catalyst constant of the enzyme $\left(k_{c a t}\right)$ and the concentration of the enzyme $\left(E_{0}\right)$. The concentration of spray dried cells used in the experiments to obtain the kinetic parameters of CNB04-01 shown in Table 6-II was 0.025 $\mathrm{mg} / \mathrm{ml}$ and for CNB03-03 it was $0.05 \mathrm{mg} / \mathrm{ml}$. Through these considerations a value of $k_{\text {cat }}$ for CNB04-01 of $1.16 \mathrm{~min}^{-1}$ was estimated and $1.45 \mathrm{~min}^{-1}$ for CNB03-03. Such values are valid when $\mathrm{V}_{\mathrm{m}}$ is in $[\mathrm{mM} / \mathrm{min}]$ and $\mathrm{E}_{\mathrm{o}}$ is in $[\mathrm{mg} / \mathrm{ml}]$; they indicate that CNB04-01 is a little less active than CNB03-03 at high substrate concentration.

\subsubsection{Optimum pH}

The characterization of optimum $\mathrm{pH}$ for free and immobilized CNB04-01 at $55{ }^{\circ} \mathrm{C}$ was done in a volume of $20 \mathrm{ml}$ of Solution 6 (Table 3-I). Ten $\mathrm{mg}$ of the enzyme in both forms were added to the system. Free enzyme was added in $1000 \mu$ of solution containing 10 mg spray dried cells per ml. Immobilized enzyme was added in $0.5 \mathrm{~g}$ of beads containing $50 \mathrm{mg}$ enzyme/g bead. The results of optimum $\mathrm{pH}$ for free and immobilized enzyme are shown in Figure 6-20. 


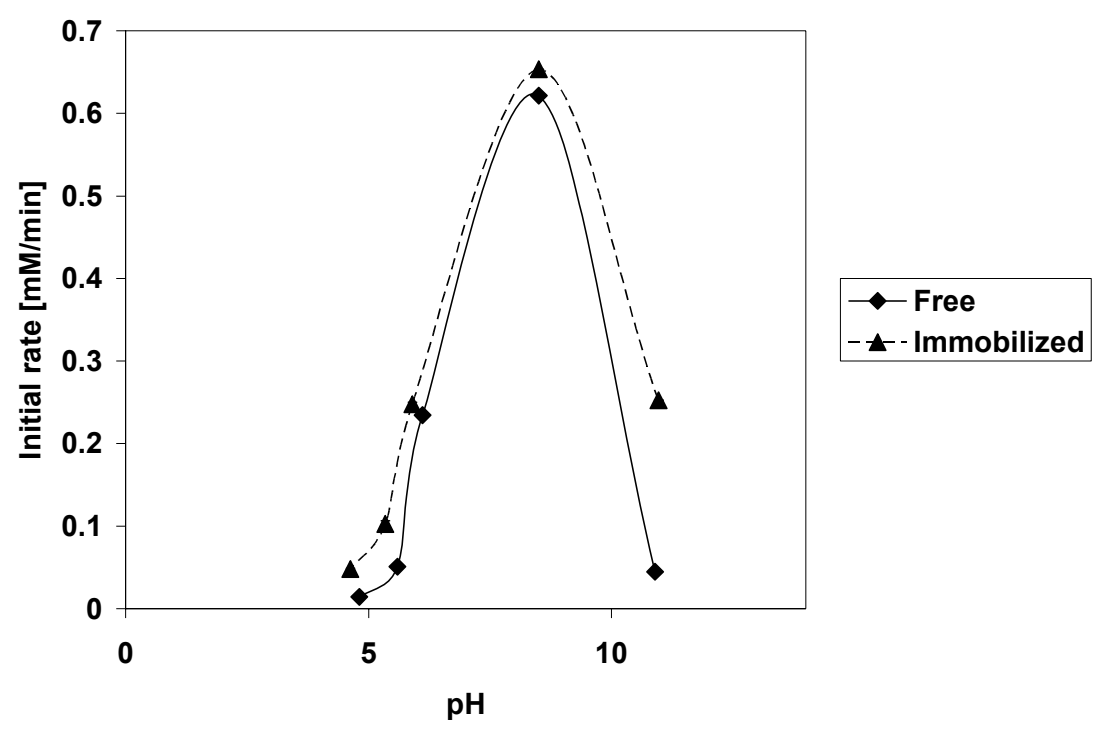

Figure 6-20: Effect pH on the activity of free and immobilized spray dried cells of CNB04-01.

Figure 6-20 shows that free and immobilized spray dried cells of CNB04-01 have, within the ability of the assay to distinguish, the same $\mathrm{pH}$ optimum, which is about 8.5. Its predecessor, CNB03-03, has the highest activity at $\mathrm{pH} 7.7$ for free spray dried cells, and for immobilized CNB03-03, pH 8.1. The enzyme CNB04-01 did not show a change in optimum $\mathrm{pH}$ upon immobilization into calcium alginate, and similar results have been published for different enzyme / substrate systems. The experiments published from other work show no shift of optimum $\mathrm{pH}$ but do exhibit changes of $\mathrm{pH}$-activity curve. Some examples of enzymes showing this behavior are $\beta$-fructofuranosidase immobilized by diazo binding with polyaminopolystyrene (Filippusson and Hornby, 1970), and asparaginase microencapsulated in nylon or polyurea (Mori et al, 1973). In both cases, $\mathrm{pH}$ did not shift, but the $\mathrm{pH}$-activity curves became narrower. 


\subsubsection{Optimum Temperature}

The effect of temperature on initial rate was investigated by adding $10 \mathrm{mg}$ of spray dried cells of CNB04-01, free and immobilized, into $20 \mathrm{ml}$ of Solution $6 \mathrm{pH} 7$ (Table 3-I). Free spray dried cells were added in $1000 \mu \mathrm{l}$ of solution containing $10 \mathrm{mg}$ of spray dried cells per ml. Immobilized enzyme was added in $0.5 \mathrm{~g}$ of beads containing $50 \mathrm{mg}$ spray dried cells/g bead. The results are shown in Figure 6-21.

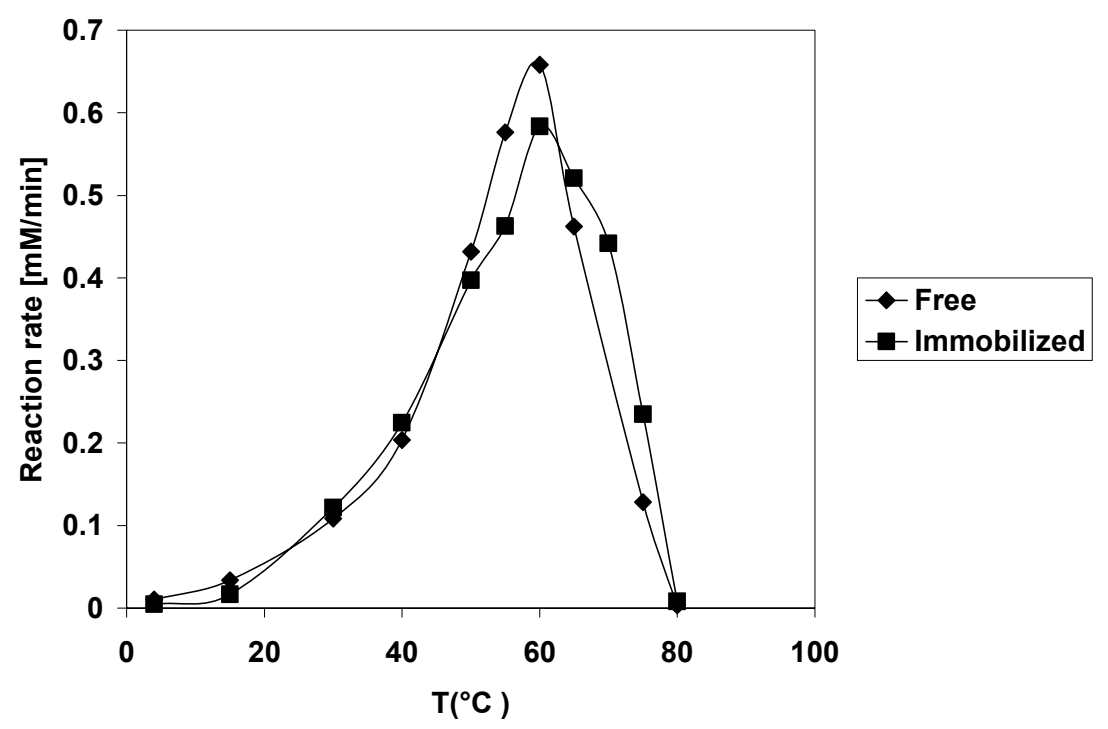

Figure 6-21: Optimum temperature for free and immobilized CNB04-01.

Figure 6-21 shows an optimum temperature for free and immobilized CNB04-01 of 60 ${ }^{\circ} \mathrm{C}$. For its predecessor, CNB03-03, the optimum temperature for free enzyme was $55{ }^{\circ} \mathrm{C}$ and $60{ }^{\circ} \mathrm{C}$ for immobilized. As stated in Section 6.1.1.3, in many cases there is a shift in optimum temperature upon immobilization from between 5 to $15^{\circ} \mathrm{C}$, but there have been many reports that no change of optimum temperature occurs upon immobilization. For example, in the cases of glucose isomerase (Strandberg and Smiley, 1972) and leucine aminopeptidase (Royer and Andrews, 1973) immobilized by diazo binding with porous 
glass, chymotrypsin (Gregor and Rauf, 1975) immobilized with CNBr-activated cellulosic membrane and trypsin (Walter, 1976) among others. The analysis of data shown in Figure 6-21 for activation energy on the activation and de-activation branches of the data is presented in Figure 6-22 and Figure 6-23.

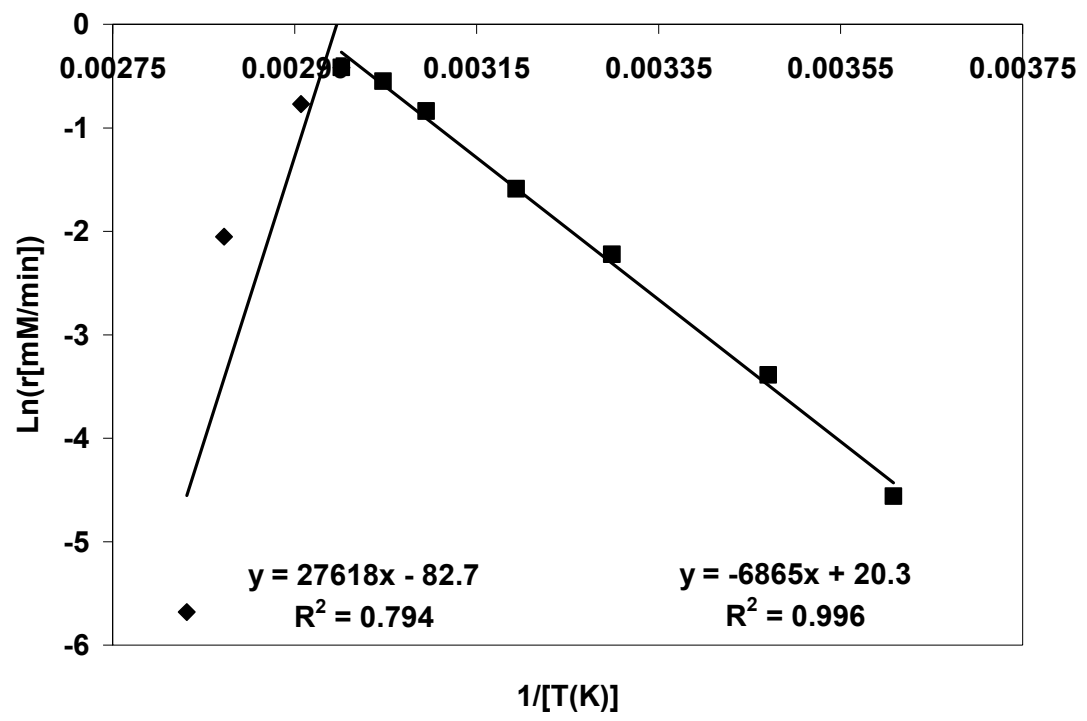

Figure 6-22: Arrhenius plot for free spray dried cells of CNB04-01.

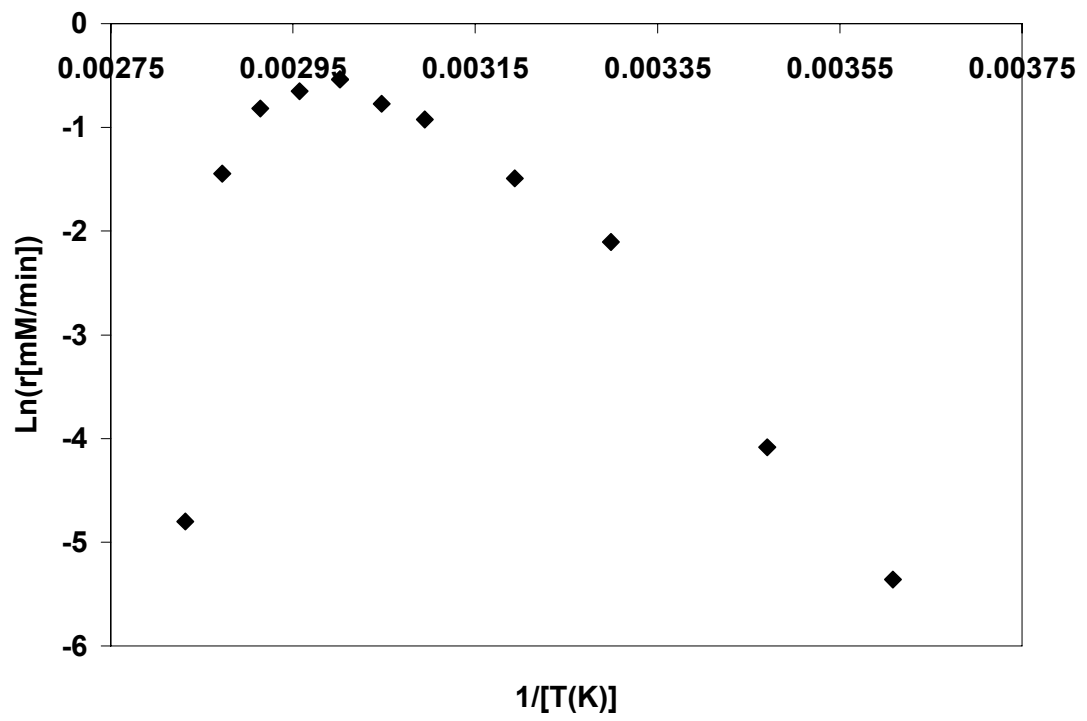

Figure 6-23: Arrhenius plot for immobilized spray dried cells of CNB04-01. 
From Figure 6-22 it was determined that the activation energy for free spray dried cells of CNB04-01 was $13.4 \mathrm{kcal} / \mathrm{mol}(15.1 \mathrm{kcal} / \mathrm{mol}$ for free CNB03-03), which is between the range of 4 to $20 \mathrm{kcal} / \mathrm{mol}$ activation energies for enzyme catalyzed reactions (Shuler \& Kargi, 2002). From the same figure deactivation energy was estimated to be 54.8 $\mathrm{kcal} / \mathrm{mol}(41.7 \mathrm{kcal} / \mathrm{mol}$ for free $\mathrm{CNB} 03-03)$, which is between the range of 40 to 130 $\mathrm{kcal} / \mathrm{mol}$ deactivation energies for enzyme catalyzed reactions (Shuler \& Kargi, 2002).

The Arrhenius plot for immobilized spray dried cells deserves especial attention. Figure 6-24 shows the interval of reciprocal temperatures where enzyme deactivation occurs, and Figure 6-25 shows activation of the enzyme.

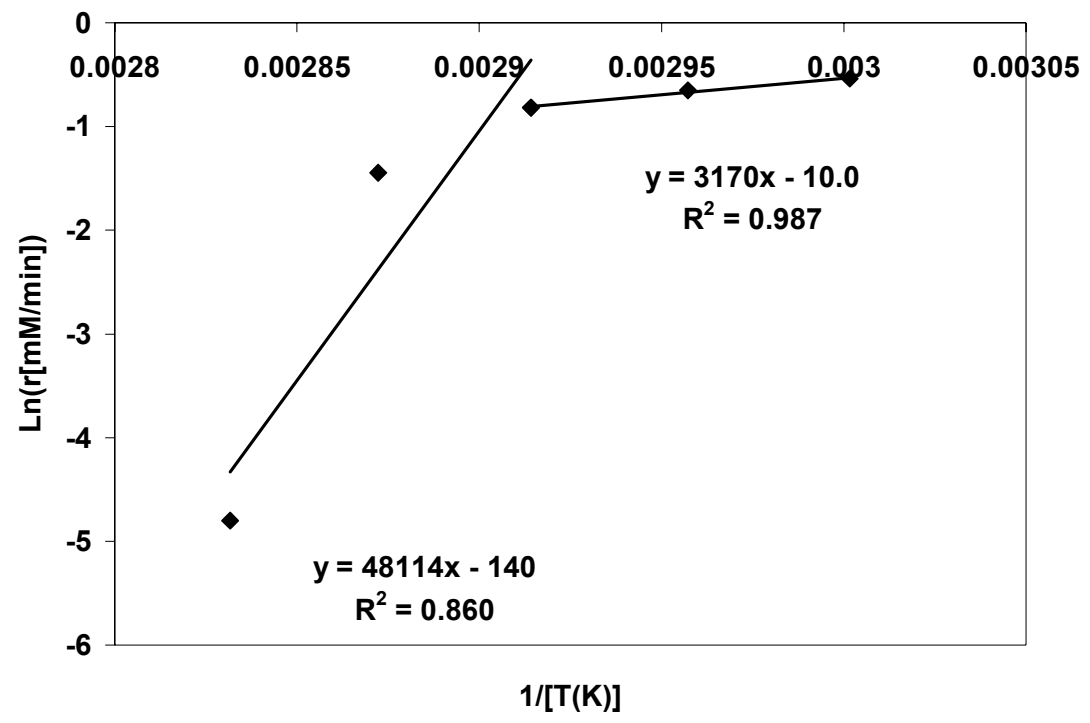

Figure 6-24: Arrhenius plot for immobilized CNB04-01. Deactivation of immobilized spray dried cells. 


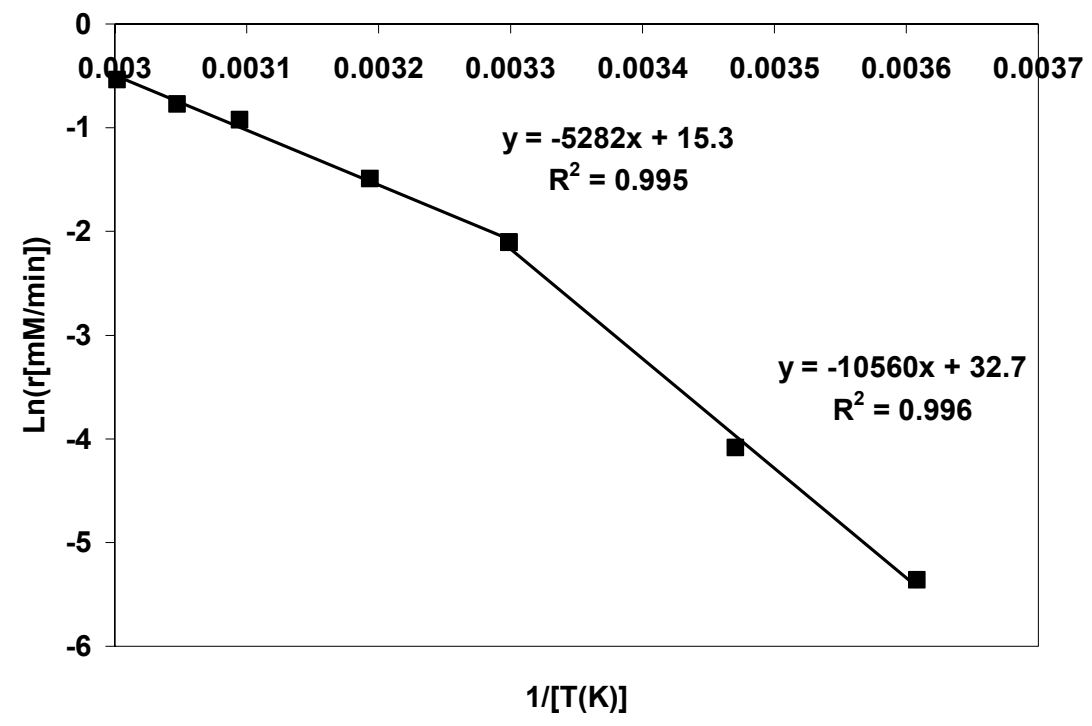

Figure 6-25: Arrhenius plot for immobilized CNB04-01. Activation of immobilized spray dried cells.

Figure 6-24 suggests that the enzyme is deactivated by temperature apparently following two different routes; one of them is related with to an exponential decay and the other to a decay more pronounced that an exponential decay; a catastrophic event. Therefore it was not possible to determine or estimate deactivation for immobilized CNB04-01. From Figure 6-25 activation energy of $21.0 \mathrm{kcal} / \mathrm{mol}(8.9 \mathrm{kcal} / \mathrm{mol}$ for immobilized CNB03-03) for immobilized spray dried cells of CNB04-01. The Arrhenius plot of the reaction rate, shown in Figure 6-25, illustrates the likely effect of diffusional resistances on the observed activation energy. At low temperatures, the reaction rate is not limited by diffusional resistances, and the observed activation energy is the true value. At high temperatures, the reaction is inhibited by diffusional resistances, and the activation energy is half the true value (Davis \& Davis, 2003). 


\subsubsection{Thermostability}

Thermostability of CNB04-01 was tested as follows. Free and immobilized spray dried cells were kept at $50{ }^{\circ} \mathrm{C}$ in a solution of $100 \mathrm{mM}$ calcium chloride, $100 \mathrm{mM}$ sodium acetate, $1 \mathrm{mM}$ pyridoxal-5-phosphate at $\mathrm{pH} 8.5$ (storage solution). Free enzyme consisted of 0.1 gram dissolved in $10 \mathrm{ml}$ of storage solution. Immobilized enzyme consisted of 15 grams of beads containing $50 \mathrm{mg}$ enzyme/g bead of spray dried cells of CNB04-01. Periodically, $1 \mathrm{ml}$ of free enzyme and 0.5 gram of immobilized enzyme were withdrawn and added to $20 \mathrm{ml}$ of Solution 6 at $\mathrm{pH} 8.5$ (Table $3-\mathrm{I}$ ) and incubated at $50{ }^{\circ} \mathrm{C}$. The change on (S)-aminotransferase activity as a function of time was measured. The results are shown in Figure 6-26.

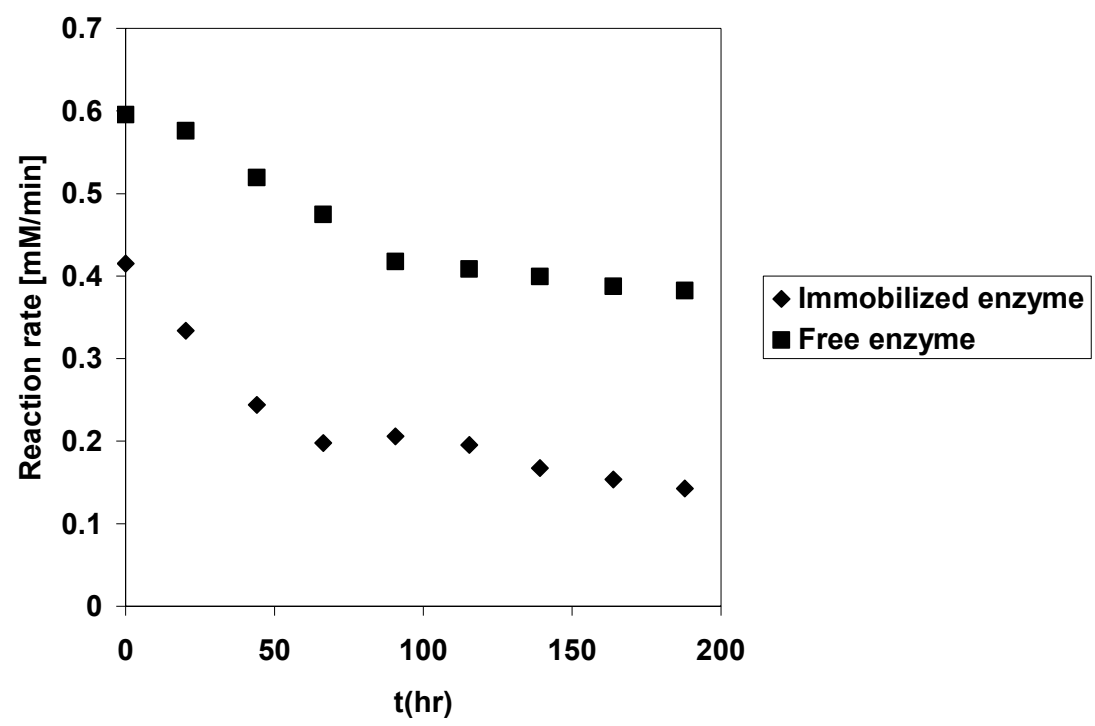

Figure 6-26: Change of (S)-aminotransferase activity as an effect of incubation at $50{ }^{\circ} \mathrm{C}$ of free and immobilized spray dried cells of CNB04-01.

Figure 6-26 shows deactivation of both preparations of CNB04-01 with time and reveals that activity of aqueous and immobilized enzyme decays at nearly the same rate. But 
fitting the data shown in this figure to a first order decay, it turns out that the deactivation constant for free enzyme is $0.011 \mathrm{hr}^{-1}$, and it is $0.021 \mathrm{hr}^{-1}$ for immobilized enzyme. The results obtained indicate that immobilized enzyme CNB04-01 decays about twice as fast as the free enzyme CNB04-01 for the system of $(\mathrm{S})-(\alpha)-(-)-$ methylbenzylamine. The estimated deactivation constant for aqueous or free enzyme CNB04-01 is close to the deactivation constant for free and immobilized CNB03-03, which are $0.011 \mathrm{hr}^{-1}$ and $0.011 \mathrm{hr}^{-1}$ respectively. Therefore, the improved thermostability seen during colony screening procedure, which was based on substituted (S)-aminotetralin, was not expressed in the system of (S)-( $\alpha)-(-)$-methylbenzylamine.

\subsection{Substituted Tetralone System}

The system of substituted tetralone consists of the reaction between this substance and isopropylamine to produce substituted (S)-aminotetralin and acetone; mediated by (S)aminotransferase. The reaction equation is shown in Figure 6-27.

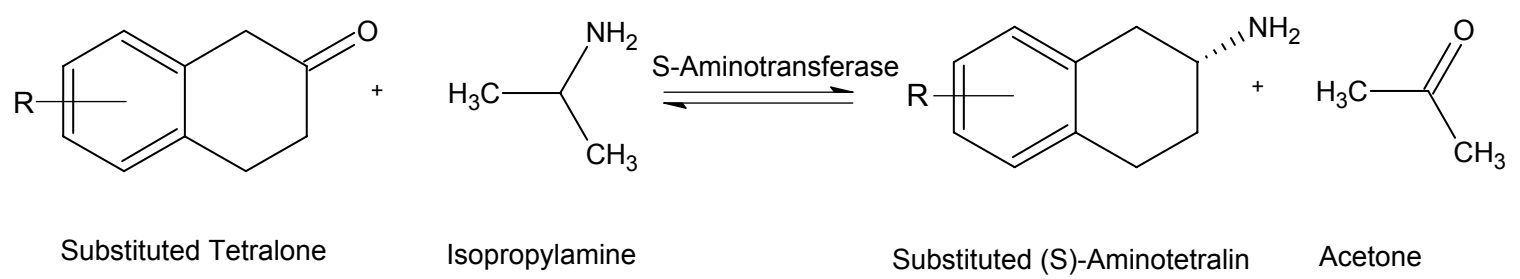

Figure 6-27: Substituted tetralone system reaction. 


\subsubsection{CNB04-01}

The partial characterization of the (S)-aminotransferase mutant CNB04-01 consisted of determining its affinity for isopropylamine.

\subsubsection{Optimum Isopropylamine Concentration}

The estimation of the optimum concentration of isopropylamine at which CNB04-01 has the highest activity was obtained, prior to the use of this enzyme in the production of substituted (S)-aminotetralin. In order to do so, $100 \mathrm{mg}$ of spray dried cells of CNB04-01 was added to $20 \mathrm{ml}$ of Solution 13 at $\mathrm{pH} 7$ (Table 3-II) and incubated at $55^{\circ} \mathrm{C}$. The isopropylamine concentration was on the range of 0.1 to $1.0 \mathrm{M}$. The results are shown in Figure 6-28.

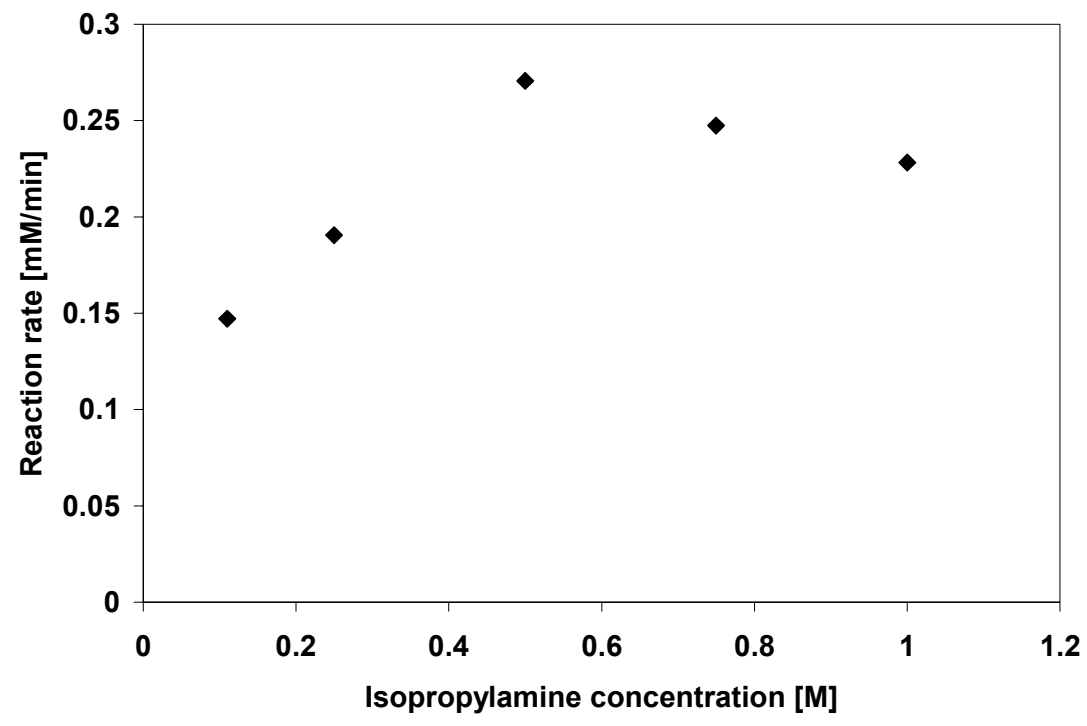

Figure 6-28: Change on reaction rate of free CNB04-01 in the production of substituted (S)aminotetralin as a function of Isopropylamine. 
From Figure 6-28 it was concluded that a concentration of $0.5 \mathrm{M}$ of isopropylamine allows the highest initial rate of reaction. Also from Figure 6-28 it is noticed that substrate inhibition is present, because at concentrations larger than $0.5 \mathrm{M}$ isopropylamine the reaction rate decreases. Such inhibition is described by the following model,

$$
v=\frac{V_{m}[S]}{K_{m}+[S]+\frac{[S]^{2}}{K_{S}}}
$$

where $v$ is reaction rate, $V_{m}$ is maximum reaction rate, $\mathrm{S}$ is substrate concentration, $K_{m}$ is the Michaelis-Menten constant, and $K_{S}$ is the inhibition constant of the substrate (Shuler \& Kargi, 2002). Fitting the data shown in Figure 6-28 to the model given in Equation (16), and using non-linear regression using the solver tool from Microsoft@ Office Excel 2003, the following values are obtained, $V_{m}=0.361 \mathrm{mM} / \mathrm{min}, K_{m}=0.160 \mathrm{M}$, and $K_{S}=$ 2.78 M. Using the obtained values of the parameters and substituting them in Equation (16), it is possible to obtain the substrate concentration that maximizes $v$. A value of 0.67 M was calculated, which is slightly different from the value observed by experimentation. Figure 6-29 show the way in which Equation (16) describes the data from Figure 6-28, when the estimations for $V_{m}, K_{m}$, and $K_{S}$ are used. 


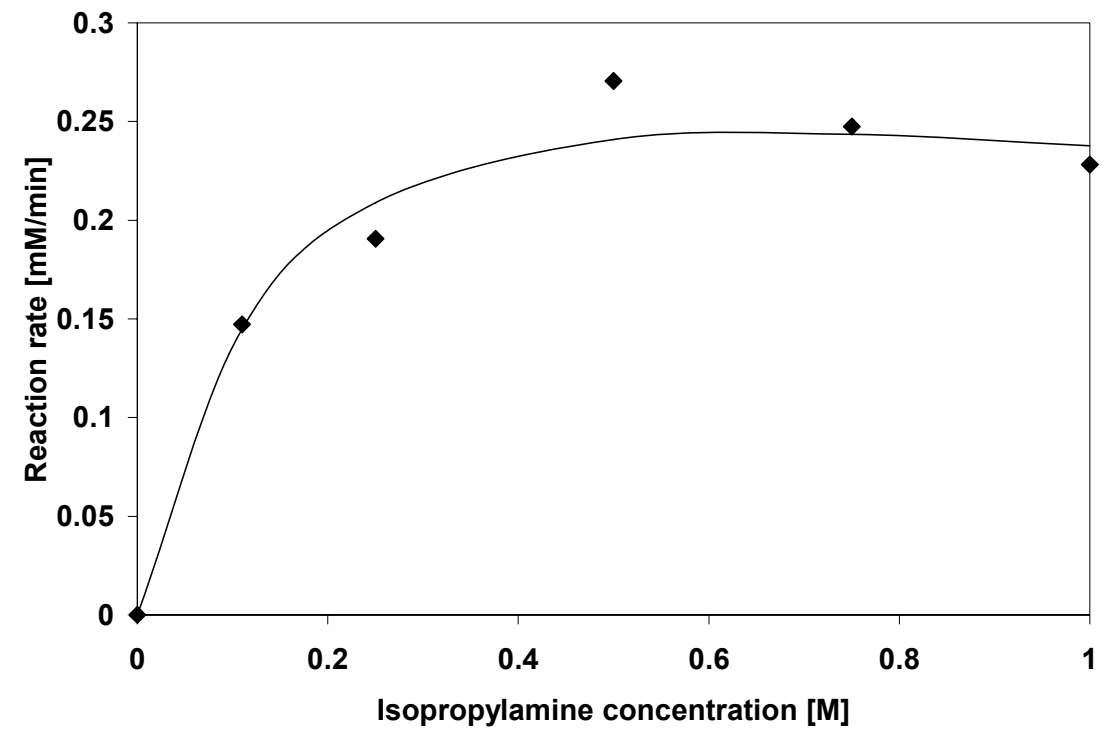

Figure 6-29: Description of the effect of isopropylamine concentration on initial rate by the model of substrate inhibition (continuous trend).

\subsubsection{CNB05-01}

(S)-aminotransferase mutant CNB05-01 was characterized extensively using the substituted tetralone system. The characterization consisted of first finding the ranges of substrates concentration in which (S)-aminotransferase activity is affected. Next based on the ranges of substrate concentration experiments were designed in order to develop a model to describe its kinetics.

\subsubsection{Optimum Temperature}

The effect of temperature on initial rate was investigated using $50 \mathrm{ml}$ of Solution $14 \mathrm{pH} 7$ (Table 3-II), at a concentration of free spray dried cells of CNB05-01 of 5 grams per liter. The results are shown in Figure 6-30. 


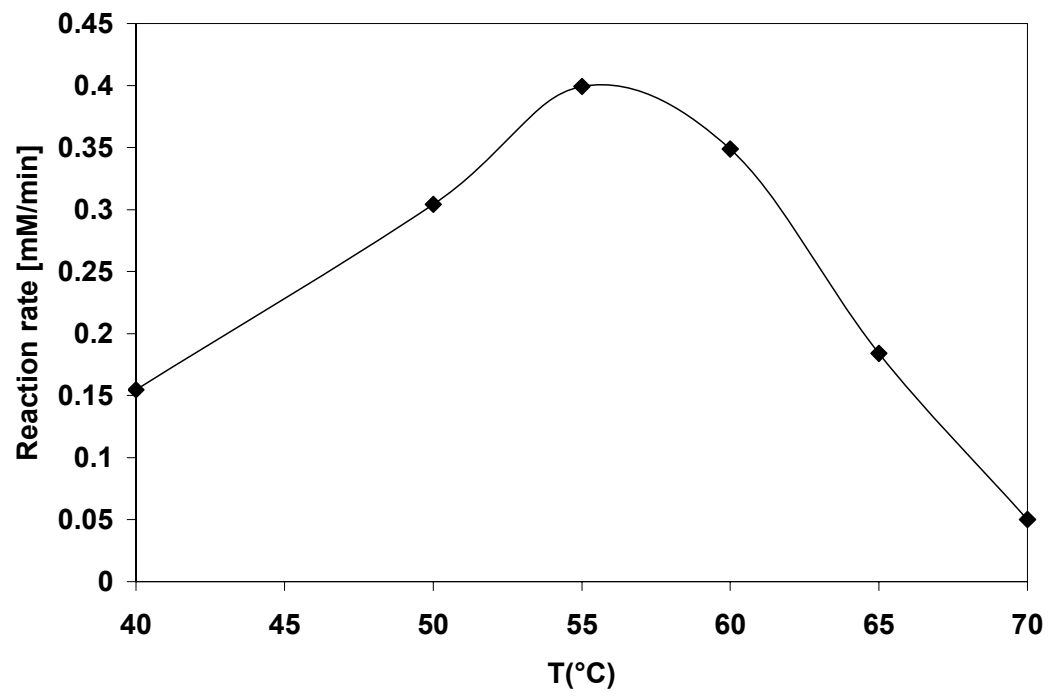

Figure 6-30: Effect of temperature on initial rate of production of substituted (S)aminotetralin by free CNB05-01.

From Figure 6-30 $55{ }^{\circ} \mathrm{C}$ is identified as the optimum temperature for CNB05-01 derived from free spray dried cells. Activation and deactivation energies of spray dried cells of CNB05-01 were estimated. The results are shown in Figure 6-31.

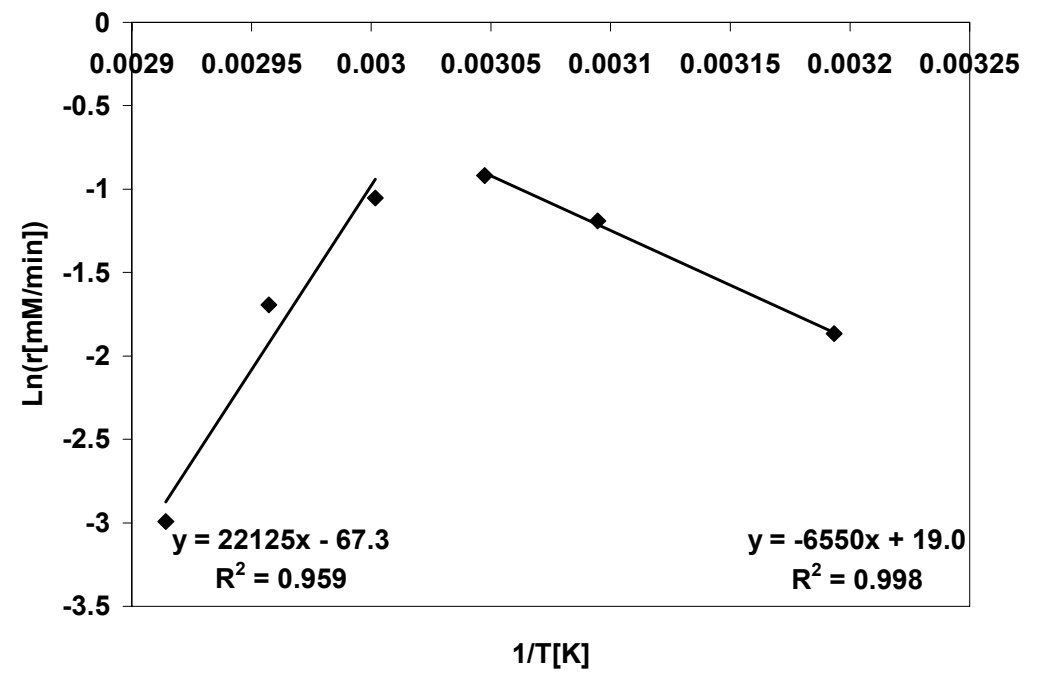

Figure 6-31: Arrhenius plot for free spray dried cells of (S)-aminotransferase CNB05-01. 
From Figure 6-31 the activation energy of free CNB05-01 was estimated as 13.0 $\mathrm{kcal} / \mathrm{mol}$, and deactivation energy as $43.9 \mathrm{kcal} / \mathrm{mol}$. Its predecessors have a value of activation energy of $15.1 \mathrm{kcal} / \mathrm{mol}$ and $13.4 \mathrm{kcal} / \mathrm{mol}$ for CNB03-03 and CNB04-01, respectively. They have deactivation energy of $41.7 \mathrm{kcal} / \mathrm{mol}$ and $54.8 \mathrm{kcal} / \mathrm{mol}$, respectively for CNB03-03 and CNB04-01. Such values for CNB03-03 and CNB04-01 were estimated using the system of (S)-(-)- $\alpha$-methylbenzylamine. Then a direct comparison between activation and deactivation energy of CNB05-01 and the same parameters of its predecessor would not be appropiate. The values of activation and deactivation energies of CNB05-01 are within the range values for many enzymes, whose values of activation energies are between 4 to $20 \mathrm{kcal} / \mathrm{mol}$, and 40 to $130 \mathrm{kcal} / \mathrm{mol}$ for deactivation energy (Shuler \& Kargi, 2002).

\subsubsection{Substrate Affinity}

The affinity for isopropylamine and for substituted tetralone was measured at $55{ }^{\circ} \mathrm{C}$. The results are shown in the next sections.

\subsection{Isopropylamine}

The affinity of free spray dried cells of (S)-aminotransferase CNB05-01 for isopropylamine $[\mathrm{A}]$, at $55^{\circ} \mathrm{C}$, was measured using $50 \mathrm{ml}$ of Solution $17 \mathrm{pH} 7$ (Table 3-II). Enzyme concentration was 5 grams per liter. The results are shown in Figure 6-32. 


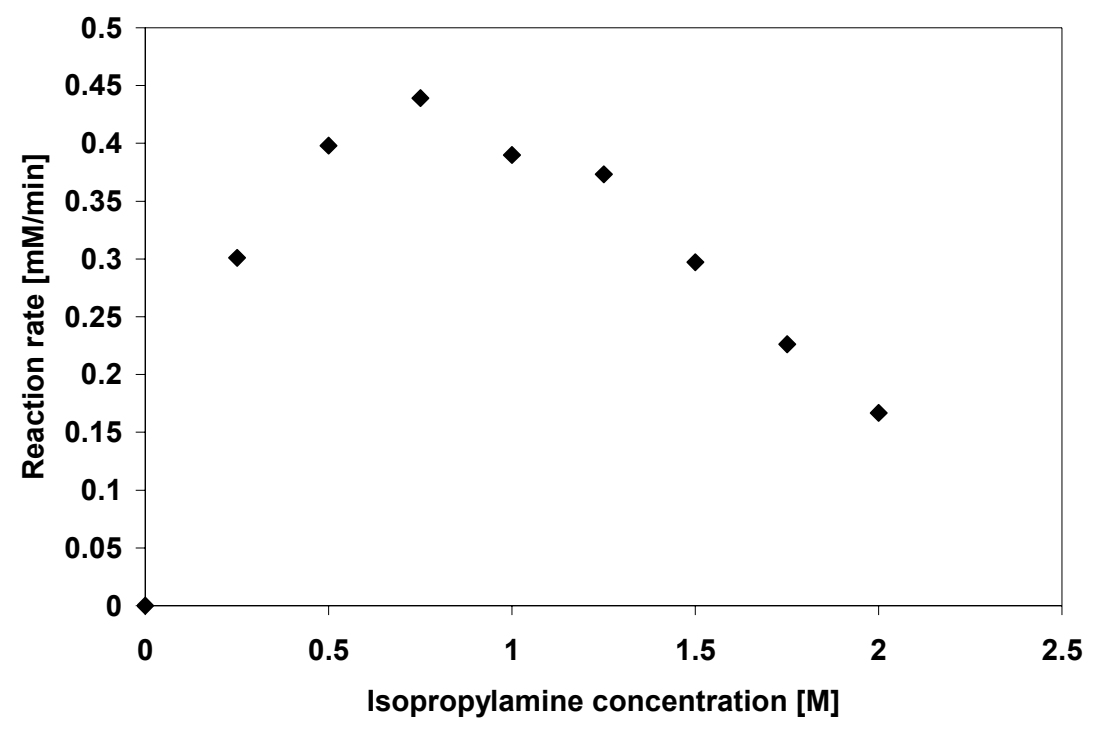

Figure 6-32: Effect of isopropylamine concentration on initial rate of production of substituted (S)-aminotetralin by free spray dried cells of CNB05-01.

The data shown in Figure 6-32 were fitted to Equation (16) (Section 6.2.1.1). The best fit of the data was given by the following values $V_{m}=1.50 \mathrm{mM} / \mathrm{min}, K_{m}=0.83 \mathrm{M}$, and $K_{S}=$ 0.45 M obtained by non-linear regression using the solver tool from Microsoft ${ }^{\circledR}$ Office Excel 2003, although Equation (16) does not match the data perfectly above $0.5 \mathrm{M}$ it accounts for the phenomena observed: incrase and decrease on activity. Such values of $K_{m}$ and $K_{S}$ indicate that the theoretical concentration of isopropylamine that maximizes reaction rate is $0.61 \mathrm{M}$, given by $\left[K_{m} K_{S}\right]^{1 / 2}$. Through experimentation, the apparent optimum concentration of isopropylamine was determined as $0.75 \mathrm{M}$, which differs by 0.14 units of concentration $(\mathrm{M})$ from the model and best fit parameters. Figure 6-33 shows a comparison between the data shown in Figure 6-32 with Equation (16), when the estimated values of $V_{m}, K_{m}$, and $K_{S}$ are used. 


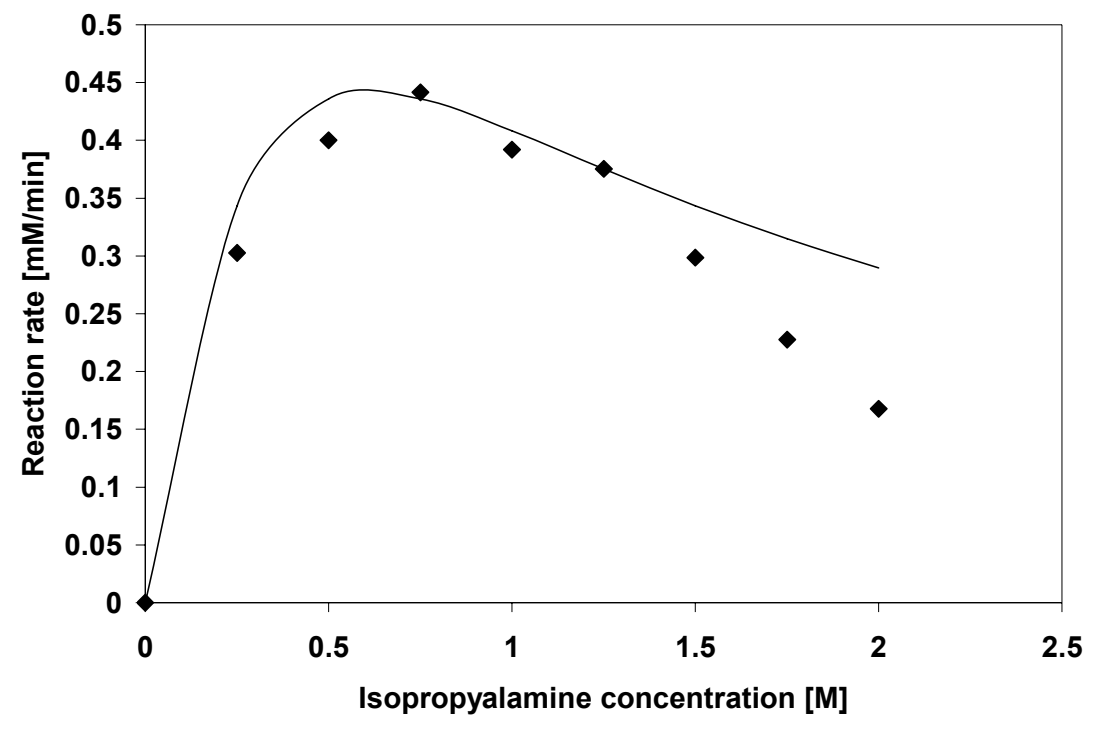

Figure 6-33: Description of the effect of isopropylamine concentration on initial rate by the model of substrate inhibition-Equation (17)- (continuous trend).

The model of substrate inhibition, given by Equation (16), allows a proper description of the effect of isopropylamine concentration on the rate of production of substituted (S)aminotetralin up to concentration of $1.5 \mathrm{M}$ of this substrate, but at concentration higher than $1.5 \mathrm{M}$ the model does not describe properly the experimental data. This difference may be due to experimental error during reaction rate measurement, oversimplification of inhibition model, or the fact that CNB05-01 may follow another mechanism of inhibition. Isopropylamine concentration of $0.75 \mathrm{M}$ was selected for further characterization of CNB05-01, presented in the next sections.

\subsection{Substituted Tetralone}

Affinity for substituted tetralone [B], at $55^{\circ} \mathrm{C}$, was measured using $50 \mathrm{ml}$ of Solution 19 pH 7 (Table 3-II), focusing the experiments within the range of solubility ( $33 \mathrm{mM}$ at 55 
$\left.{ }^{\circ} \mathrm{C}\right)$. The concentration of free spray dried cells of CNB05-01 was one gram per liter. Samples were withdrawn for measurement of substituted (S)-aminotetralin concentration at $5,10,15$, and 20 minutes. Such concentrations were plotted as a function of time, yielding the slope of the values of initial reaction system for the specific system. The results are shown in Figure 6-34, together with their best fit to Equation (15).

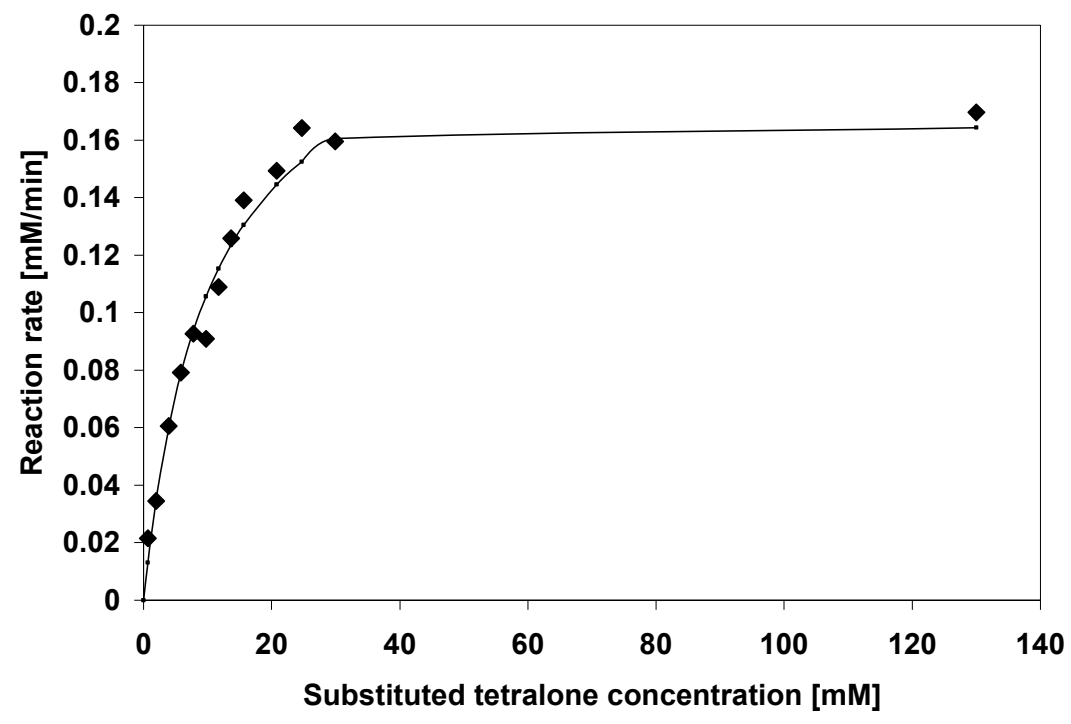

Figure 6-34: Effect of substituted tetralone concentration on production rate of substituted (S)-aminotetralin by free spray dried CNB05-01.

The data shown in Figure 6-34 were fitted to Equation (15) (Section 6.1.1.1). The value of maximum velocity $\left(\mathrm{V}_{\mathrm{m}}\right)$ was estimated as $0.22 \mathrm{mM} / \mathrm{min}$, and the value of substrate affinity $\left(\mathrm{K}_{\mathrm{m}}\right)$ was estimated to be $10.4 \mathrm{mM}$, with both parameters calculated by non-linear regression using the solver tool from Microsoft $($ Office Excel 2003. The reported values of $V_{m}$ and $K_{m}$ to model the effect of substituted tetralone only apply up to substituted tetralone concentration of about $33 \mathrm{mM}$, since this value is its solubility limit under the reaction conditions. Then, the data point in Figure 6-34 corresponding to a total 
concentration $130 \mathrm{mM}$ is predicted by the model using a value of $33 \mathrm{mM}$. There is no observed substrate inhibition by substituted tetralone.

In Section 6.2.2.2.1 the value of maximum velocity $\left(\mathrm{V}_{\mathrm{m}}\right)$ for the system of substituted tetralone was estimated by the Michaelis-Menton model with inhibition to be 1.5 $\mathrm{mM} / \mathrm{min}$ at an enzyme concentration of 5 grams per liter of spray dried cells of CNB0501. If the system whose results are described in Section 6.2.2.2.1 had been run at an enzyme concentration of one gram per liter of spray dried cells, the value of $V_{m}$ would be expected to be $0.3 \mathrm{mM} / \mathrm{min}$, which is close to the value determined during the study of the effect of substituted tetralone on initial rate $(0.22 \mathrm{mM} / \mathrm{min})$.

\subsubsection{Optimum $\mathrm{pH}$}

Optimum pH for free spray dried cells of CNB05-01, at a concentration of $\mathbf{5}$ grams per liter, was estimated by measuring substituted (S)-aminotetralin concentration after $\mathbf{2 0}$ minutes in a system of $50 \mathrm{ml}$ of Solution 18 (Table 3-II) incubated at $55{ }^{\circ} \mathrm{C}$ at a $\mathrm{pH}$ in the range of 5 to 9 . Since substituted (S)-aminotetralin is not present in the system at the beginning, it is possible to estimate the value of initial reaction rate as the ratio obtained by dividing the concentration of substituted (S)-aminotetralin by 20 minutes. The results are shown in Figure 6-35. It shows that the apparent maximum activity for CNB05-01 is in the $\mathrm{pH}$ range of 6.5 to 7 , achieving a maximum value of initial rate close to $1 \mathrm{mM} / \mathrm{min}$. The results obtained, regarding to the value of maximum initial rate, are in general agreement with the value of $\mathrm{V}_{\mathrm{m}}=1.5 \mathrm{mM} / \mathrm{min}$ obtained in Section 6.2.2.2.1. 


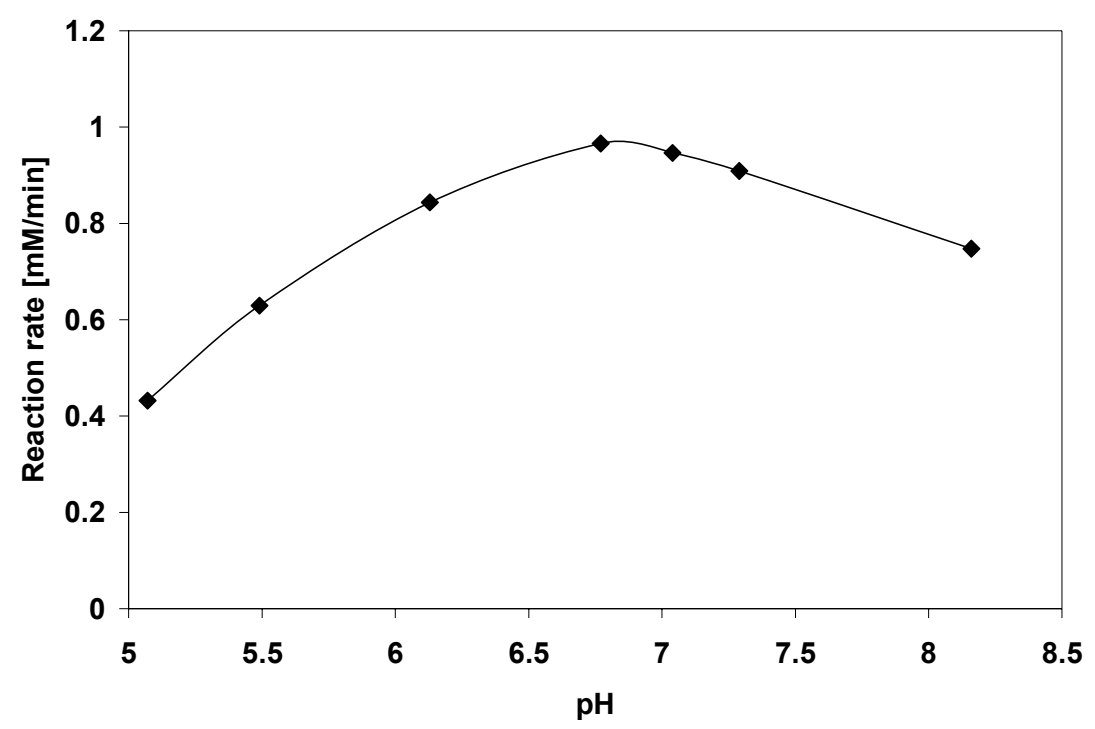

Figure 6-35: Effect of $\mathrm{pH}$ on reaction rate of production of substituted (S)-aminotetralin by free CNB05-01.

\subsubsection{Aminotransferase Model}

During the production of substituted (S)-aminotetralin by transamination reaction, the enzyme (CNB05-01) is in an environment with reactants, products, and undesirable byproducts. For the case in study, the reactants are isopropylamine and substituted tetralone, the products are acetone and substituted (S)-aminotetralin, and the undesirable byproduct is an imine formed from one molecule of substituted tetralone (reactant) and one molecule of substituted (S)-aminotetralin (product). In addition to these substances, there is one more in solution, which is pyridoxal-5-phosphate, the cofactor. As described, there are many substances in the system, and at least two main reactions, one of them mediated by an enzyme (transamination) and the other spontaneously occurring (imine formation). Both of the reactions occur with a reactant in common, substituted tetralone. 
Imine formation by the desired product and substituted tetralone masks the true capability of CNB05-01 for substituted (S)-aminotetralin production.

To find out the true capability of CNB05-01 for production of the desired product, as well as to investigate others factors (like the effect of pyridoxal-5-phosphate concentration), a series of experiments was performed. The objectives of those experiments were aimed to a) determine the effect of pyridoxal-5-phosphate concentration on initial rate, b) investigate the effect of the concentration of isopropylamine and substituted tetralone on initial rate, c) measure the effect of product concentration (acetone and substituted (S)aminotetralin) on initial rate, and d) measure rate of reaction between acetone and substituted (S)-aminotetralin. The details and results of these experiments are shown in the next sections.

\subsection{Effect of Pyridoxal-5-Phosphate}

The effect of pyridoxal-5-phosphate concentration on initial rate of (S)-aminotransferase CNB05-01 was investigated at $55^{\circ} \mathrm{C}$. It was done in systems of $50 \mathrm{ml}$ of Solution $20 \mathrm{pH}$ 7 (Table 3-II), having an enzyme concentration of 1 gram per liter. Samples were withdrawn from the systems at 5,10,15 and 20 minutes and then analyzed by HPLC to measure concentration of substituted (S)-aminotetralin. The results are shown in Figure 6-36. 


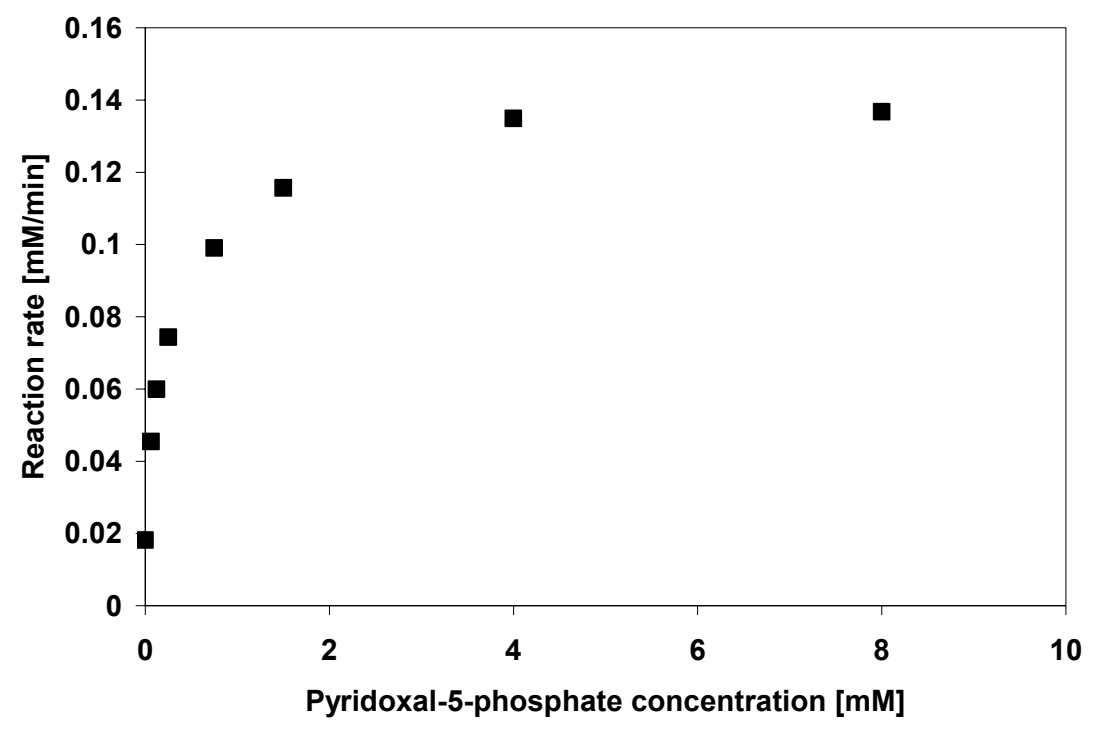

Notice that the maximum experimental reaction rate measured was about $0.14 \mathrm{mM} / \mathrm{min}$, whereas in Figure $6-34$ it is about 0.16 $\mathrm{mM} / \mathrm{min}$. Such difference is explained by the coefficient of variation of 0.12 estimated in Section 3.5.

Figure 6-36: Effect of Pyridoxal-5-phosphate (PLP) concentration on reaction rate of free (S)aminotransferase catalyzing the reaction system of substituted tetralone at $55^{\circ} \mathrm{C}, \mathrm{pH} 7$.

Figure 6-36 shows the effect of pyridoxal-5-phosphate concentration, the cofactor, on initial rate of (S)-aminotransferase CNB05-01. Using cofactor concentration at $2 \mathrm{mM}$ allows the biocatalyst to work at about $85 \%$ of its potential. For consistency with the experiments done in previous sections, cofactor concentration was not changed to the optimum value $(4 \mathrm{mM})$ in the other experiments discussed in this chapter. The data shown in Figure 6-36 were correlated to a Michaelis-Menton-like model of saturation kinetics, similar to the one represented by Equation (15) (Section 6.1.1.1). The model gave as a result a maximum value of rate $\mathrm{V}_{\mathrm{m}}$ of $0.14 \mathrm{mM} / \mathrm{min}$, and a $\mathrm{K}_{\mathrm{m}}$ of $0.22 \mathrm{mM}$ by means of non-linear regression using the solver tool from Microsoft ${ }^{\circledR}$ Office Excel 2003. Figure 6-36 also shows a reaction rate of $0.02 \mathrm{mM} / \mathrm{min}$ at a cofactor concentration of 0 $\mathrm{mM}$, obtained when the enzyme was used as it was after spray drying. Adding cofactor 
up to a concentration of $4 \mathrm{mM}$ increases the activity (reaction rate) by a factor of about 7 times. From these data the need is shown of adding the cofactor, pyridoxal-5-phosphate, to all the reactions mediated by (S)-aminotransferases expressed in Escherichia coli MG1655, since it appears that the amount of pyridoxal-5-phosphate inside of the cell is not enough to form the complex enzyme-cofactor with all the (S)-aminotransferase produced.

\subsection{Effect of Isopropylamine and Substituted Tetralone Concentration}

Isopropylamine $[\mathrm{A}]$ and substituted tetralone $[\mathrm{B}]$ concentration effects on reaction rate of (S)-aminotransferase CNB05-01 were investigated at $55^{\circ} \mathrm{C}$, as follows. Isopropylamine concentration was varied from $0.75 \mathrm{M}$ to $2.00 \mathrm{M}$, in increments of $0.25 \mathrm{M}$. Each concentration of isopropylamine was tested with four different concentrations of substituted tetralone $(2,10,20$, and $30 \mathrm{mM})$. The proper amounts of isopropylamine and substituted tetralone were added to $50 \mathrm{ml}$ of Solution $21 \mathrm{pH} 7$ (Table 3-II). Spray dried cells concentration was 1 gram per liter. Samples were withdrawn at 5, 10, 15, and 20 minutes. Substituted (S)-aminotetralin concentration was measured, and with it reaction rate was determined. The results are shown in Table 6-III.

Table 6-III: Effect of isopropylamine and substituted tetralone concentration on reaction rate (mM/min) of (S)-aminotransferase CNB05-01.

\begin{tabular}{|c|c|c|c|c|}
\hline \multirow{2}{*}{$\begin{array}{l}\text { Isopropylamine } \\
{[A] \text { concentration }}\end{array}$} & \multicolumn{4}{|c|}{ Substituted tetralone [B] concentration } \\
\hline & $2 \mathrm{mM}$ & $10 \mathrm{mM}$ & $20 \mathrm{mM}$ & $30 \mathrm{mM}$ \\
\hline $750 \mathrm{mM}$ & 0.03 & 0.09 & 0.15 & 0.16 \\
\hline $1000 \mathrm{mM}$ & 0.0 & 0.11 & 0.16 & 0.17 \\
\hline $1250 \mathrm{mM}$ & 0.04 & 0.09 & 0.12 & 0.13 \\
\hline $1500 \mathrm{mM}$ & 0.04 & 0.08 & 0.13 & 0.14 \\
\hline $1750 \mathrm{mM}$ & 0.04 & 0.08 & 0.12 & 0.13 \\
\hline $2000 \mathrm{mM}$ & 0.03 & 0.08 & 0.09 & 0.11 \\
\hline
\end{tabular}


From Table 6-III it is seen that as isopropylamine concentration increases, reaction rate increases to a maximum and then decreases. Meanwhile at a fixed isopropylamine concentration reaction rate increases as substituted tetralone concentration increases, a result that is consistent with the results obtained previously (Section 6.2.2.2). Figure 6-33 as well as Table 6-III indicate substrate inhibition by higher concentrations of isopropylamine, but such inhibition is not considered in the general kinetic model of aminotransferases, given by Equation 14 (Section 2.1.2). The elucidation of the mechanism followed by (S)-aminotransferase CNB05-01 is the goal of the next sections. A simplified model that accounts for substrate inhibition for reversible systems of two reactants two and products when the backward reaction is negligible is given by Equation (17), which is derived in Appendix 5.

$$
v=\frac{V_{m}[A][B]}{K_{m B}[A]\left(1+\frac{[A]}{K_{i A}}\right)+K_{m A}[B]+[A][B]}
$$

where $v$ is reaction rate, $V_{m}$ is maximum velocity, $\mathrm{A}$ is isopropylamine, $\mathrm{B}$ is the substituted tetralone, $K_{m A}$ and $K_{m B}$ are the apparent substrates affinities and $K_{i A}$ is the inhibition constant of substrate A. The data shown in Table 6-III were fitted to the model given by Equation (17), by means of non-linear regression using the solver tool from Microsoft ${ }^{\circledR}$ Office Excel 2003. The values of the parameters that best described the data were $V_{m}=0.19 \mathrm{mM} / \mathrm{min}, K_{m A}=0.62 \mathrm{mM}, K_{m B}=0.01 \mathrm{mM}$, and $K_{i A}=1.22 \mathrm{mM}$. The accuracy at which the model given by Equation (17), with the values of the parameters given above, is seen by comparison of the contour plots shown in Figure 6-37, where the 
model predictions exhibit the general change in reaction rate value with change in concentration of isopropylamine and substituted tetralone.

A

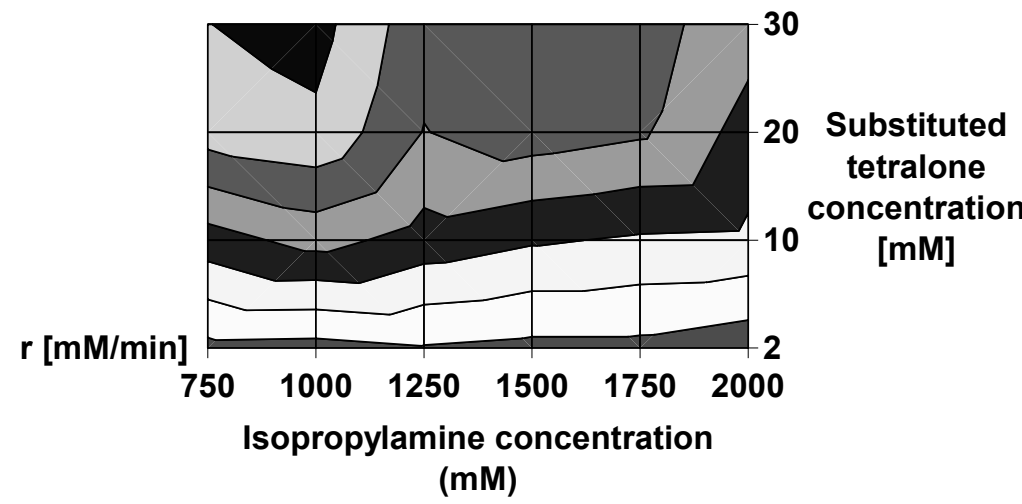

0.16-0.18

0.14-0.16

$\square 0.12-0.14$

$\square 0.1-0.12$

$0.08-0.1$

$\square$ 0.06-0.08

$\square$ 0.04-0.06

$\square$ 0.02-0.04

0-0.02

B

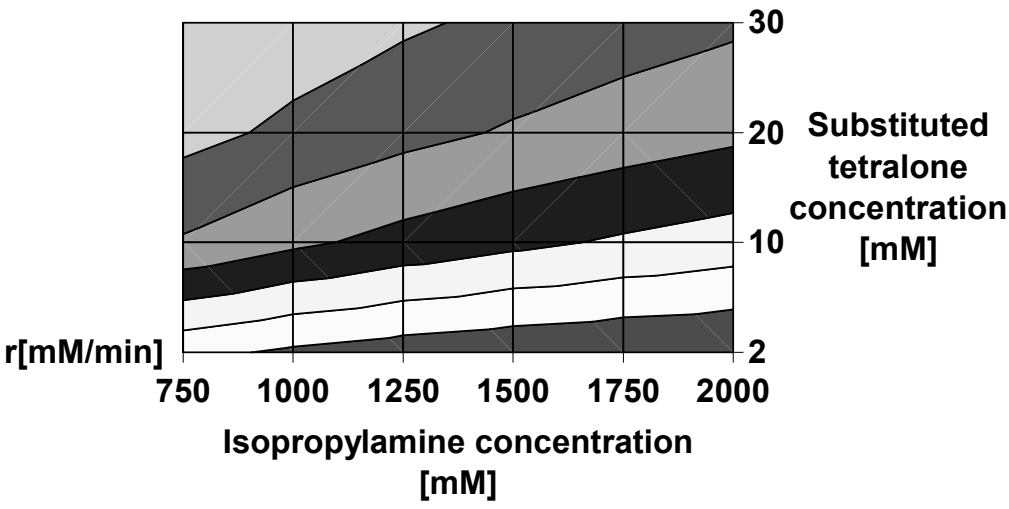

0.16-0.18

$\square$ 0.14-0.16

$\square 0.12-0.14$

$\square$ 0.1-0.12

0.08-0.1

$\square$ 0.06-0.08

0.04-0.06

0.02-0.04

0-0.02

Figure 6-37: Substrate concentration effect on reaction rate of CNB05-01. Plot A experimental data, Plot $B$ reaction rate predicted by Equation 17 with $V_{m}=0.19 \mathrm{mM} / \mathrm{min}, K_{m A}=0.62 \mathrm{mM}$, $\mathrm{K}_{\mathrm{mB}}=0.01 \mathrm{mM}$, and $\mathrm{K}_{\mathrm{iA}}=1.22 \mathrm{mM}$. 


\subsection{Rate of Reverse Reaction}

The rate of reverse reaction of (S)-aminotransferase CNB05-01 was studied at $55{ }^{\circ} \mathrm{C}$ by monitoring concentration of substituted (S)-aminotetralin, as follows. Different amounts of substituted (S)-aminotetralin [Q] and acetone [P] were added to $50 \mathrm{ml}$ of Solution 24 pH 7 (Table 3-II), and then spray dried cells were added to achieve a concentration of 1 gram per liter. Samples were withdrawn at 30,60, 90, and 120 minutes, and analyzed by HPLC to determine reaction rate. The system compositions as well as their reaction rates measured are shown in Table 6-IV.

Table 6-IV: Rate of reverse reaction at $55^{\circ} \mathrm{C}, \mathrm{pH} 7$.

\begin{tabular}{|c|c|c|}
\hline \multicolumn{2}{|c|}{ System composition } & Reaction rate \\
\hline$[\mathbf{Q}] \mathbf{( m M})$ & $[\mathbf{P}] \mathbf{( m M})$ & $\mathbf{r}[\mathbf{m M} / \mathbf{m i n}]$ \\
\hline 84.0 & 100 & $2.0 \times 10^{-3}$ \\
\hline 68.10 & 80 & 0.02 \\
\hline 50.80 & 60 & $8.0 \times 10^{-3}$ \\
\hline 34.50 & 40 & $5.0 \times 10^{-3}$ \\
\hline 18.18 & 20 & $1.2 \times 10^{-3}$ \\
\hline 63.80 & 75 & $2.0 \times 10^{-3}$ \\
\hline 50.62 & 60 & 0.02 \\
\hline 38.71 & 45 & $7.0 \times 10^{-3}$ \\
\hline 26.74 & 30 & $6.0 \times 10^{-3}$ \\
\hline 14.19 & 15 & $8.0 \times 10^{-3}$ \\
\hline
\end{tabular}

$\mathrm{Q}$ stands for substituted (S)-aminotetralin and P for acetone.

Overall, the rate of reverse reaction to form substituted tetralone was at least ten times smaller than the forward rate of reaction.

\subsection{Effect of Product Concentration on Reaction Rate}

The effect of product concentration on reaction rate of (S)-aminotransferase CNB05-01 was studied at $55^{\circ} \mathrm{C}$, as follows. There was added different amounts of substituted (S)- 
aminotetralin [Q] and/or acetone [P] to $50 \mathrm{ml}$ of Solution $18 \mathrm{pH} 7$ or Solution $23 \mathrm{pH} 7$ (Table 3-II). Spray dried cells were added to achieve a concentration of 1 gram per liter. Samples were withdrawn at 5, 10, 15, and 20 minutes, and analyzed by HPLC to determine reaction rate. The system compositions as well as their measured reaction rates for substituted (S)-aminotetralin formation are shown in Table 6-V.

Table 6-V: Effect of product concentration on reaction rate.

\begin{tabular}{|c|c|c|c|c|}
\hline \multicolumn{4}{|c|}{ System composition } & Reaction rate \\
\hline$[\mathbf{A}](\mathbf{m M})$ & {$[\mathrm{B}](\mathbf{m M})$} & {$[\mathrm{Q}](\mathbf{m M})$} & {$[\mathbf{P}](\mathbf{m M})$} & $\mathbf{r}[\mathrm{mM} / \mathbf{m i n}]$ \\
\hline 750 & 30 & 20 & 30 & 0.04 \\
\hline 750 & 30 & 30 & 20 & $-7.0 \times 10^{-3}$ \\
\hline 750 & 30 & 40 & 40 & 0.20 \\
\hline 750 & 30 & 0 & 40 & 0.12 \\
\hline 750 & $130^{(1)}$ & 20 & 30 & 0.04 \\
\hline 750 & $130^{(1)}$ & 30 & 20 & 0.03 \\
\hline 750 & $130^{(1)}$ & 40 & 40 & 0.03 \\
\hline 750 & $130^{(1)}$ & 50 & 0 & 0.02 \\
\hline 750 & $130^{(1)}$ & 0 & 50 & 0.11 \\
\hline
\end{tabular}

A stands for isopropylamine, B for substituted tetralone, Q for substituted (S)-aminotetralin, P for acetone, and $\mathrm{r}$ for reaction rate.

(1) Total concentration of B, B solubility at $55^{\circ} \mathrm{C}$ is $33-35 \mathrm{mM}$.

From Table 6-V it seems that the addition of substituted (S)-aminotetralin [Q] has a larger effect on decreasing activity than acetone $[\mathrm{P}]$. Then, the results in Table 6-V when comined with Table 6-IV suggest that substituted (S)-aminotetralin may cause product inhibition during its synthesis.

\subsection{Kinetic model of CNB05-01}

This chapter has presented the use of $\mathrm{CNB} 05-01$ at $55{ }^{\circ} \mathrm{C}, \mathrm{pH} \mathrm{7}$, spray dried cells of concentration of 1 gram per liter, $200 \mathrm{mM}$ sodium acetate, and concentration of pyridoxal-5-phosphate of $2 \mathrm{mM}$. Such conditions are the optimum for CNB05-01. The 
analysis of all of these experiments at once will allow developing a model of the kinetics of this mutant (S)-aminotransferase, which would describe its activity under the mentioned conditions. The information of CNB05-01 obtained under the conditions specified above is shown in Table 6-VI.

Table 6-VI: Kinetic information of CNB05-01 obtained at $55{ }^{\circ} \mathrm{C}$, $\mathrm{pH} 7$, at a concentration of 1 gram per liter of it and $2 \mathrm{mM}$ pyridoxal-5-phosphate.

\begin{tabular}{|c|c|c|c|c|c|}
\hline \multicolumn{4}{|c|}{ System composition (mM) } & \multirow[b]{2}{*}{$\mathbf{r}[\mathrm{mM} / \mathrm{min}]$} & \multirow[b]{2}{*}{ Section source } \\
\hline$[\mathrm{A}]$ & {$[\mathrm{B}]$} & [Q] & {$[\mathrm{P}]$} & & \\
\hline 750 & 0.7 & 0 & 0 & 0.02 & 6.2 .2 .2 .2 \\
\hline 750 & 2 & 0 & 0 & 0.04 & 6.2 .2 .2 .2 \\
\hline 750 & 4 & 0 & 0 & 0.06 & 6.2 .2 .2 .2 \\
\hline 750 & 6 & 0 & 0 & 0.08 & 6.2 .2 .2 .2 \\
\hline 750 & 8 & 0 & 0 & 0.09 & 6.2 .2 .2 .2 \\
\hline 750 & 10 & 0 & 0 & 0.09 & 6.2 .2 .2 .2 \\
\hline 750 & 12 & 0 & 0 & 0.11 & 6.2 .2 .2 .2 \\
\hline 750 & 14 & 0 & 0 & 0.13 & 6.2 .2 .2 .2 \\
\hline 750 & 16 & 0 & 0 & 0.14 & 6.2 .2 .2 .2 \\
\hline 750 & 21 & 0 & 0 & 0.15 & 6.2 .2 .2 .2 \\
\hline 750 & 25 & 0 & 0 & 0.16 & 6.2 .2 .2 .2 \\
\hline 750 & 30 & 0 & 0 & 0.16 & 6.2 .2 .2 .2 \\
\hline 2000 & 0.7 & 0 & 0 & $8.0 \times 10^{3}$ & \\
\hline 2000 & 2 & 0 & 0 & 0.03 & \\
\hline 2000 & 4 & 0 & 0 & 0.05 & \\
\hline 2000 & 6 & 0 & 0 & 0.06 & \\
\hline 2000 & 8 & 0 & 0 & 0.07 & \\
\hline 2000 & 10 & 0 & 0 & 0.08 & \\
\hline 2000 & 12 & 0 & 0 & 0.11 & \\
\hline 2000 & 14 & 0 & 0 & 0.12 & \\
\hline 2000 & 16 & 0 & 0 & 0.09 & \\
\hline 2000 & 21 & 0 & 0 & 0.10 & \\
\hline 2000 & 25 & 0 & 0 & 0.11 & \\
\hline 750 & 30 & 0 & 0 & 0.04 & 6.2 .2 .4 .2 \\
\hline 1000 & 2 & 0 & 0 & 0.03 & 6.2 .2 .4 .2 \\
\hline 1250 & 2 & 0 & 0 & 0.04 & 6.2 .2 .4 .2 \\
\hline 1500 & 2 & 0 & 0 & 0.04 & 6.2 .2 .4 .2 \\
\hline 1750 & 2 & 0 & 0 & 0.04 & 6.2 .2 .4 .2 \\
\hline 2000 & 2 & 0 & 0 & 0.03 & 6.2 .2 .4 .2 \\
\hline 750 & 10 & 0 & 0 & 0.09 & 6.2 .2 .4 .2 \\
\hline 1000 & 10 & 0 & 0 & 0.11 & 6.2 .2 .4 .2 \\
\hline 1250 & 10 & 0 & 0 & 0.09 & 6.2 .2 .4 .2 \\
\hline
\end{tabular}




\begin{tabular}{|c|c|c|c|c|c|}
\hline 1500 & 10 & 0 & 0 & 0.08 & 6.2 .2 .4 .2 \\
\hline 1750 & 10 & 0 & 0 & 0.08 & 6.2 .2 .4 .2 \\
\hline 2000 & 10 & 0 & 0 & 0.08 & 6.2 .2 .4 .2 \\
\hline 750 & 20 & 0 & 0 & 0.15 & 6.2 .2 .4 .2 \\
\hline 1000 & 20 & 0 & 0 & 0.16 & 6.2 .2 .4 .2 \\
\hline 1250 & 20 & 0 & 0 & 0.12 & 6.2 .2 .4 .2 \\
\hline 1500 & 20 & 0 & 0 & 0.13 & 6.2 .2 .4 .2 \\
\hline 1750 & 20 & 0 & 0 & 0.12 & 6.2 .2 .4 .2 \\
\hline 2000 & 20 & 0 & 0 & 0.09 & 6.2 .2 .4 .2 \\
\hline 750 & 30 & 0 & 0 & 0.16 & 6.2 .2 .4 .2 \\
\hline 1000 & 30 & 0 & 0 & 0.17 & 6.2 .2 .4 .2 \\
\hline 1250 & 30 & 0 & 0 & 0.13 & 6.2 .2 .4 .2 \\
\hline 1500 & 30 & 0 & 0 & 0.14 & 6.2 .2 .4 .2 \\
\hline 1750 & 30 & 0 & 0 & 0.13 & 6.2 .2 .4 .2 \\
\hline 2000 & 30 & 0 & 0 & 0.11 & 6.2 .2 .4 .2 \\
\hline 320 & $130^{(1)}$ & 0 & 0 & 0.15 & 6.2 .2 .4 .2 \\
\hline 440 & $130^{(1)}$ & 0 & 0 & 0.16 & 6.2 .2 .4 .2 \\
\hline 760 & $130^{(1)}$ & 0 & 0 & 0.18 & 6.2 .2 .4 .2 \\
\hline 1520 & $130^{(1)}$ & 0 & 0 & 0.14 & 6.2 .2 .4 .2 \\
\hline 2000 & $130^{(1)}$ & 0 & 0 & 0.13 & 6.2 .2 .4 .2 \\
\hline 15 & $130^{(1)}$ & 0 & 0 & 0.05 & 6.2 .2 .4 .2 \\
\hline 120 & $130^{(1)}$ & 0 & 0 & 0.12 & 6.2 .2 .4 .2 \\
\hline 225 & $130^{(1)}$ & 0 & 0 & 0.14 & 6.2 .2 .4 .2 \\
\hline 330 & $130^{(1)}$ & 0 & 0 & 0.15 & 6.2 .2 .4 .2 \\
\hline 435 & $130^{(1)}$ & 0 & 0 & 0.17 & 6.2 .2 .4 .2 \\
\hline 540 & $130^{(1)}$ & 0 & 0 & 0.17 & 6.2 .2 .4 .2 \\
\hline 645 & $130^{(1)}$ & 0 & 0 & 0.18 & 6.2 .2 .4 .2 \\
\hline 750 & $130^{(1)}$ & 0 & 0 & 0.17 & 6.2 .2 .4 .2 \\
\hline 840 & $130^{(1)}$ & 0 & 0 & 0.16 & 6.2 .2 .4 .2 \\
\hline 1000 & $130^{(1)}$ & 0 & 0 & 0.17 & 6.2 .2 .4 .2 \\
\hline 1200 & $130^{(1)}$ & 0 & 0 & 0.18 & 6.2 .2 .4 .2 \\
\hline 1840 & $130^{(1)}$ & 0 & 0 & 0.12 & 6.2 .2 .4 .2 \\
\hline 0 & 0 & 84 & 100 & $-3.0 \times 10^{-3}$ & 6.2 .2 .4 .3 \\
\hline 0 & 0 & 68 & 80 & -0.02 & 6.2 .2 .4 .3 \\
\hline 0 & 0 & 51 & 60 & -0.01 & 6.2 .2 .4 .3 \\
\hline 0 & 0 & 35 & 40 & $-5.0 \times 10^{-3}$ & 6.2 .2 .4 .3 \\
\hline 0 & 0 & 18 & 20 & -0.01 & 6.2 .2 .4 .3 \\
\hline 0 & 0 & 64 & 75 & $-2.0 \times 10^{-3}$ & 6.2 .2 .4 .3 \\
\hline 0 & 0 & 51 & 60 & -0.02 & 6.2 .2 .4 .3 \\
\hline 0 & 0 & 39 & 45 & $-7.0 \times 10^{-3}$ & 6.2 .2 .4 .3 \\
\hline 0 & 0 & 27 & 30 & $-6.0 \times 10^{-3}$ & 6.2 .2 .4 .3 \\
\hline 0 & 0 & 14 & 15 & -0.01 & 6.2 .2 .4 .3 \\
\hline 750 & 30 & 20 & 30 & 0.04 & 6.2 .2 .4 .4 \\
\hline 750 & 30 & 0 & 40 & 0.12 & 6.2 .2 .4 .4 \\
\hline 750 & 130 & 20 & 30 & 0.04 & 6.2 .2 .4 .4 \\
\hline 750 & 130 & 30 & 20 & 0.03 & 6.2 .2 .4 .4 \\
\hline 750 & 130 & 40 & 40 & 0.03 & 6.2 .2 .4 .4 \\
\hline 750 & 130 & 50 & 0 & 0.02 & 6.2 .2 .4 .4 \\
\hline 750 & 130 & 0 & 50 & 0.11 & 6.2 .2 .4 .4 \\
\hline
\end{tabular}

A stands for isopropylamine, B for substituted tetralone, Q for substituted (S)-aminotetralin, P for acetone, and $\mathrm{r}$ for reaction rate.

(1) Total concentration of B, B solubility at $55^{\circ} \mathrm{C}$ is $33-35 \mathrm{mM}$. 
The information of Table 6-VI was analyzed by four models. Among them Model 3 (Equation (20)) that correspond to the ping pong Bi Bi mechanism derived in Section 2.1.2. Since this model does not account for some of the phenomenon obserbed (substrate and product inhibition by $\mathrm{A}$ and $\mathrm{Q}$, respectively) another variations of the $\mathrm{Bi} \mathrm{Bi}$ mechanisms were considered, among them Model 4 (Equation (21)) has terms that accounts directly for substrate inhibition $\left[\mathrm{v}^{\mathrm{r}}{ }_{\max } \mathrm{k}_{\mathrm{m}} \mathrm{A}\left(1+\mathrm{A} / \mathrm{k}_{\mathrm{iA}}\right)\right]$ and product inhibition $\left[\mathrm{v}_{\text {max }}^{\mathrm{f}}\left(\mathrm{K}_{\mathrm{mp}} / \mathrm{K}_{\mathrm{eq}}\right) \mathrm{Q}\left(1+\mathrm{Q} / \mathrm{K}_{\mathrm{iQ}}\right)\right]$. The data was analyzed by fitting models 1-4 using non linear regression from Microsoft Office Excel 2003 (Appendix 5). During the determination of the best model that describes the data, some of the parameters were allowed to fluctuate around values determined experimentally. These parameters were the forward rate of reaction evaluated between $0.1-0.25 \mathrm{mM} / \mathrm{min}$, reverse rate of reaction evaluated between $0.001-0.02 \mathrm{mM} / \mathrm{min}$, substrate inhibition constant for isopropylamine evaluated between 1-1500 mM, affinity for substituted tetralone evaluated between 1-20 $\mathrm{mM}$, and affinity for isopropylamine evaluated between 1-150 $\mathrm{mM}$. The equilibrium constant was fixed at 0.33 , since it was measured experimentally (Table 9-IV). The rest of the constants regarding to acetone $[\mathrm{P}]$ and substituted (S)-aminotetralin $[\mathrm{Q}]$ were left without other restriction besides being positive or zero. 
Model 1: Ordered Bi Bi system (Equation 18).

$$
\begin{aligned}
v= & \frac{v_{\max }^{f} v_{\max }^{r}\left((A)(B)-\frac{(P)(Q)}{K e q}\right)}{v_{\max }^{r} K_{i a} K_{m B}+v_{\max }^{r} K_{m B}(A)+v_{\max }^{r} K_{m A}(B)+v_{\max }^{f} \frac{K_{m Q}}{K e q}(P)+v_{\max }^{f} \frac{K_{m P}}{K e q}(Q)} \\
& +v_{\max }^{r}(A)(B)+\frac{v_{\max }^{f} K_{m Q}}{K e q K_{i a}}(A)(P)+\frac{v_{\max }^{f}}{K e q}(P)(Q)+\frac{v_{\text {max }}^{r} K_{m A}}{K_{i q}}(B)(Q) \\
& +\frac{v_{\max }^{r}}{K_{i p}}(A)(B)(P)+\frac{v_{\max }^{f}}{K_{i b} K e q}(B)(P)(Q)
\end{aligned}
$$

Model 2: Ordered Bi Bi System with rapid equilibrium (Equation 19).

$$
\begin{aligned}
& v=\frac{v_{\max }^{f} v_{\max }^{r}\left((A)(B)-\frac{(P)(Q)}{K e q}\right)}{v_{\max }^{r} K_{i a} K_{m B}+v_{\max }^{r} K_{m B}(A)+v_{\max }^{r} K_{m A}(B)+v_{\max }^{f} \frac{K_{m Q}}{K e q}(P)+v_{\max }^{f} \frac{K_{m P}}{K e q}(Q)} \\
& +v_{\max }^{r}(A)(B)+\frac{v_{\max }^{f} K_{m Q}}{K_{e q} K_{i a}}(A)(P)+\frac{v_{\max }^{r} K_{m A}}{K_{i q}}(B)(Q)+\frac{v_{\max }^{f}}{K e q}(P)(Q)
\end{aligned}
$$

Model 3: Bi Bi system with product release between the additions of the two substrates (Equation 20).

$$
\begin{aligned}
& v=\frac{v_{\max }^{f} v_{\max }^{r}\left((A)(B)-\frac{(P)(Q)}{K e q}\right)}{v_{\max }^{r} K_{m B}(A)+v_{\max }^{r} K_{m A}(B)+v_{\max }^{f} \frac{K_{m Q}}{K e q}(P)+v_{\max }^{f} \frac{K_{m P}}{K e q}(Q)} \\
& +v_{\max }^{r}(A)(B)+\frac{v_{\max }^{f} K_{m Q}}{K_{e q} K_{i a}}(A)(P)+\frac{v_{\max }^{f}}{K e q}(P)(Q)+\frac{v_{\max }^{r} K_{m A}}{K_{i q}}(B)(Q)
\end{aligned}
$$


Model 4: Bi Bi system with product release between the additions of the substrates and inhibition by substrate and product (Equation 21).

$$
\begin{aligned}
v= & \frac{v_{\max }^{f} v_{\max }^{r}\left((A)(B)-\frac{(P)(Q)}{K e q}\right)}{v_{\max }^{r} K_{m B}(A)\left(1+\frac{(A)}{K_{i A}}\right)+v_{\max }^{r} K_{m A}(B)+v_{\max }^{f} \frac{K_{m Q}}{K e q}(P)+v_{\max }^{f} \frac{K_{m P}}{K e q}(Q)\left(1+\frac{(Q)}{K_{i Q}}\right)} \\
& +v_{\max }^{r}(A)(B)+\frac{v_{\max }^{f} K_{m Q}}{K e q K_{i A}}(A)(P)+\frac{v_{\max }^{f}}{K e q}(P)(Q)+\frac{v_{\max }^{r} K_{m A}}{K_{i Q}}(B)(Q)
\end{aligned}
$$

A stands for isopropylamine, B for substituted tetralone, Q for substituted (S)aminotetralin, and $\mathrm{P}$ for acetone. The best description of the data shown in Table 6-VI was given by Model 4 (Equation 21). Parameter values of Model 4 are reported on Table 6-VII. Correlation of experimental reaction rate with predicted reaction rate by Model 4 are shown in Figure 6-38.

In Table 6-VII $v_{\max }^{f}$ is the forward rate of reaction, $v_{\max }^{r}$ is the reverse rate of reaction, Keq is the equilibrium constant, $K_{i A}$ is inhibition constant of isopropylamine [A], $K_{i Q}$ is the inhibition constant of substituted (S)-aminotetralin, and $K_{m A}, K_{m B}, K_{m P}$ and $K_{m Q}$ are the affinities for isopropylamine $[\mathrm{A}]$, substituted tetralone $[\mathrm{B}]$, acetone $[\mathrm{P}]$ and substituted (S)-aminotetralin [Q], respectively. 
Table 6-VII: Parameter values of Model 4.

\begin{tabular}{|c|c|c|c|}
\hline Combined parameter & Value & Individual parameter & Value \\
\hline$v_{\max }^{f} v_{\max }^{r}$ & $3.0 \times 10^{-3}(\mathrm{mM} / \mathrm{min})^{2}$ & $v_{\max }^{f}$ & $0.21(\mathrm{mM} / \mathrm{min})$ \\
\hline Keq & 0.33 & $v_{\max }^{r}$ & $0.02(\mathrm{mM} / \mathrm{min})$ \\
\hline$v_{\max }^{r} K_{m B}$ & $0.03\left(\mathrm{mM}^{2} / \mathrm{min}\right)$ & Keq & 0.33 \\
\hline$K_{i A}$ & $200.10(\mathrm{mM})$ & $K_{m B}$ & $1.72(\mathrm{mM})$ \\
\hline$v_{\max }^{r} K_{m A}$ & $0.66\left(\mathrm{mM}^{2} / \mathrm{min}\right)$ & $K_{i A}$ & $200.10(\mathrm{mM})$ \\
\hline$v_{\max }^{f} \frac{K_{m Q}}{K e q}$ & $0.29\left(\mathrm{mM}^{2} / \mathrm{min}\right)$ & $K_{m A}$ & $42.59(\mathrm{mM})$ \\
\hline$v_{\max }^{f} \frac{K_{m P}}{K e q}$ & $9.59\left(\mathrm{mM}^{2} / \mathrm{min}\right)$ & $K_{m Q}$ & $0.45(\mathrm{mM})$ \\
\hline$K_{i Q}$ & $6.93(\mathrm{mM})$ & $K_{m P}$ & $14.95(\mathrm{mM})$ \\
\hline$v_{\max }^{r}$ & $0.02(\mathrm{mM} / \mathrm{min})$ & $K_{i Q}$ & $6.93(\mathrm{mM})$ \\
\hline$\frac{v_{\max }^{f} K_{m Q}}{K e q K_{i A}}$ & $1.0 \times 10^{-3}(\mathrm{mM} / \mathrm{min})$ & & \\
\hline$\frac{v_{\max }^{f}}{K e q}$ & $0.64(\mathrm{mM} / \mathrm{min})$ & & \\
\hline$\frac{v_{\max }^{r} K_{m A}}{K_{i Q}}$ & $0.10(\mathrm{mM} / \mathrm{min})$ & & \\
\hline
\end{tabular}

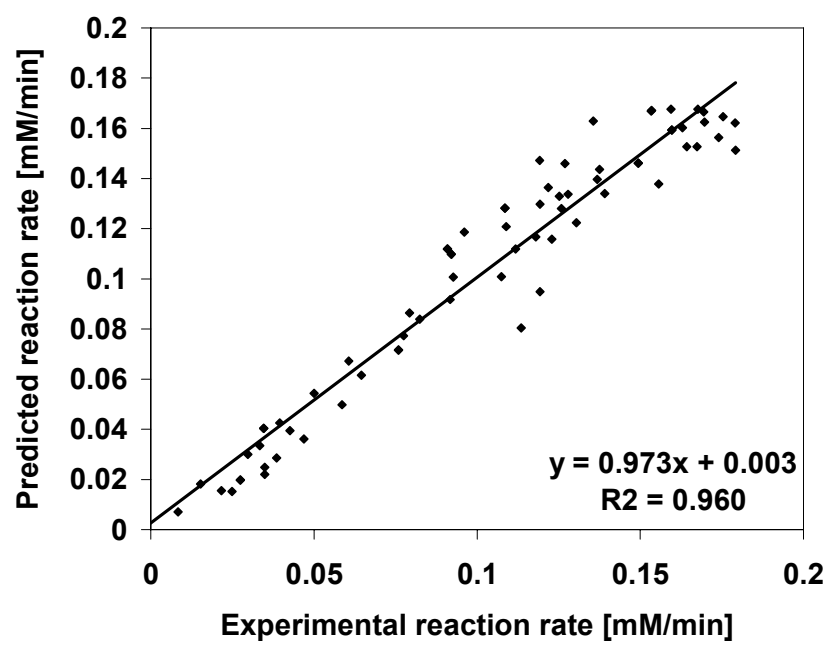

Figure 6-38: Correlation between experimental reaction rate and predicted by Model 4 at 55 ${ }^{\circ} \mathrm{C}$, pH 7, enzyme concentration of one gram per liter, and 2 mM pyridoxal-5-phosphate. 
Figure 6-38 shows an acceptable description of the experimental data by the reaction rates predicted by Model 4, using the parameters values of Table 6-VII. The data fitted by Model 4 account for the effects of isopropylamine [A] and substituted tetralone concentration [B], initial concentration of product (substituted (S)-aminotetralin [Q] and acetone $[\mathrm{P}]$ ), and the rate of reverse reaction (reaction between substituted (S)aminotetralin and acetone). The values of reaction rates used to estimate the parameters of Model 4 were obtained under differential conversion of soluble tetralone. Then the maximum concentration of substituted (S)-aminotetralin after 20 minutes was not higher than $3 \mathrm{mM}$. By means of the experiments done it was possible to summarize the two major processes in the system by mathematical models: the effect of cofactor concentration and the effect of substrates and product concentration -Equation (21) with the parameters values of Table 6-VII.

During the production of substituted (S)-aminotetralin, the reaction between substituted tetralone is not the only one taking place. Also, because of the nature of the system that has ketones and amines, imine formation is possible. The presence of this reaction (imine formation) occurring in parallel to the desired reaction has little or no effect in the model obtained for CNB05-01, since imine formation early on the reaction (up to 20 minutes) is negligible (Section 9.2). An imine is a compound containing a carbon-nitrogen double bound, formed by a ketone or aldehyde with an amine. In the system under study there are two ketones, substituted tetralone (substrate) and acetone (product), and one aldehyde [pyridoxal-5-phosphate], and two amines, substituted (S)-aminotetralin (product) and 
isopropylamine (substrate). Therefore six imines may be formed. These six imines may be formed by the following reactions.

I. Reaction between substituted tetralone and isopropylamine.

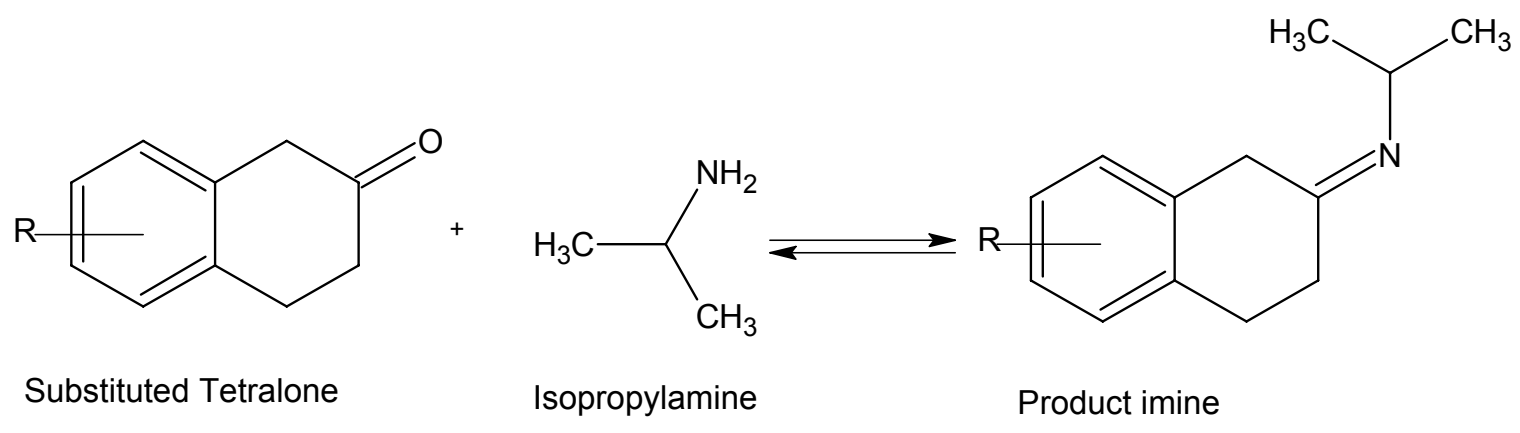

II. Reaction between substituted tetralone and substituted (S)-aminotetralin (Chapter 9).

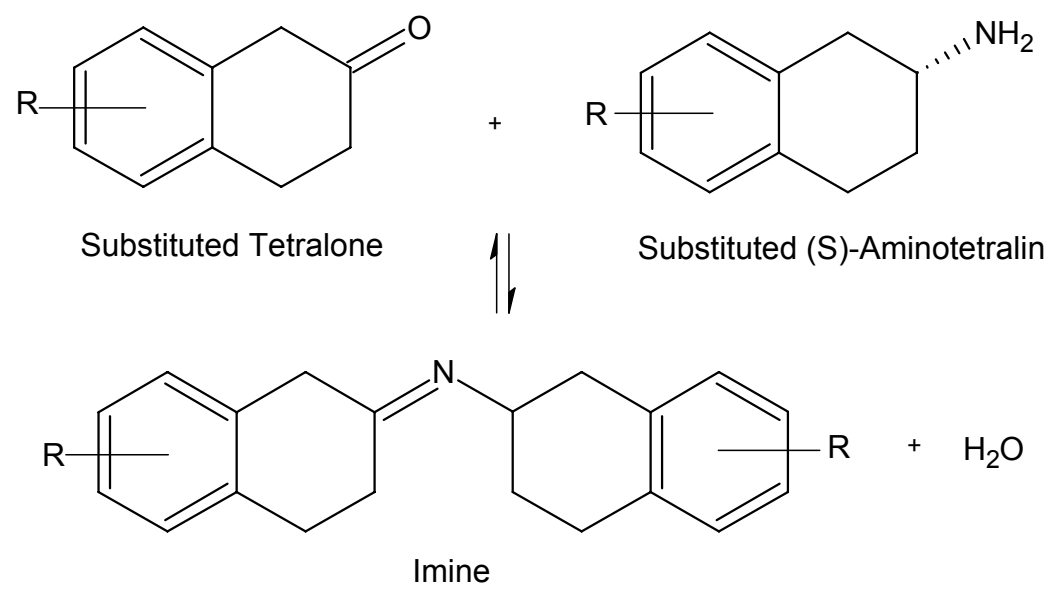


III. Reaction between acetone and isopropylamine.<smiles>CC(C)=O</smiles>

Acetone<smiles>CCCCCCC(C)N</smiles>

Isopropylamine

Product imine

IV. Reaction between substituted (S)-aminotetralin and acetone.<smiles>[R]c1ccc2c(c1)CCC(N=C(C)C)C2</smiles>

Substituted (S)-Aminotetralin

Acetone

Product imine

V. Reaction between pyridoxal-5-phosphate and isopropylamine in the bulk system, since both substances react within the enzyme environment.<smiles>Cc1ncc(COP(=O)(O)O)c(C=O)c1O</smiles>

Pyridoxal-5-phosphate<smiles>Cc1ncc(COP(=O)(O)O)c(C=NC(C)C)c1O</smiles>

Isopropylamine

Product imine 
VI. Reaction between pyridoxal-5-phosphate and substituted (S)-aminotetralin in the bulk system, since both substances react within the enzyme environment.

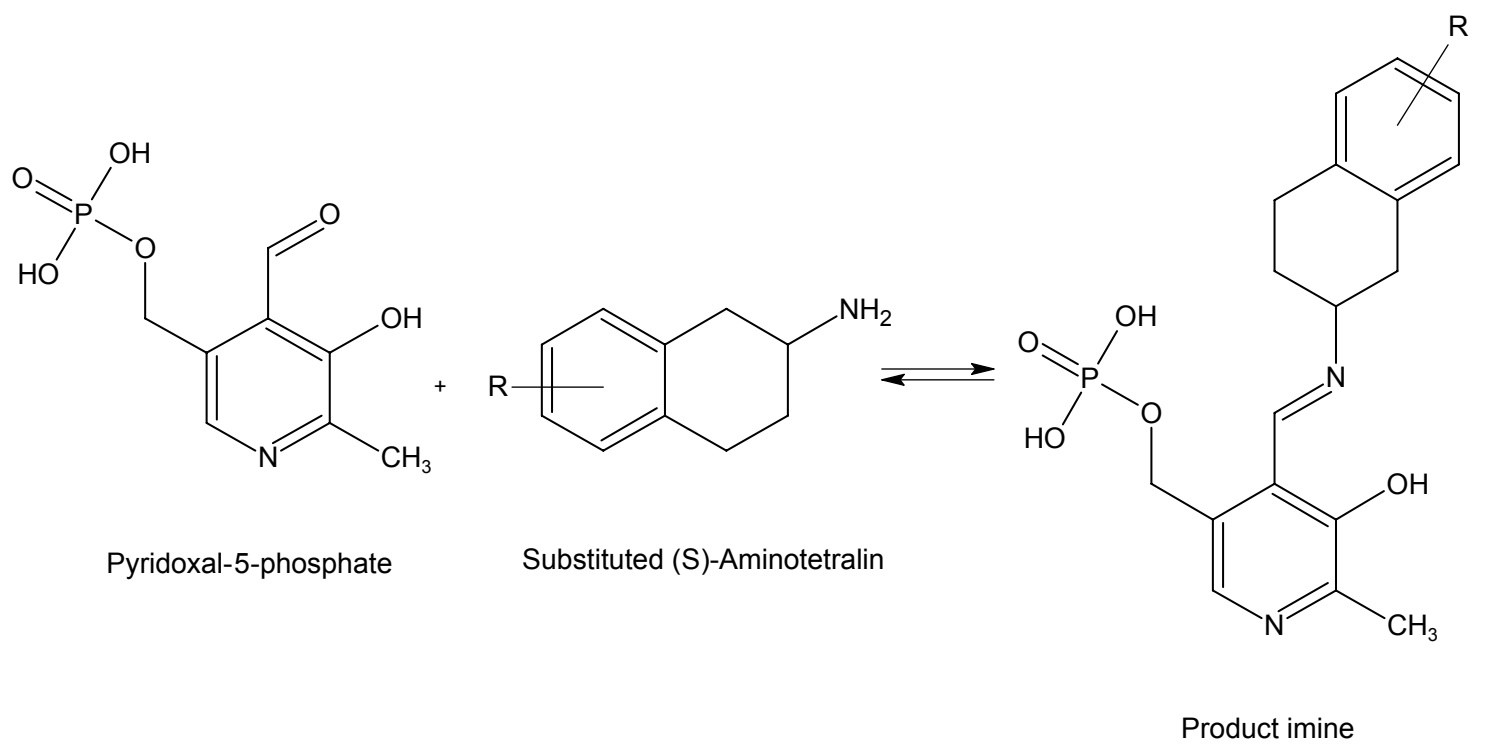

The effect of these reactions, if any, may be a subject of future research on transamination reaction. The concentration of pyridoxal-5-phosphate in solution is $2 \mathrm{mM}$, isopropylamine $750 \mathrm{mM}$, and substituted (S)-aminotetralin concentration would be up to $80 \mathrm{mM}$. Then it is obvious that if reaction V or VI proceeds, they might consume a high percent of pyridoxal-5-phosphate, withdrawing at some extent pyridoxal-5-phosphate from the complex enzyme-(pyridoxal-5-phosphate), causing therefore enzyme activity to decrease.

Chapter 7 and Chapter 8 show the effects of improvements on thermostability (Chapter 7) and activity (Chapter 8) in the production of substituted (S)-aminotetralin, under their optimum conditions determined in Chapter 6. It presents the effects categorized in two ways: the improvements on production of the desired product while applying immobilization and the improvements by using a mutant with higher activity. 


\section{Chapter 7. Effect of Immobilized (S)-Aminotransferase with Improved Thermostability in the Production of Substituted (S)-Aminotetralin}

This chapter and Chapter 8 show the effects of improvements on thermostability (Chapter 7) and activity (Chapter 8) in the production of substituted (S)-aminotetralin in long duration experiments, under their optimum conditions determined in Chapter 6 where initial rate experiments were conducted. It presents the effects categorized in two ways: the improvements on production of the desired product while applying immobilization and the improvements by using a mutant with higher activity as free enzyme.

\subsection{Immobilized CNB03-03}

In order to test for activity upon recycle of bead-immobilized enzyme (as described in Chapter 4), the following experiments were conducted. Four hundred ml of Solution 10 (Table 3-II) was incubated at $50{ }^{\circ} \mathrm{C}$ and 70 grams of immobilized CNB03-03 of concentration $50 \mathrm{mg}$ of spray dried cells/g were added, whose effectiveness factor was 0.35 (Section 4.4). After a certain time the beads were removed and fresh reaction mixture was added immediately. Results are shown in Figure 7-1 and Figure 7-2.

Figure 7-1 and Figure 7-2 shows a fast decrease of enzymatic activity for immobilized CNB03-03 during recycle at $50{ }^{\circ} \mathrm{C}$. During the first cycle (R1) initial rate was 0.26 $\mathrm{mM} / \mathrm{min}$, at the start of R2 (after 6 hours) it was $0.11 \mathrm{mM} / \mathrm{min}(43 \%$ of initial rate at $\mathrm{t}=0)$; and after 20 hours at the beginning of $\mathrm{R} 3,0.02 \mathrm{mM} / \mathrm{min}(8 \%$ of initial rate at $\mathrm{t}=0)$. The overall production of substituted (S)-aminotetralin shown in Figure 7-1 is described by Equation (21) over the entire time course of the experiments. 


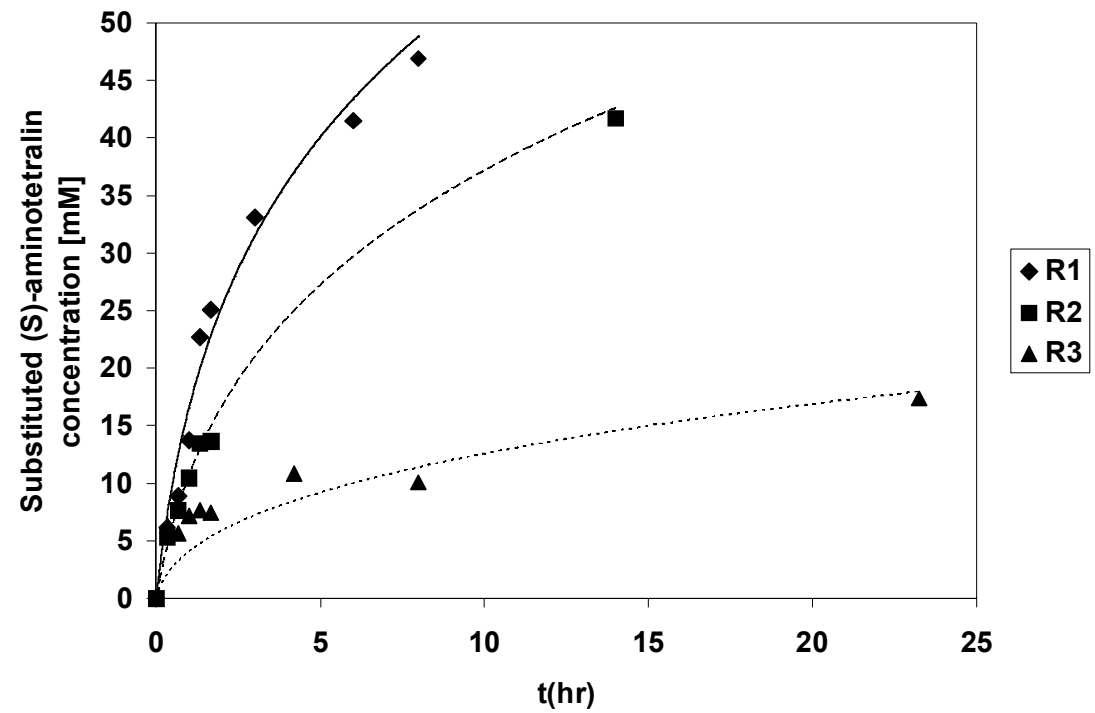

Figure 7-1: Production of substituted (S)-aminotetralin using immobilized CNB03-03 during recycle at $50{ }^{\circ} \mathrm{C}$.

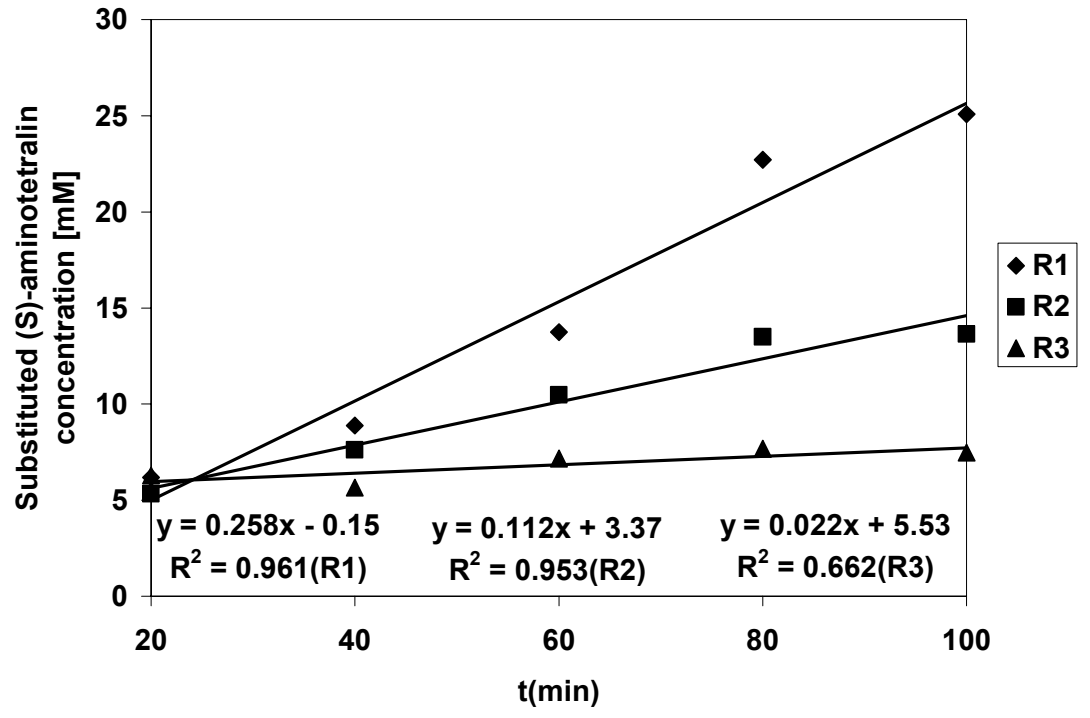

Figure 7-2: Initial rate of $\mathrm{CNB03-03}$ during recycle at $50^{\circ} \mathrm{C}$.

The experimental data of the first recycle (R1) is described by the continuous trend, the second recycle (R2) by the hyphened trend, and R3 by the doted line when Equation (21) is fitted to the parameters shown in Table 7-I obtained as described in Appendix 6, for each case repectively. 
Table 7-I: Kinetic parameters of immobilized $\mathrm{CNB03-03}$ at $50^{\circ} \mathrm{C}$

\begin{tabular}{|l|c|c|c|}
\hline Parameter & R1 & R2 & R3 \\
\hline$v_{\max }^{f}(\mathbf{m M} / \mathbf{h r})$ & 38.42 & 24.00 & 20.00 \\
\hline$v_{\max }^{r}(\mathbf{m M} / \mathbf{h r})$ & 6.72 & 2.23 & 0.10 \\
\hline$K e q$ & 0.40 & 0.40 & 0.40 \\
\hline$K_{m B}(\mathbf{m M})$ & 2.13 & 2.13 & 2.13 \\
\hline$K_{i A}(\mathbf{m M})$ & 200.60 & 200.60 & 200.60 \\
\hline$K_{m A}(\mathbf{m M})$ & 33.16 & 33.16 & 33.16 \\
\hline$K_{m Q}(\mathbf{m M})$ & 10.87 & 10.87 & 10.87 \\
\hline$K_{m P}(\mathbf{m M})$ & 6.87 & 6.87 & 6.87 \\
\hline$K_{i Q}(\mathbf{m M})$ & 1.44 & 1.44 & 1.44 \\
\hline
\end{tabular}

Under the experimental conditions $\left(50^{\circ} \mathrm{C}\right)$ solubility of $B$ was $27 \mathrm{mM}$, being $B$ concentration always $27 \mathrm{mM}$ during the recycling experimnents. $V^{\mathrm{f}} \max$ obtained from Figure 7-1 and Figure 7-2 differ because only initial data is used for Figure 7-2 whereas all of the data is used from Figure 7-1.

Table 7-I shows the parameters that best describe the performance of immobilized CNB03-03 at $50^{\circ} \mathrm{C}$. The values of $v_{\max }^{f}$ and $v_{\max }^{r}$ decrease but not in the same way as the reaction rates shown in Figure 7-2. Reaction rate of cycle 2 (R2) was $43 \%$ of the original value, and reaction rate of cycle $3(\mathrm{R} 3)$ was $8 \%$. The values of $v_{\max }^{f}$ during the second and third cycle were 62 and $52 \%$ of the original value. The kinetic parameters shown in Table 7-I for CNB03-03 strongly differs from the parameters of CNB05-01 shown in Table 6-VII in the values of $K_{m Q}$ (from $10.87 \mathrm{mM}$ in CNB03-03 to $0.45 \mathrm{mM}$ in CNB05-01 as a result of enzyme engineering) and $K_{i Q}$ (from $1.44 \mathrm{mM}$ in CNB03-03 to $6.93 \mathrm{mM}$ in CNB05-01). The high value of $K_{m Q}$ for CNB03-03 implies that it has poor affinity for Q in comparison to $\mathrm{CNB} 05-01$.

Figure 7-1 and Figure 7-2 shows that immobilized CNB03-03 have a poor operational stability upon extended use during recycle. Activity is one of the most important factors 
affecting the success of commercialization for an immobilized enzyme system. Some cases of immobilized enzymes with operational stability of activity good enough that allows applications at industrial scale are the following.

a). A column of immobilized invertase prepared by diazo binding with porous glass still retained full initial activity after 28 days of continuous operation at $23{ }^{\circ} \mathrm{C}$ with $20 \%$ sucrose solution (Mason and Weetall, 1972).

b). A column of potato phosphorylase prepared by means of glutaraldehyde on porous glass had $50 \%$ activity remaining after 28 days of continuous operation at $45{ }^{\circ} \mathrm{C}$ with 0.01 M D-glucosylphosphate (Marshall and Walter, 1972).

From the examples above, it is seen that a long term operational stability of activity is required in order for immobilized enzyme to be implemented on an industrial scale. The productivity of an immobilized enzyme must generate profits, therefore the productivity may be enough to cover the cost of carrier, immobilization reagents, and immobilization procedure. In order to use immobilized CNB03-03 at an industrial scale, 10 cycles of 24 hours each one would be required (Information obtained from Cambrex Corporation, no supporting information is shown), therefore it did not match the requirements. An (S)aminotransferase with improved operational stability (considered directly proportional to thermostability) may be necessary to perform the synthesis of substituted (S)aminotetralin in immobilized state at industrial scale. 


\subsection{Immobilized CNB04-01}

Mutant CNB04-01 was compared with mutant CNB03-03 as follows. Two hundred $\mathrm{ml}$ of Solution 14 at $\mathrm{pH} 7$ (Table 3-II) was incubated at $50{ }^{\circ} \mathrm{C}$. After reaching the desired temperature 35 grams of immobilized CNB04-01 was added consisting of $50 \mathrm{mg}$ of spray dried cells per gram of beads, whose effectiveness factor was approximately 0.35 (Section 4.4). Initial rate was measured and the immobilized CNB04-01 was left under the reaction condition about 20 hours. Periodically the reaction mixture was replaced with fresh reaction mixture and reaction rate was measured again. The values of initial reaction rate are shown in Figure 7-3.

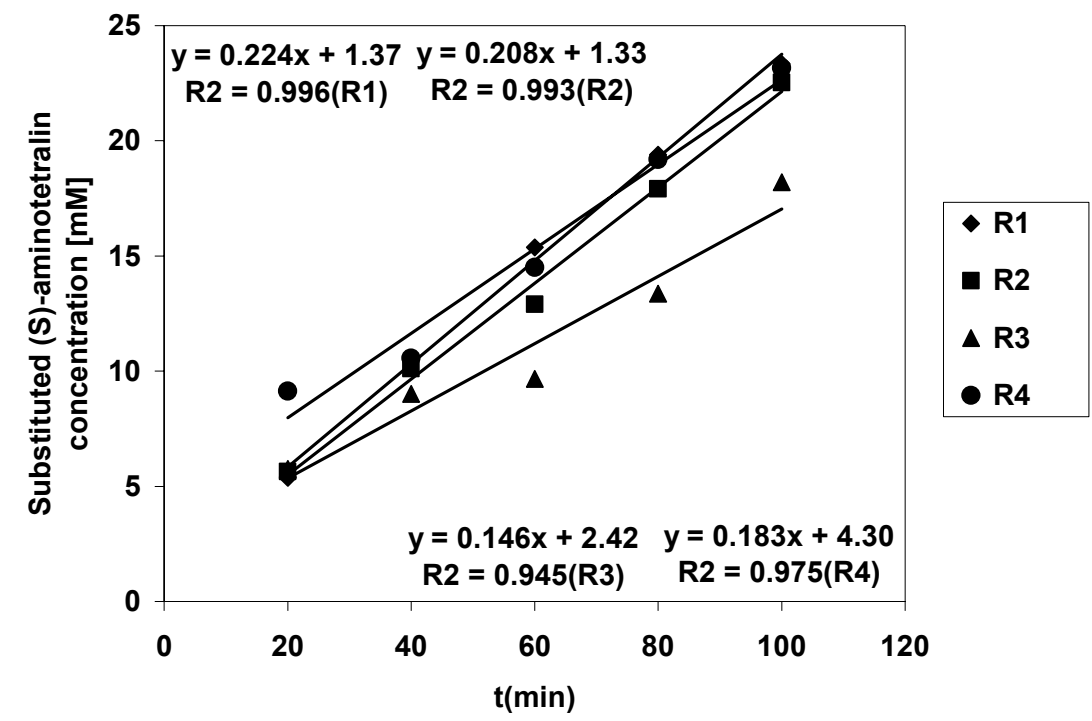

Figure 7-3: Change on reaction rate of immobilized CNB04-01 during continuous production of substituted (S)-aminotetralin at $50{ }^{\circ} \mathrm{C}$. $\mathrm{R} 1$ was the activity at $0 \mathrm{hr}, \mathrm{R} 2$ at $20 \mathrm{hr}, \mathrm{R3}$ at $42 \mathrm{hr}$, and $\mathrm{R} 4$ after $65 \mathrm{hr}$ under reactions conditions.

By means of Figure 7-3 and the information shown in Figure 7-1 and Figure 7-2, it is possible to evaluate the improvement of CNB04-01 over CNB03-03 (Figure 7-4). 


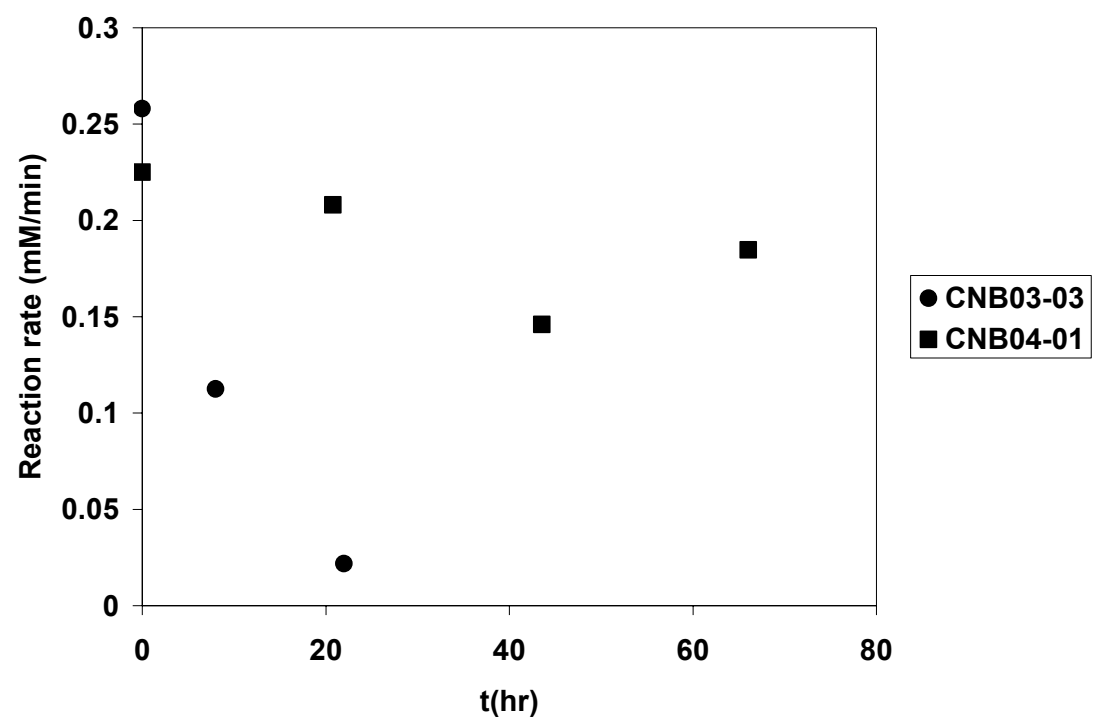

Figure 7-4: Change on initial reaction rate of immobilized CNB03-03 and CNB04-01 during continuous production of substituted (S)-aminotetralin at $50{ }^{\circ} \mathrm{C} \mathbf{p H} 7$.

Figure 7-4 shows that CNB04-01 remains with $90 \%$ of its activity after 20 hours, meanwhile CNB03-03 has only $8 \%$ of its activity after the same time. Figure $7-4$ also shows that CNB03-03 is about $15 \%$ more active than CNB04-01 during the first cycle, but loses activity faster than CNB04-01 does. The data shown in Figure 7-4 were analyzed further to estimate the deactivation constants of the immobilized enzymes at 50 ${ }^{\circ} \mathrm{C} \mathrm{pH}$ 7. The natural logarithms of reaction rates were taken and plotted as a function of time, and then linear regression was done, using the slope of the line as the deactivation constant. For CNB03-03 it was estimated to be $0.113 \mathrm{hr}^{-1}$, and $0.004 \mathrm{hr}^{-1}$ for CNB04-01. The half lifes of CNB03-03 and CNB04-01 were estimated as $6 \mathrm{hr}$ and $160 \mathrm{hr}$, respectively. 


\subsubsection{Addition of Toluene}

The results of substituted (S)-aminotetralin production presented in the previous section included the use of ethanol as cosolvents to aid in the solubility of substituted tetralone. Toluene was used. The effect of toluene for the same purpose in the production of substituted (S)-aminotetralin was tested using Solution $14 \mathrm{pH} 7$ (Table 3-II) with 3\% $(\mathrm{v} / \mathrm{v})$ of it at $50{ }^{\circ} \mathrm{C}$. Seventeen and a half grams of beads containing immobilized spray dried cells of CNB04-01 of concentration $50 \mathrm{mg}$ per gram (effectiveness factor: 0.35 ) of beads were added to $100 \mathrm{ml}$ of Solution 14 under the conditions described above. Fresh reaction mixture was added periodically. The results are shown in Figure 7-5 and Figure 7-6.

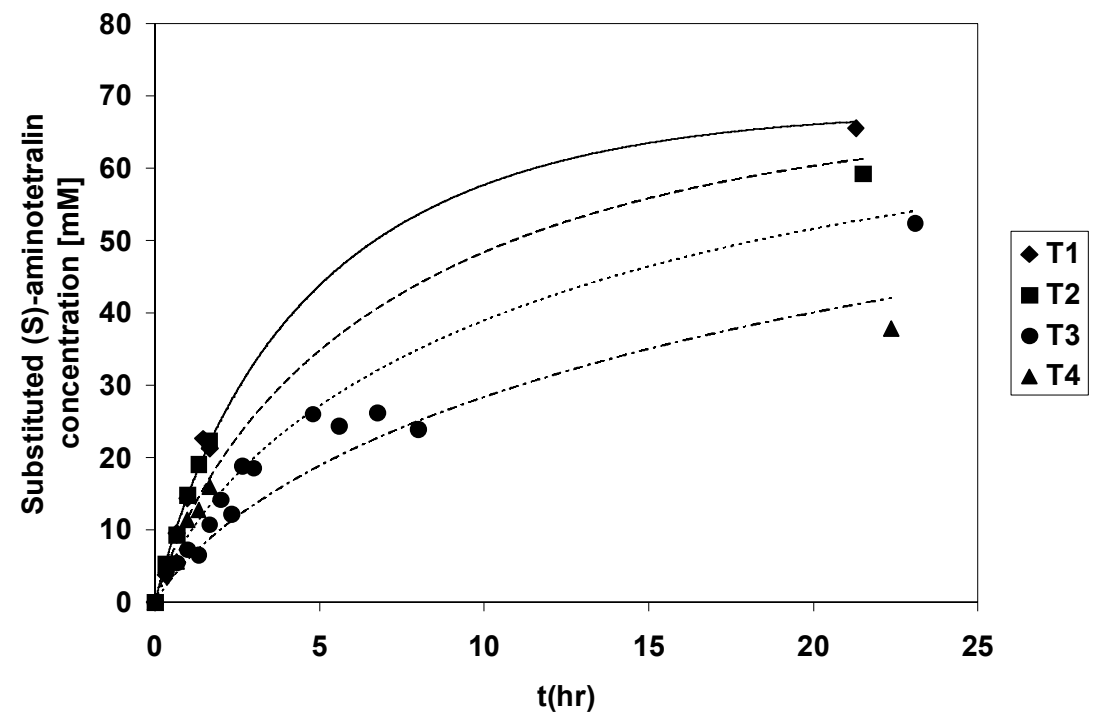

Figure 7-5: Enzymatic activity of immobilized CNB04-01 during continuous production of substituted (S)-aminotetralin at $50{ }^{\circ} \mathrm{C} \mathrm{pH} 7$ at $3 \%(v / v)$ toluene. 


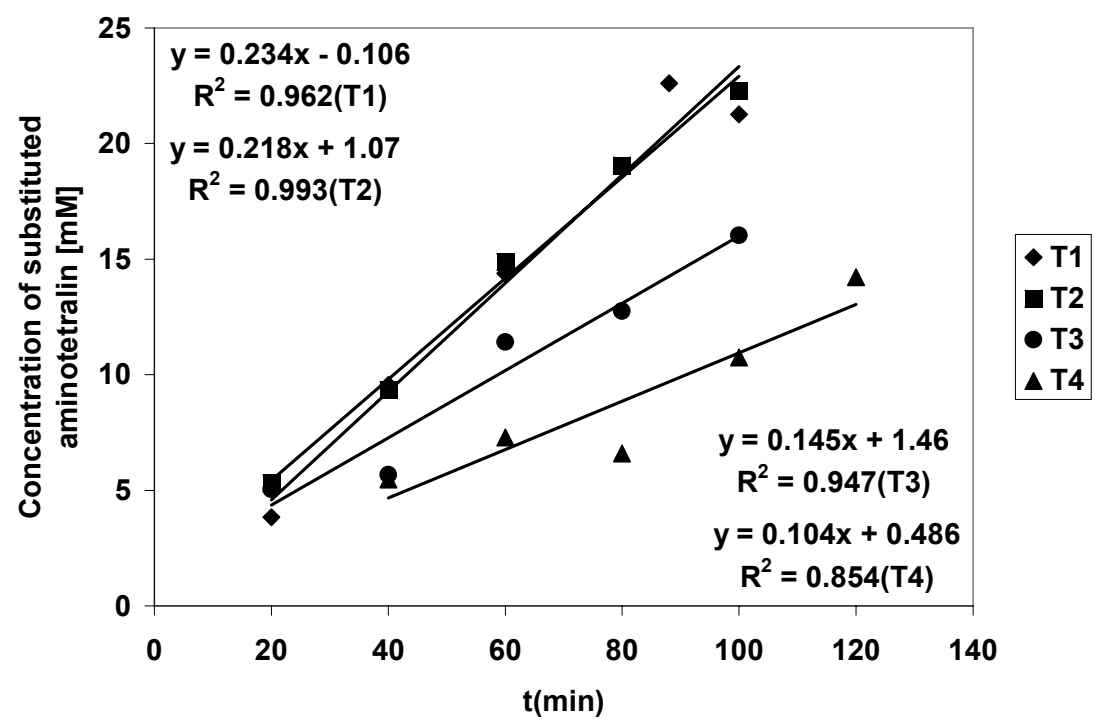

Figure 7-6: Change on reaction rate of immobilized CNB04-01 during continuous production of substituted (S)-aminotetralin at $50^{\circ} \mathrm{C}$.

From Figure 7-5 and Figure 7-6, it was concluded that toluene allowed for having a system that is similar to the one obtained when ethanol was used. Initial rates for the system with toluene seems to be slightly higher than in the system with ethanol, but the final conversion in the system with ethanol seems to be higher than in the system with toluene. The data shown in Figure 7-5 is described by Equation (21). The values of the parameters this equation, estimated as explained in Appendix 6, is shown in Table 7-II. This table shows the parameters that best describe the performance of immobilized CNB04-01 at $50^{\circ} \mathrm{C}$ in the presence of toluene. The values of $v_{\max }^{f}$ and $v_{\max }^{r}$ decrease in a similar way as the reaction rates shown in Figure 7-6. Reaction rates of cycles 2 to 4 were 91,62 , and $44 \%$ of the reaction rate of cycle 1 , whereas the values of $v_{\max }^{f}$ of cycles 2 to 4 were 82,68 , and $41 \%$ of the value for cycle 1 . The kinetic parameters shown in Table 7-II for CNB04-01 strongly differs from the parameters of CNB05-01 shown in Table 6-VII in the values of $K_{m B}$ (from $7.23 \mathrm{mM}$ in CNB04-01 to 1.72 in CNB05-01, as a 
result of enzyme engineering), $K_{m Q}$ (from $45.79 \mathrm{mM}$ in CNB04-01 to $0.45 \mathrm{mM}$ in CNB05-01), $K_{m P}$ (from $0 \mathrm{mM}$ in CNB04-01 to $14.95 \mathrm{mM}$ in CNB05-01) and $K_{i Q}$ (from $19.11 \mathrm{mM}$ in CNB04-01 to $6.93 \mathrm{mM}$ in CNB05-01). The value of $K_{m P}$ indicates that the effect of P (acetone) on CNB04-01 is negligible when toluene is present. The values of $K_{m B}$ and $K_{m Q}$ imply that CNB04-01 has less affinity for B and Q than CNB05-01.

Table 7-II: Kinetic parameters of immobilized CNB04-01 at $50{ }^{\circ} \mathrm{C}$ in the prescence of toluene

\begin{tabular}{|l|c|c|c|c|}
\hline Parameter & T1 & T2 & T3 & T4 \\
\hline$v_{\max }^{f}(\mathbf{m M} / \mathbf{h r})$ & 36.40 & 30.00 & 25.00 & 15.00 \\
\hline$v_{\max }^{r}(\mathbf{m M} / \mathbf{h r})$ & 21.03 & 10.00 & 5.00 & 2.50 \\
\hline$K e q$ & 0.40 & 0.40 & 0.40 & 0.40 \\
\hline$K_{m B}(\mathbf{m M})$ & 7.23 & 7.23 & 7.23 & 7.23 \\
\hline$K_{i A}(\mathbf{m M})$ & 201 & 201 & 201 & 201 \\
\hline$K_{m A}(\mathbf{m M})$ & 35.70 & 35.70 & 35.70 & 35.70 \\
\hline$K_{m Q}(\mathbf{m M})$ & 45.79 & 45.79 & 45.79 & 45.79 \\
\hline$K_{m P}(\mathbf{m M})$ & 0.00 & 0.00 & 0.00 & 0.00 \\
\hline$K_{i Q}(\mathbf{m M})$ & 19.11 & 19.11 & 19.11 & 19.11 \\
\hline
\end{tabular}

Under the experimental conditions $-50^{\circ} \mathrm{C}$ - solubility of B was $27 \mathrm{mM}$, being B concentration always $27 \mathrm{mM}$ during the recycling experiments.

Analyzing the data of Figure 7-6, it seems that reaction rate decays faster in the system with toluene than in the system with ethanol. The change in initial rate (measured experimentally) for CNB04-01 in ethanol and toluene is shown in Figure 7-7. 


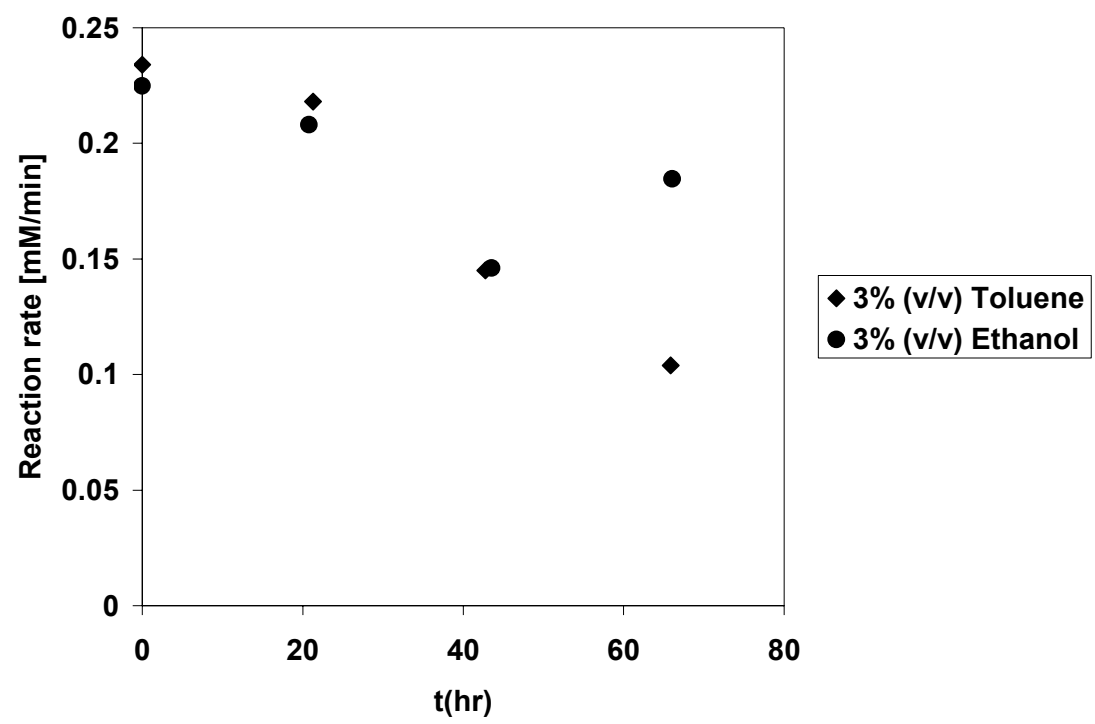

Figure 7-7: Change in initial reaction rate of immobilized CNB04-01 during continuous production of substituted (S)-aminotetralin at $50{ }^{\circ} \mathrm{C} \mathrm{pH} 7$ at $3 \%(\mathrm{v} / \mathrm{v})$ of toluene or $3 \%(\mathrm{v} / \mathrm{v})$ ethanol.

Analyzing further the data shown in Figure 7-7, the apparent deactivation constant of CNB04-01 in toluene at 3\% (v/v) was estimated as described in Section 7.2. The apparent deactivation constant of CNB04-01 at $\mathrm{pH} 7,50{ }^{\circ} \mathrm{C}, 3 \%$ (v/v) toluene is $0.013 \mathrm{hr}^{-1}$, which is three times higher than the deactivation constant of this enzyme on ethanol $\left(0.004 \mathrm{hr}^{-1}\right)$.

During the experiments conducted to determine the effect of toluene on reaction rate and conversion, the system was characterized thoroughly. After the first cycle, the beads lost 20 percent of their original mass, and thereafter bead mass on the system remained practically constant. A fifth cycle was attempted, but after 3 hours, no change was noticed on product concentration, and then the experiment was finalized. The beads obtained in the last cycle had an unusual hardness in comparison with new beads. An experiment was designed to find out the reason of the hardness of those beads. First the beads had to be disrupted, and in order to do so 4 grams of the beads were added to $10 \mathrm{ml}$ 
of $1 \mathrm{M} \mathrm{KH}_{2} \mathrm{PO}_{4}$ and agitated for 4 hours at room temperature. Calcium alginate is disrupted easily under those conditions, but the beads were not disrupted. To disrupt the beads, 4 grams of them and $10 \mathrm{ml}$ of $1 \mathrm{M} \mathrm{KH}_{2} \mathrm{PO}_{4}$ where put under agitation in a hotplate at $50{ }^{\circ} \mathrm{C}$ inside of a sealed vial for 12 hours (the volume before and after bead disruption was $14 \mathrm{ml})$. Once the beads were disrupted, they were diluted by a factor of $20 \mathrm{X}(0.5 \mathrm{ml}$ of disrupted beads $+9.5 \mathrm{ml}$ of $\mathrm{HCl} 0.1 \mathrm{~N}$ ), then this solution was analyzed by HPLC to find the total product inside of the bead. The concentration of the dilution $20 \mathrm{X}$ was 14 $\mathrm{mM}$ substituted (S)-aminotetralin; substituted tetralone was not detected. Considering all of these factors, the concentration inside of the bead, after four recycles, was estimated to be about $1 \mathrm{mmol}$ per gram of immobilized preparation after 4 cycles, or what is the same 0.176 grams of substituted (S)-aminotetralin per gram of immobilized preparation, which means that almost $20 \%(\mathrm{w} / \mathrm{w})$ of the bead mass was the desired product.

\subsubsection{Addition of Sodium Dodecyl Sulfate}

Sodium dodecyl sulfate was used in the production of substituted (S)-aminotetralin for the same purpose as ethanol and toluene, to aid as a co-solvent. First the concentration of this substance was selected, at which value it is possible to achieve a high reaction rate using free spray dried cells of CNB04-01. Two hundred and fifty mg of spray dried cells of CNB04-01 were added to fifty $\mathrm{ml}$ of Solution $14 \mathrm{pH} 7$ (Table 3-II) and incubated at 55 ${ }^{\circ} \mathrm{C}$ with a given concentration of sodium dodecyl sulfate. Reaction rates were measured. The results are shown in Figure 7-8. 


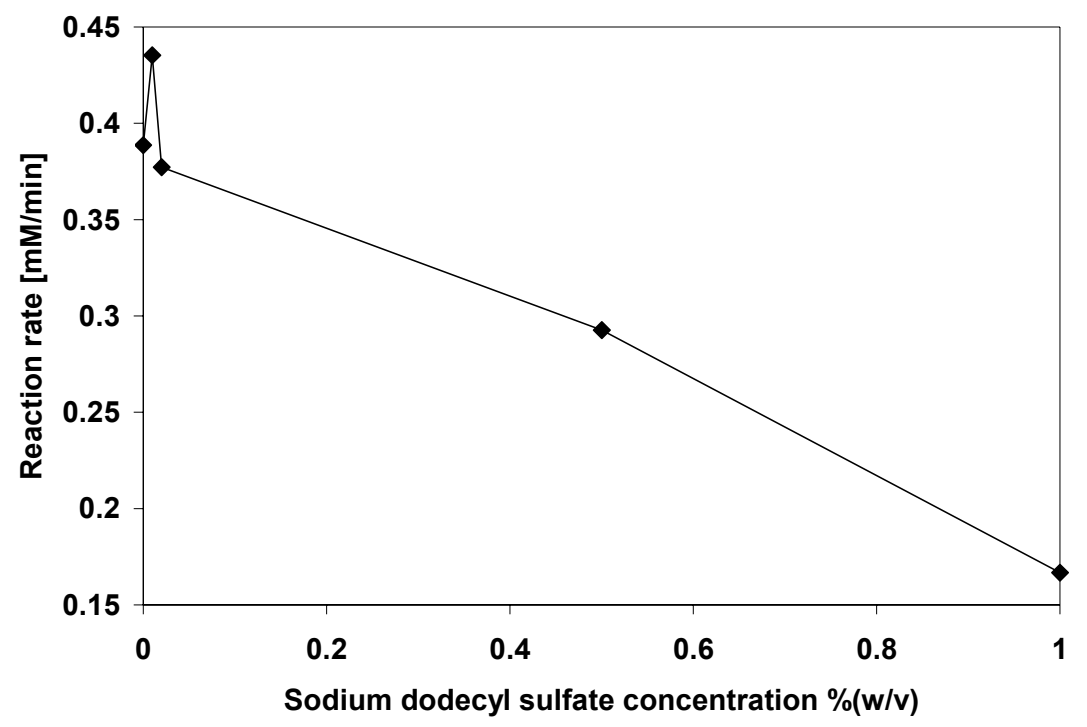

Figure 7-8: Initial reaction rate of free spray dried cells of CNB04-01 as a function of sodium dodecyl sulfate concentration.

Analyzing the data from Figure 7-8, it was concluded that the concentration of sodium dodecyl sulfate that maximizes the reaction rate for free $\mathrm{CNB} 04-01$ at $55{ }^{\circ} \mathrm{C}$ was $0.01 \%$ $(\mathrm{w} / \mathrm{v})$.

Finally, the effect of sodium dodecyl sulfate in the production of substituted (S)aminotetralin was tested using Solution 14 at pH 7 (Table 3-II) with $0.01 \%(w / v)$ of it at $50{ }^{\circ} \mathrm{C}$. A mass of 17.5 grams of beads containing immobilized spray dried cells of CNB04-01 having a concentration of $50 \mathrm{mg}$ per gram (effectiveness factor: 0.35 ) of beads was added to $100 \mathrm{ml}$ of Solution 14 under the conditions described above. New reaction mixture was added periodically. The results are shown in Figure 7-9 and Figure 7-10. 


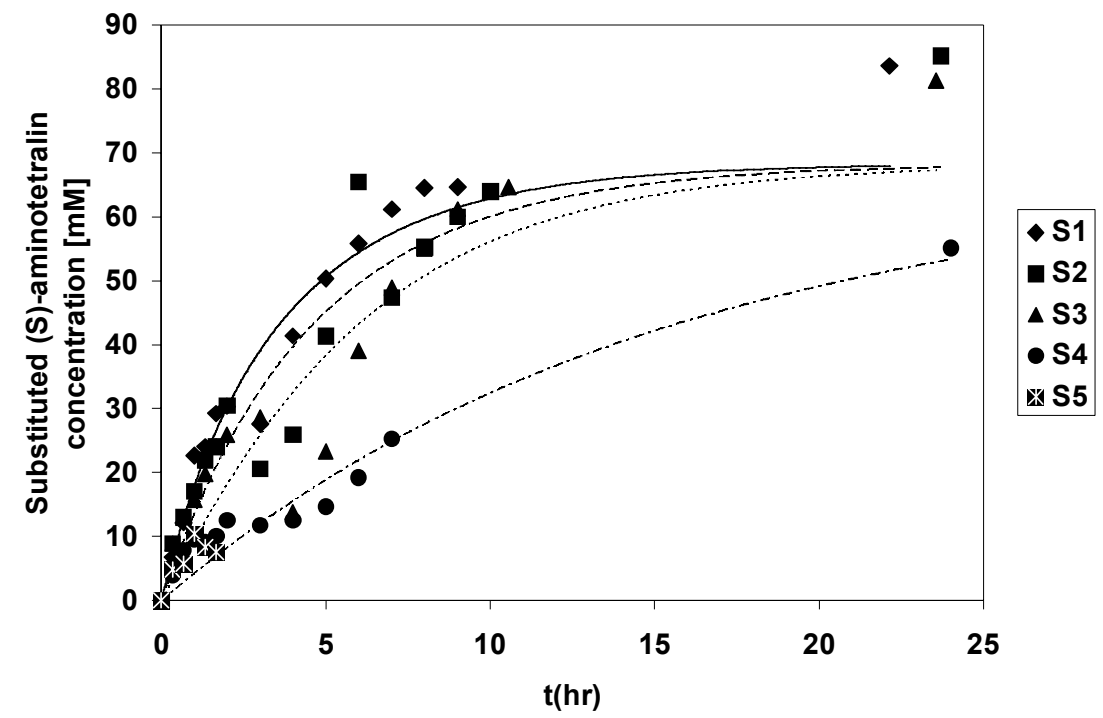

Figure 7-9: Enzymatic activity of immobilized CNB04-01 during continuous production of substituted (S)-aminotetralin at $50{ }^{\circ} \mathrm{C} \mathrm{pH} 7$ with $0.01 \%$ (w/v) sodium dodecyl sulfate.

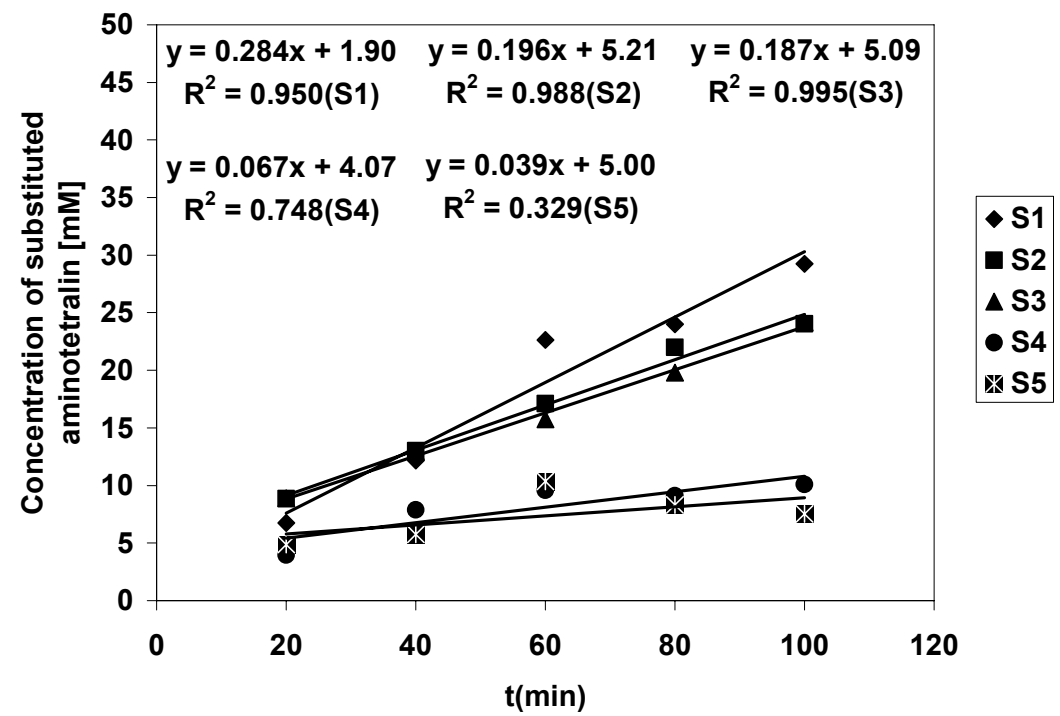

Figure 7-10: Change in initial reaction rate of immobilized CNB04-01 during continuous production of substituted (S)-aminotetralin at $50{ }^{\circ} \mathrm{C}$, $\mathrm{pH} 7$, with $0.01 \%(\mathrm{w} / \mathrm{v})$ sodium dodecyl sulfate. 
Production of substituted (S)-aminotetralin by immobilized CNB04-01 in a reaction mixture with sodium dodecyl sulfate follows Equation (21) early on the process, but Equation (21) fails to predict the final product concentration. This fact could be due to Equation (21) does not account for the effect of sodium dodecyl sulfate, if any. Apparently the overall effect of sodium dodecyl sulfate on the system is that allows higher produc concentration in the system, what could be related to the detergent properties of this compound. More details about the effect of sodium dodecyl sulfate could be a matter of future research. The kinetic parameters that best describe the recycle of immobilized CNB04-01 in sodium dodecyl sulfate are shown in Table 7-III (Appendix 6 describes their estimation).

Table 7-III: Kinetic parameters of immobilized $\mathrm{CNB04-01}$ at $50^{\circ} \mathrm{C}$ in the prescence of sodium dodecyl sulfate.

\begin{tabular}{|l|c|c|c|c|}
\hline Parameter & S1 & S2 & S3 & S4 \\
\hline$v_{\max }^{f}(\mathbf{m M} / \mathbf{h r})$ & 43.74 & 30.00 & 19.77 & 8.79 \\
\hline$v_{\max }^{r}(\mathbf{m M} / \mathbf{h r})$ & 34.70 & 36.75 & 69.25 & 0.40 \\
\hline$K e q$ & 0.40 & 0.40 & 0.40 & 7.04 \\
\hline$K_{m B}(\mathbf{m M})$ & 7.23 & 7.23 & 7.23 & 201 \\
\hline$K_{i A}(\mathbf{m M})$ & 201 & 201 & 35.70 & 35.70 \\
\hline$K_{m A}(\mathbf{m M})$ & 35.70 & 35.70 & 45.79 & 45.79 \\
\hline$K_{m Q}(\mathbf{m M})$ & 45.79 & 45.79 & 0.000 & 0.000 \\
\hline$K_{m P}(\mathbf{m M})$ & 0.000 & 0.000 & 19.11 & 19.11 \\
\hline$K_{i Q}(\mathbf{m M})$ & 19.11 & 19.11 & & 0.23 \\
\hline
\end{tabular}

Under the experimental conditions $-50^{\circ} \mathrm{C}$ - solubility of $\mathrm{B}$ was $27 \mathrm{mM}$, being $\mathrm{B}$ concentration always $27 \mathrm{mM}$ during the recycling experiments.

Table 7-III shows the parameters that best describe the performance of immobilized CNB04-01 at $50^{\circ} \mathrm{C}$ in the presence of sodium dodecyl sulfate. The values of $v_{\max }^{f}$ 
decrease in a similar way as the reaction rates shown in Figure 7-10. Reaction rates of cycles 2 to 4 were 69,66 , and $23 \%$ of the reaction rate of cycle 1 , whereas the values of $v_{\max }^{f}$ of cycles 2 to 4 were 68,45 , and $20 \%$ of the value for cycle 1 . The values of $v_{\max }^{f}$ decrease as the number of cycles increase, the values of $v_{\max }^{r}$ do not follow a determined pattern, attributed to the presence of sodium dodecyl sulfate in the system.

From Figure 7-9 and Figure 7-10, it was concluded that sodium dodecyl sulfate allowed to have a system similar to the one obtained when toluene was used. The final concentration of the product at the end of the cycle 1, 2, and 3 (S1, S2 and S3) was higher than the showed in Figure 7-1 (CNB03-03), Figure 7-5 (CNB04-01 with 3\% (v/v) toluene). Analyzing the data of Figure 7-10, it seems that reaction rate decays first at a slow rate, and then it decays faster over time. Figure 7-11 shows the change on initial reaction rate of immobilized CNB04-01 as a function of time for obtained during the test of the effect of sodium dodecyl sulfate. Figure 7-11 shows that CNB04-01 deactivates at the same rate in $0.01 \%(\mathrm{w} / \mathrm{v})$ sodium dodecyl sulfate at $50{ }^{\circ} \mathrm{C}, \mathrm{pH}$. The deactivation constant for CNB04-01 was estimated as described in Section 7.2. The apparent deactivation constant of $\mathrm{CNB} 04-01$ at $\mathrm{pH} 7,50{ }^{\circ} \mathrm{C}, 0.01 \%(\mathrm{w} / \mathrm{v})$ sodium dodecyl sulfate is $0.022 \mathrm{hr}^{-1}$, which is five times higher than the deactivation constant of this enzyme on ethanol $\left(0.004 \mathrm{hr}^{-1}\right)$. 


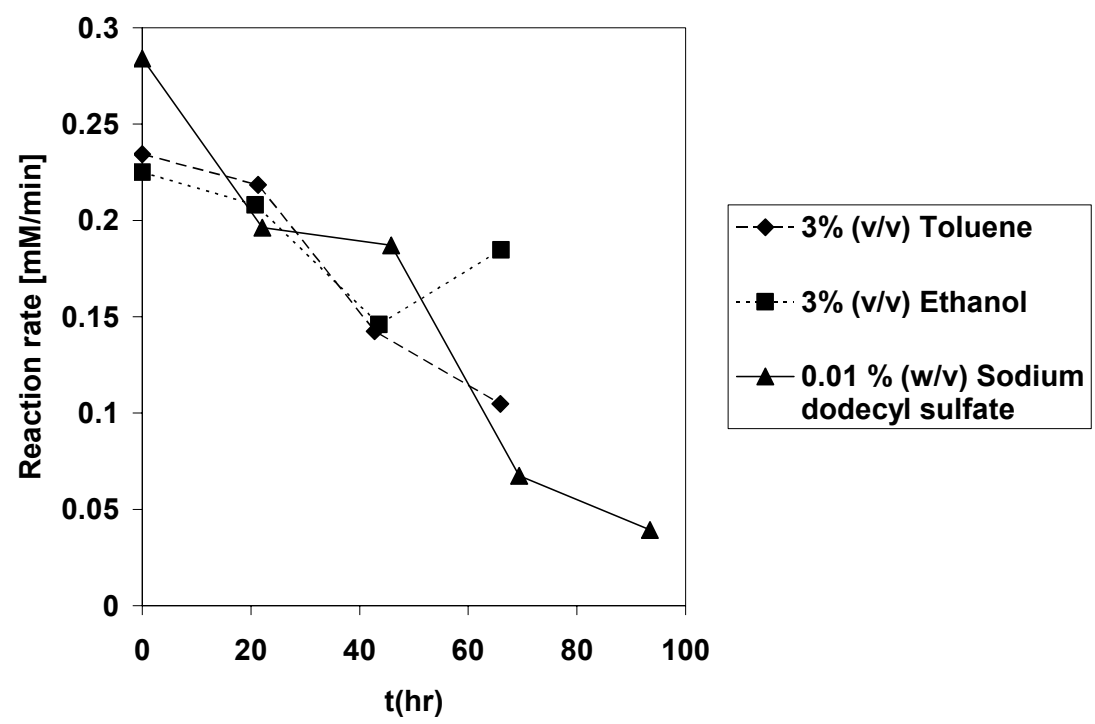

Figure 7-11: Change to initial reaction rate of immobilized CNB04-01 during continuous production of substituted (S)-aminotetralin at $50{ }^{\circ} \mathrm{C}$ pH 7 at $3 \%(v / v)$ of toluene, $3 \%(v / v)$ ethanol, and $0.01 \%(w / v)$ sodium dodecyl sulfate.

During the experiments conducted to determine the effect of $0.01 \%(\mathrm{w} / \mathrm{v})$ sodium dodecyl sulfate, the system was characterized thoroughly. After the first cycle, the beads lost 15 percent of their original mass, and after that bead mass on the system remained practically constant. A fifth cycle was attempted, but after 3 hours it was noticed that the reaction was not progressing fast, and the experiment was finalized. The beads obtained in the last cycle were harder than new beads. Then an experiment was designed to find out the reason for the hardness of those beads. Following the procedure given in Section 7.2.1, the concentration inside of one gram of disrupted beads, after four cycles, was estimated to be about $0.75 \mathrm{mmol}$ of substituted (S)-aminotetralin per gram and 0.14 mmol of substituted tetralone per gram of immobilized preparation, or what is the same 0.132 grams of substituted (S)-aminotetralin per gram, 0.025 grams of substituted 
tetralone per gram of immobilized preparation, which means that almost $13 \%(\mathrm{w} / \mathrm{w})$ of the beads contained the desired product.

From the results presented in Section 7.1 to 7.2.2 it was concluded that immobilization of CNB04-01, and any other (S)-aminotransferase mutant, on calcium alginate for the industrial production of substituted (S)-aminotetralin was not feasible, because immobilization requires many uses of the enzyme without losing activity to a high extent. The data shown in the sections mentioned above show that the maximum number of cycles in which the immobilized enzyme can be used is four cycles. Furthermore, the reason for the loss in activity and limited conversion appears to be the accumulation of product within the beads, which is expected to result in the hindering of diffusion of reactions and products in and out of the bead. In addition to deactivation of the enzyme over time, that decrease in initial reaction rate is also likely to be due to diffusional limitations.

These results suggest changing the approach to improve the economics of this process from an immobilization strategy to one targeted on developing an inherently more active free enzyme. This approach was to develop a mutant with higher activity than CNB04-01 and CNB03-03 as discussed earlier (Chapter 5).

\subsection{Immobilized CNB05-01}

Production of substituted (S)-aminotetralin by immobilized spray dried cells of CNB0501 was done at $55{ }^{\circ} \mathrm{C}$, in a volume of $100 \mathrm{ml}$ of Solution $18 \mathrm{pH} 7$ (Table 3-II), at a 
concentration of one gram of spray dried cells per liter. The purpose of immobilizing CNB05-01 was to test it in this way and to corroborate previous observations that consisted in losses of activity independient of enzyme inactivation due to substrat and product accumulation inside of the immobilized preparation. The immobilized enzyme necessary to achieve the desired concentration was added in 3.5 grams of immobilized preparation of concentration $50 \mathrm{mg}$ per gram (effectiveness factor: 0.35 ) and two cycles were run with the amount of immobilized preparation used. reaction rate of about 0.1 $\mathrm{mM} / \mathrm{min}$ was expected corresponding to one gram per liter of CNB05-01 (Section 9.1). Although the amount and concentration of immobilized preparation used implies that 175 mg were added, this was not the case, since during the preparation of beads of 50 $\mathrm{mg} / \mathrm{gram}$ not all the enzyme is available to react (Section 4.3.4). The results are shown in Figure 7-12.

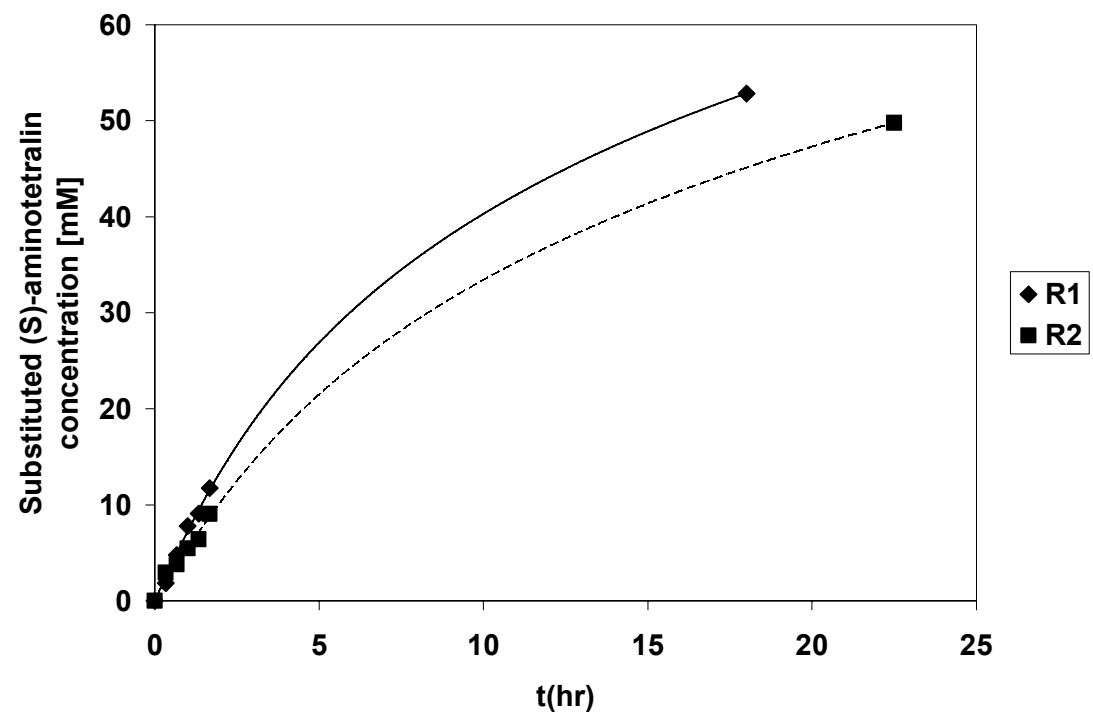

Figure 7-12: Production of substituted (S)-aminotetralin by immobilized spray dried cells of CNB05-01, in two cycles (R1 and R2, ) at a concentration of 1 grams per liter in $100 \mathrm{ml}$ of Solution $18 \mathrm{pH} 7$ at $55^{\circ} \mathrm{C}$. 
The data for trends R1 and R2 shown in Figure 7-12 were fitted to Eguation (21). The values of the corresponding kinetic parameters are shown in Table 7-IV.

Table 7-IV: Kinetic parameters of immobilized CNB05-01 at $55^{\circ} \mathrm{C}$

\begin{tabular}{|l|c|c|}
\hline Parameters & R1 & R2 \\
\hline$v_{\max }^{f}(\mathbf{m M} / \mathbf{h r})$ & 10.02 & 7.41 \\
\hline$V_{\max }^{r}(\mathbf{m M} / \mathbf{h r})$ & 2.64 & 1.71 \\
\hline$K e q$ & 0.40 & 0.40 \\
\hline$K_{m B}(\mathbf{m M})$ & 1.71 & 1.71 \\
\hline$K_{i A}(\mathbf{m M})$ & 200.10 & 200.10 \\
\hline$K_{m A}(\mathbf{m M})$ & 42.59 & 42.59 \\
\hline$K_{m Q}(\mathbf{m M})$ & 0.45 & 0.45 \\
\hline$K_{m P}(\mathbf{m M})$ & 14.95 & 14.95 \\
\hline$K_{i Q}(\mathbf{m M})$ & 6.93 & 6.93 \\
\hline
\end{tabular}

Under the experimental conditions $-55^{\circ} \mathrm{C}$ - solubility of $\mathrm{B}$ was $33 \mathrm{mM}$, being $\mathrm{B}$ concentration always $33 \mathrm{mM}$ during the recycling experiments. The value of Keq shown in this table differs from the value shown in Table 6-VII because it includes the overall contribution of product that was in the form of imine. The data shown in Table 6-VII was obtained under conditions in which imine formation was neglectible. The kinetic parameters were estimated as described in Appendix 6.

Table 7-IV shows the kinetic parameters of immobilized CNB05-01 at $55^{\circ} \mathrm{C}$. They are practically the same as the ones shown in Table 6-VII. $v_{\max }^{f}$ of cycles R1 and R2 correspond to $0.167 \mathrm{mM} / \mathrm{min}$ and $0.123 \mathrm{mM} / \mathrm{min}$. The reaction rates were $0.120 \mathrm{mM} / \mathrm{min}$ for cycle 1 and $0.074 \mathrm{mM} / \mathrm{min}$ for cycle 2 (Figure 7-12). Reaction rate for cycle 2 was $62 \%$ of the same for cycle 2 , and $v_{\max }^{f}$ for the cycle 2 was $74 \%$ of the original value.

Initial reaction rate decreased 38\% from the original value after 18 hours in the reaction system. Remarkably, the product final concentrations in both systems were about the same; $52 \mathrm{mM}$ for cycle 1 (R1) after 18 hours and $49 \mathrm{mM}$ for cycle 2 (R2) after 22 hours. 
The fractional conversions were about .37 in the experiments shown in Figure 7-12. Fractional conversions of the magnitude reported for these experiments are not desirable. Conversions such as the ones reported in Section 8.1 are desirable ( 0.60 or higher). Therefore, the production of substituted (S)-aminotetralin was carried out using free spray dried cells of (S)-aminotransferase. Immobilized spray dried cells present a major problem for the system of substituted tetralone (Section 7.2). High incorporation of the product to the immobilized preparation, up to $13 \%(\mathrm{w} / \mathrm{w})$, causes mass transfer resistances within the bead.

\subsection{Summary}

The improvements on thermostability of (S)-aminotransferase was done aiming to achieve the research objectives; which was to minimize the enzyme cost contribution to the production cost of substituted (S)-aminotetralin. In order to do so immobilization was done. The immobilization experiments of the CNB03-03 showed that it did not have the required thermostability to allow recycling. Applying molecular biology, a mutant was obtained with higher thermostability, CNB04-01. Further experiments done with CNB0401 showed a large accumulation of product inside of the immobilized preparation that reduced the overall activity of (S)-aminotransferase due to mass transfer limitations. Similar problem was also observed when CNB05-01 was immobilized. Because of this problem, the immobilization approach was abandoned. 
Chapter 8. Effect of Free (S)-aminotransferase with Improved Activity in the Production of Substituted (S)-Aminotetralin

\subsection{Free Spray Dried Cells of CNB05-01}

Production of substituted (S)-aminotetralin by free spray dried cells of CNB05-01 at 55 ${ }^{\circ} \mathrm{C}$ was done in a $100 \mathrm{ml}$ of Solution 18 at $\mathrm{pH} 7$ (Table 3-II), adding to it 0.5 grams of spray dried cells of the corresponding (S)-aminotransferase. The results are shown in Figure 8-1.

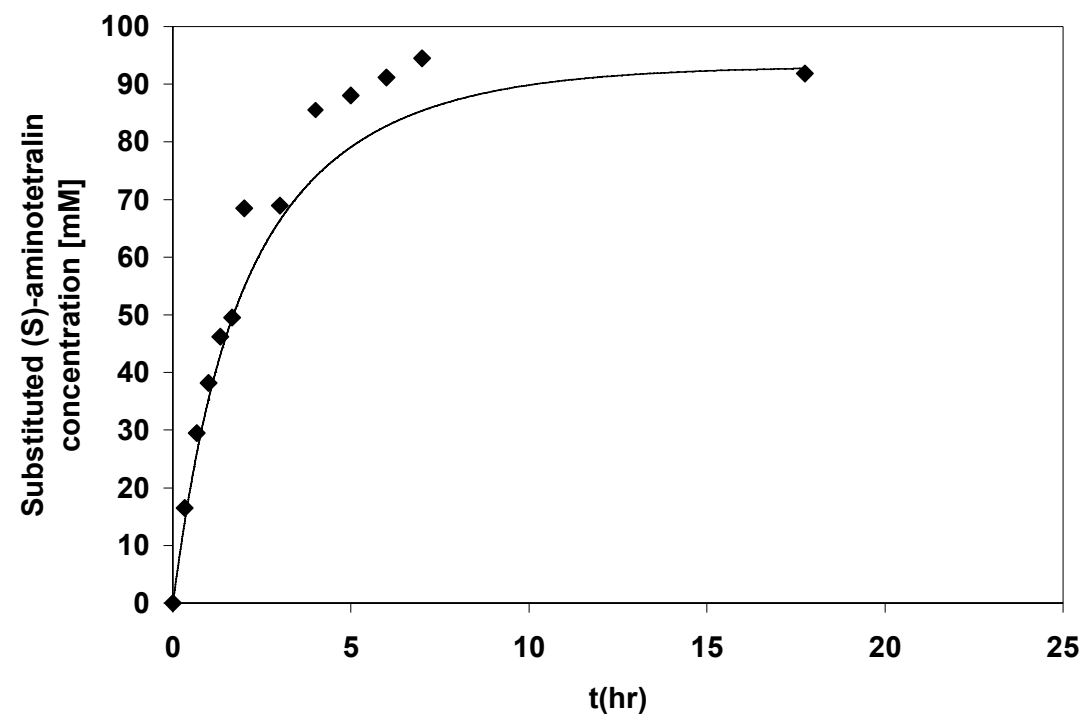

Figure 8-1: Production of substituted (S)-aminotetralin by free spray dried cells of CNB05-01 at a concentration of 5 grams per liter in $100 \mathrm{ml}$ of Solution $18 \mathrm{pH} 7$ at $55^{\circ} \mathrm{C}$.

Figure 8-1 shows that the equilibrium concentration of substituted (S)-aminotetralin is reached approximately after 7 hours. It also shows that the reaction rate (measured 
between 20 to 100 minutes) was $0.41 \mathrm{mM} / \mathrm{min}$, and the final concentration and conversion were $92 \mathrm{mM}$ and 0.70 , respectively. If the results obtained in these experiments are scalable, it may be possible to reduce reaction time of substituted (S)aminotetralin production, which is usually about 20-24 hours (Cambrex Corporation). The profile concentration of substituted (S)-aminotetralin shown in Figure 8-1 is described by Equation (21). The kinetic parameters for Equation (21) are shown in Table 8-I.

Table 8-I: Kinetic parameters of free $\mathrm{CNB05-01}$ at $55^{\circ} \mathrm{C}-5 \mathrm{~g} / \mathrm{l}$

\begin{tabular}{|l|c|}
\hline Parameters & Values \\
\hline$V_{\max }^{f}(\mathbf{m M} / \mathbf{h r})$ & 59.29 \\
\hline$V_{\max }^{r}(\mathbf{m M} / \mathbf{h r})$ & 70.00 \\
\hline$K e q$ & 0.40 \\
\hline$K_{m B}(\mathbf{m M})$ & 1.71 \\
\hline$K_{i A}(\mathbf{m M})$ & 200.10 \\
\hline$K_{m A}(\mathbf{m M})$ & 42.59 \\
\hline$K_{m Q}(\mathbf{m M})$ & 0.45 \\
\hline$K_{m P}(\mathbf{m M})$ & 14.95 \\
\hline$K_{i Q}(\mathbf{m M})$ & 6.93 \\
\hline
\end{tabular}

Under the experimental conditions at $55^{\circ} \mathrm{C}$, solubility of B was $33 \mathrm{mM}$, being $B$ concentration always $33 \mathrm{mM}$ during the recycling experiments. The value of Keq shown in this table differs from the value shown in Table 6-VII because it includes the overall contribution of product that was in the form of imine. The data shown in Table 6-VII was obtained under conditions in which imine formation was negligiible. The kinetic parameters were estimated as described in Appendix 6.

\subsection{Comparison of CNB05-01 with $\mathrm{CNB03-03}$ and $\mathrm{CNB04-01}$}

The enzymatic activities of CNB03-03, CNB04-01, and CNB05-01 were compared at different temperatures, using the optimum parameters for CNB04-01; $0.5 \mathrm{M}$ isopropylamine and $\mathrm{pH}$ 7. The comparison of these (S)-aminotransferases was done in 50 
$\mathrm{ml}$ of Solution 14 at $\mathrm{pH} 7$ (Table 3-II) at an (S)-aminotransferase concentration of 5 grams per liter of free spray dried cells. Samples were withdrawn for reaction rate estimation at 20,40,60, 80, and 100 minutes, and from these samples initial reaction rate was determined by the slope of the best-fit line to the data points. The results are shown in Figure 8-2.

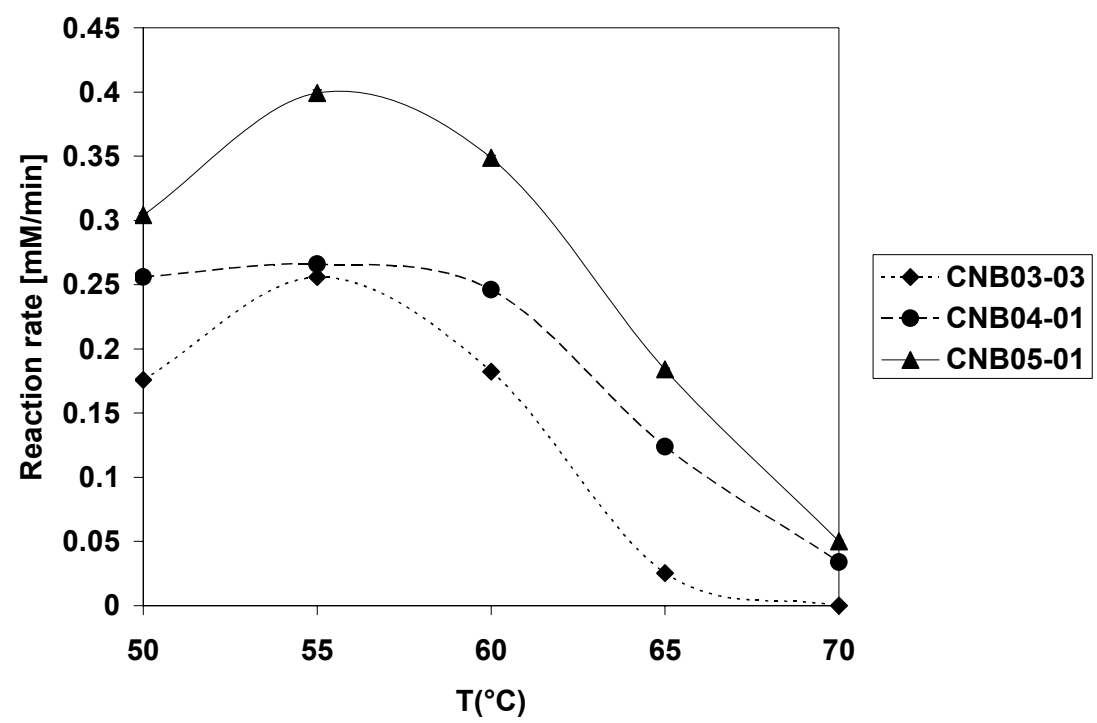

Figure 8-2: Comparison of reaction rates of $\mathrm{CNB03-03,} \mathrm{CNB04-01} \mathrm{and} \mathrm{CNB05-01}$ in $50 \mathrm{ml}$ of Solution 14 at $\mathrm{pH} 7$ for different temperatures.

From Figure 8-2 it is seen that in the range of temperatures from 50 to $60{ }^{\circ} \mathrm{C}$ the reaction rate of CNB05-01 is almost twice that of CNB03-03. In the same range of temperatures, CNB05-01 is between 1.2 to 1.6 times more active than CNB04-01. At temperatures between 60 and $70{ }^{\circ} \mathrm{C}, \mathrm{CNB} 04-01$ shows an improvement over CNB03-03 with regard to thermostability, since it gave higher reaction rates than CNB03-03 did in this range of temperatures. Also from the same range of temperatures it is concluded that CNB05-01 inherited some of the thermostable properties of CNB04-01, in addition to the property of 
higher activity. Therefore, through error prone PCR mutagenesis, the CNB03-03 (S)aminotransferase was improved to a new (S)-aminotransferase with higher activity and thermostability, after two rounds of mutagenesis.

\subsection{Summary}

The improvements on activity and thermostability of (S)-aminotransferase were aimed to achieve the research objective which was to minimize the enzyme cost contribution to the production cost of substituted (S)-aminotetralin. In order to do so, two approaches were followed: immobilization (Chapter 7) and the development of a mutant with higher activity (Chapter 8). The immobilization experiments of the CNB03-03 showed that it did not have the required thermostability to allow recycling (Chapter 7). Applying molecular biology, a mutant was obtained with higher thermostability, CNB04-01. Further experiments with CNB04-01 showed a large accumulation of product inside of the immobilized preparation that reduced the overall activity of (S)-aminotransferase due to mass transfer limitations (Chapter 7). Because of this problem, the immobilization approach was abandoned. Then mutant CNB04-01 was engineered further, obtaining as a result of it a mutant with higher activity, CNB05-01. This mutant of higher thermostability also showed higher activity and thermostability than CNB04-01 and CNB03-03, achieving a high final product concentration and conversion of reactants after 7-8 hours, instead of 24 hours. 
Chapter 9 discusses several aspects about the production of substituted (S)-aminotetralin. Previously it had been shown the effects of isopropylamine concentration, $\mathrm{pH}$ and temperature on initial rate. This chapter shows these effects during the complete biotransformation (about 20-24 hours). Besides this discussion the effect in loading different amounts of biocatalyst to the system (CNB05-01), using cosolvents and using nitrogen as a way to remove acetone and displace the equilibrium towards product formation, is discussed. 


\section{Chapter 9. Engineering of Transamination Reaction For Improved Product Yield Using Free CNB05-01}

Chapter 7 and Chapter 8 discussed results from two strategies that contributed to partial improvement in the production of substituted (S)-aminotetralin. Those strategies were related to reaction engineering (immobilization of the biocatalyst, use of cosolvents) and to enzyme engineering. This chapter will focus on the analysis of some experimental aspects that might improve yield and process time of transamination reaction from the stand point of engineering, using free CNB05-01 (S)-aminotransferase. The experimental aspects that would provide information about improvement transamination are listed below.

1. Changes on enzyme concentration and estimation of process time and conversion.

2. Temperature and $\mathrm{pH}$ effects on biotransformation, with evaluation on process time, conversion and byproduct imine formation.

3. Effect of isopropylamine concentration on biotransformation, with evaluation on process time, conversion, and imine formation.

4. Effect of the use of cosolvents (Ethanol, Toluene, SDS) on biotransformation with evaluation of conversion and process time.

5. Removal of acetone by nitrogen.

Overall, this chapter will present aspects that affect reaction conversion or yield, process time, and imine formation. Imine formation is important since it is related with reaction conversion yield. For each molecule of imine there is a molecule of substituted tetralone that is not converted to the desired product. If imine formation is small there would be 
more tetralone available to form the desired product. Chapter 6 presented the effects of temperature, $\mathrm{pH}$, and isopropylamine concentration on transamination reaction catalyzed by CNB05-01. Such effects were shown in a time interval from 0 to 100 minutes. Chapter 9 intends to show their effects during the whole biotransformation (about 24 hours).

Results for the complete transamination reaction using enzyme loads of 5 gram per liter were reported on Figure 8-1. This chapter will compare transamination reaction catalyzed by enzyme loads of $1,2.5$, and 5 grams per liter. During the characterization of CNB0303 and CNB04-01 for the production of substituted (S)-aminotetralin ethanol, toluene and SDS were used. These cosolvents showed improvement to some extent in the production of substituted for (S)-aminotetralin, e.g. the use of toluene and SDS allowed to recycle immobilized CNB04-01 four times. CNB05-01 allows running transamination reaction at $55^{\circ} \mathrm{C}$. This temperature is close to the boiling point of acetone $\left(57^{\circ} \mathrm{C}\right)$, a product of transamination reaction. A stream of nitrogen running through the system, which does not degrade tetralone, would remove acetone; therefore the equilibrium may be displaced towards formation of substituted (S)-aminotetralin.

\subsection{Enzyme concentration effect}

Substituted (S)-aminotetralin was produced at $55^{\circ} \mathrm{C}$ using enzyme loads of $1,2.5$ and 5 grams per liter of spray dried cells of CNB05-01. The required enzyme was added to 100 $\mathrm{ml}$ of Solution $18 \mathrm{pH} 7$ (Table 3-II). Samples of $0.5 \mathrm{ml}$ were withdrawn periodically and mixed with $9.5 \mathrm{ml}$ of $0.1 \mathrm{~N} \mathrm{HCl}$. Then the samples were incubated at $80{ }^{\circ} \mathrm{C}$ for 30 minutes and analyzed by HPLC, yielding a measurement of the total amount of 
substituted (S)-aminotetralin produced. These analyses accounted for both product in solution and product forming-imine. The total concentration of product in the system is shown in Figure 9-1, and overall information of the system is shown in Table 9-I and Table 9-II.

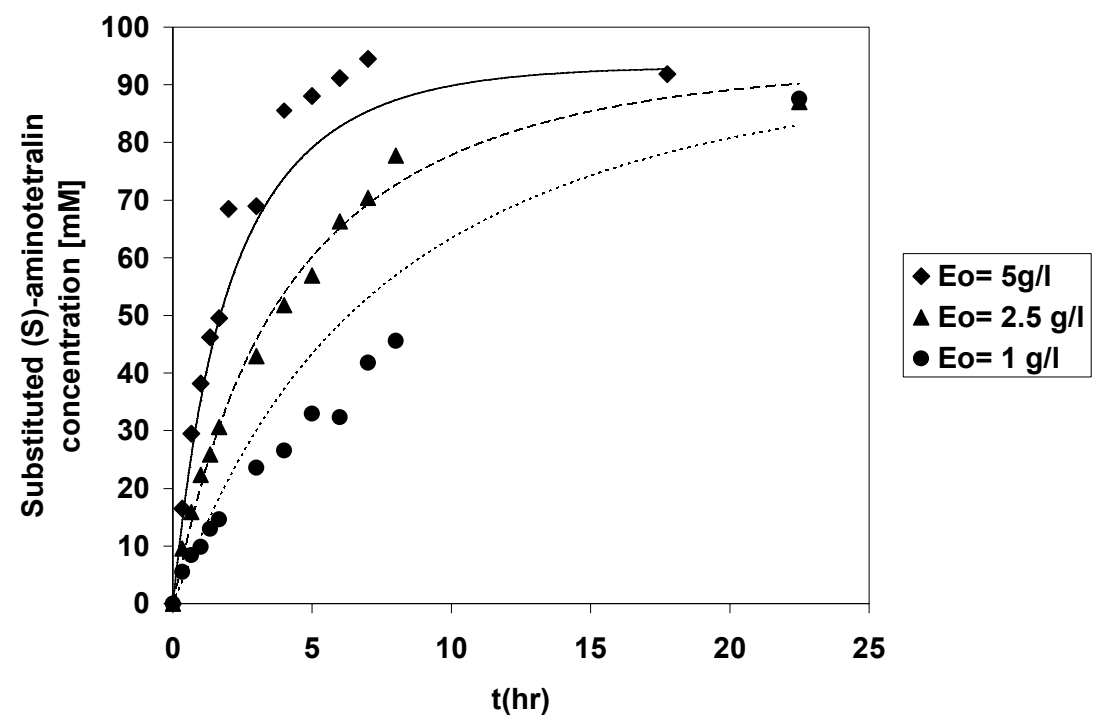

Figure 9-1: Profile concentration of total substituted (S)-aminotetralin at several enzyme (spray dried cells of $\mathrm{CNB05-01)}$ concentrations $\left(55^{\circ} \mathrm{C}\right.$, and $\left.\mathrm{pH} 7\right)$.

Table 9-I: Substituted (S)-aminotetralin production at several enzyme (spray dried cells of CNB05-01) loadings.

\begin{tabular}{|c|c|c|c|c|}
\hline $\begin{array}{l}\text { Enzyme loading } \\
\text { [g/L] }\end{array}$ & $\begin{array}{l}\text { Initial reaction } \\
\text { rate }[\mathbf{m M} / \mathbf{h}]\end{array}$ & $\begin{array}{l}\text { Final product } \\
\text { concentration } \\
{[\mathbf{m M}]}\end{array}$ & $\begin{array}{l}\text { Maximum } \\
\text { conversion }\end{array}$ & $\begin{array}{l}\text { Time required to } \\
\text { achieve maximum } \\
\text { conversion [h] }\end{array}$ \\
\hline 1 & 6.8 & 85 & 0.65 & 24 \\
\hline 2.5 & 15.6 & 85 & 0.65 & 9 \\
\hline 5 & 33.7 & 90 & 0.69 & 6 \\
\hline
\end{tabular}


Table 9-II:Description of free CNB05-01 activity at $55^{\circ} \mathrm{C}-1,2.5$, and $5 \mathrm{~g} / \mathrm{l}$

\begin{tabular}{|l|c|c|c|}
\hline Parameters & $\mathbf{E}_{\mathbf{0}}=\mathbf{1} \mathbf{g} / \mathbf{l}$ & $\mathbf{E}_{\mathbf{0}}=\mathbf{2 . 5} \mathbf{g} / \mathbf{l}$ & $\mathbf{E}_{\mathbf{0}}=\mathbf{5} \mathbf{~ g / l}$ \\
\hline$v_{\max }^{f}(\mathbf{m M} / \mathbf{h r})$ & 15.95 & 29.91 & 59.29 \\
\hline$v_{\max }^{r}(\mathbf{m M} / \mathbf{h r})$ & 19.11 & 29.25 & 70.00 \\
\hline$K e q$ & 0.40 & 0.40 & 0.40 \\
\hline$K_{m B}(\mathbf{m M})$ & 1.711 & 1.711 & 1.711 \\
\hline$K_{i A}(\mathbf{m M})$ & 200.10 & 200.10 & 200.10 \\
\hline$K_{m A}(\mathbf{m M})$ & 42.59 & 42.59 & 42.59 \\
\hline$K_{m Q}(\mathbf{m M})$ & 0.45 & 0.45 & 0.45 \\
\hline$K_{m P}(\mathbf{m M})$ & 14.95 & 14.95 & 14.95 \\
\hline$K_{i Q}(\mathbf{m M})$ & 6.93 & 6.93 & 6.93 \\
\hline
\end{tabular}

Under the experimental conditions, $55^{\circ} \mathrm{C}$, solubility of $B$ was $33 \mathrm{mM}$, being $B$ concentration always $33 \mathrm{mM}$ during the recycling experiments. The value of Keq shown in this table differs from the value shown in Table 6-VII because it includes the overall contribution of product that was in the form of imine. The data shown in Table 6-VII was obtained under conditions in which imine formation was neglectible. The kinetic parameters were estimated as described in Appendix 6.

Table 9-II shows thekinetic parameters that describe the activity of free spray dried cells of CNB05-01 at $55^{\circ} \mathrm{C}$, at a concentration of $1,2.5$, and 5 grams per liter. The values of $v_{\max }^{f}$ increase in the same ratio as the enzyme concentration increases. By comparison of the values of $v_{\max }^{f}$ shown in Table 9-II with the values of initial rates shown in Table 9-I, it is seen that they are proportionally to enzyme concentration, but about half of the value of the corresponding $v_{\max }^{f}$. Figure 9-1 and Table 9-I show the concentrations of substituted (S)-aminotetralin during its production at several enzyme concentrations. Conversions of reactants to achieve equilibrium concentrations of substituted aminotetralin product of between 85 and $90 \mathrm{mM}$ were observed for all initial enzyme concentrations. However, the rate of achieving equilibrium conversions was most rapid for the $5 \mathrm{~g} / \mathrm{L}$ initial enzyme loading as compared to lower loading levels. Under the conditions of $55^{\circ} \mathrm{C}, \mathrm{pH} 7$, and the system at 5 grams per liter, the final concentration is 
reached after 6 hours. During the interval of time monitored, the systems with 2.5 and 1 gram per liter achieved a concentration of about $85 \mathrm{mM}$, while the system with 5 grams per liter achieved a concentration of about $90 \mathrm{mM}$. These result shows that all the concentrations tested will allow maximum conversion.

By analyzing the data it is seen that running the system at 5 grams per liter results in the final concentration is being reached after 6 hours, which correspond to a decreased reaction time. For the system with one gram per liter, an acceptable conversion is reached after 23 hours, a period of time 4 times larger than the required using 5 grams per liter. If the results can be scaled up, it would allow an enzyme reduction of $80 \%$. Therefore, the choice of running the system at 5 or 1 grams per liter of CNB05-01 would be a trade off between the cost of process time and the cost of enzyme.

\subsection{Effect of Temperature}

In Section 8.2 the effect of temperature was shown on initial production rate of substituted (S)-aminotetralin using CNB05-01. In this section the effect of temperature on yield of substituted (S)-aminotetralin is presented as well as on byproduct imine formation. Imine [I] formation occurs parallel to synthesis of substituted (S)aminotetralin [Q]. Substituted tetralone [B] reacts with isopropylamine [A] in the presence of (S)-aminotransferase, rendering as products substituted (S)-aminotetralin [Q] and acetone $[\mathrm{P}]$. Substituted $(\mathrm{S})$-aminotetralin $[\mathrm{Q}]$ reacts further with substituted tetralone [B], in a reversible fashion, given as product imine [I]. The models that describe imine formation [I] and substituted (S)-aminotetralin [Q] are shown below. 


$$
A+B \underset{\text { Enzyme catalyzed process }}{\longleftrightarrow} Q+P
$$

$B+Q \underset{k_{2}}{\stackrel{k_{1}}{\leftrightarrows}} I$

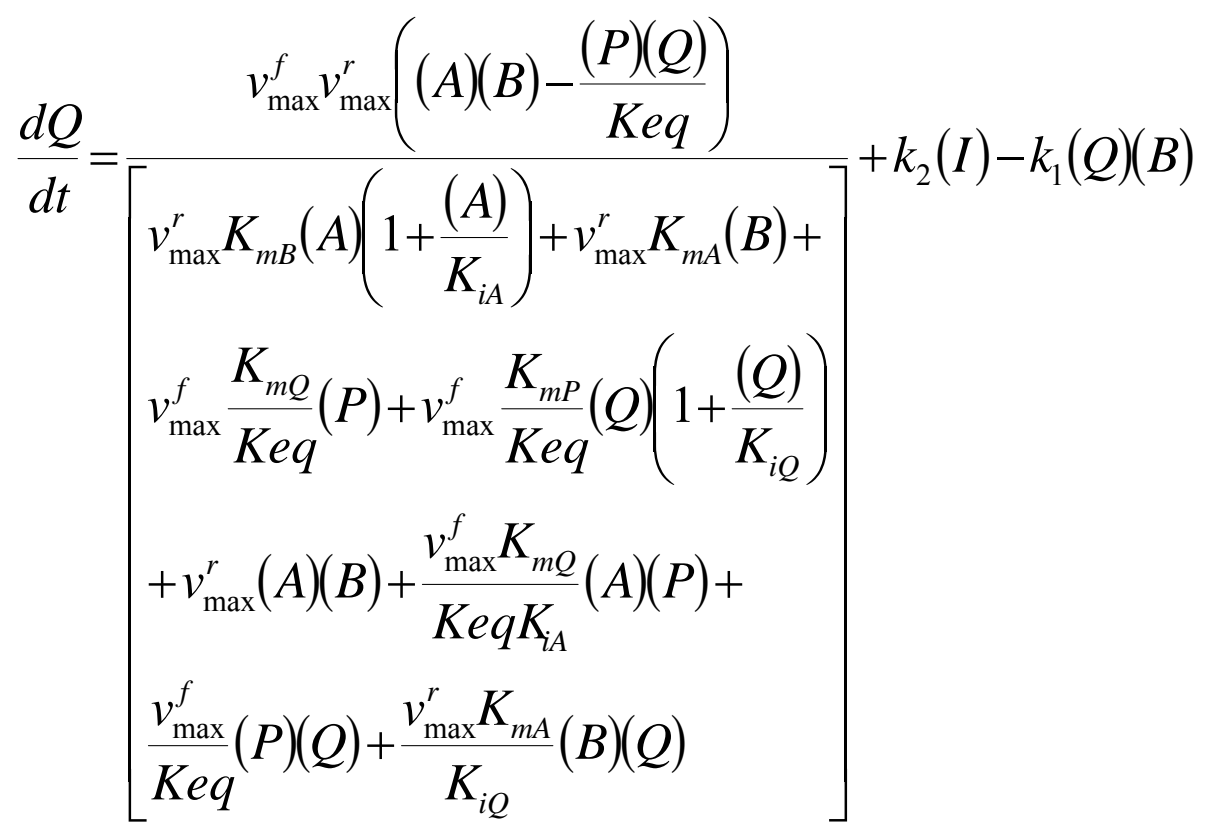

$$
\frac{d I}{d t}=k_{1}(Q)(B)-k_{2}(I)
$$

In these equations $\mathrm{A}=[\mathrm{Ao}]-([\mathrm{Q}]+[\mathrm{I}]), \mathrm{P}=([\mathrm{Q}]+[\mathrm{I}])$, and $\mathrm{B}=[\mathrm{Bo}]-[\mathrm{Q}]-2[\mathrm{I}]$. If total concentration of B is higher than the solubility of it at a given temperature, then the value of its solubility is used instead of the value of total B remaining in the system. The solubility of B at 40,50 , and $55^{\circ} \mathrm{C}$ is 20,27 , and $33 \mathrm{mM}$, respectively. 
The experiment to determine the effect of temperature on production of substituted (S)aminotetralin, as well as on imine formation was done as follows. Two and one half grams of spray dried cells of CNB05-01 were added to $500 \mathrm{ml}$ of a Solution 25 at $\mathrm{pH} 7$ (Table 3-II). The temperatures tested were 40,50 , and $55{ }^{\circ} \mathrm{C}$. Two samples of $0.5 \mathrm{ml}$ were withdrawn at each sampling time; one of them was diluted into $9.5 \mathrm{ml}$ of $0.1 \mathrm{~N} \mathrm{HCl}$, heated for 30 minutes at $80{ }^{\circ} \mathrm{C}$ and analyzed by HPLC, after centrifugation. The other sample was diluted into $9.5 \mathrm{ml}$ of water, centrifuged, and analyzed by HPLC. The analysis of the samples described gave the total concentration of substituted (S)aminotetralin on the system ( $\mathrm{HCl}$ treated samples), and the concentration of substituted (S)-aminotetralin in solution at the time of sampling. By difference, the concentration of imine was obtained. The results are shown in Figure 9-2 and Figure 9-3. Figure 9-2 shows the concentration of substituted (S)-aminotetralin in solution. Meanwhile, Figure 9-3 shows imine concentration, which upon hydrolysis will render one part of substituted (S)-aminotetralin and one parte of tetralone. Then, the total substituted (S)-aminotetralin produced, at a given temperature, is obtained by the addition of Figure 9-2 and Figure 9-3. 


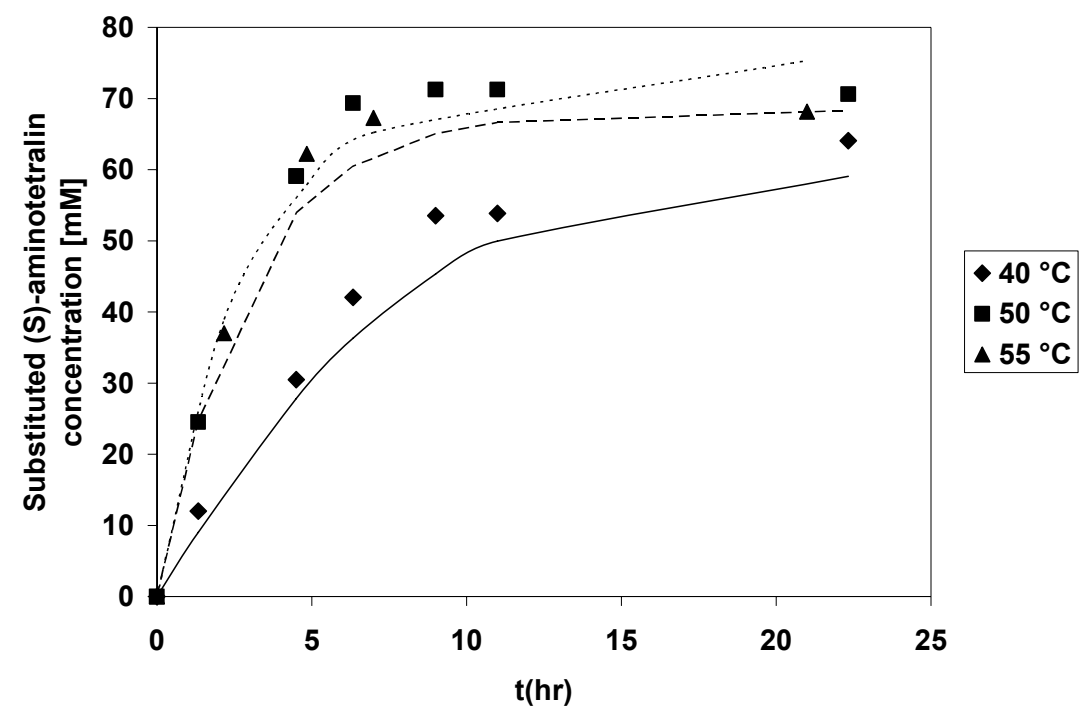

Figure 9-2: Profile concentration of substituted (S)-aminotetralin on solution at several temperatures $\left(E_{\mathrm{o}}=5 \mathrm{~g} / \mathrm{l}, \mathrm{pH} 7\right)$.

Figure 9-2 shows the concentration of substituted (S)-aminotetralin versus time at 40, 50, and $55{ }^{\circ} \mathrm{C}$. Apparently, product concentration in solution (substituted (S)-aminotetralin not forming imine), is slightly higher at $50{ }^{\circ} \mathrm{C}$ than at $55^{\circ} \mathrm{C}$.

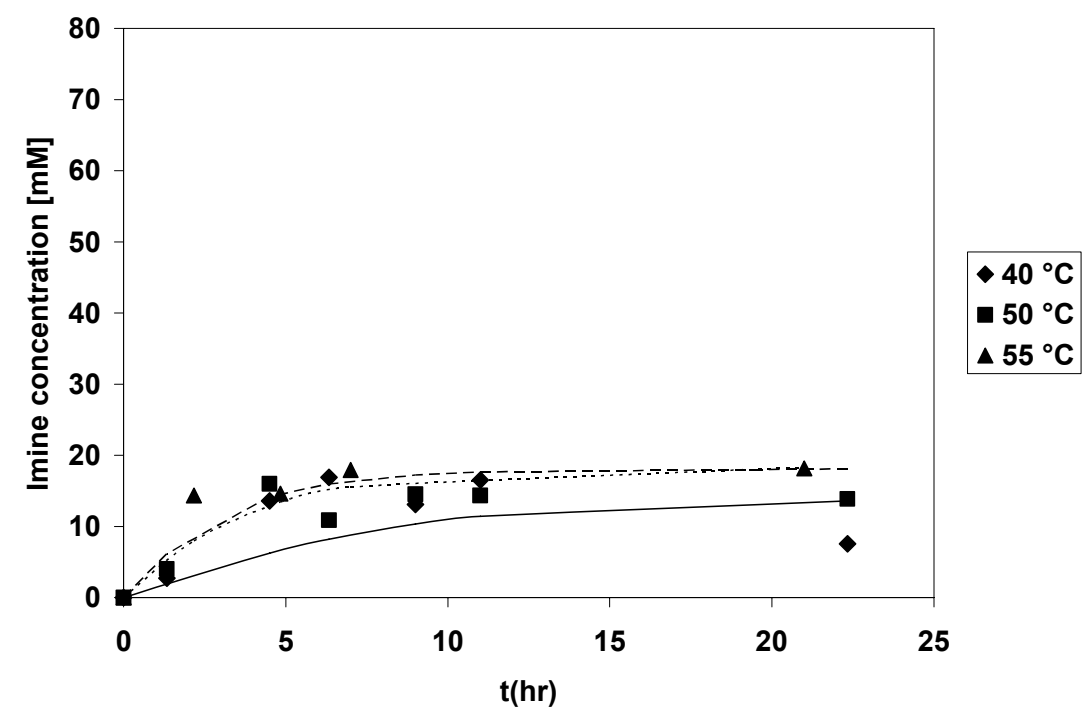

Figure 9-3: Profile concentration of imine at several temperatures $\left(E_{o}=5 \mathrm{~g} / \mathrm{l}, \mathrm{pH} 7\right)$. 
Figure 9-3 shows the profile concentration of imine. As seen in this plot the concentration of imine, early on the reaction is much smaller than the concentration of substituted (S)aminotetralin. This supports the assumption that imine formation has little or no effect in the model that describes the activity (initial rate) of (S)-aminotransferase under differential conditions (Section 6.2.2.4.5). Apparently at 50 and $55{ }^{\circ} \mathrm{C}$ imine formation is irreversible, and after reaching a certain concentration it remains constant. The total substituted (S)-aminotetralin concentration in the systems analyzed can be obtained by adding the data from Figure 9-2 and Figure 9-3, as shown in Table 9-III. As a result of this the conversions of the systems analyzed at 50 and $55{ }^{\circ} \mathrm{C}$ were 0.65 and 0.66 , respectively. The conversion of substituted tetralone at $40{ }^{\circ} \mathrm{C}$ was 0.55 .

Table 9-III: Substituted (S)-aminotetralin (Q) production at several temperatures.

\begin{tabular}{|c|c|c|c|c|c|c|c|}
\hline \multirow{2}{*}{$\mathbf{T}\left({ }^{\circ} \mathbf{C}\right)$} & \multicolumn{2}{|l|}{$\begin{array}{l}\text { Initial reaction } \\
\text { rate }[\mathbf{m M} / \mathbf{h}]\end{array}$} & \multicolumn{3}{l|}{ Final concentration $[\mathbf{m M}]$} & Conversion & $\begin{array}{l}\text { Time required to } \\
\text { achieve maximum } \\
\text { conversion [h] }\end{array}$ \\
\cline { 2 - 6 } & $\mathbf{I}$ & $\mathbf{Q}$ & $\mathbf{I}$ & $\mathbf{Q}$ & Total Q & & 11 \\
\hline 40 & 3 & 6 & 8 & 63 & 71 & 0.55 & 9 \\
\hline 50 & 4 & 12 & 14 & 70 & 84 & 0.65 & 7 \\
\hline 55 & 7 & 17 & 18 & 68 & 86 & 0.66 & \\
\hline
\end{tabular}

Using Equations (22) and (23) (as shown in Appendix 6), and equilibrium concentration; the kinetic constants as well equilibrium constants were estimated for imine and substituted (S)-aminotetralin (Table 9-IV). 
Table 9-IV: Kinetic and equilibrium constants for Substituted (S)-aminotetralin and Imine formation at several temperatures.

\begin{tabular}{|l|c|c|c|}
\hline \multirow{2}{*}{ Parameters } & \multicolumn{3}{|c|}{ Temperature $\left({ }^{\circ} \mathbf{C}\right)$} \\
\cline { 2 - 4 } & $\mathbf{4 0}$ & $\mathbf{5 0}$ & $\mathbf{5 5}$ \\
\hline$v_{\max }^{f}(\mathbf{m M} / \mathbf{h r})$ & 50.00 & 54.40 & 59.29 \\
\hline$v_{\max }^{r}(\mathbf{m M} / \mathbf{h r})$ & 59.16 & 59.72 & 59.23 \\
\hline$K e q$ & 0.33 & 0.33 & 0.33 \\
\hline$K_{m B}(\mathbf{m M})$ & 21.20 & 6.03 & 1.71 \\
\hline$K_{i A}(\mathbf{m M})$ & 200.81 & 200.46 & 200.10 \\
\hline$K_{m A}(\mathbf{m M})$ & 40.74 & 41.66 & 42.59 \\
\hline$K_{m Q}(\mathbf{m M})$ & 0.45 & 0.45 & 0.45 \\
\hline$K_{m P}(\mathbf{m M})$ & 13.12 & 14.01 & 14.95 \\
\hline$K_{i Q}(\mathbf{m M})$ & 24.30 & 12.97 & 6.93 \\
\hline $\mathbf{k}_{\mathbf{1}}\left(\mathbf{m M} \mathbf{m}^{*} \mathbf{h r}\right)^{-1}$ & 0.09 & 0.10 & 0.02 \\
\hline $\mathbf{k}_{\mathbf{2}}(\mathbf{h r})^{-1}$ & 7.76 & 10.01 & 2.04 \\
\hline $\mathrm{k}_{\mathrm{eq}}$ for Q & 0.33 & 0.32 & 0.33 \\
\hline $\mathrm{k}_{\mathrm{eq}}$ for I & $6.0 \times 10^{-3}$ & $7.0 \times 10^{-3}$ & 0.01 \\
\hline
\end{tabular}

Equilibrium constant were estimated using the values of final system composition. The kinetic parameters were estimated as described in Appendix 6.

Where, $k_{e q}=\frac{(P)(Q)}{(B)(A)}$ and $\quad k_{e q}=\frac{(I)}{(B)(Q)}$

Table 9-IV shows the kinetic constants that best describes the overall production of substituted (S)-aminotetralin at 40,50 , and $55^{\circ} \mathrm{C}$ by $\mathrm{CNB} 05-01$. It also shows that the equilibrium constant for substituted (S)-aminotetralin increases as a function of temperature. This table shows that the temperature affect greatly the values of $K_{m B}$, and $K_{i Q}$, decreasing as temperature increases, and in the value of $v_{\max }^{f}$ (increasing as temperature increases). Some kinetic parameters of CNB05-01 remains pretty constant in the range of temperatures tested; these were $v_{\max }^{r}, K e q, K_{i A}$ and $K_{m Q}$. 


\subsection{Effect of $\mathbf{p H}$}

In Section 6.1.2.2 the effect of $\mathrm{pH}$ on initial rate of CNB05-01 was shown, catalyzing the system of substituted tetralone. This section presents the effect of $\mathrm{pH}$ on yield of substituted (S)-aminotetralin as well as imine formation at two $\mathrm{pH}$ values, 6 and 7. The biotransformation was run at an enzyme concentration of 5 grams per liter, for each $\mathrm{pH}$ value. The required enzyme was added to $500 \mathrm{ml}$ of a Solution 25 (Table 3-II) and incubated at $55{ }^{\circ} \mathrm{C}$. Samples were withdrawn to measure concentration of substituted (S)aminotetralin in solution as well as imine concentrations, as explained in Section 9.2. The results are shown in Figure 9-4, Figure 9-5, and Table 9-V.

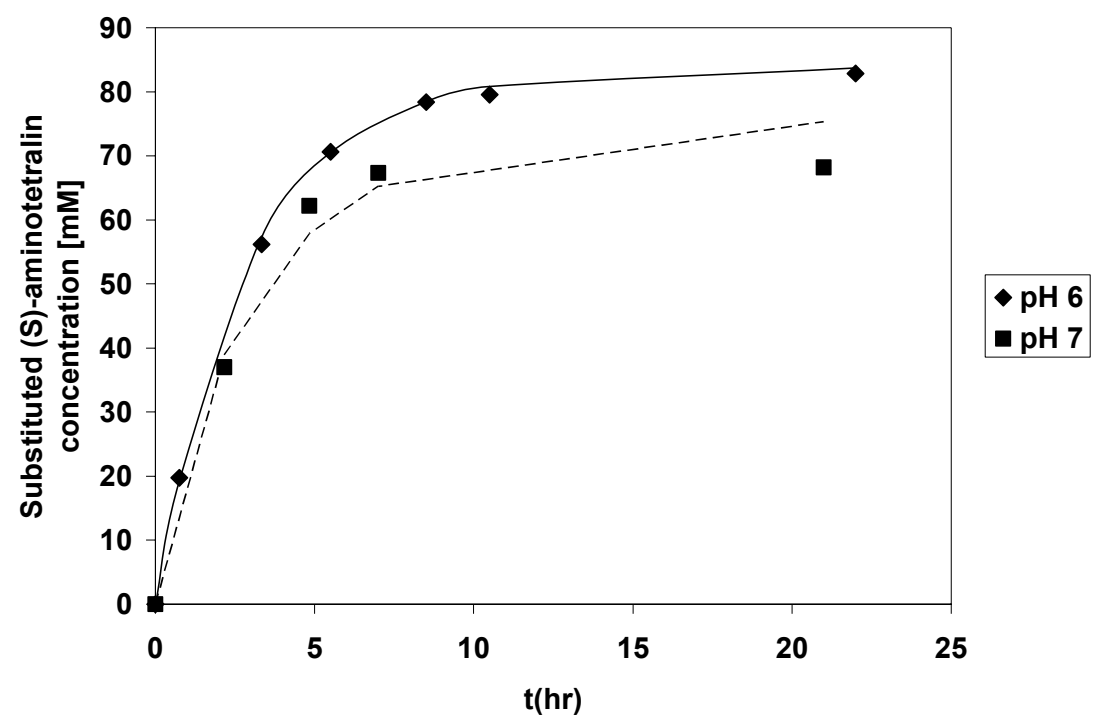

Figure 9-4: Profile concentration of substituted (S)-aminotetralin at $55^{\circ} \mathrm{C}$ using free spray dried cells of CNB05-01) $\left(E_{0}=5 \mathrm{~g} / \mathrm{l}\right)$.

Figure 9-4 shows the profile concentration of substituted (S)-aminotetralin in solution, without considering the amount of product trapped in imine, where it is $15 \%$ higher at $\mathrm{pH}$ 6 than at $\mathrm{pH} 7$. 


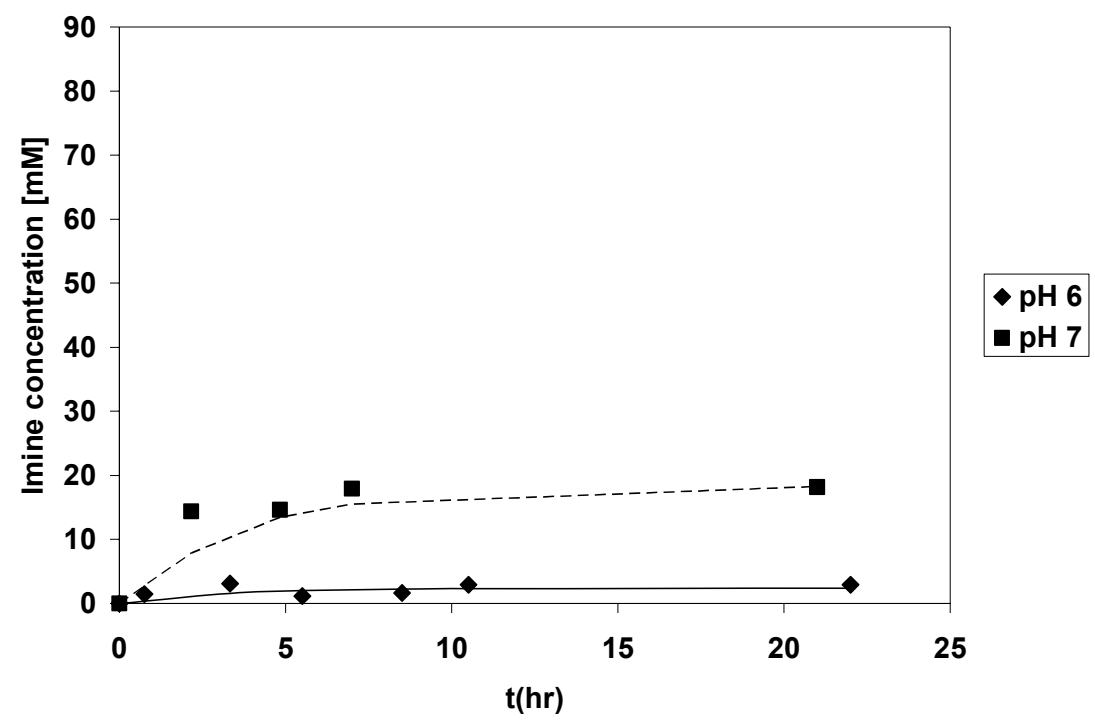

Figure 9-5: Profile concentration of imine at $55^{\circ} \mathrm{C}$ using free spray dried cells of $\mathrm{CNB05-01}$ $\left(E_{0}=5 \mathrm{~g} / \mathrm{l}\right)$.

Analyzing the figure shown above (Figure 9-5), it is seen that the system run at $\mathrm{pH} 7$ has an imine concentration about five times higher than the system run at $\mathrm{pH} 6$.

Table 9-V: Substituted (S)-aminotetralin (Q) production at pH 6 and 7.

\begin{tabular}{|c|c|c|c|c|c|l|}
\hline \multirow{2}{*}{$\mathbf{p H}$} & \multicolumn{2}{|c|}{$\begin{array}{c}\text { Initial reaction } \\
\text { rate [mM/h] }\end{array}$} & \multicolumn{3}{|c|}{ Final concentration [mM] } & \multirow{2}{*}{ Conversion } \\
\cline { 2 - 6 } & $\mathbf{I}$ & $\mathbf{Q}$ & $\mathbf{I}$ & $\mathbf{Q}$ & Total Q & \\
\hline 6 & 0.5 & 16 & 3 & 83 & 86 & 0.66 \\
\hline 7 & 7 & 17 & 18 & 68 & 86 & 0.66 \\
\hline
\end{tabular}

Table 9-V summarizes the results presented in Figure 9-4 and Figure 9-5. During the production of substituted (S)-aminotetralin at $\mathrm{pH} 6$ and 7, at a $500 \mathrm{ml}$ scale, the same overall conversion was achieved. Twenty-one percent of the substituted (S)-aminotetralin produced at $\mathrm{pH} 7$ was obtained after hydrolysis of imine, meanwhile $3.5 \%$ of the substituted (S)-aminotetralin produced at $\mathrm{pH} 6$ was originated after acid hydrolysis of imine. Therefore, low $\mathrm{pH}$ appears to decrease overall imine formation. Analyzing the 
data shown in Figure 9-4 and Figure 9-5 as shown in Appendix 6, and using the composition of the systems at equilibrium shown in Table 9-V, the kinetic parameters as well as equilibrium constants were estimated (Table 9-VI).

Table 9-VI: Kinetic and equilibrium constants for Substituted (S)-aminotetralin and Imine formation at pH 6 and 7.

\begin{tabular}{|l|c|c|}
\hline \multicolumn{1}{|c|}{ Parameters } & pH 6 & pH 7 \\
\hline$v_{\max }^{f}(\mathbf{m M} / \mathbf{h r})$ & 38.91 & 40.00 \\
\hline$v_{\max }^{r}(\mathbf{m M} / \mathbf{h r})$ & 78.33 & 55.00 \\
\hline$K e q$ & 0.33 & 0.33 \\
\hline$K_{m B}(\mathbf{m M})$ & 2.16 & 1.72 \\
\hline$K_{i A}(\mathbf{m M})$ & 200.10 & 200.10 \\
\hline$K_{m A}(\mathbf{m M})$ & 42.61 & 42.59 \\
\hline$K_{m Q}(\mathbf{m M})$ & 0.45 & 0.45 \\
\hline$K_{m P}(\mathbf{m M})$ & 13.84 & 14.95 \\
\hline$K_{i Q}(\mathbf{m M})$ & 8.66 & 6.93 \\
\hline $\mathbf{k}_{\mathbf{1}}\left(\mathbf{m M} \mathbf{M}^{*} \mathbf{h r}\right)^{-1}$ & $1.0 \times 10^{-3}$ & 0.02 \\
\hline $\mathbf{k}_{\mathbf{2}}(\mathbf{h r})^{-1}$ & 3.73 & 2.04 \\
\hline $\mathrm{k}_{\mathrm{eq}}$ for Q & 0.33 & 0.34 \\
\hline $\mathrm{k}_{\mathrm{eq}}$ for I & $1.0 \times 10^{-3}$ & 0.01 \\
\hline
\end{tabular}

The kinetic parameters were estimated as described in Appendix 6.

${ }^{\text {Where, }} k_{\text {eq }}=\frac{(P)(Q)}{(B)(A)}$ and $\quad k_{\text {eq }}=\frac{(I)}{(B)(Q)}$

Table 9-VI shows the values of the kinetic parameters that describe the formation of substituted (S)-aminotetralin at $\mathrm{pH} 6$ and 7. The equilibrium constants for substituted (S)aminotetralin formation were practically the same at $\mathrm{pH} 6$ and 7, but the equilibrium constant for imine formation was 10 times lower at $\mathrm{pH} 6$ than at $\mathrm{pH} 7$. 


\subsection{Effect of Isopropylamine Concentration}

The effect of isopropylamine on initial rate of product formation using CNB05-01 to catalyze the system of substituted tetralone has been studied in Section 6.2.2.2.1. This section will partially explore the effect of isopropylamine concentration during the entire time course of reaction. In order to do so, 2.5 grams of spray dried cells were added to $500 \mathrm{ml}$ of Solution $26 \mathrm{pH} 7$ (Table 3 -II) and incubated at $55^{\circ} \mathrm{C}$. The concentrations of isopropylamine tested were 250,500 and $750 \mathrm{mM}$. Substituted (S)-aminotetralin as well as imine concentration were monitored. The results are shown in Figure 9-6, Figure 9-7, and Table 9-VII.

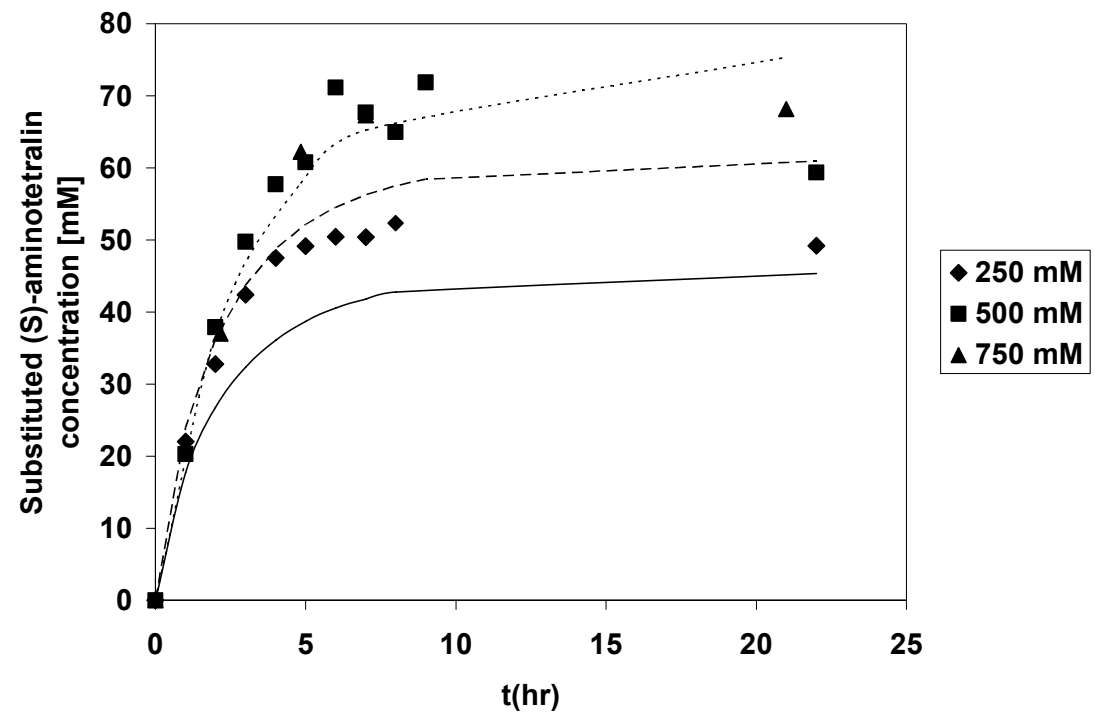

Figure 9-6: Profile concentration of substituted (S)-aminotetralin on solution $\mathrm{pH} 7, \mathrm{E}_{\mathbf{0}}=\mathbf{5} / \mathrm{l}$, at several isopropylamine concentration.

Figure 9-6 shows that the initial rate of product formation is nearly the same for each initial concentration of isopropylamine, yet the final product concentration on solution decreases with decreasing initial isopropylamine level. At isopropylamine concentration 
of $250 \mathrm{mM}$, final product concentration in solution was near $50 \mathrm{mM}$, about $60 \mathrm{mM}$ at 500 $\mathrm{mM}$ isopropylamine and around $70 \mathrm{mM}$ for $750 \mathrm{mM}$ isopropylamine. The profile of product concentration on solution at 500 and $750 \mathrm{mM}$ isopropylamine was almost the same early on the reaction, but then it gave a final product concentration with a difference of $10 \mathrm{mM}$. Concentrations of substituted tetralone product were lower for the $250 \mathrm{mM}$ case for nearly all times in the reaction.

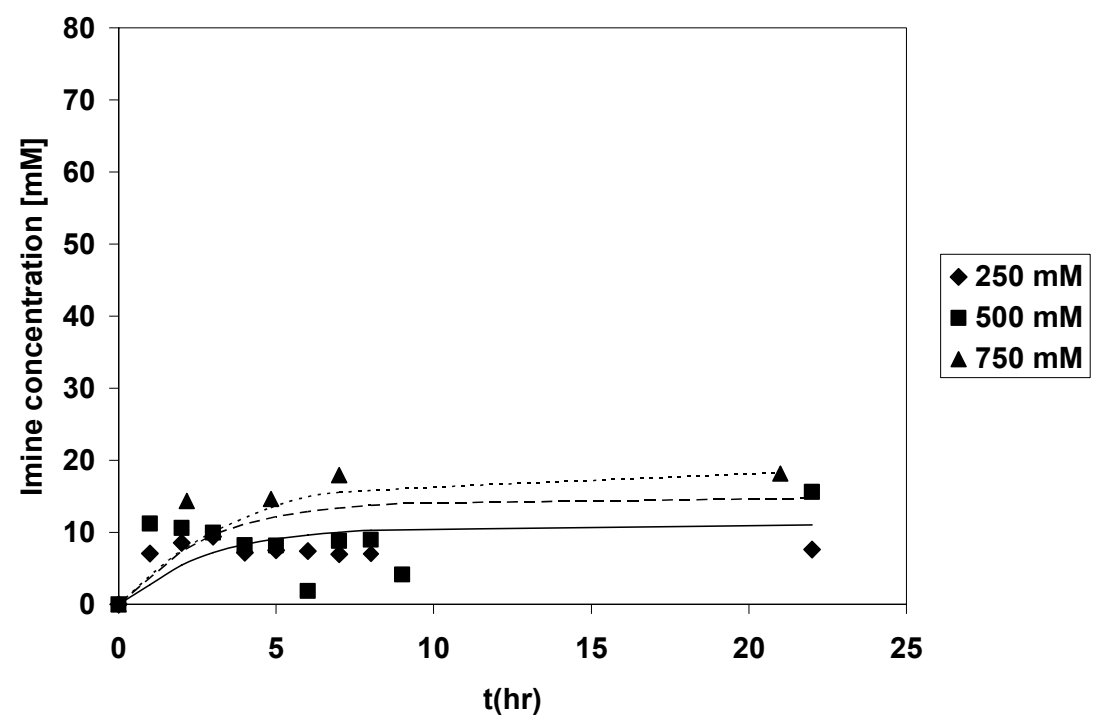

Figure 9-7: Profile concentration of imine at $\mathrm{pH} 7, \mathrm{E}_{0}=5 / \mathrm{l}$, at several isopropylamine concentration.

Figure 9-7 shows that imine formation apparently reaches an intermediate maximum concentration, then decreases and finally increases. The imine concentration shown in Figure 9-7 once hydrolyzed by $0.1 \mathrm{~N} \mathrm{HCl}$ at $80{ }^{\circ} \mathrm{C}$ would produce an equimolar amount of substituted (S)-aminotetralin and substituted tetralone. 
Table 9-VII: Substituted (S)-aminotetralin (Q) production at several isopropylamine concentrations.

\begin{tabular}{|c|c|c|c|c|c|c|}
\hline \multirow{2}{*}{$\begin{array}{l}\text { Isopropylamine } \\
\text { concentration } \\
{[\mathrm{mM}]}\end{array}$} & \multicolumn{2}{|c|}{$\begin{array}{l}\text { Formation } \\
\text { rate }[\mathrm{mM} / \mathbf{h}]\end{array}$} & \multicolumn{3}{|c|}{ Final concentration $[\mathrm{mM}]$} & \multirow[t]{2}{*}{ Conversion } \\
\hline & I & $\mathbf{Q}$ & I & $\mathbf{Q}$ & Total Q & \\
\hline 250 & 4 & 16 & 7 & 50 & 57 & 0.44 \\
\hline 500 & 5 & 17 & 15 & 60 & 75 & 0.58 \\
\hline 750 & 7 & 17 & 18 & 68 & 86 & 0.66 \\
\hline
\end{tabular}

The total substituted (S)-aminotetralin, in solution (Figure 9-6) and released by imine hydrolysis (Figure 9-7), is presented in Figure 9-8.

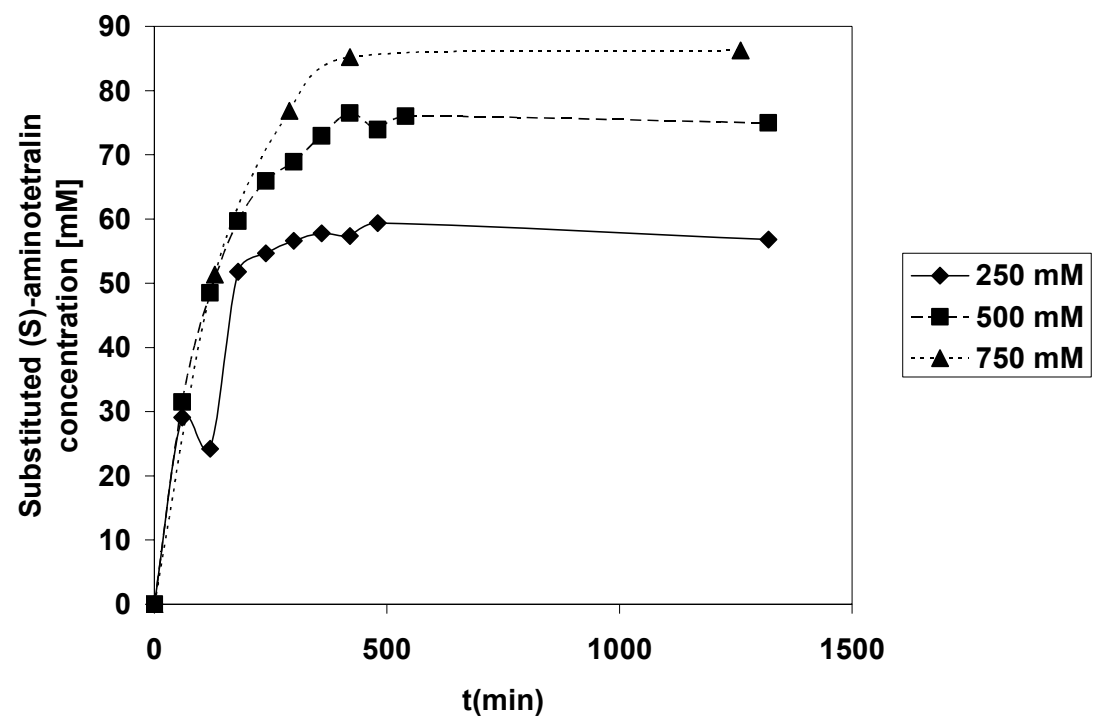

Figure 9-8: Profile concentration of total substituted (S)-aminotetralin concentration produced at several isopropylamine concentrations, $\mathrm{pH}$ 7, (free spray dried cells of CNB05-01) $\left(E_{0}=5 \mathrm{~g} / \mathrm{l}\right)$.

Figure 9-8 shows the effect of isopropylamine concentration on the overall extent of reaction. The overall conversion at $250 \mathrm{mM}$ isopropylamine was 0.44 , at $500 \mathrm{mM} .57$, and at $750 \mathrm{mM}$ isopropylamine 0.66 . The data shown in Figure 9-6 and Figure 9-7 as well as the information shown in Table 9-VII were used to estimate kinetic parameters 
and equilibrium constants (As shown in Appendix 6); the values obtained are shown in Table 9-VIII.

Table 9-VIII: Kinetic and equilibrium constants for Substituted (S)-aminotetralin and Imine formation at several isopropylamine concentrations.

\begin{tabular}{|l|c|c|c|}
\hline \multirow{2}{*}{ Parameters } & \multicolumn{3}{|c|}{ Isopropylamine concentration [mM] } \\
\cline { 2 - 4 } & $\mathbf{2 5 0}$ & $\mathbf{5 0 0}$ & $\mathbf{7 5 0}$ \\
\hline$V_{\max }^{f}(\mathbf{m M} / \mathbf{h r})$ & 35.00 & 45.00 & 40.00 \\
\hline$V_{\max }^{r}(\mathbf{m M} / \mathbf{h r})$ & 55.00 & 60.00 & 55.00 \\
\hline$K e q$ & 0.40 & 0.33 & 0.33 \\
\hline$K_{m B}(\mathbf{m M})$ & 1.72 & 1.72 & 1.72 \\
\hline$K_{i A}(\mathbf{m M})$ & 200.10 & 200.10 & 200.10 \\
\hline$K_{m A}(\mathbf{m M})$ & 42.59 & 42.59 & 42.59 \\
\hline$K_{m Q}(\mathbf{m M})$ & 0.45 & 0.45 & 0.45 \\
\hline$K_{m P}(\mathbf{m M})$ & 14.95 & 14.95 & 14.95 \\
\hline$K_{i Q}(\mathbf{m M})$ & 6.92 & 6.93 & 6.93 \\
\hline $\mathbf{k}_{\mathbf{1}}\left(\mathbf{m M} \mathbf{M}^{*} \mathbf{h r}\right)^{-\mathbf{1}}$ & 0.02 & 0.02 & 0.02 \\
\hline $\mathbf{k}_{\mathbf{2}}(\mathbf{h r})^{-1}$ & 2.04 & 2.05 & 2.04 \\
\hline $\mathrm{k}_{\mathrm{eq}}$ for Q & 0.45 & 0.32 & 0.33 \\
\hline $\mathrm{k}_{\mathrm{eq}}$ for I & $4.0 \times 10^{-3}$ & $7.0 \times 10^{-3}$ & 0.01 \\
\hline
\end{tabular}

The kinetic parameters were estimated as described in Appendix 6.

${ }^{\text {Where, }} k_{e q}=\frac{(P)(Q)}{(B)(A)}$ and $\quad k_{e q}=\frac{(I)}{(B)(Q)}$

Table 9-VIII shows the kinetic parameters that best describe the data shown in Figure 9-6 and Figure 9-7. The equilibrium constant for substituted (S)-aminotetralin at $55^{\circ} \mathrm{C}$ is about 0.36 (average). The equilibrium constant estimated for the system of $250 \mathrm{mM}$ isopropylamine differs from this value, but the estimation of the constant is of the same order as the equilibrium constants estimated for the systems of 500 and $750 \mathrm{mM}$ isopropylamine. 


\subsection{Effect of Cosolvents}

In Section 7.2 the effect of ethanol, toluene, and sodium dodecyl sulfate (SDS) on transamination reaction catalyzed by immobilized CNB04-01 was presented. This section shows the effect of the compounds mentioned earlier -as cosolvents to increase substituted tetralone solubility- on transamination reaction catalyzed by free CNB05-01. In order to do so, 2.5 grams of enzyme were added to $500 \mathrm{ml}$ of Solution $18 \mathrm{pH} 7$ (Table 3-II) with a concentration of ethanol or toluene of $3 \%(\mathrm{v} / \mathrm{v})$ or SDS $0.01 \%(\mathrm{w} / \mathrm{v})$. The biotransformation reaction was done at $55{ }^{\circ} \mathrm{C}$. The results are shown in Figure 9-9.

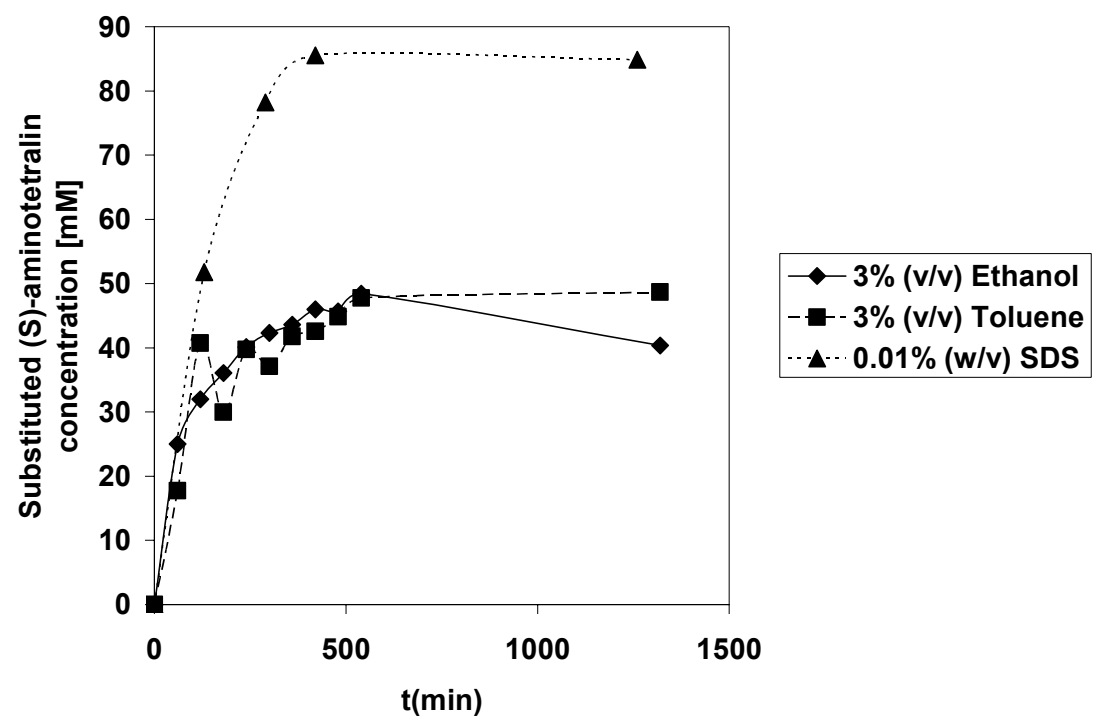

Figure 9-9: Profile concentration of total substituted (S)-aminotetralin produced using several cosolvents at $55^{\circ} \mathrm{C}, \mathrm{pH} \mathrm{7,} \mathrm{E}_{0}=5 \mathrm{~g} / \mathrm{l}$.

Figure 9-9 shows the total substituted (S)-aminotetralin produced by CNB05-01 at a concentration of 5 grams per liter using several cosolvents. The best production was obtained with the addition of SDS, but the conversion of this system (0.65) is about the same order as when SDS is not added (0.66). The addition of ethanol and toluene had a 
large negative impact in the performance of the enzyme under the specified conditions, as the conversion was not higher than 0.38 . Therefore ethanol and toluene apparently cause enzyme inhibition for CNB05-01.

\subsection{Effect of Nitrogen}

During the biotransformation reaction for the production of substituted (S)-aminotetralin, isopropylamine transfers its amine group to substituted tetralone, rendering as products the desired amine and acetone. From the reaction engineering point of view, as the reaction progresses there is accumulation of products, which decreases reaction rate and limits ultimate conversion. The removing of products would assure a rate of reaction that is fairly constant and would encourage complete conversion of reactants. In this process, acetone is a candidate to be removed from the reaction mixture, since its boiling point is around $57^{\circ} \mathrm{C}$, and the temperature at which the biotransformation is done is $55^{\circ} \mathrm{C}$, then it is expected to have a high volatility of acetone under this condition. As a standard procedure, the biotransformation reactions in a scale larger than $500 \mathrm{ml}$ are done using a flow rate of $100 \mathrm{ml} / \mathrm{min}$ to remove acetone from the system. This section shows the effect of the use of nitrogen at a flow rate of 10 and $100 \mathrm{ml} / \mathrm{min}$, pumped to the surface of the system, and a flow rate of $10 \mathrm{ml} / \mathrm{min}$ pumped into the system through a sparger. In order to do so, 0.5 grams of enzyme were added to $500 \mathrm{ml}$ of Solution $18 \mathrm{pH} 7$ (Table 3-II) at $55{ }^{\circ} \mathrm{C}$. Samples to evaluate total concentration of substituted (S)-aminotetralin were withdrawn. The results are shown in Figure 9-10. 


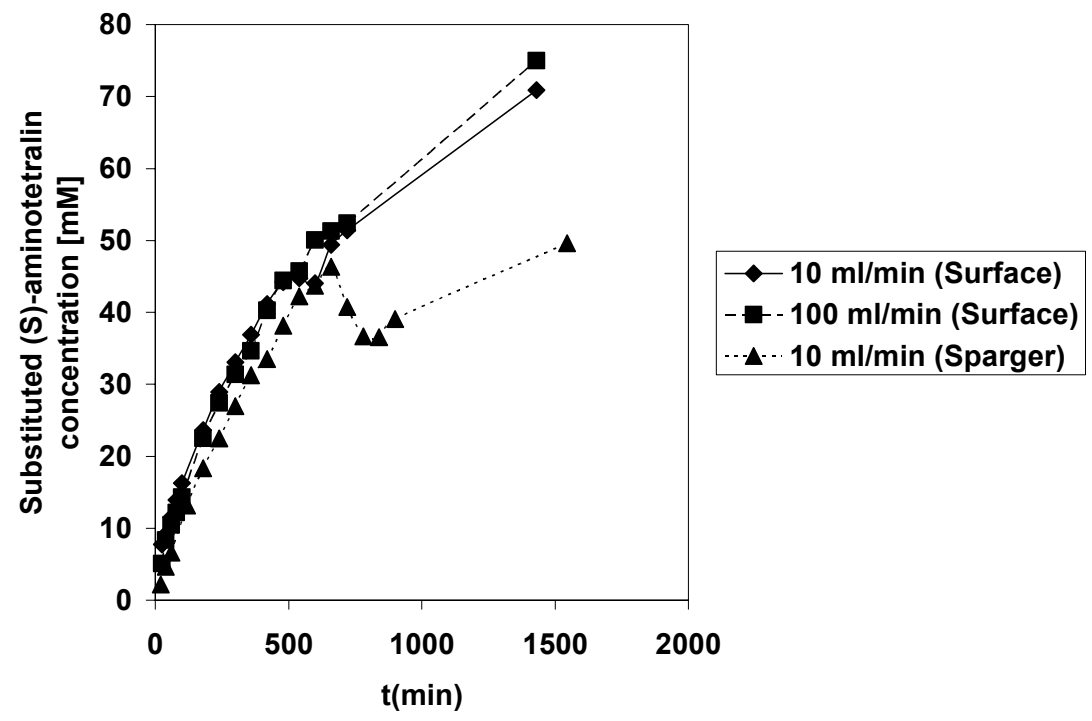

Figure 9-10: Effect of nitrogen flow in the production of (S)-aminotetralin at $55{ }^{\circ} \mathrm{C}$ using free CNB05-01 at $\mathrm{E}_{\mathrm{o}}=1 \mathrm{~g} / \mathrm{l}$.

Figure 9-10 shows the effect of nitrogen flow on the production of substituted (S)aminotetralin at $55^{\circ} \mathrm{C}$, using an enzyme concentration of 1 gram per liter. The flow of nitrogen at 10 and $100 \mathrm{ml} / \mathrm{min}$ on the surface of the system allow having the same concentration profile of product, while sending nitrogen at a flow rate of $10 \mathrm{ml} / \mathrm{min}$ into the system had a large effect on the biotransformation. Product concentration was 40 percent lower that the concentration achieved when nitrogen was pumped to the surface. When a flow rate of $100 \mathrm{ml} / \mathrm{min}$ of nitrogen was pumped through a sparger into the system, the system collapsed (data not shown). The collapsing of the system consisted of a sudden agglomeration of the substituted tetralone on the system. For the case of pumping nitrogen though a sparger at $10 \mathrm{ml} / \mathrm{min}$, the same events occurred, but over seven hours. It seems that acetone acts as a cosolvent, and then it seems that acetone is required at low concentrations in the system. The more efficient the removing of acetone (pumping gas through a sparger into the system), the lower the conversion. 


\subsection{Summary of Transamination Reaction Engineering}

Attempts to improve transamination reaction catalyzed by free CBN05-01 were done. They consisted of changes in enzyme concentration, temperature, $\mathrm{pH}$, and isopropylamine concentration, use of cosolvents, and varying flow rate of nitrogen. The experiments related to changes in enzyme concentration, at $100 \mathrm{ml}$ scale, showed that it was possible to achieve about the same final product concentration using 5 and 1 gram per liter of enzyme, in the normal operating time ( 24 hours), which may allow enzyme concentration to be reduced, although running the system at 5 grams per liter of CNB0501, the final product concentration can be achieved after 6 to 7 hours, which would reduce process time. The experiments done by changing temperature $\left(40-55^{\circ} \mathrm{C}\right)$ showed that the higher the temperature, the higher the conversion. The experiments runs at $\mathrm{pH} 6$ and $\mathrm{pH} 7$ showed that low $\mathrm{pH}$ decreases the rate at which imine is formed. Reducing imine formation may make it possible to avoid imine hydrolysis to recover substituted (S)-aminotetralin. The results obtained at $\mathrm{pH} 6$ open the possibility of future research to develop an (S)-aminotransferase with high activity at low $\mathrm{pH}$. The experiments, in which isopropylamine concentration was changed, indicated that the conversion of substituted tetralone is governed by an equilibrium relationship. It could have been thought that when running the system with a composition of $130 \mathrm{mM}$ substituted tetralone, $750 \mathrm{mM}$ isopropylamine, and $2 \mathrm{mM}$ Pyridoxal-5-phosphate, 100\% percent conversion was never achieved because of isopropylamine inhibition, but the system was run at lower isopropylamine concentration. The use of SDS as cosolvent did not improve the yield of the process significantly compared to no co-solvent. SDS during the recycling of 
immobilized CNB04-01 allowed for 3 recycles of this enzyme (Section 7.2.2). Toluene and Ethanol where used during the production of substituted (S)-aminotetralin catalyzed by immobilized CNB03-03 and CNB04-01, but apparently these co-solvents caused deactivation on CNB05-01, since the yield of the system with ethanol and toluene was about 0.40 in both cases, instead of 0.66 in the absence of it as a cosolvent. Pumping nitrogen into the system through a sparger, showed results opposite to what it was expected; an efficient acetone removal from the system would favor the formation of substituted tetralone. Instead of that, the final product concentration and overall yield was lower due to removal of this co-solvent in the system. Other process engineering approaches for selectively removing acetone, while not removing other co-solvents (SDS), might enhance the overall conversion in this reaction system. This is a candidate for a topic for future research.

Chapter 10 shows a summary of the overall improvements of the aminotransferase mutants and their sequences. It describes a partial sequence of the aminotransferase mutants from wild type to CNB05-01, the best mutant. 


\section{Chapter 10. Sequence and Properties of Aminotransferase Mutants}

\subsection{Introduction}

The production by biosynthesis of optically active amino acids and amines satisfies the pharmaceutical industry in its demand for chiral building blocks for the synthesis of various pharmaceuticals (Ager et al., 1997; Bommarius et al., 1998). Among several enzymatic methods that allow the synthesis of optically active aminoacids and amines, aminotransferase is a promising one (Cho et al., 2003) due to its broad substrate specificity and no requirement for external cofactor regeneration (Stewart, 2001). The synthesis of chiral compounds by aminotransferases can be done either by asymmetric synthesis starting from keto acids or ketones, and by kinetic resolution starting from racemic aminoacids or amines. Motivated by the rising demand for chiral amines by the pharmaceutical industry Cambrex Corporation developed its own technology to produce such compounds based on aminotransferases. The aminotransferases owned by Cambrex Corporation are aimed to satisfy the demand of the chiral amines shown in Table 10-I. 
Table 10-I: List of Chiral amine intermediates produced at an industrial scale (Cambrex Corporation).

1-Aminotetralin




6-Bromo-2-Aminotetralin

Cambrex Corporation's aminotranferases were obtained from a naturally occurring (S)aminotransferase found in Athrobacter citreus. This (S)-aminotransferase and its subsequent mutant were coded by a gene of $1.5 \mathrm{kbp}$ (kilo base pairs), have a molecular weigth of $65 \mathrm{kDa}$ and are composed by 480 amino acids. The corresponding genes were isolated, and then sub cloned into pSE420 and transformed into Escherichia coli MG1655. Once the selected gene was expressed in the host cell, it was subjected to random mutagenesis, and selected to improve the properties of the enzyme. The enzyme that motivated the research presented in this dissertation, CNB03-03, was obtained at Cambrex Corporation through several rounds of error-prone polymerase chain reaction. These steps of mutagenesis and the corresponding major changes through the generations until obtaining CNB03-03 are shown in Table 10-II. 
Table 10-II: Modifications of aminotransferases by Error-prone PCR.

\begin{tabular}{|c|c|c|c|c|}
\hline \multirow{2}{*}{$\begin{array}{l}\text { Amino acid } \\
\text { position }\end{array}$} & \multicolumn{4}{|c|}{ (S)-Aminotransferase } \\
\hline & $\begin{array}{c}\text { CEL9611 } \\
\text { (Figure 1-1 Wild type) }\end{array}$ & $\begin{array}{c}\text { CEL20065 } \\
\text { (Figure 1-1 Mutant 1) }\end{array}$ & $\begin{array}{c}\text { CHIR-9867 } \\
\text { (Figure 1-1 Mutant 2) }\end{array}$ & $\begin{array}{c}\text { CNB03-03 } \\
\text { (Figure 1-1 Mutant 3) }\end{array}$ \\
\hline 46 & $\mathrm{M}$ & $\mathrm{M}$ & $\mathrm{M}$ & $\mathrm{T}$ \\
\hline 48 & $\mathrm{D}$ & G & $\mathrm{D}$ & $\mathrm{G}$ \\
\hline 60 & $\mathrm{Y}$ & $\mathrm{Y}$ & $\mathrm{C}$ & $\mathrm{C}$ \\
\hline 164 & $\mathrm{Y}$ & $\mathrm{Y}$ & $\mathrm{F}$ & $\mathrm{F}$ \\
\hline 185 & $\mathrm{Y}$ & $\mathrm{Y}$ & $\mathrm{Y}$ & $\mathrm{Y}$ \\
\hline 186 & $\mathrm{~N}$ & $\mathrm{~N}$ & $\mathrm{~S}$ & $\mathrm{~S}$ \\
\hline 195 & $\mathrm{P}$ & $\mathrm{P}$ & $\mathrm{P}$ & $\mathrm{S}$ \\
\hline 197 & M & M & M & $\mathrm{T}$ \\
\hline 205 & $\mathrm{C}$ & $\mathrm{C}$ & $\mathrm{C}$ & $\mathrm{C}$ \\
\hline 242 & A & $\mathrm{V}$ & $\mathrm{V}$ & $\mathrm{V}$ \\
\hline 245 & A & $\mathrm{T}$ & $\mathrm{T}$ & $\mathrm{T}$ \\
\hline 252 & $\mathrm{I}$ & $\mathrm{I}$ & $\mathrm{V}$ & $\mathrm{V}$ \\
\hline 255 & $\mathrm{~F}$ & $\mathrm{~F}$ & $\mathrm{I}$ & I \\
\hline 268 & $\mathrm{~N}$ & $\mathrm{~N}$ & $\mathrm{~S}$ & $\mathrm{~S}$ \\
\hline 409 & $\mathrm{~T}$ & $\mathrm{~T}$ & $\mathrm{R}$ & $\mathrm{R}$ \\
\hline 424 & $\mathrm{~K}$ & $\mathrm{~K}$ & $\mathrm{E}$ & $\mathrm{E}$ \\
\hline 436 & $\mathrm{~V}$ & $\mathrm{~V}$ & A & A \\
\hline
\end{tabular}

Note: Sequence was obtained at SeqWright.

For aminoacid symbols see Appendix 7.

Table 10-II shows the evolution of an aminotransferase until arriving at the enzyme named CNB03-03. CEL9611 corresponds to the aminotransferase naturally occurring which is a mesophilic enzyme (Cambrex Corporation). CEL20065 is a mesophilic enzyme with higher activity than CEL9611 (Cambrex Corporation). CHIR-9867 is a thermophilic enzyme (Cambrex Corporation), and CNB03-03 is thermophilic enzyme with higher activity than CHIR-9867 (Cambrex Corporation). With this information as a background, the following sections will present the evolution of CNB03-03 until CNB0501 , and properties of the corresponding generations of mutants. 


\subsection{Mutant Sequence}

The aminotransferase CNB03-03 was screened aiming to produce substituted (S)aminotetralin at high temperature, since it is a thermophilic enzyme (optimum temperature $50{ }^{\circ} \mathrm{C}$ ). CNB03-03 catalyzed the biotransformation of substituted tetralone into substituted (S)-aminotetralin better than its predecessors. During the use of this enzyme, and similar ones, to produce the desired product, it was noticed that the cost to produce the enzyme was high and that a significant amount of the desired product was lost during the separation of the enzyme. To avoid these problems it was decided to use immobilization. This strategy would allow using the enzyme several times and an easy separation of the immobilized enzyme. CNB03-03 was immobilized, but the desired objectives as outlined before were not achieved. Analysis of the results obtained from its immobilization showed that its thermostability was not good enough to allow it to be recycled several times. Then CNB03-03 was engineered further to obtain an aminotransferase with improved thermostability that would allow its recycle. The resulting enzyme was CNB04-01. CNB04-01 showed better thermostability, therefore allowing three successful recycles; but then the activity of the immobilized enzyme dropped suddenly. It was identified that the reason of activity dropping of immobilized CNB04-01 was the accumulation of the byproduct imine inside of the immobilized preparation, which acted as a mass-transfer barrier. This problem was assumed to be present in the immobilization techniques, regardless of the immobilization procedure. After identifying this problem, it was decided to decrease the cost per batch of substituted (S)-aminotetralin and decrease product loses during biocatalyst separation by developing an enzyme of higher activity than CNB03-03 and CNB04-01. Using as a template 
CNB04-01, and enzyme with the characteristics desired before was obtained. This enzyme was CNB05-01. Changes in amino acids sequence in the evolution of aminotransferase CNB03-03 to aminotransferase CNB05-01 is shown in Table 10-III.

Table 10-III: Amino acid sequence changes in the evolution of CNB03-03 to CNB05-01.

\begin{tabular}{|c|c|c|c|}
\hline \multirow{2}{*}{$\begin{array}{c}\text { Amino } \\
\text { acid } \\
\text { position }\end{array}$} & \multicolumn{2}{|c|}{ (S)-Aminotransferase } \\
\hline 46 & CNB03-03 & CNB04-01 & CNB05-01 \\
\hline 48 & $\mathrm{~T}$ & $\mathrm{~T}$ & $\mathrm{~T}$ \\
\hline 60 & $\mathrm{G}$ & $\mathrm{G}$ & $\mathrm{G}$ \\
\hline 164 & $\mathrm{C}$ & $\mathrm{C}$ & $\mathrm{C}$ \\
\hline $\mathbf{1 8 5}$ & $\mathrm{F}$ & $\mathrm{F}$ & $\mathrm{F}$ \\
\hline 186 & $\mathrm{Y}$ & $\mathrm{S}$ & $\mathbf{C}$ \\
\hline 195 & $\mathrm{~S}$ & $\mathrm{~S}$ & $\mathrm{~S}$ \\
\hline 197 & $\mathrm{~S}$ & $\mathrm{~T}$ & $\mathrm{~S}$ \\
\hline $\mathbf{2 0 5}$ & $\mathrm{T}$ & $\mathrm{Y}$ & $\mathrm{T}$ \\
\hline 242 & $\mathrm{C}$ & $\mathrm{V}$ & Y \\
\hline 245 & $\mathrm{~V}$ & $\mathrm{~T}$ & $\mathrm{~V}$ \\
\hline 252 & $\mathrm{~T}$ & $\mathrm{~V}$ & $\mathrm{~T}$ \\
\hline 255 & $\mathrm{~V}$ & $\mathrm{I}$ & $\mathrm{V}$ \\
\hline 268 & $\mathrm{I}$ & $\mathrm{S}$ & $\mathrm{I}$ \\
\hline 409 & $\mathrm{~S}$ & $\mathrm{R}$ & $\mathrm{S}$ \\
\hline 424 & $\mathrm{R}$ & $\mathrm{E}$ & $\mathrm{R}$ \\
\hline 436 & $\mathrm{E}$ & $\mathrm{A}$ & $\mathrm{E}$ \\
\hline
\end{tabular}

Note: Sequence was obtained at SeqWright.

For aminoacid symbols see Appendix 7.

From Table 10-III it can be infered that the improvement on thermostability of CNB0401 over CNB03-03 is due to an aminoacid change on position 205 from cysteine on CNB03-03 to tyrosine in CNB04-01. Also, the improvement on activity of CNB05-01 over CNB04-01 can be related to an amino acid change in position 185 from tyrosine in CNB04-01 to cysteine on CNB05-01. CNB05-01 differs from CNB03-03 in two 
positions: position 185 from tyrosine in CNB03-03 to cysteine in CNB05-01, position 205 from cysteine in CNB03-03 to tyrosine in CNB05-01.

\subsection{Mutant properties}

The properties of the (S)-aminotransferases CNB03-03, CNB04-01, and CNB05-01 presented in Chapter 6 are summarized in Table 10-IV together with the major changes on amino acid sequence.

Table 10-IV: Aminotransferase properties and major changes on aminoacids sequence from CNB03-03 to CNB05-01.

\begin{tabular}{|c|c|c|c|c|c|c|c|}
\hline \multirow[t]{2}{*}{ Enzyme } & \multicolumn{6}{|c|}{ Enzyme properties } & \multirow{2}{*}{$\begin{array}{l}\text { Amino } \\
\text { acid } \\
\text { sequence }\end{array}$} \\
\hline & $\begin{array}{l}\text { Optimum } \\
\text { Temperature } \\
\left({ }^{\circ} \mathrm{C}\right)\end{array}$ & $\begin{array}{l}\text { Optimum } \\
\text { pH }\end{array}$ & $\begin{array}{l}\text { Optimum } \\
\mathbf{A}[\mathrm{mM}]\end{array}$ & $\begin{array}{l}V_{\max } \\
(\mathrm{mM} / \min )\end{array}$ & $\mathrm{K}_{\mathrm{m}}[\mathrm{mM}]$ & $\begin{array}{l}\text { Productivity } \\
\text { (mM/h/gram } \\
\text { spray dried } \\
\text { cells) }\end{array}$ & \\
\hline CNB03-03 & $50^{2}, 55^{1}$ & $7.7^{1}$ & $1000^{2}$ & $\begin{array}{l}0.08^{1} \\
\text { at } \mathrm{Eo}= \\
0.05 \\
\mathrm{mg} / \mathrm{ml}\end{array}$ & $1.77^{1}$ & $4.00^{2}$ & $\begin{array}{l}185 \\
\text { Tyrosine } \\
205 \\
\text { Cysteine }\end{array}$ \\
\hline CNB04-01 & $50^{2}, 55^{1}$ & $8.5^{1}$ & $500^{2}$ & $\begin{array}{l}0.03^{1} \\
\text { at Eo- } \\
0.025 \\
\mathrm{mg} / \mathrm{ml}\end{array}$ & $0.44^{1}$ & $4.00^{2}$ & $\begin{array}{l}185 \\
\text { Tyrosine } \\
205 \\
\text { Tyrosine }\end{array}$ \\
\hline CNB05-01 & $55^{2}$ & $6.5^{2}-7^{2}$ & $750^{2}$ & $\begin{array}{l}0.22^{2} \\
\text { at } \mathrm{Eo}= \\
1 \mathrm{mg} / \mathrm{ml}\end{array}$ & $10.4^{2}$ & $6.80^{2}$ & $\begin{array}{l}185 \\
\text { Cysteine } \\
205 \\
\text { Tyrosine }\end{array}$ \\
\hline
\end{tabular}

${ }^{(1)}$ Measured using the system of (S)-(-)- $\alpha$-methylbenzylamine

${ }^{(2)}$ Measured using the system of substituted tetralone

$50 \%$ in mass of spray dried cell is protein (Escherichia coli composition)

About $13 \%$ of total protein in spray dried cells is aminotransferase

Table 10-IV shows the properties measured for the different aminotransferases developed using as a template CNB03-03. From the properties shown in this table, the changes in optimum temperature for catalyzing the system of substituted tetralone and the 
productivity measured using the system of substituted tetralone are related to one aminoacid change from generation to generation. The aminoacids that changed were at positions 185 and 205. These amino acids were cysteine, which belong to the amino acid class hydroxyl or sulfur containing (Shuler and Kargi, 2002), and tyrosine, which belongs to the amino acid class of aromatics (Shuler and Kargi, 2002). From CNB03-03 to CNB04-01 optimum temperature and productivity for the system did not change, but the thermostability over time did change as shown in Chapter 8. From Table 10-III, this property can be related to the aminoacid change at position 205 from cysteine in CNB0303 to tyrosine in CNB04-01. Tyrosine as well as phenylalanine and tryptophan have been reported to contribute to thermal stability of thermophilic enzymes by formation of aromatic clusters (Kannan and Vishveshwara, 2000). Kannan and Vishveshwara reported that aromatic clusters are found to be relatively rigid regions of the protein surface and often are located close to the active site of the thermophilic enzyme. From the generation of CNB04-01 to CNB05-01 major changes in optimum temperature and productivity for the system of substituted tetralone occurred. The optimum temperature changed from 50 ${ }^{\circ} \mathrm{C}$ in $\mathrm{CNB} 04-01$ to $55{ }^{\circ} \mathrm{C}$ in $\mathrm{CNB} 05-01$, and productivity at $\mathrm{t}=0$ changed from 4 to 6.8 $\mathrm{mM} / \mathrm{h} / \mathrm{gram}$ of spray dried cells. These significant changes are related to one amino acid change at position 185, from tyrosine in CNB04-01 to cysteine in CNB05-01. Perhaps, cysteine at position 185 in CNB05-01 formed a disulfide bound that allowed having a higher turnover number. Maybe the disulfide bound formed by cysteine at position 185 in CNB05-01 allowed an easy exchange of material between the reaction media and the active site by opening up or exposing at some extent the active site to the reaction media. 
The aminotransferases CNB03-03, CNB04-01, and CNB05-01 inherited some of the major changes that took place in their predecessors. The aminoacid changes that are present on these aminotransferases that originated in their predecessors are: 1) 2 of the three amino acid changes that improve activity of CEL20065 over CEL9611, valine at position 242 and threonine at position 245; and 2) the amino acids related with improved thermostability of CHIR9867 over CEL20065, cysteine (60), phenylalanine (164), serine (186), valine (252), isoleucine (255), serine (268), arginine (409), glutamic acid (424), and alanine (436). CNB04-01 and CNB05-01 inherited from CNB03-03 the amino acids related with its improved activity over CHIR9867: threonine (46), glycine (48), serine (195), and threonine (197).

Chapter 11 summarizes the conclusions of the project titled "enzyme engineering of aminotransferases for improved activity and thermostability". 


\section{Chapter 11. Conclusions/Recommendations}

\section{Conclusions}

The conclusions of this Ph.D. research project, that had as a goal to minimize the cost contribution of spray dried cells of (S)-aminotransferase to total production cost of substituted (S)-aminotetralin, are shown below.

A. During the production of substituted (S)-aminotetralin the following variables were identified as key factors that contribute to overall production cost (percentages not shown, Cambrex North Brunswick).

1. Cost of the enzyme.

2. Process time.

3. Yield during product isolation.

The factors shown above affect the production cost in the manner explained in Chapter 1. In order to mitigate the effect of the stated production variables, immobilization of the current best enzyme for production of substituted (S)-aminotetralin, CNB03-03, was done. Immobilized CNB03-03, by entrapment on calcium alginate of concentration 3\% $(\mathrm{w} / \mathrm{v})$, showed to have a large decrease in activity as a function of time in the reaction system; also the yield of product decreased as well (Section 7.1). Therefore, the characteristics of immobilized CNB03-03 were not suitable to satisfy the requirements of the stated production variables. Analyzing the results obtained with this enzyme, it was believed that an enzyme with improved thermostability would satisfy those variables. An enzyme with better thermostability than CNB03-03 was obtained, CNB04-01 (Section

5.1). CNB04-01 was immobilized and tested in the production of substituted (S)- 
aminotetralin under the same conditions as immobilized CNB03-03. The results showed a sustained activity as a function of time under the reaction conditions (Section 7.2). The combination of immobilized CNB04-01 and sodium dodecyl sulfate at a concentration of $0.01 \%(\mathrm{w} / \mathrm{v})$ in the reaction system allowed re-using the immobilized preparation three times, obtained in each cycle considerably high product yields. These properties of immobilized preparation did not match the requirements of the production variables, which required about 10 cycles of the immobilized preparation (Number of cycles obtained as a result of an economic analysis, Cambrex confidential information). During the use of immobilized CNB04-01 a high deposition of substituted (S)-aminiotetralin and substituted tetralone was noted (Section 7.2) inside of the immobilized preparation. This product accumulation affected the mass transfer of products and reactants, slowing down the reaction and overall product yield after the third cycle. Since imine accumulation in the immobilized preparation may be common to all the immobilization techniques; immobilization was abandoned. Enzyme engineering of CNB04-01 for improved activity was selected to match the requirements of the production improvement goals. Through error prone PCR mutagenesis, CNB05-01 was obtained (Section 5.2) from CNB04-01. The new enzyme CNB05-01 showed a higher optimum temperature and better activity than CNB04-01 and CNB03-03 (Section 8.2). This enzyme, CNB05-01, would reduce the cost of the enzyme used per batch because enzyme concentrations on the reaction system of 5, 2.5, and 1 gram of spray dried cells per liter allowed the same product yield (Section 9.1). Concentration of product in reaction increased because this enzyme allows running the biotransformation at higher temperature. Using CNB05-01 would reduce the variable of process time because at an enzyme load of 5 grams of spray dried cells per 
liter, the equilibrium concentration in the system is reached after 7 hours (Section 9.1). Finally, the effect of yield during product isolation would be mitigated running the system at an enzyme load of one gram of spray dried cells per liter, since the lower the enzyme load the higher the yield during product isolation. But decreasing enzyme load would increase process time e.g. at a enzyme load of 5 grams of pray dried cells per liter the equilibrium concentration is reached after 7 hours, whereas it is reached after 24 hours at an enzyme load of one gram of spray dried cells of CNB05-01 per liter. CNB0501 has properties that allow mitigating the effect of some production variables on production cost; the way in which CNB05-01 would be used at large production scale will be determined after weighing its properties with the benefit obtained.

B. The improvements on activity and thermostability of CNB05-01 over CNB04-01 and CNB03-03 by error prone PCR mutagenesis would allow to decrease the effect of some production variables on the overall production cost of substituted (S)-aminotetralin (enzyme load/concentration or process time). Due to the confidentiality of process cost relationships, it was not possible as part of this project to quantify the magnitude of cost savings for substituting CNB05-01 for the current commercial enzyme.

C. The (S)-aminotransferase CNB04-01 has the same optimum temperature and productivity as CNB03-03 (Section 6.2). CNB04-01 differs from CNB03-03 in the amino acid at position 205, tyrosine in CNB04-01 cysteine in CNB03-03. Where tyrosine in CNB04-01 is related to the formation of aromatic clusters that improve thermostability (Kannan and Vishveshwara, 2000). CNB05-01 differs from CNB04-01 in the aminoacid at position 185; it changed from tyrosine in CNB04-01 to cysteine in CNB05-01. This 
aminoacid change allowed a higher optimum temperature and activity for CNB05-01 over its predecessors (Chapter 10).

D. The screening procedure is a critically important step for successful outcomes in errorprone PCR enzyme engineering. According to these results, the use of the reverse reaction in screening compared to the desired reaction during enzyme catalyzed production of substituted aminotetralin did not adversely affect the ability to isolate a more active mutant. During enzyme engineering, the screening procedure was determined by the desired property to improve. In the isolation of CNB04-01 from the mutants derived from $\mathrm{CNB} 03-03$, the improvements on thermostability were measured as the change on color intensity given by the reverse reaction of transamination as a function of time, where this intensity was compared to the intensity given by CNB03-03. The (S)aminotransferase CNB05-01 was isolated from mutants derived from CNB04-01. CNB05-01 was isolated for higher activity. High activity was correlated with temperature, since for certain reactions it is seen that the higher the temperature the higher the reaction rate. Also, the equilibrium constant, the ratio of concentrations of products to reactants, is a function of temperature; therefore designing a screening procedure based on temperature it was expected to find an enzyme with high activity (initial reaction rate per gram of spray dried cell) and capable of working at higher temperature that is related to a different equilibrium constant, which may be an indication of higher product yield. 


\section{Recommendations}

During the characterization of the (S)-aminotransferases studied several issues were observed that are recommended as a future work in order to improve the understanding of the reaction system and its interaction with sodium dodecyl sulfate, acetone and nitrogen.

A. The two main processes in the reaction system that occur during production of substituted (S)-aminotetralin, and the subsequent reaction of substituted (S)-aminotetralin with substituted tetralone to form imine (Section 6.2.2.4 and Section 9.2) were studied. But there is the possibility of other reactions occurring in the system, not within the enzyme environment but in the solution environment. These reactions are also related to imine formation, ketimines and aldimines. The reactions that could occur in the solution environment, shown at the end of Section 6.2.2.4.5, are the following.

a). Reaction between substituted tetralone and isopropylamine.

b). Reaction between acetone and isopropylamine.

c). Reaction between substituted (S)-aminotetralin and acetone.

d). Reaction between pyridoxal-5-phosphate and isopropylamine.

e). Reaction between pyridoxal-5-phosphate and substituted (S)-aminotetralin.

If reaction (a) is present on the reaction system, it would decrease the available substituted tetralone to react, although Section 6.2.2.4.5 shows an indication that this problem does not occur because the same activity for the cases of total concentrations of substituted tetralone of 30 and $130 \mathrm{mM}$ was measured, it could still progress to some extent. Reaction (b) if it occurs, would not interfere with the reaction since isopropylamine concentration is 5 to 6 times higher than acetone concentration during the whole reaction period. For reaction (c) there was no indication that it occurs on the 
system. Finally, reactions (d) and (e) deserve special attention because both of them are related with the reaction of pyridoxal-5-phosphate. Isopropylamine concentration is between 350 to 300 times higher that pyridoxal-5-phosphate concentration during the whole biotransformation period, and substituted (S)-aminotetralin concentration is no more than 40 times higher, at the end of the biotransformation. If these reactions proceed, they would affect the system significantly, since the concentration of pyridoxal-5phosphate is limited in solution ( $2 \mathrm{mM})$. In this case pyridoxal-5-phosphate could be withdrawn from the complex [pyridoxal-5-phosphate]-[Enzyme], therefore affecting enzyme activity as predicted in Section 6.2.2.4.1. The lower pyridoxal-5-phosphate concentration, the lower the enzyme activity would be. The reactions explained above could be a subject of future research.

B. Section 9.3 shows the effects of different $\mathrm{pH}$ on the biotransformation reaction. The $\mathrm{pH}$ values tested in this experiment were 6 and 7 . The overall result was that both systems, at $\mathrm{pH} 6$ and 7 produced about the same amount of substituted tetralin, but the the system at $\mathrm{pH} 6$ produced less imine. This suggests that if the biotransformation reaction is performed at a $\mathrm{pH}$ of 6 or lower imine formation is avoided. Avoiding imine formation implies saving on the hydrochloric acid used to hydrolize it. Therefore as future research it is suggested to perform a round of mutagenesis using as a template CNB05-01 to screen for a mutant with high activity at low $\mathrm{pH}$, e.g. lower than 6. CNB05-01 is suggested as a template since it was capable of catalyzing the system at $\mathrm{pH} 6$ without compromising its activity or final conversion of the system. 
C. Section 7.2.2 shows the effect of sodium dodecyl sulfate on the biotransformation reaction catalyzed by immobilized CNB04-01. Overall the addition of sodium dodecyl sulfate allowed having a higher product concentration on the system. Such effect is not accounted for in the (S)-aminotransferase model. It is recommended to study further its effect to couple it together with the (S)-aminotransferase model to describe the way (S)amininotransferase CNB04-01 works when immobilized.

D. Section 9.6 shows the effect of the use of nitrogen with the goal of removing acetone from the system, in order to displace the equilibrium and favor product formation. The results showed that when applying a nitrogen flow $(10$ and $100 \mathrm{ml} / \mathrm{min})$ in the surface of the reaction system there was not difference. But when applying nitrogen into the system using a sparger a large difference was noticed (Figure 9-10). Adding nitrogen through a sparger assures a more efficient removal of acetone, but the system, instead of responding with higher activity to this modification, collapsed. Based in these observations it is recommended as future research to investigate the roll of acetone in the system; does it act as a cosolvent of the system?, why did its efficient removal lead to a collapse of the system?, is it true that leaving acetone in the system is more beneficial than trying to remove it to increase conversion?

Through the understanding of all the possible ractions in the system, such as the development of an (S)-aminotransferase mutant with activity a low $\mathrm{pH}$, and the elucidation of the function of sodium dodecyl sulfate and acetone, it is belived this knowledge would improve the performance of the system towards higher yields of the biotransformation reaction to produce substituted (S)-aminotetralin. 


\section{References}

Ager DJ, Fotheringham IG, Laneman SA, Pantaleone DP, Taylo PP. 1997. The large scale synthesis of unnatural amino acids. Chimica oggi 15, 11-14.

Arnold, F. H. and Volkov, A. A. Design by directed evolution. Accounts of Chemical Research (1998), 31(3), 125-131.

Arnold, F. H. and Volkov, A. A. Directed evolution of biocatalysts. Current opinion in chemical Biology (1999), 3(1), 54-59.

Arnone, M. I.; Birolo, L.; Giamberini, M.; Cubellis, M. V.; Nitti, G.; Sannia, G.; Marino, G. Limited proteolysis as a probe of conformational changes in aspartate aminotransferase from Sulfolobus solfataricus. European Journal of Biochemistry (1992), 204(3), 1183-1189.

Austermühle-Bertola, E. (1973) Ph.D. Thesis, Eidgenössische Technische Hochscule Zürich.

Axen R., Myrin, P. A., Janson, J. C. Chemical fixation of chymotrypsin to waterinsoluble crosslinked dextran (sephadex) and solubilization of the enzyme derivatives by means of dextranase. Biopolymers (1970), 9(4), 401-413.

Berg, J. M., Tymoczko, J. L., and Stryer, L. (2002) Biochemistry. W. H. Freeman and Company. New York.

Bickerstaff, G. F. (1997) Immobilization of Enzymes and Cells. Humana Press. Totowa, New Jersey.

Bickerstaff, G.F. (1995) Impact of genetic technology on enzyme technology. Genet. Engineer Biotechnologist 15, 13-30.

Bommarius AS, Schwarm M, Drauz K. 1998. Biocatalysis to amino acid-based chiral pharmaceuticals-Examples and perspectives. J Mol Catalysis 5, 1-11.

Bornscheuer, U. T. Trends and challenges in enzyme technology. Advances in biochemical engineering/biotechnology (2005), 100 181-203.

Borri Voltattorni, C., Orlacchio, A., Giartosio, A., Conti, F., Turano, C. Binding of coenzymes and analogs of the substrate-coenzyme complex to tyrosine aminotransferase. European Journal of Biochemistry (1975), 53(1), 151-160.

Braunstein, A.E. Principal ways of assimilation \& dissimilation of nitrogen in animals. Advances in enzymology and related subjects of biochemistry (1957), 19 335-89. 
Brodelius, P (1985) Enzymes and Immobilized cells in Biotechnology, 109-148.

Brummer, W., Hennrich, N., Klockow, M., Lang, H., Orth, H. D. Preparation and properties of carrier-bound enzymes. European journal of biochemistry / FEBS (1972), 25(1), 129-135.

Cheetham, P.S. J., Blunt, K.W., and Bucke, C. Physical studies on cell immobilization using calcium alginate gels. Biotechnology and Bioengineering (1979), 21(12), 21552168.

Chibata, I., Tetsuya, T., Sato, T., Mori, T. (1978) Immobilized Enzymes, Research and Development. Kodansha, Tokyo.

Chiesi, P., Bongrani, S., Razetti, R., Civelli, M., Umile, A. Aminotetralin derivative for the therapy of cardiovascular diseases. PCT Int. Appl. (1996), 18 pp. CODEN: PIXXD2 WO 9629065 A2 19960926 CAN 125:317359 AN 1996:685385 CAPLUS

Chirumamilla, R. R., Muralidhar, R., Marchant, R., Nigam, P. Improving the quality of industrially important enzymes by directed evolution. Molecular and Cellular Biochemistry (2001), 224(1\&2), 159-168.

Christen P. and D. Metzler. (1985) Transaminases. John Wiley \& Sons. pp 642.

Cho B.K., Cho H.J., Park S.H., Yun H. 2003. Simultaneous synthesis of enantiomerically pure (S)-aminoacids and $(\mathrm{R})$-amines using coupled Transaminase reactions. Biotechnology and bioengineering 81(7), 783-789.

Cleland, W.W. The kinetics of enzyme-catalyzed reactions with two or more substrates or products. I. Nomenclature and rate equations. Biochimica et biophysica acta (1963), 67 $104-137$.

Cleland, W.W. The kinetics of enzyme-catalyzed reactions with two or more substrates or products. II. Inhibition: nomenclature and theory. Biochimica et biophysica acta (1963), 67 173-187.

Cleland, W.W. The kinetics of enzyme-catalyzed reactions with two or more substrates or products. III. Prediction of initial velocity and inhibition patterns by inspection. Biochimica et biophysica acta (1963), 67 188-96.

Crameri, A., Raillard, S. A., Bermudez, E., Stemmer, W. P. DNA shuffling of a family of genes from diverse species accelerates directed evolution. Nature (1998), 391(6664), 288-91.

Davis, E. D., Davis, R. J. (2003) Fundamentals of Chemical Reaction Engineering. First Edition. Mc-Graw Hill. New York. 
Edwards-Lévy, F., and Lévy, M. C. Serum albumin-alginate coated beads: mechanical properties and stability. Biomaterials (1999), 20(21), 2069-2084.

Faber, K. (1995) Biotransformation in Organic Chemistry, Springer-Verlag, Berlin, p. 3. Filippusson, H., Hornby, W. E. The preparation and properties of yeast betafructofuranosidase chemically attached to polystyrene. The Biochemical journal (1970), 120(1), 215-219.

Golichowski, A., Harruff, R. C., \& Jenkins, W. T. Inactivation of pig heart alanine aminotransferase by b-chloroalanine. Archives of Biochemistry and Biophysics (1978), 189(1), 109-114.

Gregor, H. P., Rauf, P. W. Enzyme-coupled ultrafiltration membranes. Biotechnology and Bioengineering (1975), 17(3), 445-449.

Guthrie, R. D., Meister, W., Cram, D. J. 1,3-Aymmetric induction in a transamination reaction. Journal of the American Chemical Society (1967), 89(20), 5288-5290.

Hornby, W. E., Lilly, M. D., Crook, E. M. Some changes in the reactivity of enzymes resulting from their chemical attachment to water-insoluble derivatives of cellulose. Biochemical Journal (1968), 107(5), 669-674.

Ikeda, S., Fukui, S. Preparation of pyridoxal 5'-phosphate-bound sepharose and its use for immobilization of tryptophanase. Biochemical and biophysical research communications (1973), 52(2), 482-8.

Ivanov, V. I., Breusov, Y. N., Karpeiskii, M. Y., Polyanovskii, O. L. Optical activity of enzyme-substrate intermediates of glutamic-aspartic Transaminase. Molekulyarnaya Biologiya (Moscow) (1967), 1(4), 588-595.

Kannan N, Vishveshwara S. 2000. Aromatic clusters: a determinant of thermal stability of thermophilic proteins. Protein Engineering 13(11), 753-761.

Kawai, K., Eguchi, Y. Preparation of immobilized NADH oxidase and its use as a regenerator. Hakko Kogaku Zasshi (1975), 53(8), 588-594.

Kim, D. S., Moses, U., Churchich, J. E. Gabaculine and m-carboxyphenyl-pyridoxamine 5-phosphate as probes of the catalytic binding sites of 4-aminobutyrate aminotransferase. European Journal of Biochemistry (1981), 118(2), 303-308.

Klibanov, A. M. Immobilized enzymes and cells as practical catalysts. Science (Washington, DC, United States) (1983), 219(4585), 722-727.

Kobayashi K., Miyazawa, S., Endo, A. Isolation and inhibitory activity of gabaculine, a new potent inhibitor of gamma-aminobutyrate aminotransferase produced by a Streptomyces. FEBS letters (1977), 76(2), 207-210. 
Kuby, S. A. (1991) A study of Enzymes volume I, CRC Press, pp 472.

Marshall, D. L., Walter, J. L. Polysaccharide synthesis on immobilized phosphorylase. Carbohydrate research (1972), 25(2), 489-495.

Martinez-Carrion M., Tiemeier, D. C., Peterson, D. L. Conformational properties of the isoenzymes of aspartate transaminase and the enzyme-substrate complexes. Biochemistry (1970), 9(13), 2574-2582.

Martinez-Carrion, M. Phosphorus-31 nuclear magnetic resonance studies of pyridoxal and pyridoxamine phosphates. Interaction with cytoplasmic aspartate transaminase. European Journal of Biochemistry (1975), 54(1), 39-43.

Martinez-Carrion, M.,Slebe, J. C., Gonzalez, M. Stereochemistry of holoaspartate transaminase after modification of the active site Lys-258. Journal of Biological Chemistry (1979), 254(9), 3160-3162.

Mason, R. D., Weetall, H. H. Invertase covalently coupled to porous glass: preparation and characterization. Biotechnology and bioengineering (1972), 14(4), 637-645.

Mattingly, M. E., Mattingly, J. R., Martinez-Carrion, M. Phosphorus-31 nuclear magnetic resonance of mitochondrial aspartate aminotransferase. The effects of solution pH and ligand binding. Journal of Biological Chemistry (1982), 257(15), 8872-8878.

May, S. W., Padgette, S. R. Oxidoreductase enzymes in biotechnology: current status and future potential. Biotechnology (1983), 1(8), 677-686.

Metzler, D. E., Jansonius, J. N., Arnone, A., Martinez-Carrion, M., Manning, J. M. Transaminases. Federation proceedings (1982), 41(8), 2432-2436.

Montanari, S., Cavalleri, P., Santangelo, F., Marchini, F. Preparation of 6-hydroxy-5hydroxymethyl-2-aminotetralins as cardiovascular agents. PCT Int. Appl. (1998), 19 pp. CODEN: PIXXD2 WO 9838155 A1 19980903 CAN 129:216427 AN 1998:608593 CAPLUS

Monsan, P. Durand, G. Preparation of insolubilized invertase by adsorption on bentonite. FEBS Letters (1971), 16(1), 39-42.

Mori, T., Sato, T., Tosa, T., Chibata, I. Studies on immobilized enzymes. X. Preparation and properties of aminoacylase entrapped into acrylamide gel-lattice. Enzymologia (1972), 43(4), 213-226.

Mori, T., Tosa, T., Chibata, I. Enzymatic properties of microcapsules containing asparaginase. Biochimica et biophysica acta (1973), 321(2), 653-661.

Muller, G. W. (1997) Chemtech, January, 21-25. 
O'Driscoll, K. F. Techniques of enzyme entrapment in gels. Methods in enzymology (1976), 44 169-83.

Pannuri, S., Kamat, S. V., Garcia, A. R. M. Methods for engineering Arthrobacter citreus w-transaminase variants with improved thermostability for use in enantiomeric enrichment and stereoselective synthesis. PCT Int. Appl. (2006(a)), 54 pp. CODEN: PIXXD2 WO 2006063336 A2 20060615 AN 2006:566797

Pannuri, S., Martin, A., Shonnard, D., Kamat, S., DiSanto, R., Plotnikov, I. Targeting Biocatalytic Processes for Improvment Based on Economic Analysis. Drug development 2006 (2006(b)), 73-74. Reference Section: 3 pages. Available at: http://www.touchbriefings.com/pdf/1842/ACF1A5.pdf on November 30, 2006.

Pannuri, S., DiSanto, R., \& Kamat, S. (2002) Encyclopedia of Catalysis. 1. John Wiley \& Sons Inc, 722-737.

Park, H. J., Khang, Y. H. Production of cephalosporin C by immobilized Cephalosporium acremonium in polyethyleneimine-modified barium alginate. Enzyme and Microbial Technology (1995), 17(5), 408-12.

Rando, R. R., Bangerter, F. W. The irreversible inhibition of mouse brain gaminobutyric acid (GABA)-a-ketoglutaric acid transaminase by gabaculine. Journal of the American Chemical Society (1976), 98(21), 6762-6764.

Rando, R. R. Mechanism of the irreversible inhibition of g-aminobutyric acid-aketoglutaric acid transaminase by the neurotoxin gabaculine. Biochemistry (1977), 16(21), 4604-4610.

Reetz, M. T. Application of directed evolution in the development of enantioselective enzymes. Pure and Applied Chemistry (2000), 72(9), 1615-1622.

Relimpio, A., Slebe, J. C., Martinez-Carrion, M. Fluorinated amino acids and phosphopyridoxyl fluoroamino acids as reversible active site directed inhibitors of aspartate transaminase. Biochemical and Biophysical Research Communications (1975), 63(3), 625-34.

Royer, G. P., Andrews, J. P. Immobilized derivatives of leucine aminopeptidase and aminopeptidase M. Applications in protein chemistry. The Journal of biological chemistry (1973), 248(5), 1807-1812.

Sato, T., Mori, T; Tosa, T., Chibata, I. Studies on immobilized enzymes. IX. Preparation and properties of aminoacylase covalently attached to halogenoacetylcelluloses. Archives of biochemistry and biophysics (1971), 147(2), 788-796. 
Scheller D., Breidenbach, A., Selve, N. Substituted 2-aminotetralins for the treatment of depression. PCT Int. Appl. (2005(a)), 34 pp. CODEN: PIXXD2 WO 2005009425 A1 20050203 CAN 142:191296 AN 2005:96454 CAPLUS

Scheller, D., Dressen, F. Use of substituted 2-aminotetralins for the preventative treatment of Parkinson's disease. PCT Int. Appl. (2005(b)), 35 pp. CODEN: PIXXD2 WO 2005063238 A1 20050714 CAN 143:109815 AN 2005:612083 CAPLUS

Shuler, M. L., and Kargi, F. (2002) Bioprocess Engineering Basic Concepts. Second Edition. Prentice Hall International Series in the Physical and Chemical Engineering Sciences. Upper Saddle River, New Jersey.

Smidsrod, O., Skjak-Braek, G. Alginate as immobilization matrix for cells. Trends in biotechnology (1990), 8(3), 71-78.

Smith, J. C., Stratford, I. J., Hutchinson, D. W., Brentnall, H. J. Insoluble derivatives of polynucleotide phosphorylase. FEBS Letters (1973), 30(2), 246-248.

Song, J. K.,Rhee, J. S. Simultaneous enhancement of thermostability and catalytic activity of phospholipase A1 by evolutionary molecular engineering. Applied and Environmental Microbiology (2000), 66(3), 890-894.

Stemmer, W. P. Searching sequence space. Biotechnology (1995), 13, 549-533

Stemmer, W. P. DNA shuffling by random fragmentation and reassembly: in vitro recombination for molecular evolution. Proceedings of the National Academy of Sciences of the United States of America (1994), 91(22), 10747-51.

Stirling, D. I. (1993) Biocatalysis - a commercial reality? Celgene Corporation. Chiral'93.

Storey, K. B., Schafhauser-Smith, D. Y. Immobilization of polysaccharide-degrading enzymes. Biotechnology \& Genetic Engineering Reviews (1994), 12 409-465.

Strandberg, G. W., Smiley, K. L. Glucose isomerase covalently bound to porous glass beads. Biotechnology and bioengineering (1972), 14(3), 509-513.

Stewart JD. 2001. Dehydrogenases and Transaminases in asymmetric synthesis. Curr Opin Chem Biol 5, 120-129.

Takami, T., Ando, T. Studies on trypsin and chmotrypsin chemically bound to carboxymethylcellulose. Seikagaku. The Journal of Japanese Biochemical Society (1968), 40(10), 749-759. 
Tosa, T., Mori, T., Fuse, N., Chibata, I. Continuous enzyme reactions. V. Kinetics and industrial application of aminoacylase columns for continuous optical resolution of acylDL-amino acids. Agricultural and Biological Chemistry (1969), 33(7), 1047-1052.

Tosa, T., Mori, T., Fuse, N., Chibata, I. Studies on continuous enzyme reactions. 3. Enzymatic properties of the DEAE-cellulose-aminoacylase complex. Enzymologia (1967), 32(3), 153-168.

Tsai, M. D., Byrn, S. R., Chang, C. J., Floss, H. G., Weintraub, H. J. R. Conformational analysis of pyridoxal Schiff's bases. Nuclear magnetic resonance studies of the conformations about the C4-C4', Ca-Cb, and N-Ca bonds of the pyridoxal Schiff's bases of amino acids. Biochemistry (1978), 17(16), 3177-3182.

Tumanyan, V. G.; Mamaeva, O. K.; Bocharov, A. L.; Ivanov, V. I.; Karpeisky, M. Y.; Yakovlev, G. I. Conformation of pyridoxal phosphate imine in solution and in aspartate aminotransferase active site. European Journal of Biochemistry (1974), 50(1), 119-127.

Usami, S., Kuratsu, Y., Preparation and properties of water-insoluble saccharase immobilized on polyacrylamide gel. Hakko Kogaku Zasshi (1973), 51(11), 789-794.

Walter, B. Characterization of agarose-bound trypsin. Biochimica et biophysica acta (1976), 429(3), 950-953.

Warawa, E. J., Migler, B. Preparation of aminotetralins for the treatment or prevention of movement disorders. U.S. (1998), 16 pp. CODEN: USXXAM US 5807897 A 19980915 CAN 129:230541 AN 1998:604667 CAPLUS

Weetall, H. H., Baum, G., Ward, F. B. Acetylcholinesterase-siloxane-glass adducts. Amer. Chem. Soc. Div. Org. Coatings Plast Chem. (1971), 31(2).

Weetall, H. H. Enzymes immobilized on inorganic carriers. Research/Development (1971), 22(12), 18-22.

Wong, D. W. S., Batt, S. B., Lee, C. C., Robertson, G. H. High-Activity Barley aAmylase by Directed Evolution. Protein Journal (2004), 23(7), 453-460.

Zhang, Y., Zhihu, Z., Fuguang, L., Cheng, C. Chuanxuan, L., Qingjun, M. High-level espression of a polypeptides encoded by a large segment of the envelope gene of HIV-1 in E. coli by directed evolution. Biotechnology Letters (2000), 22, 947-950.

Zito, S. W., Martinez-Carrion, M. Stereospecificity of sodium borohydride reduction of Schiff bases at the active site of aspartate aminotransferase. The Journal of Biological Chemistry (1980), 255(18), 8645-9. 


\section{Appendices}

\section{Appendix 1: Calibration curve for acetophenone.}

A solution of acetophenone (Aldrich) $15 \mathrm{mM}$ was prepared in water at $25^{\circ} \mathrm{C}$, and then used to make standards of $10 \mathrm{ml}$ of concentrations $12.5,10,7.5,5,3,1,0.75,0.5,0.25$, and $0.05 \mathrm{mM}$. To achieve such a volume, pipettes of $0.2,1,5$ and $10 \mathrm{ml}$ were used, therefore incurring in the errors given by them. The volume of standard (Vs) to achieve the desired concentration was given by $\mathrm{Vs}_{\mathrm{s}}=\mathrm{V}_{(5-10) \mathrm{S}}+\mathrm{V}_{(.2-1) \mathrm{S}}$, where $\mathrm{V}_{(5-10) \mathrm{S}}$ was the volume of standard measured with the pipettes of 5 or $10 \mathrm{ml}$, and $\mathrm{V}_{(.2-1) \mathrm{S}}$ the one measured with the pipettes of 0.2 or $1 \mathrm{ml}$. The volume of water $(\mathrm{Vw})$ to achieve the desired concentration was given by $\mathrm{Vw}=\mathrm{V}_{(5-10) \mathrm{W}}+\mathrm{V}_{(.2-1) \mathrm{W}}$, where $\mathrm{V}_{(5-10) \mathrm{W}}$ was the volume of water measured with the pipettes of 5 or $10 \mathrm{ml}$, and $\mathrm{V}_{(.2-1) \mathrm{W}}$ the one measured with the pipettes of 0.2 or $1 \mathrm{ml}$. Then the concentration of the standard was given by the following equation.

$C_{S}=\frac{\left(V_{(5-10) S}+V_{(.2-1) S}\right) C_{S 0}}{V_{(5-10) S}+V_{(.2-1) S}+V_{(5-10) W}+V_{(.2-1) W}}$

Where Cs 0 was $15 \mathrm{mM}$. Then, the error of Cs is given by the following equation.

$$
\begin{aligned}
\Delta C_{S}= & \frac{\left(V_{(5-10) W}+V_{(.2-1) W}\right) C_{S 0}}{\left(V_{(5-10) S}+V_{(.2-1) S}+V_{(5-10) W}+V_{(.2-1) W}\right)^{2}}\left(\Delta V_{(5-10) S}+\Delta V_{(.2-1) S}\right) \\
& -\frac{\left(V_{(5-10) S}+V_{(.2-1) S}\right) C_{S 0}}{\left(V_{(5-10) S}+V_{(.2-1) S}+V_{(5-10) W}+V_{(.2-1) W}\right)^{2}}\left(\Delta V_{(5-10) W}+\Delta V_{(.2-1) W}\right)
\end{aligned}
$$

Where $\Delta \mathrm{V}_{(\mathrm{i})}$ was given by $\Delta \mathrm{V}_{(\mathrm{i})}=\mathrm{V}_{(\mathrm{i})} * \mathrm{EV}(\mathrm{i})$. 
The error incurred in the preparation of the standards is shown in Table 1.1.

Table 1.1: Error incurred in the preparation of the standards

\begin{tabular}{|r|r|r|r|r|r|r|r|r|r|}
\hline$C_{S}$ & $V_{(5-10) S}$ & $V_{(.2-1) S}$ & $V_{(5-10) W}$ & $V_{(.2-1) W}$ & $\Delta V_{(5-10) S}$ & $\Delta V_{(.2-1) S}$ & $\Delta V_{(5-10) W}$ & $\Delta V_{(.2-1) W}$ & $\Delta C_{S}$ \\
\hline 15 & 10 & 0 & 0 & 0 & 0.04 & 0 & 0 & 0 & 0 \\
12.5 & 8 & 0.33 & 1 & 0.67 & 0.03 & $2.5 \times 10^{-3}$ & 0.01 & $5.0 \times 10^{-3}$ & 0.04 \\
10 & 6 & 0.67 & 3 & 0.33 & 0.02 & $5 \times 10^{-3}$ & 0.05 & $2.5 \times 10^{-3}$ & 0.07 \\
7.5 & 5 & 0 & 5 & 0 & 0.08 & 0 & 0.08 & 0 & 0.13 \\
5 & 3 & 0.33 & 6 & 0.67 & 0.05 & $2.5 \times 10^{-3}$ & 0.02 & $5.0 \times 10^{-3}$ & 0.07 \\
3 & 2 & 0 & 8 & 0 & 0.03 & 0 & 0.03 & 0 & 0.05 \\
1 & 0 & 0.67 & 9 & 0.33 & 0 & $5 \times 10^{-3}$ & 0.03 & $2.5 \times 10^{-3}$ & 0.01 \\
0.75 & 0 & 0.5 & 9 & 0.5 & 0 & $3.8 \times 10^{-3}$ & 0.03 & $3.8 \times 10^{-3}$ & $8.2 \times 10^{-3}$ \\
0.5 & 0 & 0.33 & 9 & 0.67 & 0 & $2.5 \times 10^{-3}$ & 0.03 & $5.0 \times 10^{-3}$ & $5.6 \times 10^{-3}$ \\
0.25 & 0 & 0.17 & 9 & 0.83 & 0 & $1.3 \times 10^{-3}$ & 0.03 & $6.3 \times 10^{-3}$ & $2.9 \times 10^{-3}$ \\
0.05 & 0 & 0.03 & 9 & 0.97 & 0 & $2.6 \times 10^{-4}$ & 0.03 & $7.3 \times 10^{-3}$ & $5.9 \times 10^{-4}$ \\
\hline
\end{tabular}

After preparing the standards of the concentration shown above, $0.2 \mathrm{ml}$ of those standards were diluted with $0.8 \mathrm{ml}$ of $\mathrm{HCl}$ (sigma) $0.1 \mathrm{~N}$. The analysis of error incurred in this process is shown below.

The concentration was given by the following equation.

$C=\frac{V_{S} C_{S}}{V_{S}+V_{A}}$

Where $\mathrm{C}$ is the concentration of the final standard to be loaded to HPLC, Vs and Cs are the volume and concentration of the standard, and $\mathrm{VA}$ was the volume of $\mathrm{HCl} 0.1 \mathrm{~N}$. The error on $\mathrm{C}$ was given by the following equation. 
$\Delta C=\frac{C_{S}}{\left(V_{S}+V_{A}\right)^{2}}\left(V_{A} \Delta V_{S}-V_{S} \Delta V_{A}\right)+\frac{V_{S}}{V_{S}+V_{A}}\left(\Delta C_{S}\right)$

Where $\Delta \mathrm{V}_{\mathrm{s}}$ was $0.00155 \mathrm{ml}$, and $\Delta \mathrm{V}_{\mathrm{A}}$ was $0.006 \mathrm{ml}$.

The error on $\mathrm{C}$ is shown in Table 1.2.

Table 1.2: Error on C

\begin{tabular}{|c|c|c|c|c|c|c|c|}
\hline$C_{S}$ & $\Delta C_{S}$ & $V_{S}$ & $V_{A}$ & $\Delta V_{S}$ & $\Delta V_{A}$ & $C$ & $\Delta C$ \\
\hline 15 & 0 & 0.2 & 0.8 & $1.6 \times 10^{-3}$ & $6.0 \times 10^{-3}$ & 3 & 0.04 \\
\hline 12.5 & 0.04 & 0.2 & 0.8 & $1.6 \times 10$ & $6.0 \times 10^{-3}$ & 2.5 & 0.04 \\
\hline 10 & 0.07 & 0.2 & 0.8 & $1.6 \times 10$ & $6.0 \times 10^{-3}$ & 2 & 0.04 \\
\hline 7.5 & 0.13 & 0.2 & 0.8 & $1.6 \times 10$ & $6.0 \times 10^{-3}$ & 1.5 & 0.04 \\
\hline 5 & 0.07 & 0.2 & 0.8 & $1.6 \times 10$ & $6.0 \times 10^{-3}$ & 1 & 0.02 \\
\hline 3 & 0.05 & 0.2 & 0.8 & $1.6 \times 10$ & $6.0 \times 10^{-3}$ & 0.6 & 0.02 \\
\hline 1 & 0.011 & 0.2 & 0.8 & $1.6 \times 10$ & $6.0 \times 10^{-3}$ & 0.2 & $4.5 \times 10^{-3}$ \\
\hline 0.75 & 0.01 & 0.2 & 0.8 & $1.6 \times 10$ & $6.0 \times 10^{-3}$ & 0.15 & $3.5 \times 10^{-3}$ \\
\hline 0.5 & $5.6 \times 10^{-3}$ & 0.2 & 0.8 & $1.6 \times 10$ & $6.0 \times 10^{-3}$ & 0.1 & $2.3 \times 10^{-3}$ \\
\hline 0.25 & $2.9 \times 10^{-3}$ & 0.2 & 0.8 & $1.6 \times 10$ & $6.0 \times 10^{-3}$ & 0.05 & $1.2 \times 10^{-3}$ \\
\hline 0.05 & $5.9 \times 10^{-4}$ & 0.2 & 0.8 & $1.6 \times 10$ & $6.0 \times 10^{-3}$ & 0.01 & $2.4 \times 10^{-4}$ \\
\hline
\end{tabular}

Finally, the samples of concentration $\mathrm{C}$ were analyzed by triplicate as described in Chapter 3. The results are shown in Table 1.3.

Table 1.3: Analysis of the standards

\begin{tabular}{|c|c|c|c|c|c|c|}
\hline$C_{S}$ & $\Delta C_{S}$ & $\begin{array}{l}\text { Signal 1 } \\
{\left[\mathrm{mAU}^{*} \mathrm{~s}\right]}\end{array}$ & $\begin{array}{l}\text { Signal 2 } \\
{\left[\mathrm{mAU}^{*} \mathrm{~s}\right]}\end{array}$ & $\begin{array}{l}\text { Signal } 3 \\
\text { [mAU*s] }\end{array}$ & $\begin{array}{l}\text { Average } \\
{\left[\mathrm{mAU}^{*} \mathrm{~s}\right]}\end{array}$ & $\begin{array}{l}\text { Standard } \\
\text { deviation } \\
{\left[\mathrm{mAU}^{*} \mathrm{~s}\right]}\end{array}$ \\
\hline 0.01 & $2.4 \times 10^{-4}$ & 84.67 & 85.32 & 85.20 & 85.06 & 0.34 \\
\hline 0.05 & $1.2 \times 10^{-3}$ & 383.68 & 382.71 & 384.45 & 383.61 & 0.87 \\
\hline 0.1 & $2.3 \times 10^{-3}$ & 748.28 & 748.46 & 747.80 & 748.18 & 0.34 \\
\hline 0.15 & $3.5 \times 10^{-3}$ & 1121.74 & 1120.71 & 1122.10 & 1121.52 & 0.72 \\
\hline 0.2 & $4.6 \times 10^{-3}$ & 1570.10 & 1568.45 & 1635.60 & 1591.38 & 38.29 \\
\hline 0.6 & 0.02 & 4623.21 & 4558.17 & 4555.27 & 4578.88 & 38.41 \\
\hline 1 & 0.03 & 7320.61 & 7366.22 & 7319.94 & 7335.59 & 26.52 \\
\hline 1.5 & 0.04 & 11188.50 & 11113.20 & 11125.20 & 11142.30 & 40.45 \\
\hline 2 & 0.04 & 13149.40 & 13156.90 & 13169.00 & 13158.43 & 9.88 \\
\hline 2.5 & 0.04 & 17300.30 & 17411.20 & 17308.60 & 17340.03 & 61.77 \\
\hline 3 & 0.04 & 20257.00 & 20238.80 & 20225.20 & 20240.33 & 15.95 \\
\hline
\end{tabular}

With the data shown above, two calibration curves were derived, one covering the range of 0.01 to $0.15 \mathrm{mM}$ (Figure 1.1), and another from 0.15 to $3 \mathrm{mM}$ (Figure 1.1). 


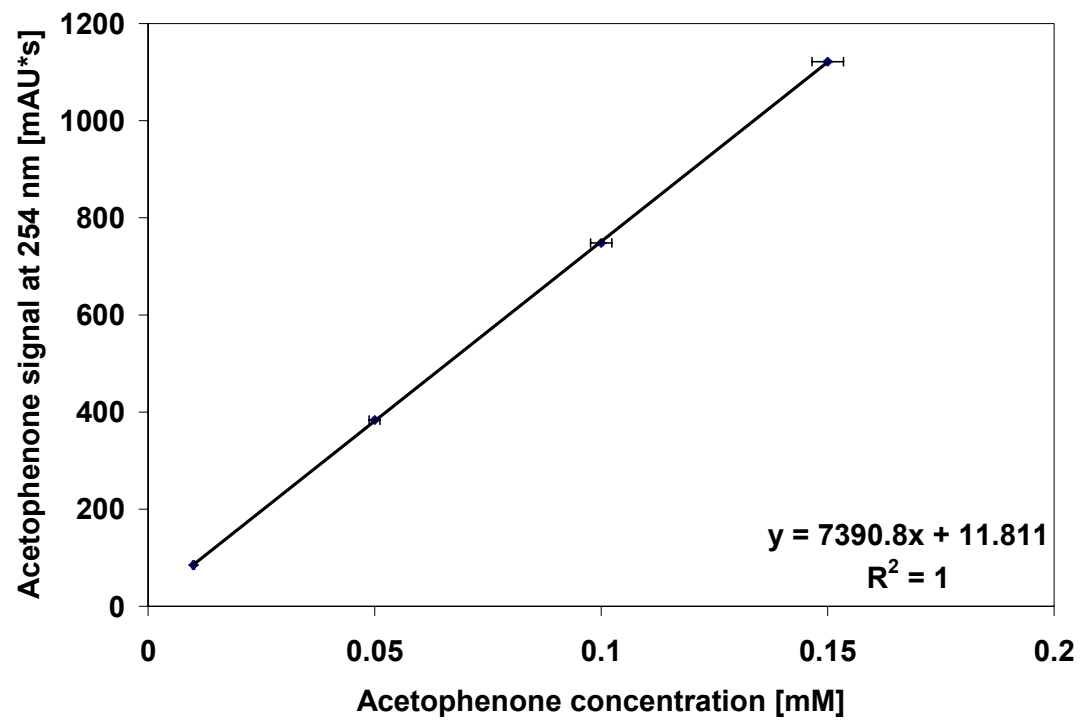

Figure 1.1: Calibration curve for acetophenone for low concentrations

Acetophenone concentration $=\frac{Y-11.811}{7390.8}$

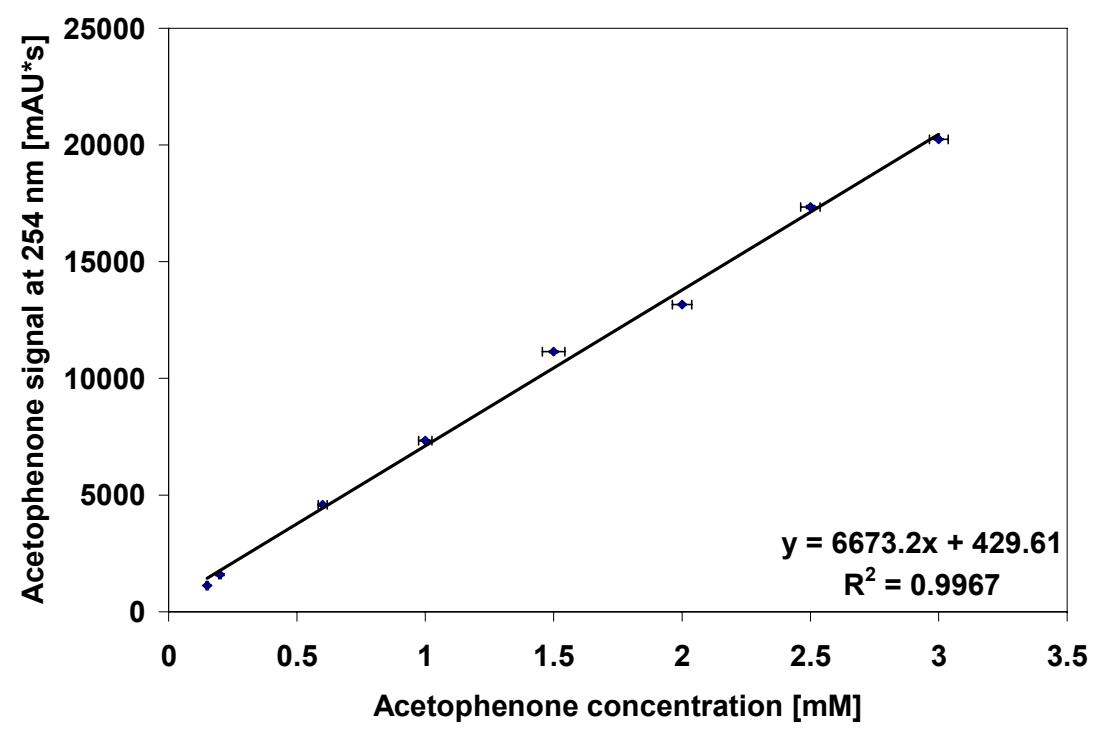

Figure 1.2: Calibration curve for acetophenone for high concentrations 
Acetophenone concentration $=\frac{Y-429.61}{}$

6673.2

The uncertainty in the values of acetophenone concentration in the interval from 0.01 to $0.15 \mathrm{mM}$ can be estimated from Figure 1.3.

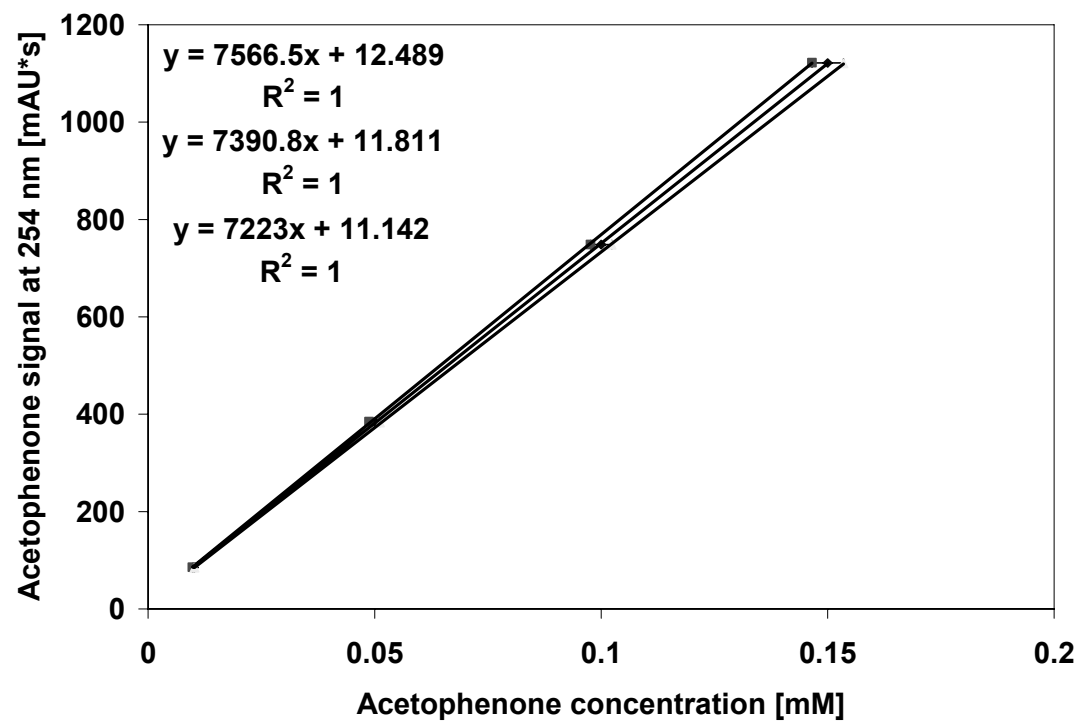

Figure 1.3: Uncertainty on acetophenone concentration for Figure 2.1

$$
\Delta X=\frac{(Y-11.811)}{7390.8}-\frac{[Y-12.489]}{7566.5}=3.1418 \times 10^{-6}(Y)+5.2497 \times 10^{-5}
$$

Where $\mathrm{X}$ was acetophenone concentration and $\mathrm{Y}$ was the signal of acetophenone at 254 nm.

The uncertainty in the values of acetophenone concentration in the interval from 0.15 to 3 $\mathrm{mM}$ can be estimated from Figure 1.4. 


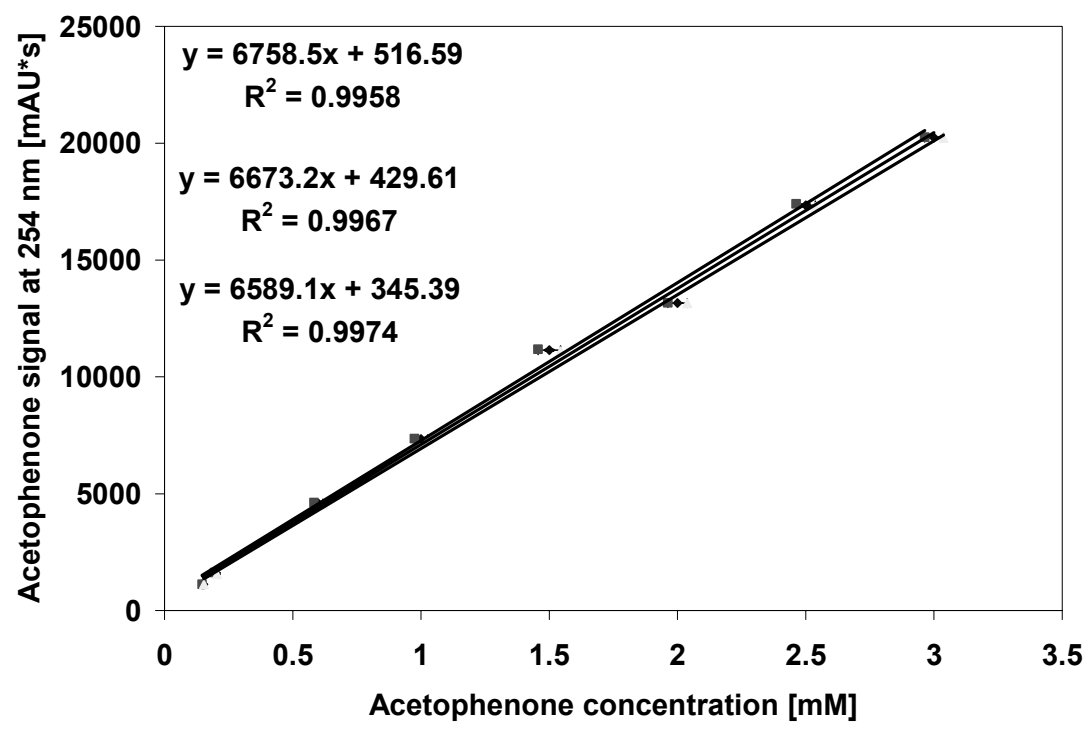

Figure 1.4: Uncertainty on acetophenone concentration for Figure 1.2

$$
\Delta X=\frac{(Y-429.61)}{6673.2}-\frac{[Y-516.59]}{6758.5}=1.8913 \times 10^{-6}(Y)+0.0120
$$

Where $\mathrm{X}$ was acetophenone concentration and $\mathrm{Y}$ was the signal of acetophenone at 254 $\mathrm{nm}$.

\section{Appendix 2: Calibration curve for substituted (S)-aminotetralin.}

A solution of substituted (S)-aminotetralin (Cambrex) $5 \mathrm{mM}$ was prepared on water at 25 ${ }^{\circ} \mathrm{C}$, and then used to make standards of $1 \mathrm{ml}$ of concentrations $4,3,2,1,0.5,0.25$, and $0.1 \mathrm{mM}$. To achieve such a volume, pipettes of 0.2 , and 1 were used, therefore incurring in the errors given by them. The volume of standard Vs to achieve the desired concentration was diluted with a volume of water Vw. Then the concentrations of the standards are given by the following equation. 


$$
C_{S}=\frac{V_{S} C_{S 0}}{V_{S}+V_{W}}
$$

The error incurred in preparing the standards in such a way is given by the following equation.

$$
\Delta C_{S}=\frac{C_{S 0}}{\left(V_{S}+V_{W}\right)^{2}}\left(V_{W} \Delta V_{S}-V_{S} \Delta V_{W}\right)
$$

Where $\Delta \mathrm{V}_{\mathrm{s}}=\Delta \mathrm{V}_{\mathrm{W}}=0.00155 \mathrm{~V}$, for volume up to $0.2 \mathrm{ml}, \Delta \mathrm{V}_{\mathrm{s}}=\Delta \mathrm{VW}_{\mathrm{W}}=0.00155 \mathrm{~V}$ for volume between 0.2 and $1 \mathrm{ml}$. The error incurred in the preparation of the standards is shown in Table 2.1.

\begin{tabular}{|c|c|c|c|c|c|}
\hline$C_{S}$ & $V_{S}$ & $V_{W}$ & $\Delta V_{S}$ & $\Delta V_{W}$ & $\Delta C_{S}$ \\
\hline 0.1 & 0.02 & 0.98 & $1.6 \times 10^{-4}$ & $7.3 \times 10^{-3}$ & $1.5 \times 10^{-3}$ \\
\hline 0.25 & 0.05 & 0.95 & $3.9 \times 10^{-4}$ & $7.1 \times 10^{-3}$ & $3.6 \times 10^{-3}$ \\
\hline 0.5 & 0.1 & 0.9 & $7.8 \times 10^{-4}$ & $6.7 \times 10^{-3}$ & $6.9 \times 10^{-3}$ \\
\hline 1 & 0.2 & 0.8 & $1.6 \times 10^{-3}$ & $6.0 \times 10^{-3}$ & 0.01 \\
\hline 2 & 0.4 & 0.6 & $3.0 \times 10^{-3}$ & $4.5 \times 10^{-3}$ & 0.02 \\
\hline 3 & 0.6 & 0.4 & $4.5 \times 10^{-3}$ & $3.0 \times 10^{-3}$ & 0.02 \\
\hline 4 & 0.8 & 0.2 & $6.0 \times 10^{-3}$ & $1.6 \times 10^{-3}$ & 0.01 \\
\hline 5 & 1 & 0 & $7.5 \times 10^{-3}$ & 0 & 0 \\
\hline
\end{tabular}

Table 2.1: Errors in concentration in the preparation of standards

The standards were analyzed by duplicate as described in Chapter 3. The results are shown in Table 2.2. 
Table 2.2: Signal concentration of the standards of substituted (S)-aminotetralin

\begin{tabular}{|r|r|r|r|r|r|}
\hline \multicolumn{1}{|c|}{$C_{S}$} & \multicolumn{1}{|l|}{$\begin{array}{l}\text { Signal 1 } \\
{\left[\mathrm{mAU}_{S} \mathrm{~s}\right]}\end{array}$} & $\begin{array}{l}\text { Signal 2 } \\
{\left[\mathrm{mAU}{ }^{*} \mathrm{~s}\right]}\end{array}$ & $\begin{array}{l}\text { Average } \\
{\left[\mathrm{mAU}^{*} \mathrm{~s}\right]}\end{array}$ & $\begin{array}{l}\text { Standard } \\
\text { deviation } \\
{\left[\mathrm{mAU}{ }^{*} \mathrm{~s}\right]}\end{array}$ \\
\hline 0.1 & $1.5 \times 10^{-3}$ & 26.03 & 33.17 & 29.60 & 5.04 \\
0.25 & $3.6 \times 10^{-3}$ & 65.31 & 94.81 & 80.06 & 20.86 \\
0.5 & $6.9 \times 10^{-3}$ & 130.51 & 143.06 & 136.78 & 8.86 \\
1 & 0.01 & 263.60 & 274.44 & 269.02 & 7.66 \\
2 & 0.02 & 539.90 & 597.23 & 568.56 & 40.53 \\
3 & 0.02 & 803.26 & 813.75 & 808.50 & 7.42 \\
4 & 0.01 & 1063.05 & 1083.88 & 1073.47 & 14.73 \\
5 & 0 & 1325.98 & 1341.13 & 1333.55 & 10.71 \\
\hline
\end{tabular}

With the data shown above, a calibration curve was obtained (Figure 2.1).

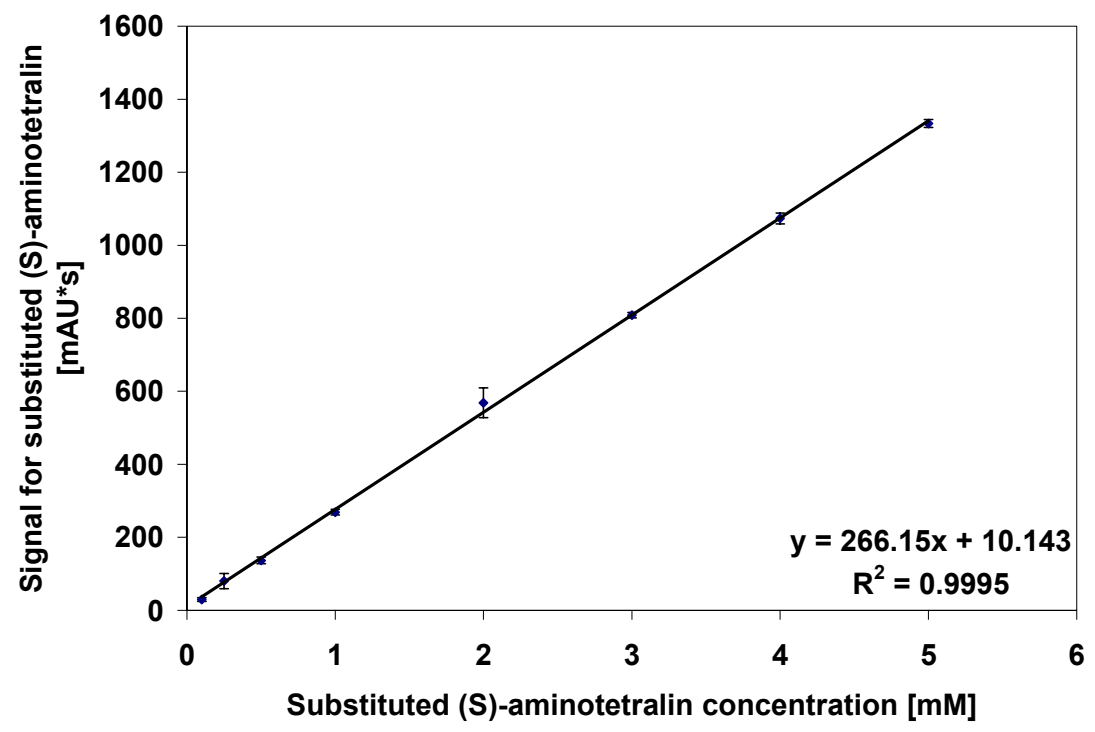

Figure 2.1: Calibration curve for substituted (S)-aminotetralin

The uncertainty in the values of substituted (S)-aminotetralin concentration can be estimated from Figure 2.2. 


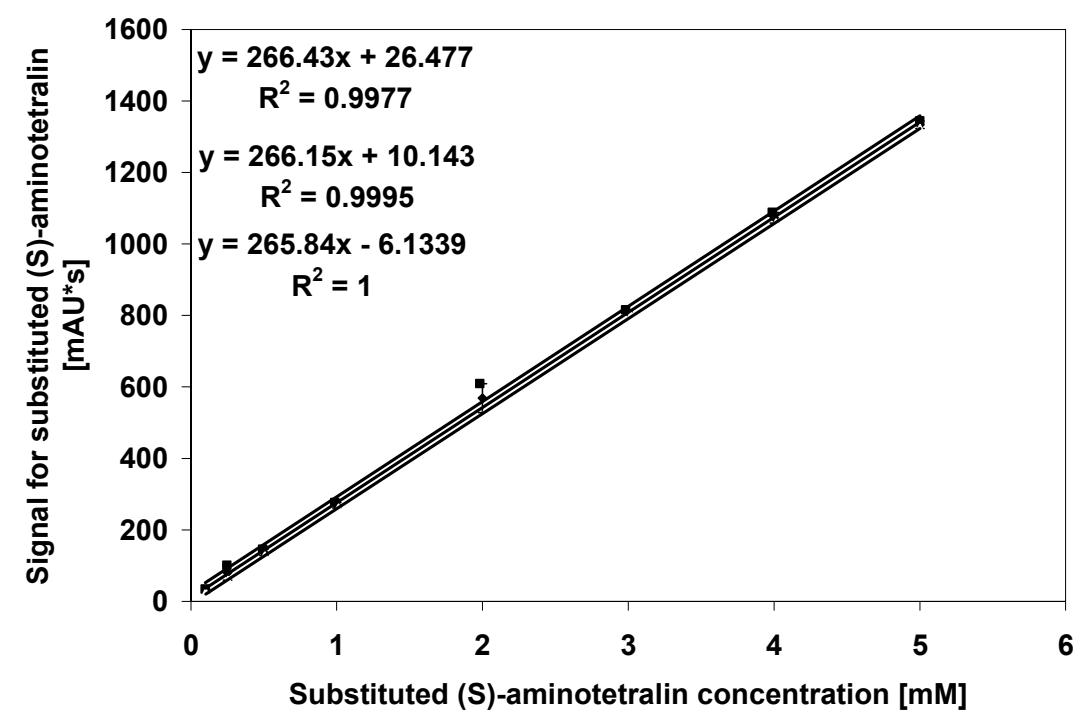

Figure 2.2: Uncertainty on substituted (S)-aminotetralin concentration

$$
\Delta X=\frac{(Y-10.143)}{266.15}-\frac{[Y-26.477]}{266.43}=3.9486 \times 10^{-6}(Y)+0.0613
$$

\section{Appendix 3: Affinity for (S)-(-)-a-Methylbenzylamine.}

Solutions of several concentrations of (S)-(-)- $\alpha$-Methylbenzylamine were prepared and incubated at the specified temperature, enzyme was added and samples were withdrawn periodically. Those were analyzed by HPLC. The concentration of acetophenone of the samples withdrawn is given by the following equation.

Acetophenone concentration $=\frac{5(Y-11.811)}{7390.8}$

The uncertainty (or variation) in acetophenone concentration is given by the following equation. 
$\Delta X=3.1418 \times 10^{-6}(Y)+5.2497 \times 10^{-5}$

Once that concentration of samples were determined for a system of given composition of (S)-(-)- $\alpha$-Methylbenzylamine, the reaction rate (the change on concentration with respect time; slope) was determined. Finally, to estimate the uncertainty on the value of initial rate the following steps were followed.

Estimate the uncertainty (or variation) on acetophenone concentration.

Add the value of uncertainty to the corresponding value of acetophenone concentration.

Estimate reaction rate with the values obtained on $b$ ).

Get the absolute difference between the value obtained on c) and the one obtained using acetophenone concentration without addition of uncertainty.

The results are shown in Table 3.1.

Table 3.1: Uncertainty on acetophenone concentration

\begin{tabular}{|c|c|c|c|c|}
\hline $\mathrm{t}(\min )$ & $0.02 \mathrm{mM}$ & Error $(\mathrm{E})$ & $\begin{array}{l}\text { Concentration } \\
\text { (C) }\end{array}$ & $E+C$ \\
\hline 2 & 37.170 & 0.001 & 0.020 & 0.018 \\
\hline 4 & 44.370 & 0.001 & 0.020 & 0.023 \\
\hline 6 & 46.880 & 0.001 & 0.020 & 0.025 \\
\hline 8 & 47.330 & 0.001 & 0.020 & 0.025 \\
\hline & & $\begin{array}{l}\text { Slope } \\
\text { (S) } \\
\text { CC } \\
\text { Error on } \\
\text { S }\end{array}$ & $\begin{array}{r}0.00112 \\
0.90716 \\
4 \mathrm{E}-05\end{array}$ & $\begin{array}{l}0.00116 \\
0.90716\end{array}$ \\
\hline
\end{tabular}

\begin{tabular}{|c|c|c|c|c|}
\hline $\mathrm{t}(\mathrm{min})$ & $0.08 \mathrm{mM}$ & Error $(\mathrm{E})$ & $\begin{array}{l}\text { Concentration } \\
\text { (C) }\end{array}$ & $\mathrm{E}+\mathrm{C}$ \\
\hline 2 & 43.640 & 0.001 & 0.022 & 0.023 \\
\hline 4 & 77.610 & 0.002 & 0.045 & 0.047 \\
\hline 6 & 101.070 & 0.003 & 0.060 & 0.063 \\
\hline
\end{tabular}




\begin{tabular}{|l|l|l|r|r|}
8 & 112.700 & 0.003 & 0.068 & 0.071 \\
\hline & Slope & & \\
& (S) & 0.0078 & 0.0081 \\
& CC & 0.9773 & 0.9773 \\
& Error on & & \\
\cline { 2 - 4 } & S & 0.0003 & \\
\hline
\end{tabular}

\begin{tabular}{|r|r|r|r|r|}
\hline $\mathrm{t}(\min )$ & $0.16 \mathrm{mM}$ & Error $(\mathrm{E})$ & \multicolumn{2}{|l|}{$\begin{array}{l}\text { Concentration } \\
(\mathrm{C})\end{array}$} \\
\hline 2 & 55.720 & 0.002 & 0.030 & 0.031 \\
4 & 105.710 & 0.003 & 0.064 & 0.066 \\
6 & 151.840 & 0.004 & 0.095 & 0.099 \\
8 & 191.020 & 0.005 & 0.121 & 0.126 \\
\hline & & Slope & & \\
& & (S) & 0.0153 & 0.0159 \\
& & CC & 0.9986 & 0.9986 \\
& & Error on & & \\
\cline { 3 - 5 } & S & & 0.0006 & \\
\hline
\end{tabular}

\begin{tabular}{|r|r|l|r|r|}
\hline $\mathrm{t}(\min )$ & $0.25 \mathrm{mM}$ & Error $(\mathrm{E})$ & \multicolumn{2}{|l|}{$\begin{array}{l}\text { Concentration } \\
(\mathrm{C})\end{array}$} \\
\hline 2 & 67.484 & 0.002 & 0.038 & 0.040 \\
4 & 117.420 & 0.003 & 0.071 & 0.075 \\
6 & 173.993 & 0.005 & 0.110 & 0.114 \\
8 & 222.346 & 0.006 & 0.142 & 0.148 \\
\hline & & Slope & & \\
& & (S) & 0.0176 & 0.0183 \\
& & CC & 0.9996 & 0.9996 \\
& & Error on & & \\
\cline { 3 - 5 } & S & & 0.0007 & \\
\hline
\end{tabular}

\begin{tabular}{|c|c|c|c|c|}
\hline $\mathrm{t}(\min )$ & $0.50 \mathrm{mM}$ & Error (E) & $\begin{array}{l}\text { Concentration } \\
\text { (C) }\end{array}$ & $\mathrm{E}+\mathrm{C}$ \\
\hline 2 & 76.169 & 0.002 & 0.044 & 0.046 \\
\hline 4 & 141.692 & 0.004 & 0.088 & 0.092 \\
\hline 6 & 209.198 & 0.005 & 0.134 & 0.139 \\
\hline 8 & 269.977 & 0.007 & 0.175 & 0.182 \\
\hline & & $\begin{array}{l}\text { Slope } \\
\text { (S) } \\
\text { CC } \\
\text { Error on } \\
\text { S }\end{array}$ & $\begin{array}{l}0.0220 \\
0.9998 \\
0.0008\end{array}$ & $\begin{array}{l}0.0228 \\
0.9998\end{array}$ \\
\hline
\end{tabular}

\begin{tabular}{|c|c|c|c|c|}
\hline $\mathrm{t}(\min )$ & $0.80 \mathrm{mM}$ & Error (E) & $\begin{array}{l}\text { Concentration } \\
\text { (C) }\end{array}$ & $\mathrm{E}+\mathrm{C}$ \\
\hline 2 & 89.938 & 0.002 & 0.053 & 0.055 \\
\hline 4 & 157.778 & 0.004 & 0.099 & 0.103 \\
\hline 6 & 222.210 & 0.006 & 0.142 & 0.148 \\
\hline 8 & 281.493 & 0.007 & 0.182 & 0.190 \\
\hline & & Slope & 0.0216 & 0.0224 \\
\hline
\end{tabular}




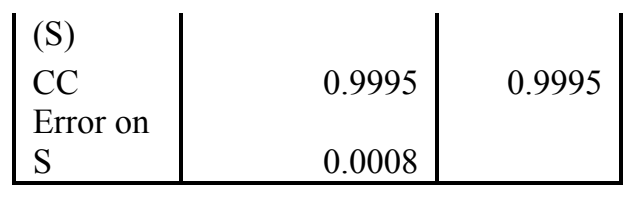

\begin{tabular}{|c|c|c|c|c|}
\hline $\mathrm{t}(\mathrm{min})$ & $0.04 \mathrm{mM}$ & Error (E) & $\begin{array}{l}\text { Concentration } \\
\text { (C) }\end{array}$ & $\mathrm{E}+\mathrm{C}$ \\
\hline 2 & 30.775 & 0.001 & 0.013 & 0.014 \\
\hline 4 & 50.298 & 0.001 & 0.026 & 0.027 \\
\hline 6 & 59.779 & 0.002 & 0.032 & 0.034 \\
\hline 8 & 63.016 & 0.002 & 0.035 & 0.036 \\
\hline & & $\begin{array}{l}\text { Slope } \\
(\mathrm{S}) \\
\mathrm{CC} \\
\text { Error on } \\
\mathrm{S}\end{array}$ & $\begin{array}{l}0.0036 \\
0.9454 \\
0.0001\end{array}$ & $\begin{array}{l}0.0037 \\
0.9454\end{array}$ \\
\hline
\end{tabular}

\begin{tabular}{|c|c|c|c|c|}
\hline $\mathrm{t}(\mathrm{min})$ & $0.12 \mathrm{mM}$ & Error $(\mathrm{E})$ & $\begin{array}{l}\text { Concentration } \\
\text { (C) }\end{array}$ & $\mathrm{E}+\mathrm{C}$ \\
\hline 2 & 55.698 & 0.002 & 0.030 & 0.031 \\
\hline 4 & 96.677 & 0.003 & 0.057 & 0.060 \\
\hline 6 & 132.658 & 0.003 & 0.082 & 0.085 \\
\hline 8 & 163.048 & 0.004 & 0.102 & 0.107 \\
\hline & & $\begin{array}{l}\text { Slope } \\
(\mathrm{S}) \\
\mathrm{CC} \\
\text { Error on } \\
\mathrm{S}\end{array}$ & $\begin{array}{l}0.0121 \\
0.9978 \\
0.0004\end{array}$ & $\begin{array}{l}0.0126 \\
0.9978\end{array}$ \\
\hline
\end{tabular}

\begin{tabular}{|c|c|c|c|c|}
\hline $\mathrm{t}(\mathrm{min})$ & $0.20 \mathrm{mM}$ & Error (E) & $\begin{array}{l}\text { Concentration } \\
\text { (C) }\end{array}$ & $\mathrm{E}+\mathrm{C}$ \\
\hline 2 & 67.045 & 0.002 & 0.037 & 0.039 \\
\hline 4 & 116.946 & 0.003 & 0.071 & 0.074 \\
\hline 6 & 170.478 & 0.004 & 0.107 & 0.112 \\
\hline 8 & 217.485 & 0.006 & 0.139 & 0.145 \\
\hline & & $\begin{array}{l}\text { Slope } \\
(\mathrm{S}) \\
\mathrm{CC} \\
\text { Error on } \\
\mathrm{S}\end{array}$ & $\begin{array}{l}0.0171 \\
0.9997 \\
0.0006\end{array}$ & $\begin{array}{l}0.0177 \\
0.9997\end{array}$ \\
\hline
\end{tabular}

\begin{tabular}{|c|c|c|c|c|}
\hline $\mathrm{t}(\mathrm{min})$ & $0.4 \mathrm{mM}$ & Error (E) & $\begin{array}{l}\text { Concentration } \\
\text { (C) }\end{array}$ & $\mathrm{E}+\mathrm{C}$ \\
\hline 2 & 74.311 & 0.002 & 0.042 & 0.044 \\
\hline 4 & 134.454 & 0.004 & 0.083 & 0.086 \\
\hline 6 & 193.980 & 0.005 & 0.123 & 0.128 \\
\hline 8 & 256.923 & 0.007 & 0.166 & 0.172 \\
\hline & & $\begin{array}{l}\text { Slope } \\
\text { (S) } \\
\text { CC }\end{array}$ & $\begin{array}{l}0.0205 \\
0.9999\end{array}$ & $\begin{array}{l}0.0213 \\
0.9999\end{array}$ \\
\hline
\end{tabular}




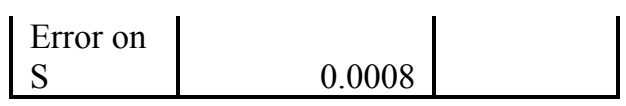

\begin{tabular}{|c|c|c|c|c|}
\hline $\mathrm{t}(\mathrm{min})$ & $0.75 \mathrm{mM}$ & Error (E) & $\begin{array}{l}\text { Concentration } \\
\text { (C) }\end{array}$ & $\mathrm{E}+\mathrm{C}$ \\
\hline 2 & 92.580 & 0.002 & 0.055 & 0.057 \\
\hline 4 & 158.651 & 0.004 & 0.099 & 0.103 \\
\hline 6 & 222.198 & 0.006 & 0.142 & 0.148 \\
\hline 8 & 282.874 & 0.007 & 0.183 & 0.191 \\
\hline & & $\begin{array}{l}\text { Slope } \\
(\mathrm{S}) \\
\mathrm{CC} \\
\text { Error on } \\
\mathrm{S}\end{array}$ & $\begin{array}{l}0.0215 \\
0.9998 \\
0.0008\end{array}$ & $\begin{array}{l}0.0223 \\
0.9998\end{array}$ \\
\hline
\end{tabular}

\begin{tabular}{|r|r|l|r|r|}
\hline $\mathrm{t}(\min )$ & $1 \mathrm{mM}$ & Error $(\mathrm{E})$ & \multicolumn{2}{|l|}{$\begin{array}{l}\text { Concentration } \\
(\mathrm{C})\end{array}$} \\
\hline 2 & 105.866 & 0.003 & 0.064 & 0.066 \\
4 & 174.386 & 0.005 & 0.110 & 0.114 \\
6 & 247.157 & 0.006 & 0.159 & 0.166 \\
8 & 315.232 & 0.008 & 0.205 & 0.213 \\
\hline & & Slope & & \\
& & (S) & 0.0237 & 0.0246 \\
& & CC & 0.9999 & 0.9999 \\
& Error on & & \\
\cline { 3 - 5 } & S & & 0.0009 & \\
\hline
\end{tabular}

From the data shown above the Table 3.2 was obtained.

Table 3.2: Uncertainty on reaction rate

\begin{tabular}{|c|r|r|}
\hline $\begin{array}{l}\text { S-MBA } \\
{[\mathrm{mM}]}\end{array}$ & $\begin{array}{l}\text { Rate } \\
{[\mathrm{mM} / \mathrm{min}]}\end{array}$ & $\begin{array}{l}\text { Error on Rate } \\
{[\mathrm{mM} / \mathrm{min}]}\end{array}$ \\
\hline 0.12 & 0.012 & 0.0004 \\
0.16 & 0.015 & 0.0006 \\
0.20 & 0.017 & 0.0006 \\
0.25 & 0.018 & 0.0007 \\
0.40 & 0.021 & 0.0008 \\
0.50 & 0.022 & 0.0008 \\
0.75 & 0.021 & 0.0008 \\
0.80 & 0.022 & 0.0008 \\
1.00 & 0.024 & 0.0009 \\
\hline
\end{tabular}

Then it was plotted the reciprocal of the quantities shown above. 
Table 3.3: Reciprocal of (S)-(-)- $\alpha$-methylbenzylamine and reaction rate

\begin{tabular}{|c|c|}
\hline $\begin{array}{l}1 /[\mathrm{S}- \\
\mathrm{MBA}]\end{array}$ & $1 /[$ Rate $]$ \\
\hline 8.33 & 82.57 \\
6.25 & 65.39 \\
5 & 58.55 \\
4 & 56.72 \\
2.5 & 48.67 \\
2 & 45.55 \\
1.33 & 46.59 \\
1.25 & 46.25 \\
1 & 42.18 \\
\hline $\mathrm{y}=4.9075 \mathrm{x}+37.457$ \\
$\mathrm{R} 2=0.9583$ \\
\hline
\end{tabular}

Table 3.4: Reciprocal of (S)-(-)- $\alpha$-methylbenzylamine and reaction rate corrected by the uncertainty on it

\begin{tabular}{|c|c|}
\hline $1 /[\mathrm{S}-\mathrm{MBA}]$ & $1 /[$ Rate+Error on Rate $]$ \\
\hline 8.33 & 79.62 \\
6.25 & 63.06 \\
5 & 56.47 \\
4 & 54.70 \\
2.5 & 46.94 \\
2 & 43.93 \\
1.33 & 44.93 \\
1.25 & 44.60 \\
1 & 40.67 \\
\hline $\mathrm{y}=4.7326 \mathrm{x}+36.123$ \\
$\mathrm{R} 2=0.9583$
\end{tabular}

From $1 /[\mathrm{S}-\mathrm{MBA}]$ and $1 /[$ Rate]

$\mathrm{Vm}=1 / 37.457=0.026697 \mathrm{mM} / \mathrm{min}$

$\mathrm{Km}=0.026697(4.9075)=0.131017 \mathrm{mM}$

From $1 /[\mathrm{S}-\mathrm{MBA}]$ and $1 /[$ Rate + Error on rate $]$

$\mathrm{Vm} 2=1 / 36.123=0.027683 \mathrm{mM} / \mathrm{min}$

$\mathrm{Km} 2=0.027683(4.7326)=0.131013 \mathrm{mM}$ 
$\Delta \operatorname{Vm}=\operatorname{abs}(0.027683 \mathrm{mM} / \mathrm{min}-0.026697 \mathrm{mM} / \mathrm{min})=0.00986$

$\Delta \mathrm{Km}=\operatorname{abs}(0.131017 \mathrm{mM}-0.131013 \mathrm{mM})=0.000004$

\section{Appendix 4: Effect of gelation time on activity.}

Beads of $10 \mathrm{mg}$ of spray dried cells of 20065 per gram were prepared as described in Chapter 5, using several gelation times. The data is shown in Table 4.1.

Table 4.1: Signal of acetophenone for several gelation times

\begin{tabular}{|c|c|c|c|c|c|c|}
\hline $\mathrm{t}(\min )$ & $7.5(\min )$ & $15(\min )$ & $30(\min )$ & $45(\min )$ & $60(\min )$ & $12(\min )$ \\
\hline 2 & 2034.549 & 2105.361 & 2056.022 & 2066.329 & 2127.422 & 2506.447 \\
4 & 2798.499 & 3004.510 & 2811.186 & 2876.905 & 2974.690 & 3715.656 \\
6 & 3564.700 & 3904.890 & 3568.793 & 3689.416 & 3823.823 & 4779.519 \\
8 & 4411.202 & 4893.853 & 4406.699 & 4585.235 & 4759.369 & 5727.005 \\
\hline
\end{tabular}

Table 4.2: Acetophenone concentration for several gelation times

\begin{tabular}{|c|c|c|c|r|r|r|}
\hline $\mathrm{t}(\mathrm{min})$ & 7.5 & 15 & 30 & 45 & 60 & 120 \\
\hline 2 & 1.203 & 1.256 & 1.219 & 1.226 & 1.272 & 1.556 \\
4 & 1.775 & 1.929 & 1.784 & 1.834 & 1.907 & 2.462 \\
6 & 2.349 & 2.604 & 2.352 & 2.442 & 2.543 & 3.259 \\
8 & 2.983 & 3.345 & 2.980 & 3.114 & 3.244 & 3.969 \\
\hline Rate & & & & & & \\
{$[\mathrm{mM} / \mathrm{min}]$} & 0.296 & 0.347 & 0.293 & 0.314 & 0.328 & 0.402 \\
\hline Correlation & 1.000 & 1.000 & 1.000 & 1.000 & 1.000 & 0.999 \\
\hline
\end{tabular}

To show statistically, that the rates shown in Table 4.2 are different, averages changes of acetophenone concentration were estimates using the data at $2 \mathrm{~min}$ (S2), 4 min (S4), 6 min (S6) and 8 min (S8).

Table 4.3: Average change on acetophenone concentration $(\mathrm{mM} / \mathrm{min})$ for different gelation times

\begin{tabular}{|c|c|c|c|c|c|c|}
\hline $\mathrm{t}(\min )$ & $7.5(\mathrm{~A})$ & $15(\mathrm{~B})$ & $30(\mathrm{C})$ & $45(\mathrm{D})$ & $60(\mathrm{E})$ & $120(\mathrm{~F})$ \\
\hline$(\mathrm{S} 8-\mathrm{S} 2) / 6$ & 0.297 & 0.348 & 0.294 & 0.315 & 0.329 & 0.402 \\
$(\mathrm{~S} 4-\mathrm{S} 2) / 2$ & 0.286 & 0.337 & 0.283 & 0.304 & 0.317 & 0.453 \\
$(\mathrm{~S} 6-\mathrm{S} 2) / 2$ & 0.287 & 0.337 & 0.284 & 0.304 & 0.318 & 0.399 \\
$(\mathrm{~S} 8-\mathrm{S} 6) 2$ & 0.317 & 0.370 & 0.314 & 0.336 & 0.350 & 0.355 \\
\hline
\end{tabular}


Using software to run statistical analysis, called Origin, the following output was obtained, which shows that the rates are statistically different.

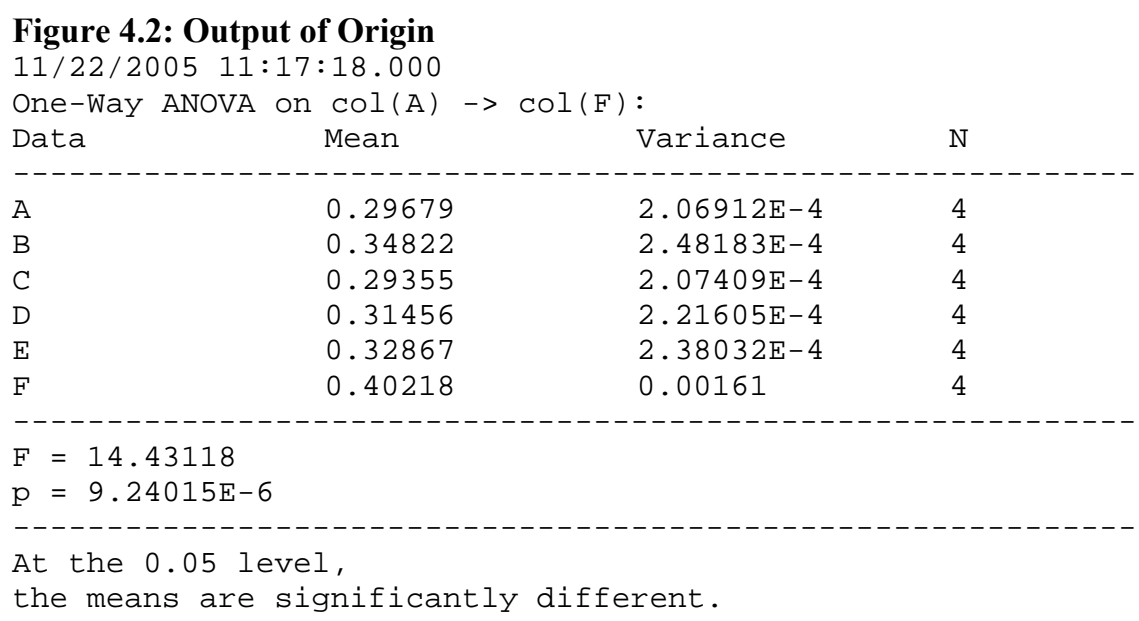

\section{Appendix 5: Transaminase model.}

The data shown in Table 6-VIwas fitted by nonlinear regression (Microsoft Office Excel 2003, Solver) to the following models.

Model 1: Ordered Bi Bi system.

$$
\begin{aligned}
v= & \frac{v_{\max }^{f} v_{\max }^{r}\left((A)(B)-\frac{(P)(Q)}{K e q}\right)}{v_{\max }^{r} K_{i a} K_{m B}+v_{\max }^{r} K_{m B}(A)+v_{\max }^{r} K_{m A}(B)+v_{\max }^{f} \frac{K_{m Q}}{K e q}(P)+v_{\max }^{f} \frac{K_{m P}}{K e q}(Q)} \\
& +v_{\max }^{r}(A)(B)+\frac{v_{\max }^{f} K_{m Q}}{K e q K_{i a}}(A)(P)+\frac{v_{\max }^{f}}{K e q}(P)(Q)+\frac{v_{\max }^{r} K_{m A}}{K_{i q}}(B)(Q) \\
& +\frac{v_{\max }^{r}}{K_{i p}}(A)(B)(P)+\frac{v_{\max }^{f}}{K_{i b} K e q}(B)(P)(Q)
\end{aligned}
$$


Model 2: Ordered Bi Bi System with rapid equilibrium.

$$
\begin{aligned}
v= & \frac{v_{\max }^{f} v_{\max }^{r}\left((A)(B)-\frac{(P)(Q)}{K e q}\right)}{v_{\max }^{r} K_{i a} K_{m B}+v_{\max }^{r} K_{m B}(A)+v_{\max }^{r} K_{m A}(B)+v_{\max }^{f} \frac{K_{m Q}}{K e q}(P)+v_{\max }^{f} \frac{K_{m P}}{K e q}(Q)} \\
& +v_{\max }^{r}(A)(B)+\frac{v_{\max }^{f} K_{m Q}}{K e q K_{i a}}(A)(P)+\frac{v_{\max }^{r} K_{m A}}{K_{i q}}(B)(Q)+\frac{v_{\max }^{f}}{K e q}(P)(Q)
\end{aligned}
$$

Model 3: Bi Bi system with product release between the additions of the two substrates.

$$
\begin{aligned}
& v=\frac{v_{\max }^{f} v_{\max }^{r}\left((A)(B)-\frac{(P)(Q)}{K e q}\right)}{v_{\max }^{r} K_{m B}(A)+v_{\max }^{r} K_{m A}(B)+v_{\max }^{f} \frac{K_{m Q}}{K e q}(P)+v_{\max }^{f} \frac{K_{m P}}{K e q}(Q)} \\
& +v_{\max }^{r}(A)(B)+\frac{v_{\max }^{f} K_{m Q}}{K e q K_{a}}(A)(P)+\frac{v_{\max }^{f}}{K e q}(P)(Q)+\frac{v_{\max }^{r} K_{m A}}{K_{i q}}(B)(Q)
\end{aligned}
$$

Model 4: Bi Bi system with product release between the additions of the substrates and inhibition by substrate and product.

$$
\begin{aligned}
& v=\frac{v_{\max }^{f} v_{\max }^{r}\left((A)(B)-\frac{(P)(Q)}{K e q}\right)}{v_{\max }^{r} K_{m B}(A)\left(1+\frac{(A)}{K_{i A}}\right)+v_{\max }^{r} K_{m A}(B)+v_{\max }^{f} \frac{K_{m Q}}{K e q}(P)+v_{\max }^{f} \frac{K_{m P}}{K e q}(Q)\left(1+\frac{(Q)}{K_{i Q}}\right)} \\
& +v_{\max }^{r}(A)(B)+\frac{v_{\max }^{f} K_{m Q}}{K e q K_{i A}}(A)(P)+\frac{v_{\max }^{f}}{K e q}(P)(Q)+\frac{v_{\max }^{r} K_{m A}}{K_{i Q}}(B)(Q)
\end{aligned}
$$

The parameter values as well as the goodness of fitting are presented in the following sections. 
Model 1: Value parameters and goodness of fitting

\begin{tabular}{|c|l|}
\hline Parameters of Model 1 & Value \\
\hline$v_{\max }^{f}$ & 0.250 \\
\hline$v_{\max }^{r}$ & 0.010 \\
\hline Keq & 0.330 \\
\hline$K_{i a}$ & 200.0 \\
\hline$K_{m B}$ & 12.40 \\
\hline$K_{m A}$ & 43.40 \\
\hline$K_{m Q}$ & 4.786 \\
\hline$K_{m P}$ & 17.58 \\
\hline$K_{i q}$ & 0.424 \\
\hline$K_{i p}$ & 58.46 \\
\hline$K_{i b}$ & 14.42 \\
\hline
\end{tabular}

Goodness of fitting of Model 1

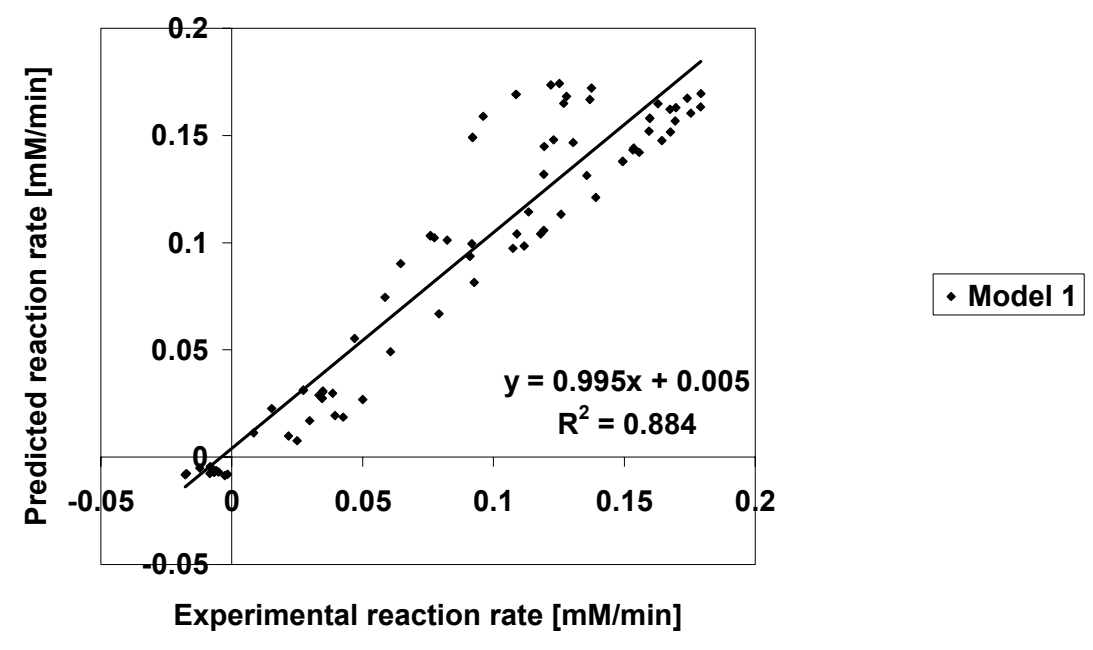


Model 2: Value parameters and goodness of fitting

\begin{tabular}{|c|c|}
\hline Parameters of Model 2 & Value \\
\hline & \\
\hline$v_{\max }^{f}$ & 0.251 \\
\hline$v_{\max }^{r}$ & 0.014 \\
\hline$K e q$ & 0.330 \\
\hline$K_{i a}$ & 183.494 \\
\hline$K_{m B}$ & 13.851 \\
\hline$K_{m A}$ & 0.098 \\
\hline$K_{m Q}$ & 1.226 \\
\hline$K_{m P}$ & 3.824 \\
\hline$K_{i q}$ & 0.001 \\
\hline
\end{tabular}

Goodness of fitting of Model 2

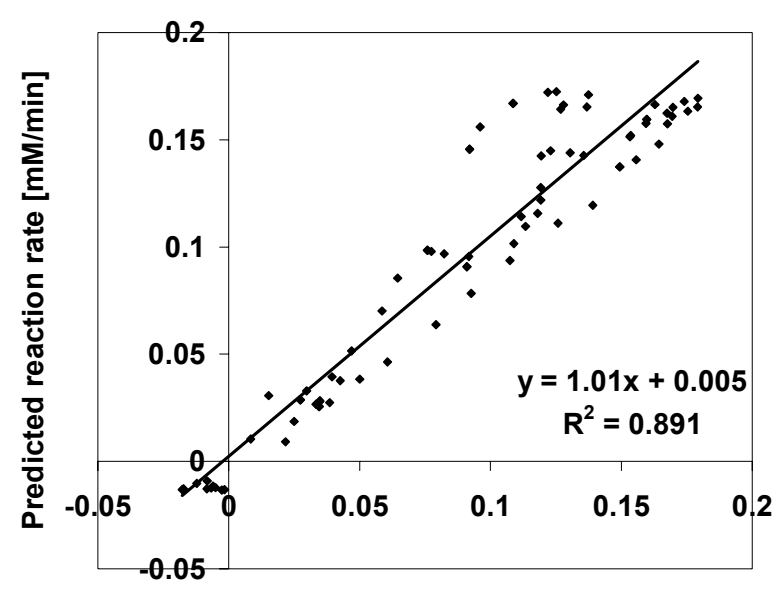

- Model 2

Experimental reaction rate $[\mathrm{mM} / \mathrm{min}]$ 
Model 3: Value parameters and goodness of fitting

\begin{tabular}{|c|c|}
\hline Parameters of Model 3 & Value \\
\hline$v_{\max }^{f}$ & 0.250 \\
\hline$v_{\max }^{r}$ & 0.008 \\
\hline$K_{e q}$ & 0.330 \\
\hline$K_{m B}$ & 16.185 \\
\hline$K_{m A}$ & 45.129 \\
\hline$K_{m Q}$ & 0.675 \\
\hline$K_{m P}$ & 23.680 \\
\hline$K_{i a}$ & 200.019 \\
\hline$K_{i q}$ & 3.570 \\
\hline
\end{tabular}

Goodness of fitting of Model 3

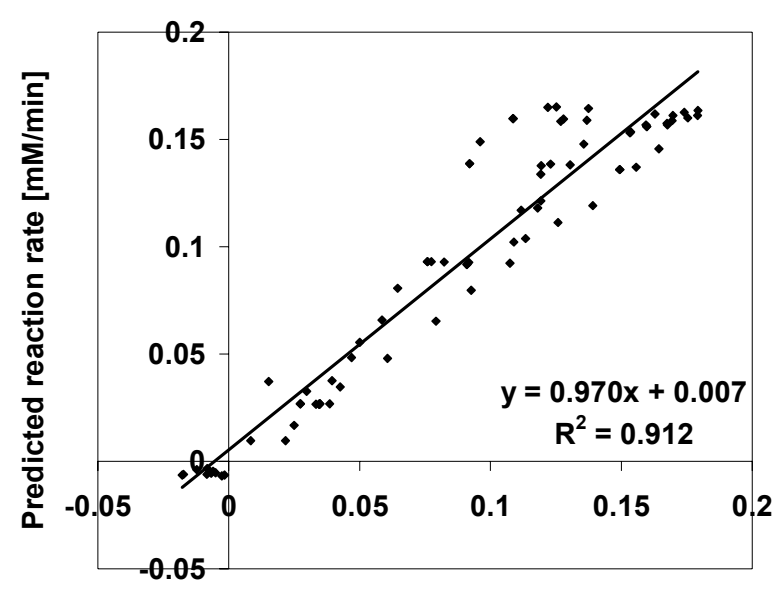

- Model 3

Experimental reaction rate $[\mathrm{mM} / \mathrm{min}]$ 
Model 4: Value parameters and goodness of fitting

\begin{tabular}{|c|c|}
\hline Parameters of Model 4 & Value \\
\hline$v_{\max }^{f}$ & \\
$v_{\max }^{r}$ & 0.212 \\
Keq & 0.016 \\
$K_{m B}$ & 0.330 \\
$K_{m A}$ & 1.715 \\
$K_{m Q}$ & 42.593 \\
$K_{m P}$ & 0.454 \\
$K_{i A}$ & 14.948 \\
$K_{i Q}$ & 200.098 \\
& 6.926 \\
\hline
\end{tabular}

Goodness of fitting of Model 4

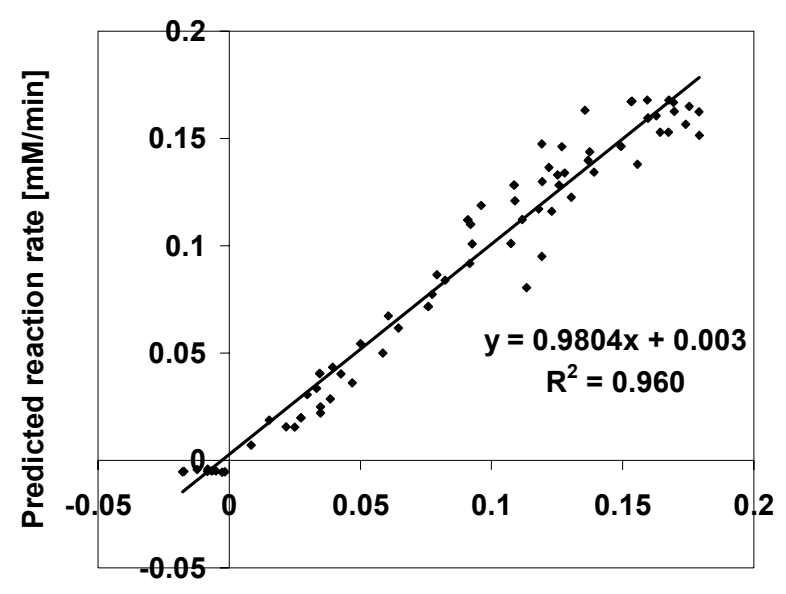

Experimental reaction rate $[\mathrm{mM} / \mathrm{min}]$

Comparison of the goodness of fitting of Models 1, 2, 3 and 4 . 

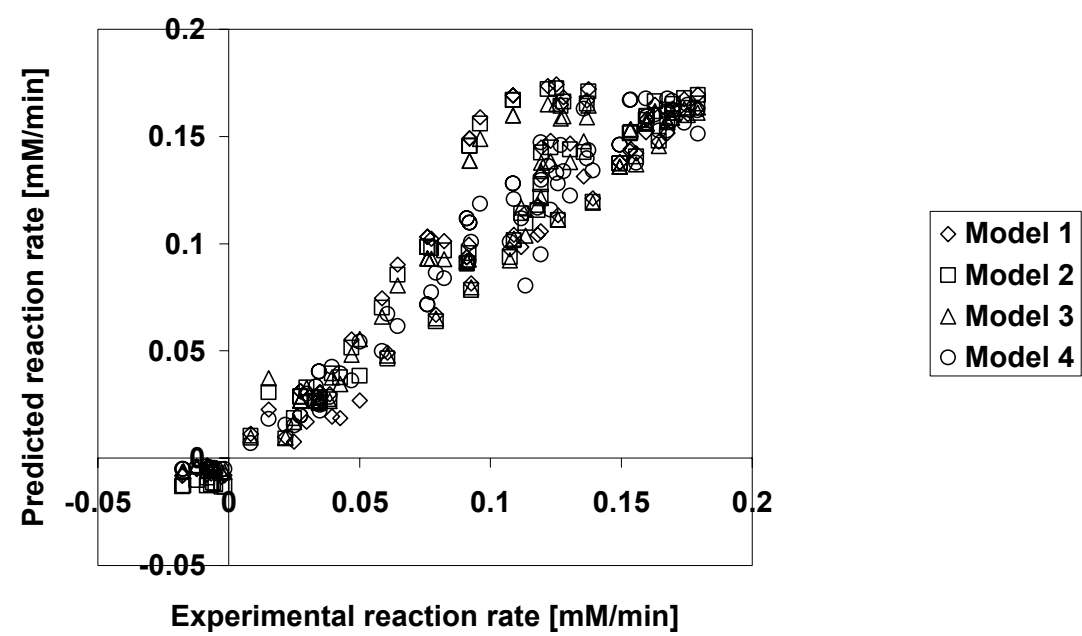

The comparison of models 1-4 was done upon the evaluation of slope (m) and intercept (b) of the $y=m * x+b$, and the correlation coefficient.

\begin{tabular}{|l|l|l|l|l|}
\hline & Slope & Intercept & Correlation & \\
& & & coefficient & \\
\hline Model 1 & 0.995 & 0.005 & 0.884 & \\
\hline Model 2 & 1.01 & 0.005 & 0.891 & \\
\hline Model 3 & 0.970 & 0.007 & 0.912 & \\
\hline Model 4 & 0.980 & 0.003 & 0.960 & Best model \\
\hline
\end{tabular}

The model that best described the experimental data was model 4. Altough model 1 and model 2 have slope values closer to one, they show to have a lot of dispersion of data along the line, whereas model 4 show to have less dispersion; therefore describing the experimental data in a better way. 
Once that model 4 was identified as the model that best describes the experimental data, it was desired to identify which out of its nine constant affects the more to the ouput of the model. Such information was obtained exploring the changes of the best fit of the plot of preditec data vs. experimental data, changing one variable at the time varying its value $\pm 10 \%$. The results are shown in the following table.

\begin{tabular}{|c|c|c|c|c|c|}
\hline \multicolumn{4}{|c|}{$\begin{array}{l}\text { Correlation of experimental data and values } \\
\text { given by the model using the best values of } \\
\text { the parameters }\end{array}$} & \multirow{2}{*}{$\begin{array}{l}\mathbf{y}=0.980 x+0.003, R^{2}=0.960 \\
\text { Data description (Mdl vs. Exp) }\end{array}$} & \multirow[t]{2}{*}{$\begin{array}{l}\text { Most } \\
\text { important } \\
\text { parameters }\end{array}$} \\
\hline \multicolumn{2}{|c|}{$\begin{array}{l}\text { Best values of the } \\
\text { parameters }\end{array}$} & \multicolumn{2}{|c|}{ Variation } & & \\
\hline \multirow{2}{*}{$V_{\max }^{f}$} & \multirow[b]{2}{*}{0.212} & $+10 \%$ & 0.233 & $y=\mathbf{1 . 0 7 9} x+0.003, R^{2}=0.960$ & \multirow[t]{2}{*}{$v_{\max }^{f}$} \\
\hline & & $-10 \%$ & 0.191 & $\mathrm{y}=\mathbf{0 . 8 8 2} \mathrm{x}+0.003, \mathrm{R}^{2}=0.960$ & \\
\hline \multirow{2}{*}{$v_{\max }^{r}$} & \multirow{2}{*}{0.016} & $+10 \%$ & 0.018 & $\mathrm{y}=0.980 \mathrm{x}+0.003, \mathrm{R}^{2}=0.960$ & \multirow{4}{*}{ Keq } \\
\hline & & $-10 \%$ & 0.014 & $\mathrm{y}=0.981 \mathrm{x}+0.003, \mathrm{R}^{2}=0.960$ & \\
\hline \multirow{2}{*}{ Keq } & \multirow{2}{*}{0.33} & $+10 \%$ & 0.363 & $y=\mathbf{0 . 9 7 8 x}+0.003, R^{2}=0.960$ & \\
\hline & & $-10 \%$ & 0.297 & $\mathrm{y}=\mathbf{0 . 9 8 3 x}+0.002, R^{2}=0.960$ & \\
\hline \multirow{2}{*}{$K_{m B}$} & \multirow[b]{2}{*}{1.715} & $+10 \%$ & 1.887 & $y=\mathbf{0 . 9 6 2 x}+0.002, R^{2}=0.959$ & \multirow{2}{*}{$K_{m B}$} \\
\hline & & $-10 \%$ & 1.543 & $y=\mathbf{0 . 9 9 9} x+0.004, R^{2}=0.961$ & \\
\hline \multirow{2}{*}{$K_{i A}$} & \multirow[b]{2}{*}{200.097} & $+10 \%$ & 220.1 & $y=\mathbf{0 . 9 9 4 x}+0.004, R^{2}=0.961$ & \multirow[t]{2}{*}{$K_{i A}$} \\
\hline & & $-10 \%$ & 180.1 & $\mathrm{y}=\mathbf{0 . 9 6 4 x}+0.002, \mathrm{R}^{2}=0.959$ & \\
\hline \multirow{2}{*}{$K_{m A}$} & \multirow[b]{2}{*}{42.593} & $+10 \%$ & 46.85 & $\mathrm{y}=\mathbf{0 . 9 7 5 x}+0.003, \mathrm{R}^{2}=0.961$ & \multirow{2}{*}{$K_{m A}$} \\
\hline & & $-10 \%$ & 38.33 & $\mathrm{y}=\mathbf{0 . 9 8 5 x}+0.003, \mathrm{R}^{2}=0.959$ & \\
\hline \multirow{2}{*}{$K_{m Q}$} & \multirow[b]{2}{*}{0.454} & $+10 \%$ & 0.499 & $\mathrm{y}=0.980 \mathrm{x}+0.003, \mathrm{R}^{2}=0.960$ & \\
\hline & & $-10 \%$ & 0.409 & $y=0.980 x+0.003, R^{2}=0.960$ & \\
\hline \multirow[b]{2}{*}{$K_{m P}$} & \multirow[b]{2}{*}{14.948} & $+10 \%$ & 16.44 & $\mathrm{y}=0.981 \mathrm{x}+0.003, \mathrm{R}^{2}=0.960$ & \\
\hline & & $-10 \%$ & 13.45 & $\mathrm{y}=0.980 \mathrm{x}+0.003, \mathrm{R}^{2}=0.960$ & \\
\hline \multirow{2}{*}{$K_{i Q}$} & \multirow[b]{2}{*}{6.926} & $+10 \%$ & 7.62 & $y=0.980 x+0.003, R^{2}=0.960$ & \\
\hline & & $-10 \%$ & 6.23 & $y=0.980 x+0.003, R^{2}=0.960$ & \\
\hline \multicolumn{4}{|c|}{ All the values of the constants $10 \%$ higher } & \multirow{2}{*}{\multicolumn{2}{|c|}{$\begin{array}{l}\mathrm{y}=1.067 \mathrm{x}+0.003, \mathrm{R}^{2}=0.961 \\
\mathrm{y}=0.892 \mathrm{x}+0.002 \mathrm{R} 2=0.959\end{array}$}} \\
\hline \multicolumn{4}{|c|}{ All the values of the constants $10 \%$ smaller } & & \\
\hline
\end{tabular}


From this simplified analysis it was found that the parameters that affect the more the output of model 4 are $v_{\max }^{f}, K e q, K_{m B}, K_{i A}$, and $K_{m A}$. Since these are the parameters that contribute the more to model 4 it is possible to adapt model 4 for special cases. At the beging of the biotransformation ( 0 to 20 minutes) the concentration of substituted (S)-aminotetralin [Q] and acetone [P] are low; then for the case of estimating initial rates they could be neglected -this is supported by the fact that any constant related to them was of high significance to the model- and only considered the concentration of isopropylamine [A] and substituted tetralone [B].

$$
\begin{aligned}
v= & \frac{v_{\max }^{f} v_{\max }^{r}\left((A)(B)-\frac{(\mathbf{P})(Q)}{K e q}\right)}{v_{\max }^{r} K_{m B}(A)\left(1+\frac{(A)}{K_{i A}}\right)+v_{\max }^{r} K_{m A}(B)+v_{\max }^{f} \frac{K_{m Q}}{K e q}(P)+v_{\max }^{f} \frac{K_{m P}}{K e q}(Q)\left(1+\frac{(Q)}{K_{i Q}}\right)} \\
& +v_{\max }^{r}(A)(B)+\frac{v_{\max }^{f} K_{m Q Q}}{K_{e q} K_{i A}}(A)(P)+\frac{v_{\text {max }}^{f}}{K e q}(P)(Q)+\frac{v_{\text {max }}^{r} K_{m A}}{K_{i Q}}(B)(Q)
\end{aligned}
$$

Rewriting the equation after eliminating the crossed quatities that were neglected. It is obtained the following expression

$$
v=\frac{v_{\max }^{f} v_{\max }^{r}((A)(B))}{v_{\max }^{r} K_{m B}(A)\left(1+\frac{(A)}{K_{i A}}\right)+v_{\max }^{r} K_{m A}(B)+v_{\max }^{r}(A)(B)}
$$


Since $V_{\max }^{r}$ is common to numerator and denominator is canceled, finally obtaining the following equation.

$$
v=\frac{v_{\max }^{f}(A)(B)}{K_{m B}(A)\left(1+\frac{(A)}{K_{i A}}\right)+K_{m A}(B)+(A)(B)}
$$

\section{Appendix 6: Substituted (S)-Aminotetralin and Imine overall kinetics.}

The main reaction occurring during production of substituted (S)-aminotetralin are shown below.

a)<smiles>[R]c1ccc2c(c1)CCC(=O)C2</smiles>

Substituted Tetralone

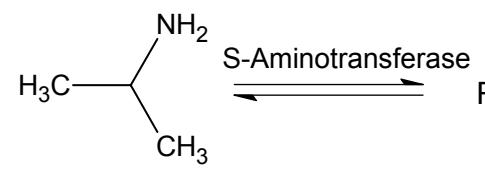

Isopropylamine<smiles>N[C@H]1CCc2ccccc2C1</smiles>

Substituted Tetralin<smiles>CC(=O)CO</smiles>

Acetone

b)<smiles>[R]c1ccc2c(c1)CCC(=O)C2</smiles><smiles></smiles><smiles>[R]c1ccccc1CC</smiles>

Reaction a) and b) can be modeled as follows. 
When imine formation [I] is not measured in the system, which is the case when substituted (S)-aminotetralin is measured after assuring imine hydrolysis by acid and thermal treatment $\left(30 \mathrm{~min}\right.$ at $\left.80^{\circ} \mathrm{C}\right)$, the system can be described by the following equation.

$$
\frac{d Q}{d t}=\frac{v_{\max }^{f} v_{\max }^{r}\left((A)(B)-\frac{(P)(Q)}{K e q}\right)}{\left[\begin{array}{l}
v_{\max }^{r} K_{m B}(A)\left(1+\frac{(A)}{K_{i A}}\right)+v_{\max }^{r} K_{m A}(B)+ \\
v_{\max }^{f} \frac{K_{m Q}}{K e q}(P)+v_{\max }^{f} \frac{K_{m P}}{K e q}(Q)\left(1+\frac{(Q)}{K_{i Q}}\right) \\
+v_{\max }^{r}(A)(B)+\frac{v_{\max }^{f} K_{m Q}}{K e q K_{i A}}(A)(P)+ \\
\frac{v_{\max }^{f}(P)(Q)+\frac{v_{\max }^{r} K_{m A}}{K_{i Q}}(B)(Q)}{K e q}
\end{array}\right]}
$$


For systems in which imine [I] as well substituted (S)-aminotetralin [Q] ig going to be monitored, the system can be described by the following equations.

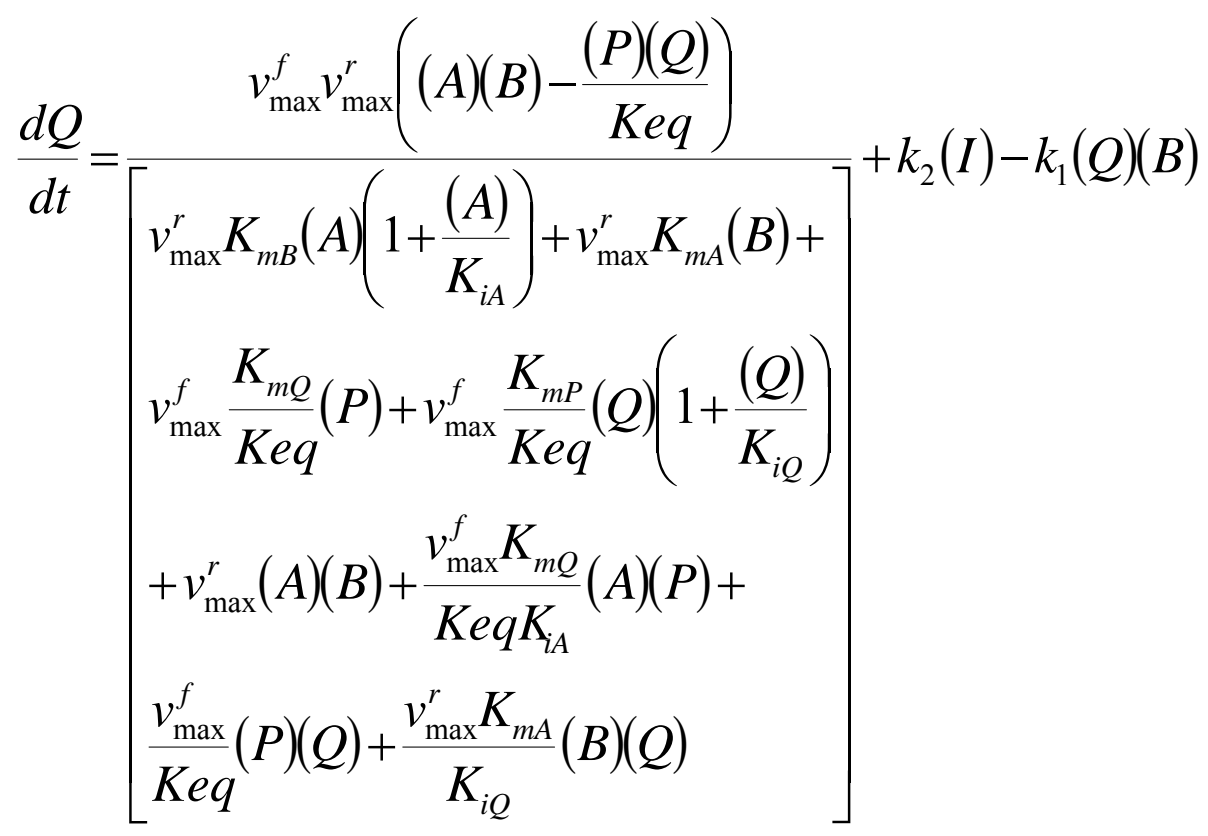

$$
\frac{d I}{d t}=k_{1}(Q)(B)-k_{2}(I)
$$

The study the overall kinetics of reaction for the case when imine formation is not considered was done in Microsoft Office Excel 2003 ‥ An Add-ins for Microsoft Office Excel 2003 @ provided by Dr. Tomas B. Co ${ }^{1}$, who is an Associate professor at Michigan Technological University.

The procedure followed is shown below.

Write the data to analyze in a file with extension "dat".

\footnotetext{
${ }^{1}$ (http://www.chem.mtu.edu/ tbco/cm416/RK4_v3_0.html, 04/16/2006)
} 


\begin{tabular}{|c|c|}
\multicolumn{2}{|c|}{$\mathrm{t}(\mathrm{hr})$} \\
\hline \multicolumn{1}{|c|}{$\mathrm{Q}(\mathrm{mM})$} \\
\hline 0 & 0 \\
\hline 0.33 & 6.19 \\
\hline 0.67 & 8.88 \\
\hline 1 & 13.74 \\
\hline 1.33 & 22.71 \\
\hline 1.67 & 25.08 \\
\hline 3 & 33.06 \\
\hline 6 & 41.49 \\
\hline 8 & 46.86 \\
\hline
\end{tabular}

Write in a file with extension "rk4" the differential equations that describes the system, with their initials conditions, step size, range of independent variable to explore, and a guess of the values of the kinetics constants, named parameters in the Add-ins.

' Sampling interval and final time

$$
\text { ' }
$$

1

dt: 0.001

tfinal: 24

' Differential Equations

'

[x1], Initial Value: 0, Deriv: $[\mathrm{c} 1] /([\mathrm{c} 2]+[\mathrm{c} 3]+[\mathrm{c} 4]+[\mathrm{c} 5])^{\prime}$

' Algebraic Equations 
[c1], Eqn: k1*k2*((750-[x1])*33-[x1]*[x1]/k3)

[c2], Eqn: k2*k4*(750-[x1])*(1+(750-[x1])/k5)+k2*k6*33

[c3], Eqn:k1*(k7/k3)*[x1]+k1*(k8/k3)*[x1]*(1+[x1]/k9)

[c4], Eqn: k2*33*(750-[x1])+(k1*k7/(k3*k5))*(750-[x1])*[x1]

[c5], Eqn: $(\mathrm{k} 1 / \mathrm{k} 3) *[\mathrm{x} 1]^{*}[\mathrm{x} 1]+\mathrm{k} 2 *(\mathrm{k} 6 / \mathrm{k} 9) * 33 *[\mathrm{x} 1]^{\prime}$

\section{' Parameters}

k1, Value: 0.212

k2, Value: 0.01

k3, Value: 0.5

k4, Value: 1.715

k5, Value: 200.097

k6, Value: 42.552

k7, Value: 0.438

k8, Value: 14.938

k9, Value: 6.957

Where

$$
\begin{aligned}
& \mathrm{k} 1=v_{\max }^{f} \\
& \mathrm{k} 2=v_{\max }^{r} \\
& \mathrm{k} 3=K e q \\
& \mathrm{k} 4=K_{m B} \\
& \mathrm{k} 5=K_{i A}
\end{aligned}
$$


$\mathrm{k} 6=K_{m A}$

$\mathrm{k} 7=K_{m Q}$

$\mathrm{k} 8=K_{m P}$

$\mathrm{k} 9=K_{i Q}$

Initialize the Add-ins RK4, load the file *.rk4, select the option of PARAMETER ESTIMATION, add the file o files *.dat.

Once the Add-ins RK4 has processed the files from part 3, apply the Add-ins Solver from Microsoft Office Excel 2003 (c) to find the values that best describe the experimental data, which would be the estimated values of the kinetic constants that best describe imine and substituted (S)-aminotetralin production. For the cases when imine formation was considered, the equation were solved using Runge-Kutta of fourth order on Microsoft Excel $2003 \AA$. Then the square differences between the experimental data and the outputs given the solution of the differential equations were stablished. Once done this step, the add ins Solver of Microsoft excel 2003 ® was used to estimate the parameters.

Appendix 7: Chemical structure of 21 amino acids.

\begin{tabular}{|l|l|l|l|l|}
\hline Structure & Name & Abbreviation & Symbol & Class \\
\hline & Glycine & GLY & G & Aliphatic \\
\hline
\end{tabular}




\begin{tabular}{ll|l|l|l|} 
& & & \\
\end{tabular}




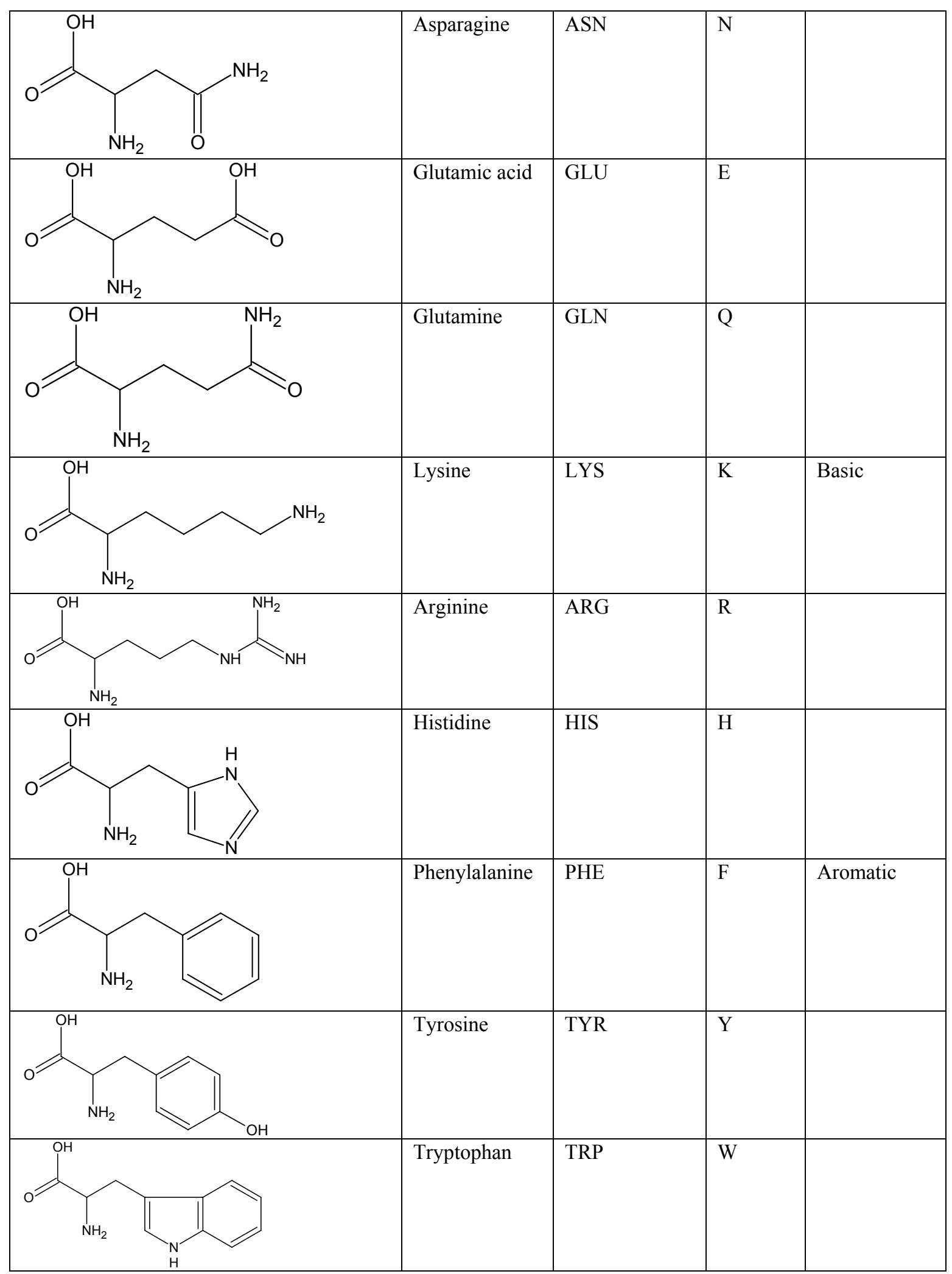




\begin{tabular}{|l|l|l|l|l|}
\hline & & & & \\
\hline
\end{tabular}

\section{Appendix 8: (S)-Aminotransferase purification}

Purification of mutant 1 (S)-aminotransferase was done as described in Section 3.2.4. The overall efficiency of purification process was $8 \%$. The major steps, at which activity was measured for the system of (S)-(-)- $\alpha$-Methylbenzylamine, are shown on Figure 8-1. To a $20 \mathrm{ml}$ of Solution $1 \mathrm{pH} 7$ (Table 3-I) was added $1 \mathrm{ml}$ of enzyme solution from every step of purification, reaction rate was determined at $30^{\circ} \mathrm{C}$. Table 8 -I shows the magnitude of activity as well as the amount of enzyme left in each step.

At the end of purification (step 13, after resuspension of the pellets with $70 \%(\mathrm{w} / \mathrm{v})$ $\left.\left(\mathrm{NH}_{4}\right)_{2} \mathrm{SO}_{4}\right)$ only $8 \%$ of the aminotransferase contained on the spray dried cells was recovered. Approximately 50 percent of it was lost on the pellet after centrifugation; which indicates that half of the aminotransferase is in a state that allows its fast solubilization, maybe due to the ratio of broken to whole spray dried cells.

The pellets obtained after centrifugation of sonicated sample, addition of 40 and $55 \%$ $\left(\mathrm{NH}_{4}\right)_{2} \mathrm{SO}_{4}$, have more aminotransferase than the corresponding supernatants, but with larger amount of impurities. A crude purification up to $55 \%\left(\mathrm{NH}_{4}\right)_{2} \mathrm{SO}_{4}$ would produce a 
pellet with a high aminotransferase concentration and reduced amount of impurities, but it would imply to lose between 60 to $70 \%$ of aminotransferase on spray dried cells.

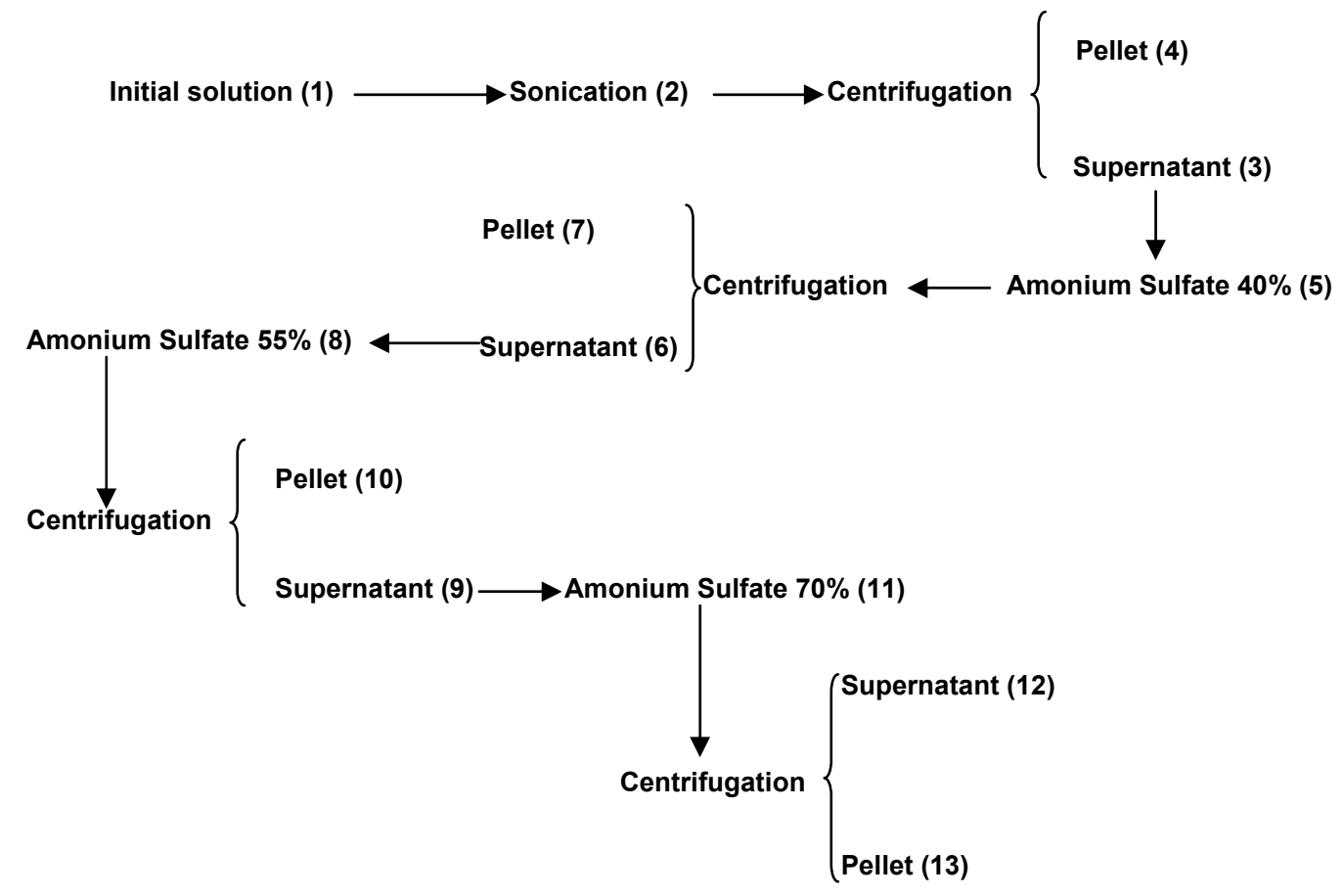

Figure8-1: Purification diagram

Table 8-I: Activity of mutant 1 (S)-Aminotransferase during purification

\begin{tabular}{|c|c|c|}
\hline $\begin{array}{l}\text { Purification } \\
\text { step }\end{array}$ & $\begin{array}{l}\text { Enzymatic activity } \\
{[\mathrm{mM} / \mathrm{min}]}\end{array}$ & Enzyme left \% [(Activity i)/(Activity 1)] \\
\hline 1 & 0.102 & 100 \\
\hline 2 & 0.101 & 99 \\
\hline 3 & 0.056 & 55 \\
\hline 4 & 0.051 & 50 \\
\hline 5 & 0.061 & 60 \\
\hline 6 & 0.046 & 45 \\
\hline 7 & 0.017 & 17 \\
\hline 8 & 0.042 & 41 \\
\hline 9 & 0.008 & 8 \\
\hline 10 & 0.036 & 35 \\
\hline 11 & 0.005 & 5 \\
\hline 12 & No detected & No detected \\
\hline 13 & 0.008 & 8 \\
\hline
\end{tabular}

